\title{
Characterization of exhaust emissions from catalyzed trap- equipped non-road heavy-duty diesel engines
}

Vinay Nagendran

West Virginia University

Follow this and additional works at: https://researchrepository.wvu.edu/etd

\section{Recommended Citation}

Nagendran, Vinay, "Characterization of exhaust emissions from catalyzed trap-equipped non-road heavyduty diesel engines" (2003). Graduate Theses, Dissertations, and Problem Reports. 1391.

https://researchrepository.wvu.edu/etd/1391

This Thesis is protected by copyright and/or related rights. It has been brought to you by the The Research Repository @ WVU with permission from the rights-holder(s). You are free to use this Thesis in any way that is permitted by the copyright and related rights legislation that applies to your use. For other uses you must obtain permission from the rights-holder(s) directly, unless additional rights are indicated by a Creative Commons license in the record and/ or on the work itself. This Thesis has been accepted for inclusion in WVU Graduate Theses, Dissertations, and Problem Reports collection by an authorized administrator of The Research Repository @ WVU. For more information, please contact researchrepository@mail.wvu.edu. 


\title{
Characterization of Exhaust Emissions from Catalyzed Trap-Equipped Non-Road Heavy-Duty Diesel Engines
}

\author{
Vinay Nagendran \\ Thesis submitted to the \\ College of Engineering and Mineral Resources \\ at West Virginia University \\ in partial fulfillment of the requirements \\ for the degree of
}

Masters of Science

In

Mechanical Engineering

Mridul Gautam, Ph.D., Chaiman

Gregory J. Thompson, Ph.D.

W. Scott Wayne, Ph.D.

Department of Mechanical and Aerospace Engineering

\section{Morgantown, WV}

2003

Keywords: Non-road, low sulfur diesel, transient cycle, emissions testing 


\section{ABSTRACT \\ Characterization of Exhaust Emissions from Trap-Equipped Non-Road Heavy-Duty \\ Diesel Engines \\ Vinay Nagendran}

An emissions and engine performance study was conducted to explore the effects of ultra low sulfur fuels on an off-road, heavy-duty engine retrofitted with catalyzed traps. The study was conducted, on an 8 cylinder, mechanically controlled Caterpillar 3408, rear engine of a Scraper. An in-field transient duty cycle was determined by logging the engine speed and torque using an Electronic Control Unit (ECU) communication adapter on the Scraper. The test fuels included California Air Resources Board (CARB) off-road diesel fuel, Fischer-Tropsch and Emission Control Diesel-1 (ECD1) diesel fuels. The engine was retrofit with two different types of diesel particulate filters (DPF) (Johnson-Matthey CRT and Engelhard DPX). The in-field cycle was recreated in the West Virginia University engine laboratory for engine dynamometer studies. The Caterpillar 3408 was mounted on a heavy-duty direct current dynamometer and the engine was exercised through the 25-minute transient scraper cycle that was representative of in-field operation. The engine was run on both the ISO 8178 8-mode cycle and the transient cycles for different configurations of fuels and DPFs. There was a remarkable reduction in particulate matter (PM), hydrocarbons (HC) and carbon monoxide (CO) in all the combinations of fuel with filters tested under transient loading. Brake specific PM emissions were as low as $0.01 \mathrm{~g} / \mathrm{bhp}-\mathrm{hr}$ on both the filters with the ECD1 and Fischer-Tropsch diesel, compared to $0.34 \mathrm{~g} / \mathrm{bhp}$-hr for the baseline configuration with ECD1 diesel. This amounted to a 98\% reduction of PM emissions for the low-sulfur fuels-DPF configurations. Brake specific hydrocarbon emissions for both ECD1CRT and Fischer-Tropsch-CRT configurations were $0.02 \mathrm{~g} / \mathrm{bhp}-\mathrm{hr}$, and the emissions for ECD1DPX configuration were $0.06 \mathrm{~g} / \mathrm{bhp}-\mathrm{hr}$. Brake specific CO emissions were reduced by $96 \%$ to a value of $0.07 \mathrm{~g} / \mathrm{bhp}$-hr with the ECD1-CRT setup. These emission levels comply with the California emission standards for 2001. 


\section{ACKNOWLEDGEMENTS}

This is the one of those rare moments in life when you see the end and beginning at the same time, in that order. At the end of my graduate program there is an immense sense of gratitude towards many people who have helped me along the way.

None more important than Dr. Gautam. You are better than the best. Thanks for believing in me. You have been a good friend, and a patient advisor all along. If there is one thing I've learned from you, that is to get the job done with whatever it takes. I'll always remember that. I wish to thank you and your family for showering me with all the love and support.

The guys at ERC deserve all the thanks that I can offer. I have learned something new everyday I have spent there. Dan Carder, you have been wonderful to work with. I have always had my problems solved when I have asked you and always had a good laugh at the end of it. I also wish to thank Wes, Richard, Tom, Andy, Aaron, Ares, Glen, Dave, and Sandeep. It has been a pleasure working with you fellows. My sincere thanks to Dr. Thompson for all the patience he has shown while I was trying to find my way around the lab. I also wish to thank Dr. Wayne for his expertise and support. Thanks also to Booz-Allen and Hamiltion Inc. and AQMD for funding my research project.

And thanks to those monkeys called friends. I am so lucky and proud to have such a bunch of hooligans as friends. Life would surely be a drag without them. Thanks to all my friends. A special thanks to Praveen who got me enrolled into the graduate program and made my life comfortable in Morgantown. I cannot thank Guru, Hemanth and Sam enough for spending long hours in the lab and helping me finish the project. You guys will surely make it big.

Lastly, but surely not the least, my dearest mom, dad and sister. Thanks for letting me do what I wanted to, while always helping me decide between right and wrong. Thanks to my lovely sister, I would be a mess if not for your love. 


\section{TABLE OF CONTENTS}

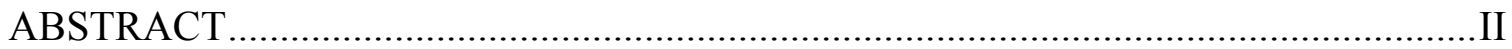

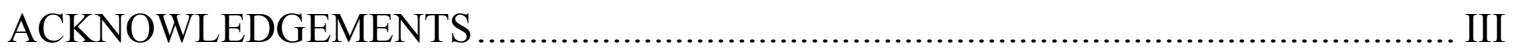

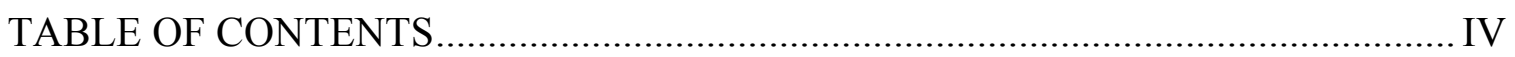

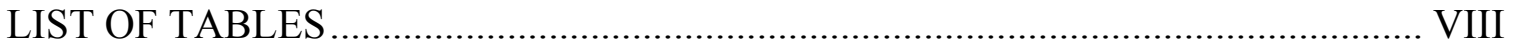

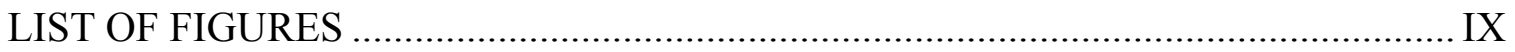

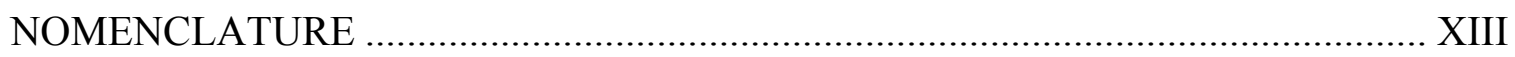

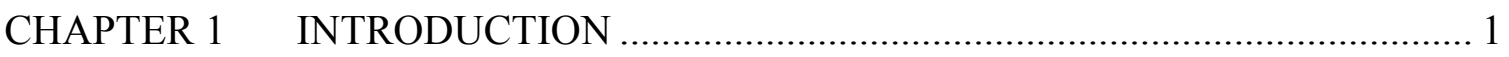

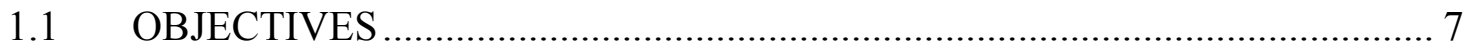

CHAPTER 2 REVIEW OF LITERATURE ……….......................................... 9

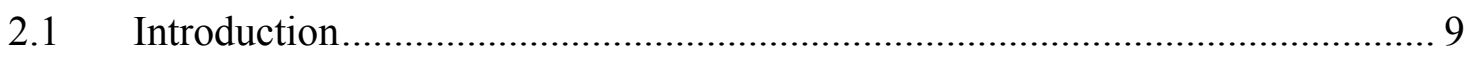

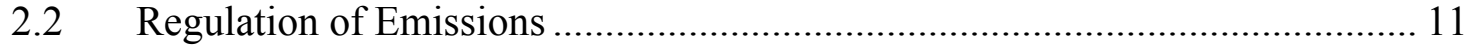

2.3 Northeast States for Coordinated Air Use Management (NESCAUM), 199712

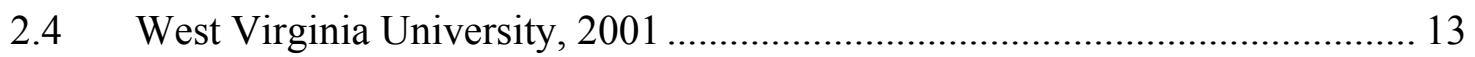

2.5 Emissions Modeling and In-Use Testing .......................................................... 14

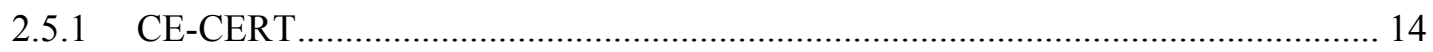

2.5.2 Georgia Tech Research Partnership...................................................................... 14

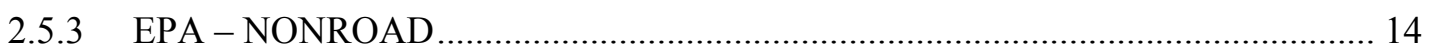

2.5.4 Cummins Engine Company ……………………………………………..... 15

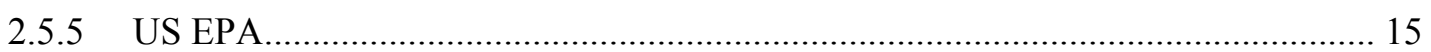

2.6 Engine Design Enhancements.................................................................. 15

2.7 Exhaust After-treatment Research and Systems ........................................... 17

2.7.1 Diesel Particulate Filters..................................................................................... 19

2.7.2 CARB Retrofit Verification Program ……………………………………….... 25

2.7.3 West Virginia University, 2002 ………………………………………….... 25

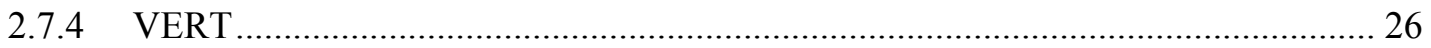

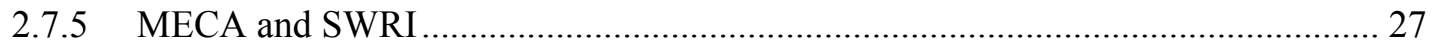

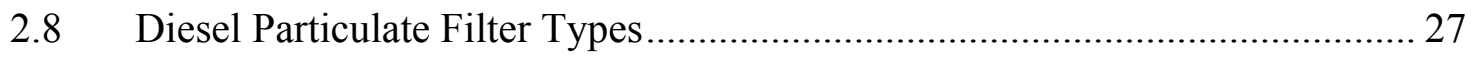

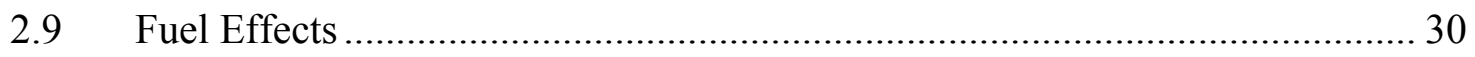

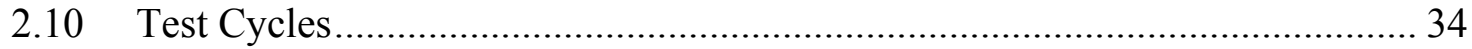

2.10.1 Federal Transient Procedure.............................................................................. 34

2.10.2 Non-road Transient Cycle (NRTC) ………………………………………….... 34 
CHAPTER 3 EXPERIMENTAL EQUIPMENT AND PROCEDURES .................. 39

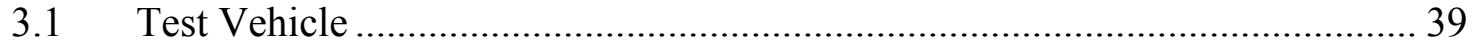

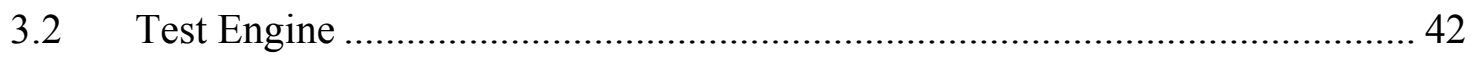

3.3 In-field Data Acquisition Equipment/Procedures ...................................... 43

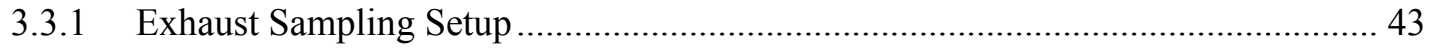

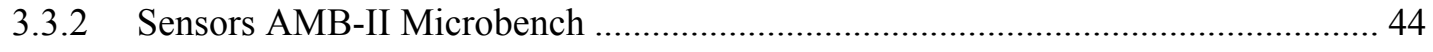

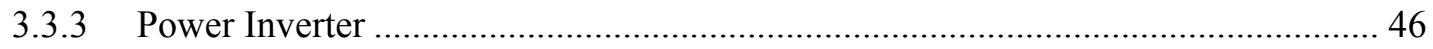

3.3.4 Caterpillar Electronic Technician Communication Adapter (CAT ET) .................. 46

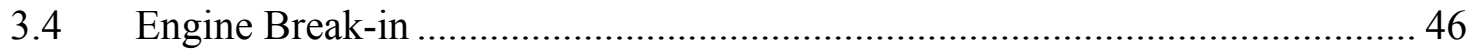

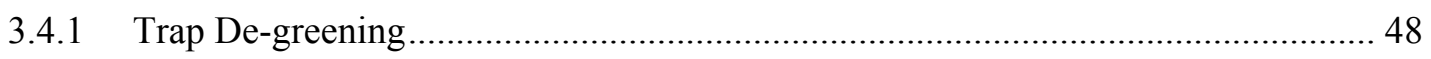

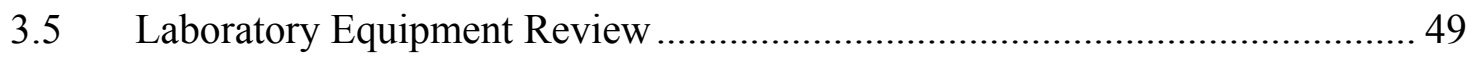

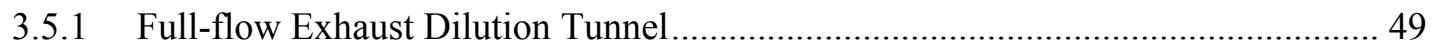

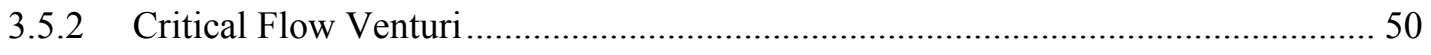

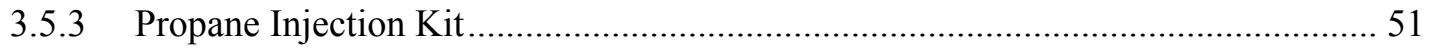

3.5.4 Secondary Dilution, Flow Measurement and Particulate Sampling System ........... 53

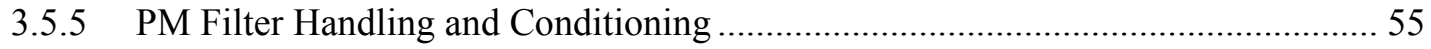

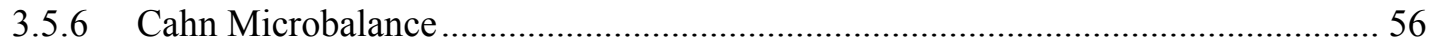

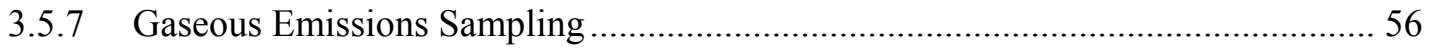

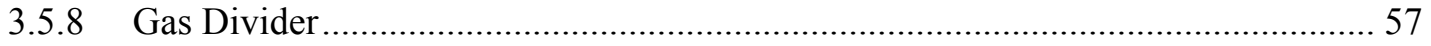

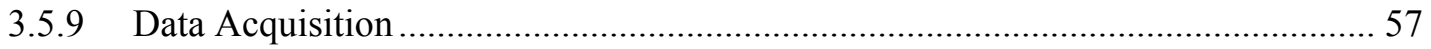

3.5.9 Exhaust Sample Gas Analysis Equipment ........................................................... 57

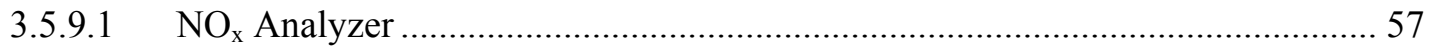

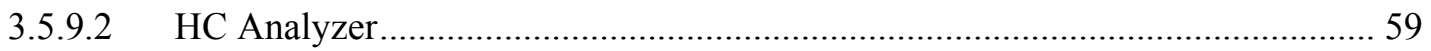

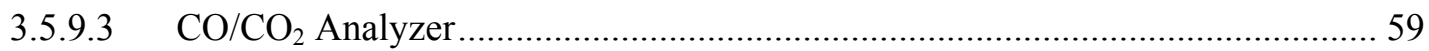

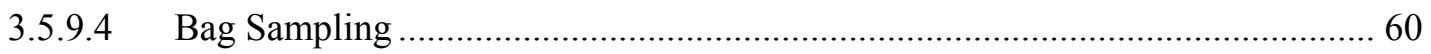

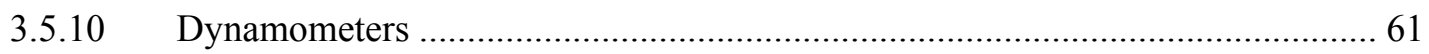

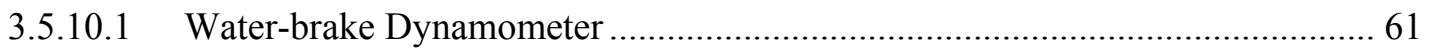

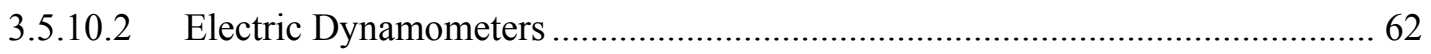

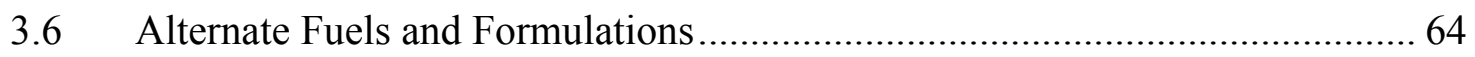

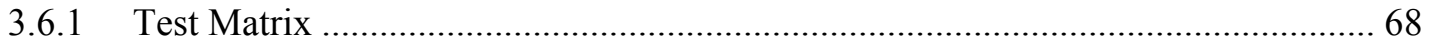

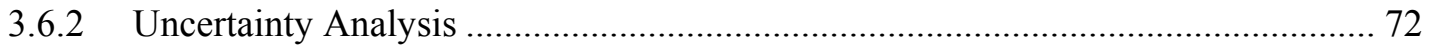

CHAPTER $4 \quad$ LABORATORY TESTING RESULTS ….................................... 73

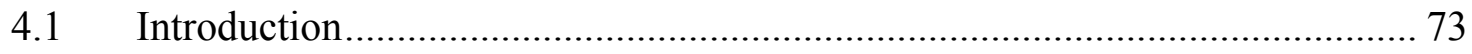




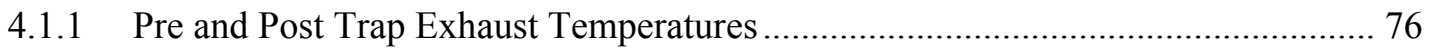

4.2 Engine Mapping and 8-mode Data .............................................................. 79

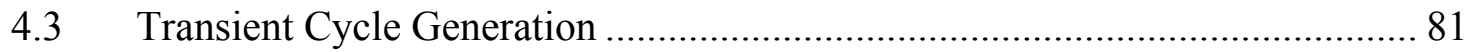

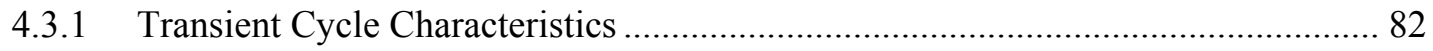

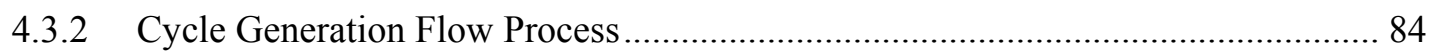

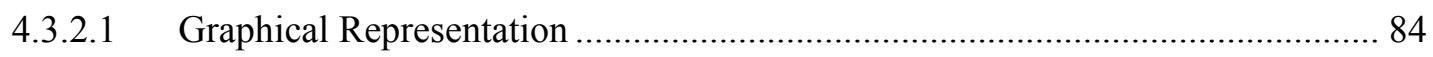

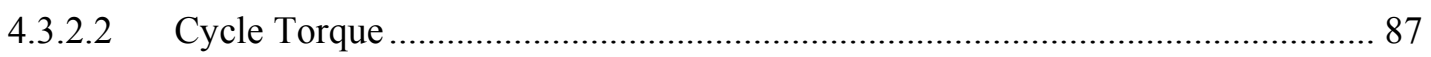

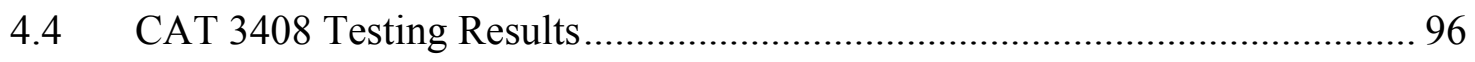

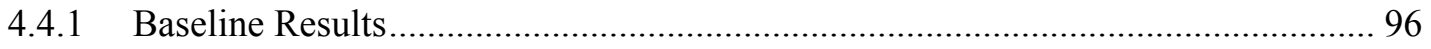

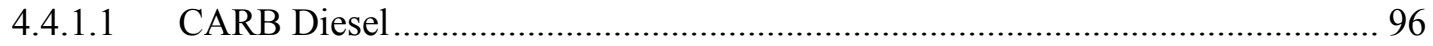

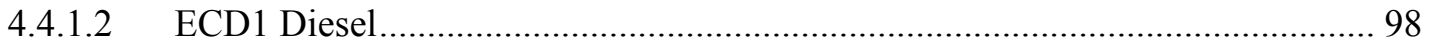

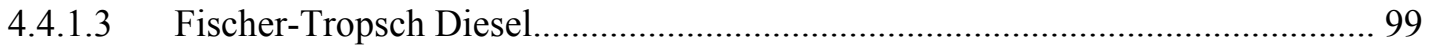

4.4.2 Emissions from ECD1 and Fischer-Tropsch Diesel Fueled Engine with DPX

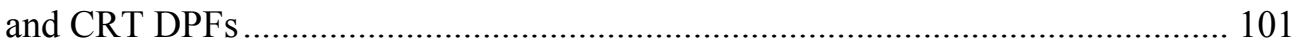

4.4.2.1 Effect of ECD1 on Regulated Emissions .......................................................... 101

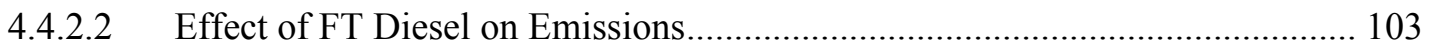

4.4.3 Retrofit versus CARB Baseline Evaluation............................................................ 104

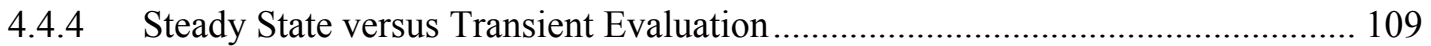

4.4.5 Effects of Fuel Properties on Emissions .................................................................. 111

4.5 AQMD Construction Equipment Trap In-field Durability Study Report.............. 116

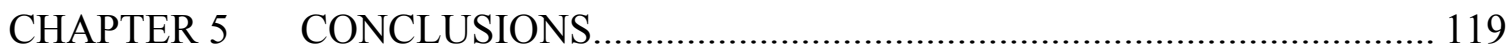

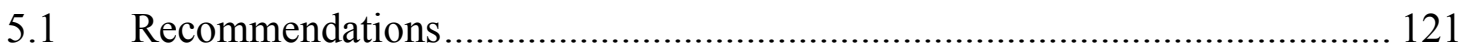

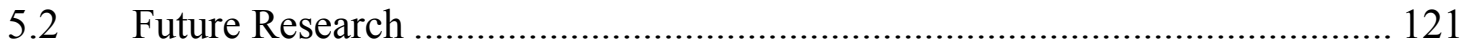

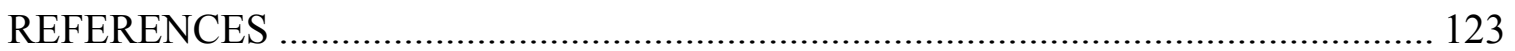

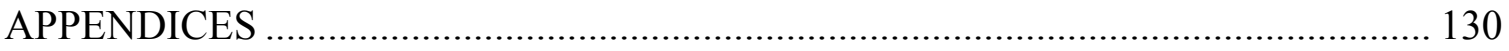

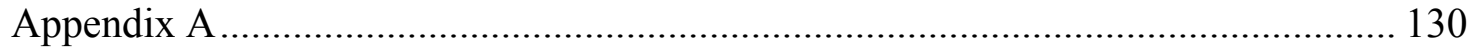

Additional Data for the 657E Scraper - Specifications of the Tractor and

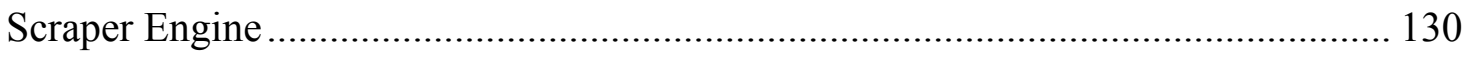

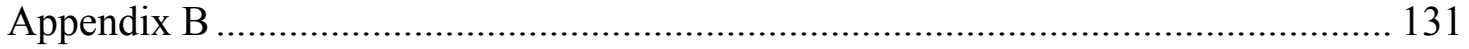

Transient Cycle Engine Speed and Torque Distribution using ECD1 Diesel ........... 131

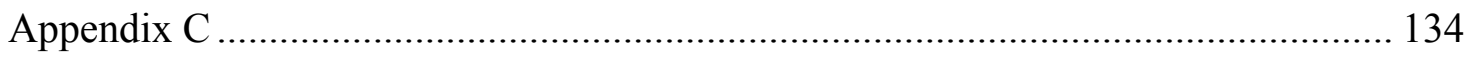

8-mode and Transient Data with Standard Deviation and Coefficient of Variance for $\mathrm{HC}, \mathrm{CO} . \mathrm{NO}_{\mathrm{x}}$, and $\mathrm{PM}$ respectively.......................................................... 134 


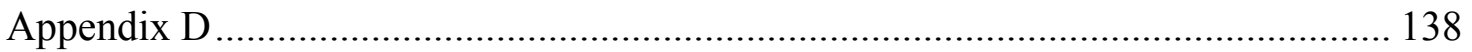

Reduction Percentages Compared to CARB Baseline for $\mathrm{HC}, \mathrm{CO}, \mathrm{NO}_{\mathrm{x}}$, and $\mathrm{PM}$

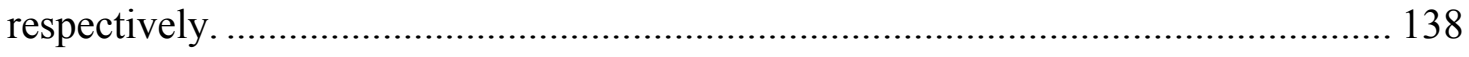

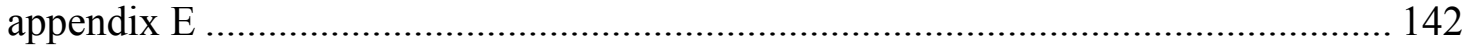

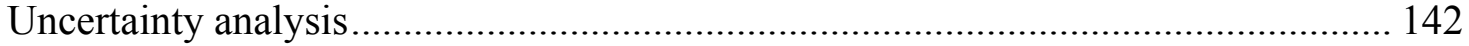




\section{LIST OF TABLES}

Table 1.1: California and Federal emissions standards [3] 3

Table 1.2: Federal standards set forth by the US EPA [1] 3

Table 1.3: Trap installation matrix for the construction off-road trap study 5

Table 1.4: Filter distribution matrix for the construction off-road trap study 5

Table 2.1: US EPA and California standards for non-road CI engines [3] 10

Table 3.1: Description of the recorded activities of a scraper duty cycle, in time and distance 41

Table 3.2: CAT 3408 engine specifications $\quad 42$

Table 3.3: 4-mode set points used during break-in 47

Table 3.4: ASTM fuel analysis performed at Saybolt Laboratories, Carson, California 65

Table 3.5: WVU's engine-dynamometer test matrix 69

Table 4.1: The ISO 8178 8-mode test cycle 74

Table 4.2: ISO 8178 C1 8-mode set points for CARB diesel 80

Table 4.3: ISO $8178 \mathrm{C1}$ 8-mode set points for ECD1 diesel 81

Table 4.4: ISO 8178 C1 8-mode set points for FT diesel 81

Table 4.5: Comparison of transient test cycles 87

Table 4.6: Overall weighted emissions for steady state and average continuous $\begin{array}{ll}\text { emissions for transient cycle } & 110\end{array}$

Table 4.7: Total aromatics versus $\mathrm{HC}, \mathrm{CO}, \mathrm{NO}_{\mathrm{x}}$ and $\mathrm{PM}$ under transient operation 114

Table 5.1: Status summary for traps and construction vehicles as of August $2003 \quad 119$ 


\section{LIST OF FIGURES}

Figure 2.1: $\quad \mathrm{PM}$ versus $\mathrm{NO}_{\mathrm{x}}$ regulations

Figure 2.2: Open-pore wall flow system of a DPF, depicting the flow of exhaust gas [3].

Figure 2.3: $\quad \mathrm{NO}_{2}$ reaction in a CRT filter [3]

Figure 2.4: Cut-away view of the patented Johnson-Matthey CRT DPF [3] 21

Figure 2.5: Picture of the Johnson-Matthey CRT used in laboratory testing 21

Figure 2.6: Picture of the Engelhard DPX used in laboratory testing 24

Figure 2.7: Target engine speed (left) and torque (right) versus time for the FTP based on engine map on a DDC Series 60 heavy-duty diesel engine [47]. 34

Figure 2.8: Normalized speed and torque over NRTC cycle (left), for constant speed engines (right) 35

Figure 2.9: Agricultural tractor cycle (left) and Backhoe loader cycle (right) 35

Figure 2.10: Crawler tractor cycle (left) and Excavator cycle (right) 35

Figure 2.11: Skid steer loader high speed (left) and high torque (right) transient cycles 36

Figure 2.12: Wheel loader high speed (left) and high torque (right) transient cycles 36

Figure 2.13: Arc welder high speed (left) and high torque (right) transient cycles 36

Figure 2.14: Agricultural tractor composite cycle 37

Figure 3.1: The 657E Scraper 39

Figure 3.2: $\quad$ Test engine - Caterpillar 3408

Figure 3.3: In-field data acquisition setup 44

Figure 3.4: Sensors Inc. AMB-II microbench analyzer 45

Figure 3.5: New adapter plate, machined on one side to couple the engine and water-brake, and the other side to couple the engine and DC dynamometer shaft coupling.

Figure 3.6: Engine break-in setup with cooling tower, instrumentation rack, and DTC throttle and dynamometer controllers 48

Figure 3.7: Engine retrofit with Engelhard particulate filter during break-in 49

Figure 3.8 Schematic of the emissions sampling and measurement system at the EERL, WVU [53] 52

Figure 3.9: Gaseous emissions analyzer bench and_PM sampling cart at the EERL 54 
Figure 3.10: Go-Power water-brake dynamometer connected to the test engine during break-in

Figure 3.11: Test engine coupled with GE DC dynamometer

Figure 4.1: Total backpressure (TBP) during break-in for Johnson-Matthey CRT 75

Figure 4.2: Total backpressure (TBP) during break-in for Engelhard DPX

Figure 4.3: Continuous 8-mode exhaust temperature data on ECD1 baseline. The 8-mode set points are shown on top of each mode

Figure 4.4: Maximum exhaust temperatures for each mode of ECD1 baseline

Figure 4.5: Maximum exhaust temperatures for each mode of CARB baseline. The last column depicts the maximum exhaust temperature on the CARB baseline transient run.

Figure 4.6: Maximum post-trap exhaust temperature during break-in set points for Johnson-Matthey trap using ECD1 diesel

Figure 4.7: Maximum post-trap exhaust temperature during break-in set points for Engelhard trap using ECD1 diesel

Figure 4.8: Engine map on CARB, ECD1 and FT fuels

Figure 4.9: Preliminary piece-wise graph of actual operation times with dummy idle times highlighted by the thick orange lines

Figure 4.10: Selected transient test cycle developed from in-field 657E scraper operation data, used in laboratory testing

Figure 4.11: Transient test cycle- 2 developed from in-field 657E scraper operation data

Figure 4.12: Transient test cycle-3 developed from in-field 657E scraper operation data

Figure 4.13: Example of engine lug curve generated by curve fitting different torque inference equations

Figure 4.14: Example of the engine lug curve with the no-load friction curve below it 89 Figure 4.15: Transient cycle for CARB fuel in terms of speed and cycle torque values 90

Figure 4.16: Transient cycle for ECD1 fuel in terms of speed and cycle torque values 91

Figure 4.17: Representative engine speed frequency distribution, 300-rpm increments, for CARB diesel 
Figure 4.18: Representative engine torque frequency distribution, for CARB diesel 93

Figure 4.19: Percentage of total cycle time for load ranges versus percent load range in transient cycle-1

Figure 4.20: Percentage of total cycle time for speed ranges versus speed ranges, CARB diesel

Figure 4.21: Percentage of total speed range time for cycle torque ranges versus cycle torque ranges in the 1601-1900 rpm speed range. Total $1600-1900 \mathrm{rpm}$ time is 760 seconds.

Figure 4.22: Percentage of total speed range time for cycle torque ranges versus cycle torque ranges in the 1901-2200 rpm speed range. Total $1901-2200 \mathrm{rpm}$ time is 848 seconds.

Figure 4.23: Comparison of PM mass emission rates between CARB baseline and ECD1 baseline

Figure 4.24: Transient cycle continuous emissions data plotted against time for CARB diesel

Figure 4.25: Transient cycle continuous emissions data plotted against time for ECD1 baseline

Figure 4.26: Baseline comparison of all test fuels under transient operation

Figure 4.27: ECD1 8-mode weighted average results for all regulated emissions

Figure 4.28: ECD1 transient cycle average results for all regulated emissions

Figure 4.29: Comparison of cycle averaged emissions of Fisher-Tropsch diesel with CRT trap and CARB baseline, under steady state operation

Figure 4.30: Comparison of cycle averaged emissions of Fisher-Tropsch diesel with CRT trap and CARB baseline, under transient operation

Figure 4.31: Comparison of CARB baseline with ECD1, with and without trap, under 8-mode steady state operation

Figure 4.32: Comparison of CARB baseline with ECD1, with and without trap, under transient operation

Figure 4.33: Overall brake-specific and corresponding reduction percentages for PM emissions, compared to CARB baseline

Figure 4.34: View of the inlet face of PM laden Engelhard DPF (post-testing) 
Figure 4.35: View of the downstream end of Engelhard DPF (post-testing), note the clean filter element

Figure 4.36: View of the inlet face of PM laden Johnson-Matthey DPF (post-testing) 108

Figure 4.37: View of the downstream end of Johnson-Matthey DPF (post-testing), note the clean filter element

Figure 4.38: $\quad$ PM versus fuel sulfur content against all fuel/filter configurations

Figure 4.39: Percentage weight of aromatics in the test fuels

Figure 4.40: Distillation recovery percentages and temperatures for all test fuels

Figure 4.41: Failure of mounting bracket on Engelhard trap (left) and exhaust pipeline (right)

Figure 4.42: Damage to flex pipe connecting Engelhard trap to exhaust outlet (left) and exhaust pipe reinforcement on Johnson-Matthey trap (right)

Figure 4.43: Filter damage on Engelhard trap

Figure $\mathrm{C} 1$ : Representative engine speed frequency distribution, $300 \mathrm{rpm}$ increments

Figure $\mathrm{C} 2$ : Representative engine torque frequency distribution

Figure C3: Percentage of total cycle time for load ranges versus percent load range in the selected test cycle

Figure C4: Percentage of total cycle time for speed ranges versus speed ranges

Figure C5: Percentage of total cycle time versus cycle torque ranges in the $1601-1900 \mathrm{rpm}$ speed range. Total $1600-1900 \mathrm{rpm}$ time is 847.5 seconds.

Figure C6: Percentage of total cycle time for cycle torque ranges versus cycle torque ranges in the 1901-2200 rpm speed range. 


\section{NOMENCLATURE}

\begin{tabular}{|c|c|}
\hline $\mathrm{AC}$ & Alternating Current \\
\hline CARB & California Air Resources Board \\
\hline CARB Baseline & Engine operated on CARB diesel with no particulate filter \\
\hline CE-CERT & Center for Environmental Research and Technology \\
\hline CFR & Code of Federal Regulations \\
\hline CRT & Continuous Regenerating Trap \\
\hline $\mathrm{DC}$ & Direct Current \\
\hline DPF & Diesel Particulate Filter \\
\hline DPM & Diesel Particulate Matter \\
\hline ECD1 & Emission Control Diesel-1 \\
\hline ECD1 Baseline & Engine operated on ECD1 diesel with no particulate filter \\
\hline ECD1-CRT & Engine operated on ECD1 diesel with CRT filter \\
\hline ECD1-DPX & Engine operated on ECD1 diesel with DPX filter \\
\hline $\mathrm{ECM}$ & Electronic Control Module \\
\hline EERL & Engines and Emissions Research Laboratory \\
\hline EGR & Exhaust Gas Recirculation \\
\hline FT-CRT (GTL-CRT) & Engine operated on Fischer-Tropsch diesel with CRT filter \\
\hline GTL & Gas-to-Liquid \\
\hline GVW & Gross Vehicle Weight \\
\hline HFID & Heated Flame Ionization Detector \\
\hline IARC & International Agency for Research on Cancer \\
\hline MECA & Manufacturers of Emission Controls Association \\
\hline MSHA & Mine Safety and Health Administration \\
\hline
\end{tabular}




$\begin{array}{ll}\text { NDIR } & \text { Non Dispersive Infra Red } \\ \text { NIOSH } & \text { National Institute of Occupational Safety and Health } \\ \text { NIST } & \text { National Institute of Standards and Technology } \\ \text { OSHA } & \text { Occupational Safety and Health Administration } \\ \text { ppm } & \text { parts per million } \\ \text { SCR } & \text { Selective Catalytic Reduction } \\ \text { SWRI } & \text { Southwest Research Institute } \\ \text { ULEV } & \text { Ultra Low Emission Vehicle } \\ \text { USEPA } & \text { United States Environmental Protection Agency } \\ \text { WVU } & \text { West Virginia University }\end{array}$




\section{CHAPTER 1 INTRODUCTION}

The reduction of exhaust emissions from diesel engines is one of the more challenging areas of research today. Several different techniques and methodologies have been applied to reduce emissions from diesel engines. Like any other internal combustion engine, diesel engines convert the chemical energy contained in the fuels to mechanical power, through combustion. The main by-products of combustion are carbon monoxide $(\mathrm{CO})$, carbon dioxide $\left(\mathrm{CO}_{2}\right)$, total hydrocarbons (THC), oxides of nitrogen $\left(\mathrm{NO}_{\mathrm{x}}\right)$, and particulate matter (PM). Diesel particulate matter (DPM) and $\mathrm{NO}_{\mathrm{x}}$ are two of the most potentially harmful components of the diesel engine exhaust. DPM mainly consists of elemental carbon, metallic ash, sulphates, heavy hydrocarbons and water. Since 1970, the US EPA has regulated on-road diesel emissions [1]. Only in 1990 nonroad diesel emissions were regulated have been imposed on diesel engine manufacturers. As a result engine-specific $\mathrm{NO}_{\mathrm{x}}$ has decreased by approximately $80 \%$, and new engines emit approximately 90\% less PM than was emitted in the 1970s. The 1974 standards allowed 16 $\mathrm{g} / \mathrm{bhp}-\mathrm{hr}$ of $\mathrm{HC}$ and $\mathrm{NO}_{\mathrm{x}}$ and $40 \mathrm{~g} / \mathrm{bhp}-\mathrm{hr}$ of CO. Tier 1 non-rioad standards effective since 1994 are given in Table 1.2.

The two most promising solutions to this problem of DPM emissions till the late 1990's were engine design changes, and alternative fuels. Exhaust after-treatment technology has been used since the start of 2000. Devices such as diesel particulate filters (DPF), also known as particulate traps, control emissions by physically capturing particulate matter and by using catalysts to convert the chemical compositions of exhaust matter. They not only help reduce gaseous emission levels using ultra low sulfur fuels (sulfur levels below 50 ppm weight percent), but also capture the particulate matter through innovative filtration methods.

The two DPFs used in the current study were the continuously regenerating trap (CRT) from Johnson-Matthey and the catalyzed diesel particulate filter $\left(\mathrm{DPX}^{\mathrm{TM}}\right)$ from Engelhard. The 
CRT is a two-stage, passive, catalytic, ceramic wall-flow filter. The DPX ${ }^{\mathrm{TM}}$ from Engelhard used a patented catalytic technology to change the chemical structure of diesel exhaust. A detailed description of the filters is given in Section 2.7.1.

The first California standards, for the mobile, off-road, heavy-duty category were formulated in 1996, for engines of $175 \mathrm{Hp}$ and greater [3]. The United States Environmental Protection Agency (EPA) then followed with a $\mathrm{NO}_{\mathrm{x}}$ regulation on vehicles of $50 \mathrm{Hp}$ and higher [1]. In 1998, CARB identified particulate matter from diesel-fueled engines as a toxic air contaminant. As a result, in September 2000, the Board approved the Risk Reduction Plan for Diesel-Fueled Engines and Vehicles. This plan outlines individual particulate matter control measures for possible future development and adoption by the Board. At the time of the October 1998 rulemaking, post-2005 particulate matter standards were not specified for off-road compression-ignition engines between 50 and 750 horsepower. The Risk Reduction Plan for Diesel-Fueled Engines and Vehicles included a measure to adopt 0.02 grams/brake-horsepowerhour emission standard for particulate matter from off-road compression-ignition engines. The current and future standards (ARB and EPA) are given in the following table. The engine tested was rated at $400 \mathrm{Hp}(299 \mathrm{KW})$ at $1900 \mathrm{rpm}$. The Federal standards remain the same as the 1996+ California standards. Table 1.2 shows the drastic reduction in emission levels required to meet the regulations. These are the standards put forth in the CFR 40, Part 89, Subpart A. The EPA supports retrofitting non-road compression ignition engines, provided the standards set forth for retrofitting in the state of California are met. 
Table 1.1: California and Federal emissions standards [3]

\section{California Emission Standards Reference for Non-road CI Engines}

\begin{tabular}{|c|c|c|c|c|c|}
\hline Rated Power & Year & $\mathrm{CO}(\mathrm{g} / \mathrm{bhp}-\mathrm{hr})$ & $\mathrm{HC}(\mathrm{g} / \mathrm{bhp}-\mathrm{hr})$ & $\mathrm{NO}_{\mathrm{x}}$ (g/bhp-hr) & $\mathrm{PM}$ (g/bhp-hr) \\
\hline \multirow{3}{*}{$175 \leq \mathrm{hp} \leq 750$} & $1996-2000$ & 8.5 & 1.0 & 6.9 & 0.4 \\
\cline { 2 - 6 } & $2001+$ & 2.6 & 1.0 & 5.8 & 0.16 \\
\hline
\end{tabular}

Table 1.2: Federal standards set forth by the US EPA [1]

\begin{tabular}{|c|c|c|c|c|c|c|}
\hline \multirow{2}{*}{$\begin{array}{c}\text { Rated Power } \\
(\mathrm{KW})\end{array}$} & Tier & Model Year & $\mathrm{CO}$ & $\mathrm{HC}$ & $\mathrm{NO}_{\mathrm{x}}$ & $\mathrm{PM}$ \\
\cline { 2 - 7 } & & & & & & \\
\hline \multirow{3}{*}{$25<\mathrm{KW}<450$} & Tier 1 & 1996 & 11.4 & 1.3 & 9.2 & 0.54 \\
\cline { 2 - 7 } & Tier 2 & 2001 & 3.5 & & & \multirow{2}{*}{0.2} \\
\cline { 2 - 7 } & Tier 3 & 2006 & 3.5 & & & 0.2 \\
\hline
\end{tabular}

In 1998, EPA adopted more stringent emissions standards for non-road diesel engines [3].

Tier 3 of the standards addressed newer technologies for controlling PM. Major engine manufacturing companies also researched emission control technologies to meet the standards. These standards are expected to drastically reduce emissions from non-road diesel engines, which are already a major source of particulate matter and ozone-forming compounds. The EPA has also taken steps towards developing in-use emissions concerns (such as developing a transient cycle to better characterize in-use PM emissions). They have developed newer standards to take effect in 2004 and even more stringent standards are to take effect in 2007. As part of this approach, the Voluntary Retrofit Diesel Program was started, which evaluates the effectiveness of DPFs as an after-treatment device and helps in the reduction of particulate matter [4]. The program evaluates the emission reduction performance of the after-treatment technologies, including their durability, and identifies engine operating conditions that must exist for these technologies to achieve those reductions. As the individual states, EPA, CARB, and other 
agencies look for different methodologies to reduce PM, exhaust emission control of non-road engines become critical, and hence the need for this research.

In 2000, the South Coast Air Quality Management District (SCAQMD) along with the California Air Resources Board (CARB), County Sanitation Districts of Los Angeles County (CSDLAC), and Construction Industry Air Quality Coalition (CIAQC) joined efforts to investigate (i) the emission benefits of retrofitting existing off-road heavy-duty equipment mainly with particulate filter technology, and (ii) determine the durability of the retrofitted DPM filters. The project was titled "Emissions Characterization of Particulate Trap Equipped Existing OffRoad Heavy-duty Construction Equipment Operating on Low-Sulfur Diesel Fuel". The work plan called for testing the durability of twenty-eight pieces of off-road vehicles with ultra low sulfur fuels and retrofit with passive DPFs. The work also involved evaluation of emissions from a representative scraper (Caterpillar 657E) engine (Caterpillar 3408) in an engine test cell. The engine dynamometer testing of a representative engine was done at the EERL, WVU. Diesel particulate filters used in this study were retrofitted on vehicles in the field and removed for laboratory testing. Tables 1.3 and 1.4 show the vehicle and DPF combinations, which were included in the study. Subsequent to the laboratory testing, the DPFs were installed back on the respective vehicles to accumulate an additional 1400 hours of field exposure prior to the second round of laboratory testing in Fall 2003. A similar study was undertaken by LeTavec et al. [5]. 
Table 1.3: Trap installation matrix for the construction off-road trap study

\begin{tabular}{|c|c|c|c|c|c|c|c|c|c|c|c|c|}
\hline Owner & Eq\# & Equip Type & Engine Type & Trap & Trap Type & Trap\# & $\begin{array}{l}\text { Install } \\
\text { date }\end{array}$ & Fuel & Eng Yr & Rated HP & Controls & Type \\
\hline CSDLAC & 6604 & 657E scraper & 3408 (Rear) & $\mathrm{JM}$ & 20X15 CRT & 4002 & $10 / 7 / 02$ & ULSD & 1996 & 400 & & \\
\hline CSDLAC & 6604 & 657E scraper & 3412 (Front) & $\mathrm{JM}$ & 15X15 CRT & 4004 & $10 / 7 / 02$ & ULSD & 1996 & 550 & JM trap w/ testing & \\
\hline CSDLAC & 6604 & 657E scraper & 3412 (Front) & $\mathrm{JM}$ & 15X15 CRT & 4004 & $10 / 7 / 02$ & ULSD & 1996 & 550 & JM trap w/ testing & \\
\hline CSDLAC & 6605 & 657E scraper & 3408 (Rear) & Eng & DPX 20X15 & 9177 & & ULSD & 1996 & 400 & & DPX9177 \\
\hline CSDLAC & 6605 & 657E scraper & 3412 (Front) & Eng & DPX 20X15 & 9177 & & ULSD & 1996 & 550 & Englehard trap w/o testing & DPX9177 \\
\hline CSDLAC & 6605 & 657E scraper & 3412 (Front) & Eng & DPX 20X15 & 9177 & & ULSD & 1996 & 550 & Englehard trap w/o testing & DPX9177 \\
\hline CSDLAC & 6606 & 657E scraper & 3408 (Rear) & Eng & DPX 20X15 & 9177 & & ULSD & 1996 & 400 & & \\
\hline CSDLAC & 6606 & 657E scraper & 3412 (Front) & Eng & DPX 20X15 & 9177 & & ULSD & 1996 & 550 & Englehard trap $\mathrm{w} /$ testing & DPX9177 \\
\hline CSDLAC & 6606 & 657E scraper & 3412 (Front) & Eng & DPX 20X15 & 9177 & & ULSD & 1996 & 550 & Englehard trap $\mathrm{w} /$ testing & DPX9177 \\
\hline CSDLAC & 6607 & 657E scraper & 3408 (Rear) & $\mathrm{Ctl} \mathrm{C}$ & Control (C) & -- & -- & CARB & 1996 & 400 & Control Unit & \\
\hline CSDLAC & 6607 & 657E scraper & 3412 (Front) & $\mathrm{Ctl} \mathrm{C}$ & Control (C) & -- & -- & CARB & 1996 & 550 & Control Unit & \\
\hline CSDLAC & 6608 & 657E scraper & 3408 (Rear) & $\mathrm{Ctl} \mathrm{U}$ & Control (U) & -- & -- & ULSD & 1996 & 400 & Control Unit & \\
\hline CSDLAC & 6608 & 657E scraper & 3412 (Front) & Ctl U & Control (U) & -- & -- & ULSD & 1996 & 550 & Control Unit & \\
\hline CSDLAC & 6620 & D9N dozer & 3408 & $\mathrm{Ctl} \mathrm{C}$ & Control (C) & -- & -- & CARB & 1989 & 400 & Control Unit & \\
\hline CSDLAC & 6621 & D9N dozer & 3408 & JM & 20X15 CRT & $4001 / 3$ & $10 / 9 / 02$ & ULSD & 1989 & 400 & JM trap w/ testing & \\
\hline CSDLAC & 6653 & D9R dozer & 3408 & Ctl U & Control (U) & -- & -- & ULSD & 2000 & $405(370)$ & Control Unit & \\
\hline CSDLAC & 6654 & D9R dozer & 3408 & Eng & DPX 20X15 & 9177 & & ULSD & 2000 & $405(370)$ & Englehard trap $\mathrm{w} /$ testing & DPX9177 \\
\hline CSDLAC & 6655 & D9R dozer & 3408 & JM & 20X15 CRT & $4001 / 3$ & $11 / 26 / 02$ & ULSD & 2000 & $405(370)$ & JM trap w/ testing & \\
\hline C. W. Poss & 402 & 824B dozer & D343 & Eng & DPX 15X15 & 9121/9248 & & ULSD & 1967 & 315 & Was \#401 & DPX9248(2) \\
\hline C. W. Poss & 409 & 834B dozer & D343 & $\mathrm{JM}$ & 15X15 CRT & 4005 & $11 / 22 / 02$ & ULSD & 1999rbld & 450 & Was \#403, then \#402 & \\
\hline C. W. Poss & 407 & 824B dozer & D343 & JM & 15X15 CRT & 4005 & $11 / 21 / 02$ & ULSD & & 315 & Was \#406 & \\
\hline C. W. Poss & 579 & 623B water pull & 3406 Tractor & Eng & DPX 11x14 & 9216 & & ULSD & 1974 & & & DPX9216 \\
\hline C. W. Poss & 629 & 651B scraper & D346 & Ctl U & Control (U) & -- & -- & ULSD & & 550 & Was \#592 & \\
\hline C. W. Poss & 600 & 651B scraper & D346 & Eng & DPX $20 \times 15$ & 9177 & & ULSD & 1975 & 550 & & DPX9177 \\
\hline C. W. Poss & 600 & 651B scraper & D346 & Eng & DPX 20X15 & 9177 & & ULSD & 1975 & 550 & & \\
\hline C. W. Poss & 611 & 651B scraper & D346 & Eng & DPX 20X15 & 9177 & & ULSD & & 550 & Was \#601 & \\
\hline C. W. Poss & 611 & 651B scraper & D346 & Eng & DPX 20X15 & 9177 & & ULSD & & 550 & Was \#601 & \\
\hline C. W. Poss & 605 & 651B scraper & D346 & JM & 20X15 CRT & 4006 & $11 / 20 / 02$ & ULSD & 1973 & 550 & & \\
\hline C. W. Poss & 605 & 651B scraper & D346 & JM & 20X15 CRT & 4006 & $11 / 20 / 02$ & ULSD & 1973 & 550 & & \\
\hline C. W. Poss & awol & 824B dozer & 3406 & Ctl U & Control (U) & -- & -- & ULSD & & & Control Unit & \\
\hline
\end{tabular}

Table 1.4: Filter distribution matrix for the construction off-road trap study

\begin{tabular}{|c|c|c|c|c|c|c|c|c|c|c|}
\hline \multicolumn{2}{|c|}{ Vehicles } & \multicolumn{2}{|c|}{ CSDLAC } & \multicolumn{2}{|c|}{ C.W.Poss } & \multicolumn{2}{|c|}{ Total Program } & \multicolumn{2}{|c|}{ Total Program } & \multirow{2}{*}{$\begin{array}{l}\text { Program, } \\
\text { Both } \\
\text { Suppliers }\end{array}$} \\
\hline Equipment Model \# & $\begin{array}{c}\text { Engine } \\
\text { Model \# }\end{array}$ & Engelhard & Johnson Matthey & Engelhard & Johnson Matthey & $\begin{array}{c}\text { Engel- } \\
\text { hard }\end{array}$ & $\begin{array}{l}\text { Johnson } \\
\text { Matthey }\end{array}$ & CSDLAC & CWPoss & \\
\hline D9R dozer (elect) & 3408 & $1(6654)$ & $1(6655)$ & & & 1 & 1 & 0 & 0 & 0 \\
\hline D9N dozer (mech) & 3408 & & $1(6621)$ & & & & 1 & 0 & 0 & 0 \\
\hline 651B scraper & D346 & & & $2(600,601)$ & $1(605)$ & 2 & 1 & 0 & 0 & 0 \\
\hline 824B dozer & D343 & & & $1(401)$ & $2(403,406)$ & 1 & 2 & 0 & 0 & 0 \\
\hline 623B water pull & 3406 & & & $1(579)$ & & 1 & & 0 & 0 & 0 \\
\hline Total Number of & Vehicles & 3 & 3 & 4 & 3 & 7 & 6 & 6 & 7 & 13 \\
\hline
\end{tabular}

\begin{tabular}{|c|c|c|c|c|c|c|c|c|c|c|}
\hline \multicolumn{2}{|c|}{ Engines } & \multicolumn{2}{|c|}{$\overline{\text { CSDLAC }}$} & \multicolumn{2}{|c|}{ C.W.Poss } & \multicolumn{2}{|c|}{ Total Program } & \multicolumn{2}{|c|}{ Total Program } & \multirow{2}{*}{$\begin{array}{l}\text { Program, } \\
\text { Both } \\
\text { Suppliers }\end{array}$} \\
\hline Equipment Model \# & $\begin{array}{l}\text { Engine } \\
\text { Model \# }\end{array}$ & Engelhard & Johnson Matthey & Engelhard & Johnson Matthey & $\begin{array}{c}\text { Engel- } \\
\text { hard }\end{array}$ & $\begin{array}{l}\text { Johnson } \\
\text { Matthey }\end{array}$ & CSDLAC & CWPoss & \\
\hline D9R dozer (elect) & 3408 & 1 & 1 & & & 1 & 1 & 2 & 0 & 2 \\
\hline D9N dozer (mech) & 3408 & & 1 & & & & 1 & 1 & 0 & 1 \\
\hline 657E scraper rear & 3408 & 2 & 1 & & & 2 & 1 & 3 & 0 & 3 \\
\hline 651B scraper & D346 & & & 2 & 1 & 2 & 1 & 0 & 3 & 3 \\
\hline 824B dozer & D343 & & & 1 & 2 & 1 & 2 & 0 & 3 & 3 \\
\hline 623B water pull & 3406 & & & 1 & & 1 & & 0 & 1 & 1 \\
\hline
\end{tabular}

\begin{tabular}{|c|c|c|c|c|c|c|c|c|c|c|}
\hline \multicolumn{2}{|l|}{ Filters } & \multicolumn{2}{|c|}{$\overline{\text { CSDLAC }}$} & \multicolumn{2}{|c|}{ C.W.Poss } & \multicolumn{2}{|c|}{ Total Program } & \multicolumn{2}{|c|}{ Total Program } & \begin{tabular}{|c|} 
Program, \\
Both \\
Suppliers
\end{tabular} \\
\hline D9R dozer (elect) & 3408 & DPX 20x15 & 20x15CRT & & & 1 & 1 & 2 & & 2 \\
\hline D9N dozer (mech) & 3408 & & $20 \times 15 \mathrm{CRT}$ & & & & 1 & 1 & & 1 \\
\hline 657E scraper rear & 3408 & DPX 20x15 2/2 & $20 \times 15 \mathrm{CRT}$ & & & 2 & 1 & 3 & & 3 \\
\hline 651B scraper & D346 & & & DPX20x15 4/2 & $20 \times 15$ CRT $2 / 1$ & 4 & 2 & & 6 & 6 \\
\hline $824 \mathrm{~B}$ dozer & D343 & & & DPX15x15 & 15x15CRT $2 / 2$ & 1 & 2 & & 3 & 3 \\
\hline 623B water pull & 3406 & & & DPX11×14 & & 1 & & & 1 & 1 \\
\hline
\end{tabular}


WVU tested the engine using a steady state cycle and also employed a transient cycle that was developed using in-field operational data. The development of on-board emission measurement systems has helped in acquisition of emissions data while the vehicle in question is operating through its in-field duty cycle. The engine speed can be obtained from the tachometer signal from the alternator, or from some other type of speed sensor. The temperature readings for intake and exhaust systems are acquired using thermocouples. Torque may be measured through torque sensing devices placed in the driveline of the drive shaft. However, the difficulty of accessing the shafts makes this option almost impossible. Modern engines control the fuel rate through an Electronic Control Unit (ECU) that is integral to the engine. The ECU broadcasts speed and percent load (or torque) in addition to information on other engine operating parameters. An ECU protocol adapter was used in this study to obtain speed and torque information. Inferring torque from $\mathrm{CO}_{2}$ data was also explored in this study. A Sensors Inc. AMB-II solid state non-dispersive infrared detector (NDIR) based microbench was used to collect $\mathrm{CO}_{2}$ concentration data from the raw exhaust stream. Since the amount of $\mathrm{CO}_{2}$ emitted and the engine power are linearly related, the engine speed along with $\mathrm{CO}_{2}$ can be used to predict torque. Due to technical difficulties experienced in obtaining the speed signal from the engine and other software problems relating to the Sensors micro bench, the data from the micro bench was not used to infer torque values.

An after-treatment device is a component used to reduce engine exhaust emissions downstream of the combustion chamber. Catalytic converters and particulate traps are examples of after-treatment devices. These devices are currently being used to reduce PM emissions extensively. The filtration devices along with reformulated fuels form an excellent combination in filtering out the particulate matter from the exhaust stream. The three primary types are the oxidation catalysts, particulate traps and the continuously regenerating traps. They have also been used to reduce $\mathrm{NO}_{\mathrm{x}}$, by using systems such as SCR and EGR. In SCR systems, urea solution is added to a catalyst, which reacts with the exhaust to reduce $\mathrm{NO}_{x}$. In EGR, the exhaust gas is fed 
back to the intake, which in turn cools the intake air. This reduces the combustion temperatures, reducing $\mathrm{NO}_{\mathrm{x}}$ formation. Reformulated fuels have been researched as an option for reducing emissions. Fuels with high cetane number, low aromatic content, and low sulfur content have known to be beneficial. After-treatment devices require low sulfur fuels for their proper operation and hence fuels like the Fischer-Tropsch synthetic diesel look promising.

\subsection{OBJECTIVES}

The global objective of the year-long construction equipment trap study was to determine the mechanical durability of DPFs that were retrofit on construction equipment, over prolonged periods of in-field operation, and to assess the emission benefits of particulate trap retrofit on construction equipment.

The specific objectives of this study were to evaluate the exhaust emissions from a Caterpillar 3408 engine on an engine dynamometer. The engine was exercised over ISO 8178 steady state schedule and a transient cycle that was representative of the in-field duty cycle. The engine was operated on a CARB specification diesel fuel, followed by ultra low sulfur ECD1 fuel without any DPF, and then with a Johnson-Matthey CRT and an Engelhard DPX. Emissions were evaluated at the beginning of the yearlong program, and once again after 1400 hours of engineDPF operation. The test engine was a rebuilt, mechanically controlled, 8-cylinder, Caterpillar 3408 , a rear engine taken out of a 657E Scraper. The in-field data was collected from a $657 \mathrm{E}$ Scraper with a Caterpillar 3408E electronically controlled rear engine. The engine speed and torque were logged using the Electronic Technician software to record the ECU generated data, using a communication adapter, both supplied by Caterpillar.

The tasks over the year long testing period included fuel and diesel particulate filter procurement (Johnson-Matthey and Engelhard), engine baseline emissions testing, engine dynamometer testing, retrofit of equipment with traps, on-board PM emission testing, engine 
emission testing, and final engine dynamometer testing on the same engine tested previously. The specific tasks included:

1. Procure the Caterpillar engine for laboratory testing from Sukut Construction Inc.

2. Collect in-field transient speed and torque data, in Calabasas, California.

3. Develop a representative cycle from in-field transient data at EERL, WVU.

4. Measure brake-specific emissions from the retrofitted test engine, on a representative transient cycle and the ISO 8178 8-mode cycle, using ultra low sulfur fuels. 


\section{CHAPTER 2 REVIEW OF LITERATURE}

\section{$2.1 \quad$ INTRODUCTION}

This chapter describes, in brief, previous research conducted related to heavy-duty diesel in-use, off-road, and on-board emissions testing. It also discusses a few of the laboratory test cycles used presently to recreate real world conditions. Some of the programs on diesel particulate filter testing have also been reviewed.

Diesel engines form an important part of the transportation and industrial sector. Heavyduty equipment in the form of buses, trucks, tractors, scrapers, and bulldozers form the majority of the numbers of this sector. During the last decade of extensive off-road emissions control, the US EPA has stepped up its activities and regulations towards more stringent emission levels. Both on and off-highway vehicles have been the major sources of air pollution. The regulations for off-road emissions has been more recent, starting only in 1994 and has steadily kept a check on the emissions levels from the off-road category of equipment [3]. Table 2.1 presents the gradual decrease in the allowable levels of gaseous and particulate emissions from a three tiered emissions reduction scheme for non-road compression ignition engines, as set forth in the CFR 40, Part 89, Subpart A [2].

Diesel engines are highly robust and reliable machines and can be used for a number of years. Their usual life span is around 10-15 years but can be substantially increased by rebuilding the engines, which takes the life span up to 30 years. Though off-road engines generally operate in large open spaces, improper operation and irregular maintenance cause an increase in the pollution in the surrounding areas. One of the major problems in assessing the damage done by diesel exhaust alone is the difficulty in quantifying the amount of diesel matter in the atmosphere. The atmosphere is a mixture of numerous gases and particulate matter. Diesel exhaust also changes its physical and chemical structure once it is exposed to these gases. The advent of new technologies in the form of newer engine design enhancements, post-exhaust technologies and 
newer fuel formulations also cause changes in the form of diesel exhaust. Hence, generating an emissions inventory in itself is quite a challenging task. A recent study conducted by the Health Effects Institute has revealed the harmful effects of diesel particulate matter, particularly $\mathrm{PM}_{10}$ and $\mathrm{PM}_{2.5}$, causing lung disorders and other respiratory problems [6]. Extensive research has been conducted over the years, to reduce the risk of air pollution due to diesel engines. There have been significant developments in fuel injection systems, engine combustion chamber designs, injection timing studies, and alternate fuel formulations. The efforts have gone further in trying to control the post-combustion stage, by using after-treatment devices, reaction catalysts to convert incomplete combustion products into much safer compounds. Several organizations have ventured into the area of exhaust gas re-circulation, electronically controlled injection and cooling systems to meet regulated emission levels. Khair [7] explains the latest technical advances towards the twenty-first century diesel engine. In this matter, the off-highway research closely follows the on-highway research trend. Off-road emission standards were first implemented in California in 1996. Table 2.1 gives the current and future emissions standards being followed.

Table 2.1: US EPA and California standards for non-road CI engines [3]

\begin{tabular}{|c|c|c|c|c|c|c|}
\hline & Rated Power & Year & $\begin{array}{l}\text { CO } \\
\text { (g/bhp-hr) }\end{array}$ & $\begin{array}{l}\text { HC } \\
\text { (g/bhp-hr) }\end{array}$ & $\begin{array}{l}\mathrm{NO}_{\mathrm{x}} \\
\text { (g/bhp-hr) }\end{array}$ & $\begin{array}{l}\text { PM } \\
\text { (g/bhp-hr) }\end{array}$ \\
\hline $\begin{array}{l}\bar{\pi} \\
\frac{\pi}{0} \\
\frac{0}{0} \\
4\end{array}$ & $175<=h p<750$ & $1996+$ & 8.5 & 1.0 & 6.9 & 0.4 \\
\hline \multirow{6}{*}{ 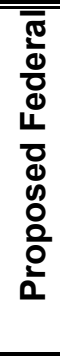 } & \multirow[b]{2}{*}{$175<=h p<300$} & 2003 & 2.6 & & 4.9 & 0.15 \\
\hline & & $2006+$ & 2.6 & & 3.0 & \\
\hline & \multirow[b]{2}{*}{$300<=\mathrm{hp}<600$} & 2001 & 2.6 & & 4.8 & 0.15 \\
\hline & & $2006+$ & 2.6 & & 3 & \\
\hline & \multirow[b]{2}{*}{$600<=h p<750$} & 2002 & 2.6 & & 4.8 & 0.15 \\
\hline & & $2006+$ & 2.6 & & 3 & \\
\hline \multirow{2}{*}{ 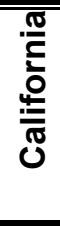 } & \multirow[b]{2}{*}{$175<=\mathrm{hp}<750$} & $\begin{array}{l}1996- \\
2000 \\
\end{array}$ & 8.5 & 1.0 & 6.9 & 0.4 \\
\hline & & $2001+$ & 8.5 & 1.0 & 5.8 & 0.16 \\
\hline
\end{tabular}




\subsection{REGULATION OF EMISSIONS}

Mobile emissions are broadly classified as On-road and Off-road. Based on different test cycles used in laboratory testing, emissions are quantified in terms of grams of pollutant per unit of work done or grams of pollutant per unit distance. Different test cycles are used during engine dynamometer testing, such as the FTP-75, US-06, and SC03 for the on-road engine tests and the FTP, ESC for the off-road engine tests. The on-road cycles are more commonly speed versus time cycles whereas the off-road cycles are based on speed and torque or percent load versus time. Off-road certification is generally done in different tiers for different horsepower groups. These engines are certified using steady state cycles.

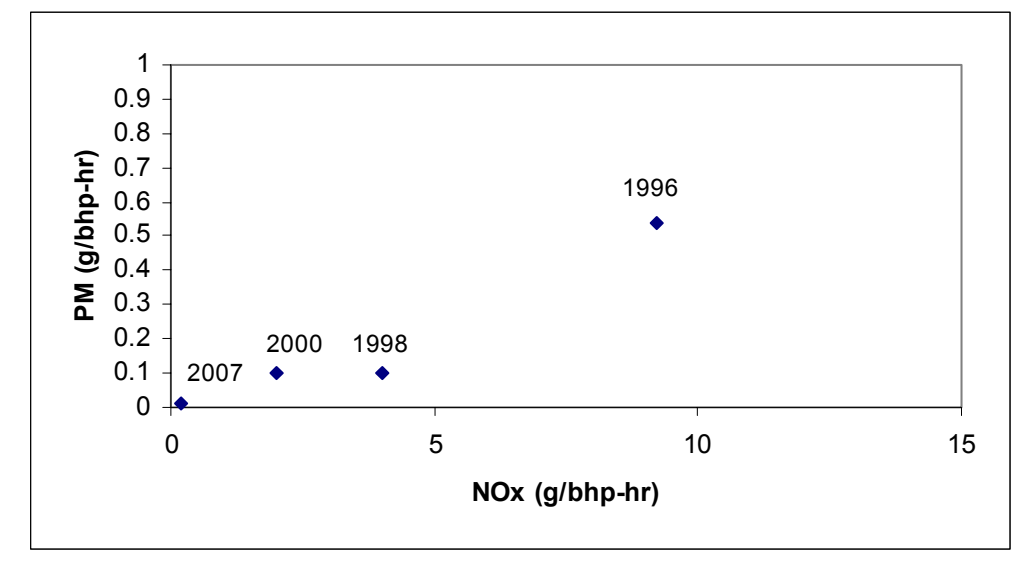

Figure 2.1: $\mathrm{PM}$ versus $\mathrm{NO}_{\mathrm{x}}$ regulations

The Figure 2.1 shows the $\mathrm{PM}$ versus $\mathrm{NO}_{\mathrm{x}}$ regulations that has been the issue of major concern while reducing emissions. With the current engine technologies and extreme fuel economy losses, levels of PM and $\mathrm{NO}_{\mathrm{x}}$ can be brought below the year 2000 standards. However, to achieve emission levels to agree with the year 2007 standards alternate solutions are required. NO formation is directly related to combustion temperatures. Higher temperatures result in higher $\mathrm{NO}_{\mathrm{x}}$ formation. $\mathrm{PM}$ on the other hand, results from incomplete combustion of fuel. Aftercooling, 
turbocharging, optimizing combustion chamber design, retarding injection timing and highpressure fuel injection are some of the ways of reducing these emissions. The three most positive areas are engine design enhancement, after-treatment devices and alternate fuels.

Testing for off-highway diesel engines have been undergoing lots of changes. With the addition of many different off-road vehicles, a standardized test cell steady state dynamometer testing does not suffice any more. Different cycles have been developed, for both steady state and transient testing. Many different factors affect the emissions of off-road vehicles. Vehicle weight, percent loading, fuel used, accessories and after-treatment devices used and operator-driving habits all add characteristics to the development of a true representative cycle. Most off-road equipment rarely operate under steady state conditions, hence the need for further research into developing transient cycles mimicking real-world conditions.

\subsection{NORTHEAST STATES FOR COORDINATED AIR USE MANAGEMENT (NESCAUM), 1997}

In 1997, the NESCAUM performed a study to determine the effects of exhaust aftertreatment devices on diesel emissions [8]. Oxidation catalysts, fuel borne catalysts, and active and passive particulate filters were selected for this study. The parameter measured was exhaust gas temperature. The temperatures were monitored during laboratory tests to maintain adherence to the in-field test cycles. The sample was diluted in a mini-dilution tunnel, and integrated bag samples and gravimetric PM data were collected. The project illustrated one attempt to derive representative testing cycles for off-road vehicles, and exhibited that methods were available to correlate the laboratory test cycle with an in-field operation cycle. 


\subsection{WEST VIRGINIA UNIVERSITY, 2001}

WVU performed testing on off-highway vehicles as part of a project contracted by CARB, to provide data that represented actual in-use emissions [5]. The vehicles selected were a John Deere 444 end loader with a 6059 D engine and an Elgin Pelican Street sweeper with a John Deere 4039T engine. Raw $\mathrm{CO}_{2}$ and engine speed data were recorded during the tests. The engines were also removed from the vehicles and tested on a stationery dynamometer in the laboratory. Transient test cycles were developed by an iterative process, using the in-field data. The set points were iterated until they matched the recorded speed and $\mathrm{CO}_{2}$ traces. The engines were operated on the ISO $8178 \mathrm{C} 8$-Mode test. Brake specific emissions results were 100-500 percent higher in value than the transient tests.

Barnett [9] and Rohrbaugh [10] developed transient cycles for different off-road diesel powered equipment based on the in-field vehicle activity duty cycles. Carder et al. [11] have described the research in a SAE paper. In-field activity and emissions data was collected on four different vehicles: a streetsweeper, a rubber-tired loader, an excavator, and a track-type tractor. Representative cycles were created on an engine test bed using this data by a micro trip approach. This data was used to calculate torque by a process of iterative engine testing to obtain similarities between in-field $\mathrm{CO}_{2}$ and laboratory $\mathrm{CO}_{2}$ data. Brake-specific $\mathrm{CO}_{2}$ maps were used to infer engine loads from the recorded in-field cycle and applied to the dynamometer load. The engine was then operated according to these set points while raw exhaust $\mathrm{CO}_{2}$ emissions were recorded. The in-field cycle was characterized into micro trips and specific activities. The micro trips are later combined to produce a transient cycle that more accurately represented the duty cycle. The load points for each iteration of the cycle were found by exercising the engine according to the initial speed/load set points. The load levels were adjusted by comparing the infield and laboratory obtained $\mathrm{CO}_{2}$ data. The test was repeated till the $\mathrm{CO}_{2}$ readings matched. 


\subsection{EMISSIONS MODELING AND IN-USE TESTING}

The EPA uses inventory models to evaluate rules and policies, and to generate inventories for state implementation plans. One of the latest models is the MOBILE6, which updates emissions, fleet, and activity data as well as structural changes including calculating by hour and roadway type, and separation of start and running emissions [12].

\subsubsection{CE-CERT}

The CE-CERT at the University of California, Riverside, published a study that compared emission rates between three emissions models (CARB's EMFAC, EPA's MOBILE, and CE-CERT's Comprehensive Modal Emissions Model (CMEM) and an in-use light duty fleet [13]. The resulting emission outputs of the three models were found to be relatively close for CO. EMFAC and MOBILE produced similar results for HC. CMEM and EMFAC produced similar results for $\mathrm{NO}_{\mathrm{x}}$.

\subsubsection{Georgia Tech Research Partnership}

Over the past five years, the Georgia Tech Research Partnership has been developing a modal emissions model, the MEASURE (Mobile Emission Assessment System for Urban and Regional Evaluation) to predict on-road mobile source emissions for regulatory and research purposes [13].

\subsubsection{EPA - NONROAD}

EPA is developing a non-road mobile source emissions inventory model called NONROAD [13]. This model will provide a tool for the EPA, regional air pollution organizations, and local air pollution control agencies to use in estimating pollution from nonroad equipment. NONROAD allocates national equipment population estimates using indicators related to each equipment category. The EPA has developed several application-specific non-road transient heavy duty cycles designed to generate real-world emissions data. Examples are the 
excavator duty cycle, the rubber-tired loader duty cycle, the skid-steer loader duty cycle, and the agricultural tractor duty cycle.

\subsubsection{Cummins Engine Company}

A computer modeling system to predict PM based on engine speed and torque was developed [14]. The model was based on data collected during steady-state testing to predict FTP cycle emissions. The model was able to accurately predict fuel flow, airflow, and equivalence ratio for the FTP cycle. The model was able to predict PM based on equivalence ratios, which was better than the experimental method using dilution tunnels, where only total PM could be measured.

\subsubsection{US EPA}

The EPA developed a transient dynamometer test cycle from real-time excavator operation and emissions data. Engines from two diesel excavators were placed on engine dynamometers, while engine torque output was correlated with fuel pump rack position over the speed range of each engine. The excavators were operated at actual construction sites. Three 7minute engine duty cycles were assembled from 78 hours of real-time engine speed and load data. The cycles were assembled into a 22-minute long composite diesel excavator engine duty cycle, which was used to gather HD engine emissions data on units of similar application.

\subsection{ENGINE DESIGN ENHANCEMENTS}

There are numerous studies supplying information on innovative design changes in engine and associated parts. Optimization of piston-bowl arrangements, fuel spray patterns, timing arrangements, and fuel/air ratios have been some of the most researched subjects.

In 1993, Caterpillar enhanced its 3406 heavy-duty model by adding electronic unit injectors and control modules [15]. The newer model, 3406E, had fewer engine components, and modified cylinder head with a new air inlet manifold, which were later duplicated in other diesel heavy-duty models. Mano et al. in accordance with the US EPA regulations, designed a turbo- 
charged, after-cooled, 6-8 cylinder engine, which have reduced $\mathrm{NO}_{\mathrm{x}}$ and $\mathrm{PM}$ emissions [16]. The engines have a 4-valve valve train design, centered nozzle arrangement, new piston design which lowers oil consumption and an optimum design chamber, which aids in uniform combustion. Diesel fuel properties have a profound effect on emissions [17]. Increasing cetane number reduces all emissions; reducing aromatic content reduces $\mathrm{NO}_{\mathrm{x}}$ and $\mathrm{PM}$.

General Motors presented a technical paper reporting the development of a modified manifold for improved EGR using CFD techniques, in a direct injection diesel engine [18]. The EGR design attempted to reduce the EGR misdistribution by using analytical and experimental techniques. The diesel engine used for this study was in-line, four-cylinder, turbocharged and inter-cooled for a maximum power rating of $74 \mathrm{KW}$ at $4300 \mathrm{rpm}$ producing a maximum torque of $205 \mathrm{~N}-\mathrm{m}$ from 1600 to $2750 \mathrm{rpm}$. Both intake ports were of the directed design. The flow path of the EGR system from the exhaust manifold to the entrance of the intake manifold was through the cylinder head. EGR was then introduced into the center of the intake manifold at a single point. EGR flow was in a vertical direction and perpendicular to the air flow, hence enhancing mixing. CFD calculations showed an agreement with the actual EGR flux entering the cylinders.

Engines with higher compression ratio have a smaller ignition delay period. Thus, the injection timing retard can be increased for controlling levels of $\mathrm{NO}_{\mathrm{x}}$ emissions. The high compression ratios also increase the temperature of the cylinder thus reducing PM and white smoke [19].

Improved fuel injection can help reduce injection timing, pressure, and rate and consequently have an effect on engine emissions. Manufacturers have been constantly trying to improve the parameters on a fuel injector in order to achieve a better combustion process. Parameters like nozzle geometry, rate shaping, and multiple injections have come under close scrutiny. Nozzle hole diameter, number of nozzles, spray angle and the Sauter Mean Diameter (SMD) are all important while reviewing nozzle geometry. Researchers from the University of Wisconsin-Madison and Caterpillar Inc. found that the spray angle was related to the SMD and to 
$\mathrm{NO}_{\mathrm{x}}$ and $\mathrm{PM}$ formation. They found that a large injection angle produces a narrow spray angle and a larger average SMD [20]. It was also shown that small nozzle hole sizes used in conjunction with high injection pressures produce small average SMD and reduce particulate emissions. The number of nozzle holes should be matched to the fuel injection pressure and combustion chamber geometry to best utilize the intake air for fuel atomization.

Rate shaping is the process by which the rate of fuel injected into the cylinder is controlled, which in turn reduces emissions. The amount of fuel injected is reduced to decrease $\mathrm{NO}_{\mathrm{x}}$ formation. The fuel is then injected a high injection rate to control particulates. This method is known as pilot injection. Some studies done on injection rate shaping explain injection timing retard and stability of the combustion process [7].

Multiple injections have been shown to reduce $\mathrm{NO}_{\mathrm{x}}$ and $\mathrm{PM}$ by 15 and 40 percent respectively. These results were published using a setup characterized by a double injection of 50 percent of fuel mass evenly distributed to two injections separated with a 10 degree crank angle [20].

\subsection{EXHAUST AFTER-TREATMENT RESEARCH AND SYSTEMS}

Diesel fuel improvements have resulted in a substantial decrease in $\mathrm{SO}_{2}$ and PM [21]. Fuel sulfur content affects engine wear, deposit formation, and emissions. Sulfur that is not deposited on the engine components is emitted as sulfur compounds into the atmosphere. To meet the California standards, fuels must have a sulfur content less than 500 ppmw. Beginning 2006, US refiners have to produce highway diesel fuel that meets a maximum sulfur standard of 15 ppmw by weight. All 2007 and later model year diesel-fueled vehicles must operate with this new low-sulfur fuel. EU countries will limit sulfur in diesel fuel to $50 \mathrm{ppm}$ by 2005 . Early introduction of retrofitted vehicles is possible due to the production of the low-sulfur fuels. In addition to the low sulfur content, the alternate fuels have low density, with low aromatic content. The FischerTropsch synthetic diesel is one of the cleanest burning fuels. There are other alternatives to diesel, 
such as, natural gas, biodiesel, liquefied petroleum gas, methanol, and dimethyl ether. Various experiments have been conducted over the years, to research the possibilities of using reformulated fuels along with exhaust after-treatment devices. There are numerous types of exhaust after-treatment devices, such as, diesel oxidation catalysts (DOC), lean $\mathrm{NO}_{\mathrm{x}}$ catalysts, diesel particulate filters, selective catalytic reduction (SCR) catalysts, etc. Each system has an advantage or disadvantage over mainly reducing $\mathrm{NO}_{\mathrm{x}}$ or PM. Most exhaust after-treatment devices are highly successful in reducing $\mathrm{CO}$ and $\mathrm{HC}$.

DOCs were one of the premier exhaust after-treatment devices used to reduce $\mathrm{CO}, \mathrm{HC}$, while having little effect on $\mathrm{NO}_{\mathrm{x}}$ and $\mathrm{PM}$. With ever tightening standards on $\mathrm{NO}_{\mathrm{x}}$ and $\mathrm{PM}$ these devices are slowly losing their market. A study conducted by SWRI saw PM reductions from $0.073 \mathrm{~g} / \mathrm{bhp}-\mathrm{hr}$ to $0.042 \mathrm{~g} / \mathrm{bhp}-\mathrm{hr}$, a 42 percent reduction using a fuel-borne catalyst. However, it was also noticed that for a DOC to be completely effective; it must be approximately equal in volume to the engine displacement, meaning that for large diesel engines, the catalyst has to be almost as large as the engine, which is not feasible [22].

Lean $\mathrm{NO}_{\mathrm{x}}$ catalysts provide a catalytic reduction of $\mathrm{NO}_{\mathrm{x}}$ through a lean fuel approach. The system used $\mathrm{HC}$ in the exhaust to reduce the high temperatures, hence reducing $\mathrm{NO}_{\mathrm{x}}$ formation. Nevertheless, since the system is susceptible to sulfur poisoning and requires a high amount of $\mathrm{HC}$ to be generated, it has not gained enough popularity with diesel manufacturers. To supplement the additional $\mathrm{HC}$ required either an excess quantity of fuel can be injected directly in the exhaust stream or urea can be used. Ammonia in the form of urea forces catalytic reactions to convert $\mathrm{NO}_{\mathrm{x}}$ to $\mathrm{N}_{2}$ and water. Khair and McKinnon [22], have reported that DOCs along with DPFs reduce $\mathrm{NO}_{\mathrm{x}}$ and PM substantially. $1.1 \mathrm{~g} / \mathrm{bhp}-\mathrm{hr}$ and $0.01 \mathrm{~b} / \mathrm{bhp}-\mathrm{hr}$ emission values, for $\mathrm{NO}_{\mathrm{x}}$ and PM, respectively, were obtained with 368 ppm sulfur fuel. 


\subsubsection{Diesel Particulate Filters}

Diesel Particulate Filters (DPF) were first researched in the late 1970s, when they were characterized by wall flow systems that forced exhaust gases through porous walls of the filter element. The systems had problems with regeneration and performance. The temperatures required to burn soot were too high. The introduction of catalysts in the filters brought the temperatures down to manageable limits [7].

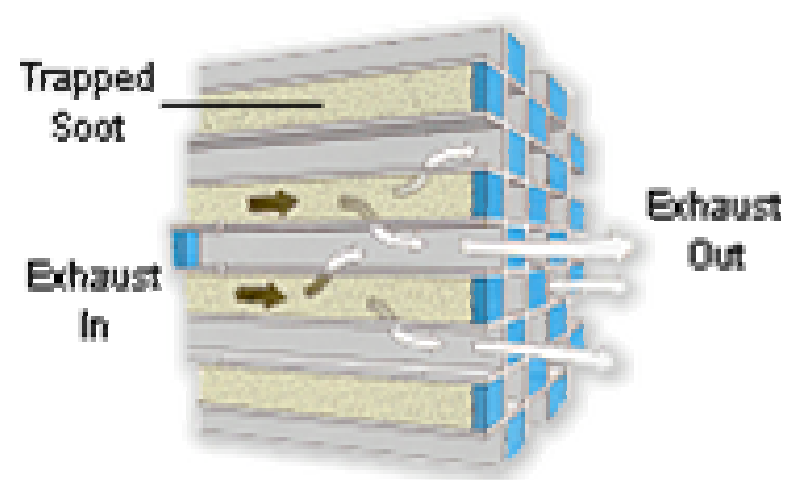

Figure 2.2: Open-pore wall flow system of a DPF, depicting the flow of exhaust gas [3].

A particulate filter is an after-treatment device with open-pore, wall-flow systems. They are usually designed as foams or loosely sintered structures made of materials such as, ceramic and porous metal. These materials are highly thermal-shock resistant but have a brittle nature. The trapping of particles occurs due to impaction on the filter material, or due to interception and diffusion. The particulate trap affects the tailpipe emissions from a diesel engine due to the presence of catalysts in its filter medium or due to the effect of backpressure created on the engine. Catalytic material is coated on to the walls of the filter medium to aid in the oxidation of hydrocarbons, $\mathrm{CO}$, and in the regeneration process of the DPF. Exhaust gases may react with the catalysts having either a positive or a negative influence on the emissions. Excessively high backpressure is known to reduce the $\mathrm{NO}_{\mathrm{x}}$ formation through internal exhaust gas recirculation (EGR) but increases $\mathrm{CO}$ emissions and adversely affects fuel economy. 
The Johnson-Matthey CRT and the Engelhard DPX diesel particulate filters were used in this study. It is engineered as a totally passive emission control system, which does not require the use of supplemental heat $[23,24]$. The nitrogen dioxide $\left(\mathrm{NO}_{2}\right)$ necessary for filter regeneration is generated in the oxidation catalyst from Nitric Oxide (NO) present in diesel exhaust, according to the following reaction:

$$
\mathrm{NO}+\frac{1}{2} \mathrm{NO}_{2} \leftrightarrow \mathrm{NO}_{2}
$$

DPM that is being trapped in the filter is oxidized as follows:

$$
\begin{aligned}
& \mathrm{NO}_{2}+\mathrm{C} \rightarrow \mathrm{NO}+\mathrm{CO} \\
& \mathrm{NO}_{2}+\mathrm{C} \rightarrow \frac{1}{2} \mathrm{~N}_{2}+\mathrm{CO}_{2}
\end{aligned}
$$

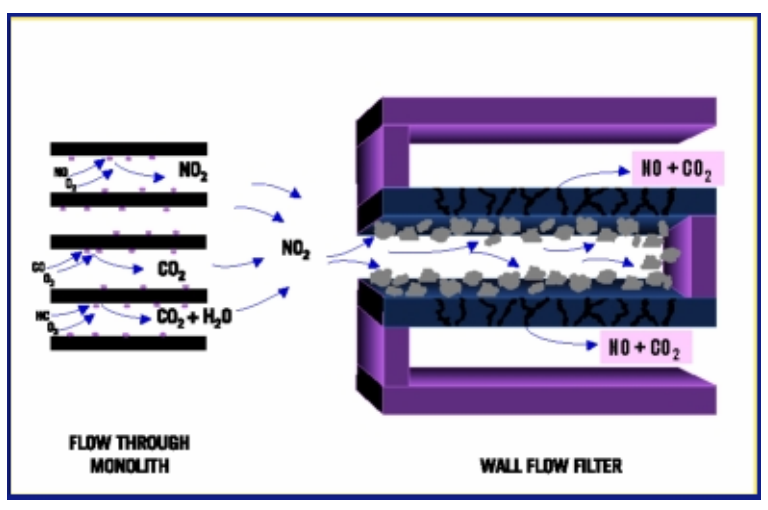

Figure 2.3: $\mathrm{NO}_{2}$ reaction in a CRT filter [3] 


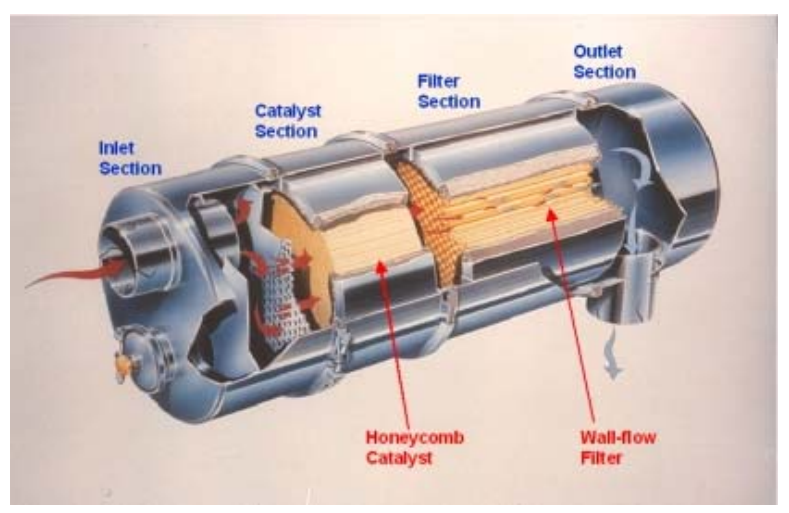

Figure 2.4: Cut-away view of the patented Johnson-Matthey CRT DPF [3]

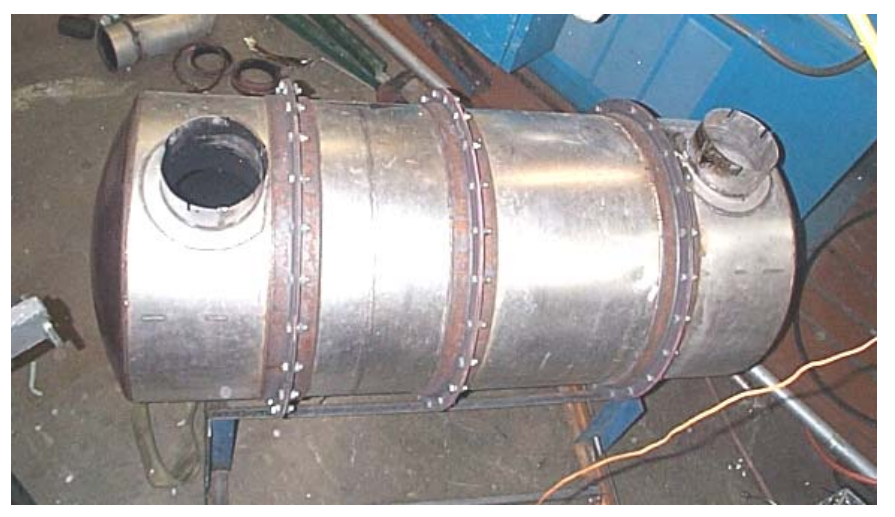

\section{Figure 2.5: Picture of the Johnson-Matthey CRT used in laboratory testing}

CRT particulate filters usually contain a combination of an oxidation catalyst and an uncatalyzed filter, which requires ultra low sulfur fuel. The device is made up of two chambers where the oxidation step is separate from the soot collection/combustion process. The first chamber contains a substrate coated with a proprietary highly active platinum oxidation catalyst, which is designed to oxidize a portion of the $\mathrm{NO}$ in the exhaust to $\mathrm{NO}_{2}$, which is the key to the elimination of soot collected by the CRT filter. The catalyst also oxidizes $\mathrm{CO}$ and $\mathrm{HC}$ into $\mathrm{CO}_{2}$ and $\mathrm{H}_{2} \mathrm{O}$. In the second chamber, the exhaust flows through a particulate filter, where gaseous 
components pass through but soot is trapped on the walls of the filter, where it is destroyed by the $\mathrm{NO}_{2}$ produced by the catalyst in the first chamber. The fuel sulfur level must not exceed 50ppm, but less than $30 \mathrm{ppm}$ is preferable for reliable regeneration (burning of soot). In order to achieve very low levels of PM emissions, the CRT requires fuel with a sulfur level of $<15 \mathrm{ppm}$ sulfur. In the CDPF, the catalyst is coated directly onto the wall-flow monolith.

Tests were conducted on a CRT DPF to understand effects of fuel sulfur on filter regeneration and a much smaller advantage of $60^{\circ} \mathrm{F}\left(15^{\circ} \mathrm{C}\right)$ was found [26]. The DPFs require ultra low sulfur for proper functioning and regeneration at low temperatures. High sulfur content in the fuel reduces the chances of the engine exhaust $\mathrm{NO}_{2}$ to be reduced to $\mathrm{NO}$, by increasing the regeneration temperature. In other words, the sulfur content poisons the filter. The CRT system patented by Johnson-Matthey has shown great promise in reducing the PM emission levels. It was understood that the Platinum catalyst is affected by the presence of sulfur in the fuel. It was seen that as the fuel sulfur level increases above the $50 \mathrm{ppm}$ level, the NO oxidation process fails in the low temperature region. At low temperatures the $\mathrm{SO}_{2}$ dominates the $\mathrm{NO}_{2}$ molecules for occupation of the Platinum sites and hence reduces the NO conversion. Once the temperature rises above $350-400{ }^{\circ} \mathrm{C}$, the effect of sulfur poisoning becomes negligible. The DPF was also tested with a high sulfur fuel of $350 \mathrm{ppm}$. The system was first heated to $425{ }^{\circ} \mathrm{C}$ and maintained at that temperature for two days. It was seen that the DPF performs satisfactorily even with high sulfur fuel for at least a day at low temperatures. However, the system emits large amounts of sulfate.

Johnson-Matthey claims that the CRT DPF reduces particulate matter and carbon monoxide by greater than $90 \%$ while reducing $\mathrm{NO}_{\mathrm{x}}$ by $10 \%$. The CRT undergoes passive regeneration and hence requires an exhaust temperature of greater than $500{ }^{\circ} \mathrm{F}\left(260{ }^{\circ} \mathrm{C}\right)$ for at least 40 percent of the time, less than $15 \mathrm{ppm}$ sulfur fuel, and a $\mathrm{NO}_{\mathrm{x}} / \mathrm{PM}$ ratio of at least 25 . It also requires cleaning and maintenance between every 60,000 and 100,000 miles. Studies on heavy duty Euro 1 and Euro 2 engines have shown that $\mathrm{CO}$ and $\mathrm{HC}$ emissions are reduced by about 85- 
95\% when tested on ECE R49, ESC, or ETC test cycles [23]. The ESC cycle, due to its high average engine load and high exhaust temperature, may be considered disadvantageous for the CRT performance. A number of studies using 10-30 ppm sulfur fuel have shown reductions in PM over $90 \%$. The DPF commonly contains a platinum catalyst with cell density of 200 cells/in 2 . The CRT weighs $300 \mathrm{lbs}$. The CRT is a commercial product in North America. It has been verified under the EPA's NESCAUM Third Party Verification Process as well as for the CARB Diesel risk Reduction Program.

An important limitation of the CRT regeneration is its dependence on the $\mathrm{NO}_{\mathrm{x}} / \mathrm{PM}$ ratio in the engine-out emissions. Higher $\mathrm{NO}_{\mathrm{x}} / \mathrm{PM}$ ratios result in higher $\mathrm{NO}_{2}$ concentrations and better filter regeneration. The $\mathrm{NO}_{\mathrm{x}} / \mathrm{PM}$ ratio required for good regeneration can be calculated based on Equation 1 and 2. If all $\mathrm{NO}$ was converted to $\mathrm{NO}_{2}$, the required $\mathrm{NO}_{\mathrm{x}} / \mathrm{PM}$ ratio would be $3.83: 1$ $\left(\mathrm{NO}_{\mathrm{x}}\right.$ as $\mathrm{NO}_{2}$ equivalent, $\mathrm{PM}$ as pure carbon). However, this does not happen in reality. Some older published literature state the ratio required as $8: 1$, but 20:1-25:1 is generally used. 


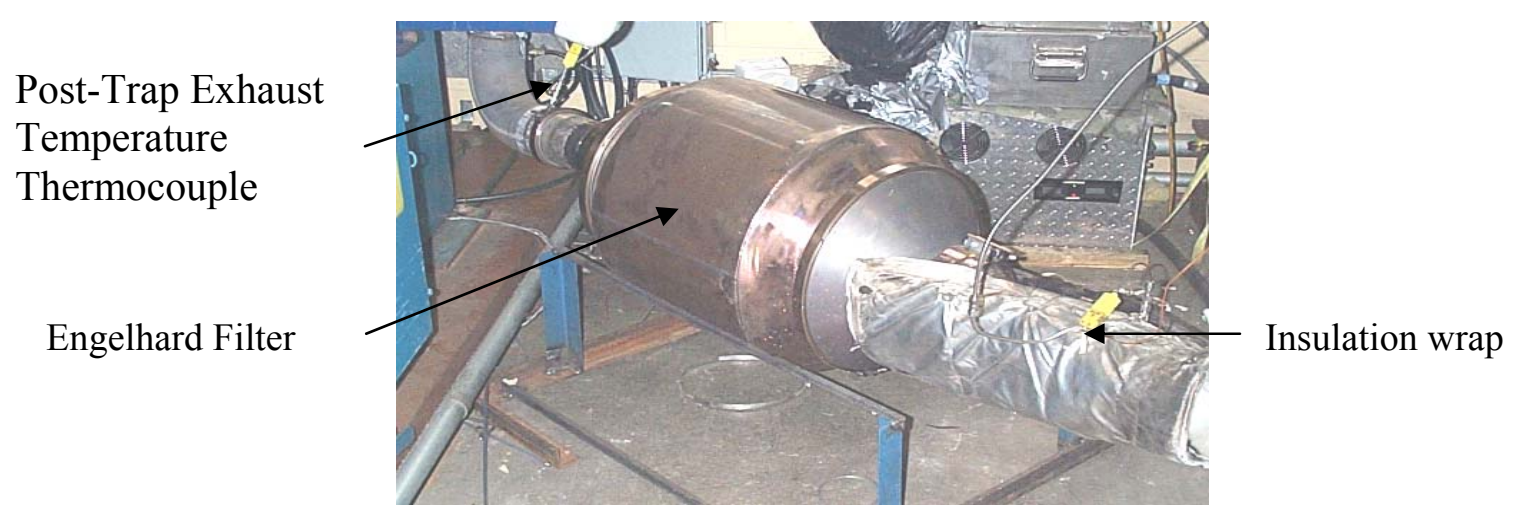

Figure 2.6: Picture of the Engelhard DPX used in laboratory testing

Engelhard claims that the DPX reduces PM, CO and HC by $90 \%$ [24]. When exhaust temperatures are $700{ }^{\circ} \mathrm{F}\left(375^{\circ} \mathrm{C}\right)$ for at least 25 percent of the time, the DPX with its proprietary catalyst coating makes it possible to burn soot upon contact with the catalyst. It does not require regular maintenance and low sulfur fuel. The DPX weighs $100 \mathrm{lbs}$. The DPFs are used in a wide range of applications, including heavy-duty trucks and buses, construction equipment, power generators, forklifts and other industrial equipment. When exhaust temperatures and packaging constraints make the DPX unsuitable, the Engelhard STX soot filters are used. Where high exhaust gas temperatures necessary for passive regeneration do not exist, STX soot filters provide greater than 90 percent reduction in PM. They are used in vehicles used in material handling, such as diesel powered forklift trucks. The soot is trapped by a series of ceramic, fiber-wound cartridges contained in a stainless steel canister. As the particulate collects on the cartridges, the back pressure increase is monitored by an on-board ECU. This activates alarms for cleaning or regeneration.

The DECSE program has reported results on the balance point temperatures being dependent on fuel sulfur levels [25]. The tests done on a CAT 3126 industrial engine using the DECSE method, have shown that the filter could regenerate at low temperatures of around $570{ }^{\circ} \mathrm{F}$ 
$\left(300^{\circ} \mathrm{C}\right)$, provided ultra low sulfur fuel was used. Relatively high balance temperature advantage of $140^{\circ} \mathrm{F}\left(60^{\circ} \mathrm{C}\right)$ was found.

\subsubsection{CARB Retrofit Verification Program}

Particulate filters are open-pore wall-flow systems, designed either as foams, loosely sintered grains, or textile fiber structures. Materials may be ceramic or of other high-temperature resistant materials. As part of the Diesel Risk Reduction Program undertaken by the CARB, a verification program has been set up to verify the use of after-treatment devices with both on-road and off-road vehicles [21]. The program verifies the capabilities and durability of a variety of emission control strategies as part of a retrofit in-use program. This procedure requires a minimum PM reduction of at least 25 percent. A three-level classification has been established with 25 percent being level 1. Level 2 includes devices with greater than or equal to 50 percent reduction capacity and level 3 holds anything equal to or greater than 85 percent. The CARB verified the Engelhard DPX and the Johnson-Matthey CRT DPFs for use with most 1994-2002 model year diesel engines in on-road applications. Caterpillar, Mack, Cummins, Navistar (International), Detroit Diesel and Volvo engine families have been approved for use of these DPFs.

\subsubsection{West Virginia University, 2002}

In 2002, a program for testing ultra-low sulfur fuels and particulate filters was completed in Southern California. Trucks and Buses retrofitted with filters fueled by ECD and ECD1 low sulfur fuels were tested. The test vehicles included grocery trucks, tanker trucks, refuse haulers, school buses and transit buses. The filters used were the Johnson-Matthey CRT and the Engelhard DPX. Two rounds of chassis dynamometer testing were done over a period of one year to determine if emissions deteriorated over time. The ECD had less than 15 ppm sulfur, less than $12 \%$ aromatics by volume, and a cetane number of greater than 60 . However, this formulation 
had a negligible effect on filter regeneration and conversion efficiency. Hence, a second generation EC diesel named ECD-1 was formulated with similar properties as ECD. The vehicles were tested using the WVU Transportable Emissions Laboratory. It consists of a heavy-duty chassis dynamometer and an emissions measurement laboratory. The laboratory uses an exhaust dilution tunnel mounted atop the trailer. Certification testing procedures are used for sampling and measurement. Typically, 70mm Teflon filters are used for PM measurement. Test vehicles retrofitted with catalyzed filters and fueled with ultra-low sulfur fuels had over $90 \%$ lower particulate matter emissions than vehicles without after treatment. For vehicles without filters the PM emissions increased over a year. It was concluded that $\mathrm{CO}, \mathrm{HC}$ and $\mathrm{PM}$ were reduced due to the installation of the filters. The effect on $\mathrm{NO}_{\mathrm{x}}$ was inconclusive.

In 2000, WVU conducted experiments on a 1995 direct injection, turbocharged diesel engine to study the fuel effects on emissions [25]. The fuels used were low sulfur diesel, CARB diesel, several biodiesel blends, and two natural gas-derived FT fuels. The biodiesel blends showed reduction in $\mathrm{PM}$ with a slight increase in $\mathrm{NO}_{\mathrm{x}}$. The FT fuels showed reduction in all regulated emissions.

Many projects were undertaken by WVU to evaluate the combination of particulate filter and reformulated fuels to reduce diesel emissions. In general, data in the literature have shown the benefits of filters and reformulated fuels in reducing PM with slight increases in $\mathrm{NO}_{\mathrm{x}}$. Clark, Schaberg, and Norton, have all shown that reformulated and synthetic fuels offer reductions of both $\mathrm{PM}$ and $\mathrm{NO}_{\mathrm{x}}$ emissions relative to diesel fuels purchased at the pump [27, 28, 29].

\subsubsection{VERT}

VERT is a joint project of several European environmental and occupational health agencies [30]. The project established a trap verification protocol that studies the influence of trap regeneration and soot deposition. The test is performed on a single trap from a family of traps selected to be retrofit to a particular diesel engine and certified for all possible applications. Two 
tests are done, the VERT filter test (VFT) and the VERT secondary emissions test (VSET). The tests are done on one engine for consistency of data and ease of verification. Fuel and lubricants used are as free of sulfur as possible. VERT uses less than $10 \mathrm{ppm}$ sulfur diesel. Test cycle for the VFT is the ISO $8178 \mathrm{C} 1$, but only 4 operating points at $100 \% / 60 \%$ speed and $100 \% / 50 \%$ load. Test cycle for VSET is also ISO 8178, with all operating points investigated. Transient effects are investigated during free acceleration. Regeneration too is investigated. Electronic systems are set up to monitor both the engine and trap. Physical and chemical aspects of a trap can be verified by the VERT procedure. This procedure has been approved by the United States National Institute of Occupational Safety and Health (NIOSH) and CARB. Only systems, which successfully complete the entire suitability test, are enrolled in the VERT Filter-list. The Johnson-Matthey CRT is part of this list.

\subsubsection{MECA and SWRI}

The MECA and SWRI jointly conducted research on after-treatment technologies to meet 2002 EPA emissions standards [22]. The research intended to show that with the use of commercial diesel and DPFs, the 2002 EPA standards could be met. Results indicated that PM emissions of $0.03 \mathrm{~g} / \mathrm{bhp}-\mathrm{hr}$ with commercial diesel and $0.01 \mathrm{~g} / \mathrm{bhp}$-hr with ultra low sulfur diesel were attainable.

\subsection{DIESEL PARTICULATE FILTER TYPES}

DPFs, as the name implies, remove particulate matter in diesel exhaust by filtering exhaust from the engine. The accumulated PM is either burnt or oxidized over time. By doing this, the filter is cleaned or regenerated. A report from MECA [31] describes the different filter material and regeneration strategies available. A number of filter materials have been used, which include ceramic, silicon carbide, fiber wound cartridges, knitted silica fiber coils, ceramic foam, 
wire mesh, sintered metal substrates, and temperature resistant paper. Several other studies present detailed description and characteristics of PM filters [32, 33, 34].

MECA [35] also conducted a program with SWRI to evaluate the performance of a variety of exhaust emission control technologies on a heavy-duty diesel engine with federal diesel number 2 (368 ppm), lower sulfur (54 ppm) diesel fuel, and zero ppm sulfur fuel. One of the technologies evaluated was the DPFs. Three different types of DPFs were employed. Two filters were tested with regular diesel fuel. One had a catalytic coating applied directly to the filter element and the other incorporated a fuel-borne catalyst used in conjunction with an uncatalyzed filter element. These filters reduced transient emissions of PM by 70 percent, HC by 94 percent, and CO by up to 63 percent. On low sulfur diesel, the DPFs reduced PM to $0.022 \mathrm{~g} / \mathrm{bhp}-\mathrm{hr}$ and $0.016 \mathrm{~g} / \mathrm{bhp}-\mathrm{hr}$. One of the filters tested on $368 \mathrm{ppm}$ sulfur was tested on zero sulfur. PM levels of $0.005 \mathrm{~g} / \mathrm{bhp}$-hr were achieved. 62 and 52 percent reductions were measure for $\mathrm{CO}$ and $\mathrm{HC}$ emissions, respectively.

Commonly used regeneration methods include: passive and active systems [36], onboard and replaceable filters, and permanent and snap-on filters. Passive systems do not rely on external devices to heat-up the filter and/or direct exhaust flow between two DPFs. They fully rely on self controlled catalytic mechanisms. Thus, these systems must attain regeneration conditions during normal operation without any additional control systems. Passive regeneration strategies include catalyst-based regeneration using either a catalyst applied to the surfaces of the filter or an upstream oxidation catalyst; fuel-borne catalysts, and $\mathrm{NO}_{2}$ traps. Active systems include airintake throttling, post top-dead-center fuel injection, catalyst injection systems, and on-board or off-board fuel burners or electrical heaters. Konstandopoulos et al. described a mathematical model for periodically reducing the soot ignition temperature and hence regenerate filters through reverse flow [37]. Onboard systems are those in which all functions can be performed without dismounting the trap. Replaceable traps must be removed for regeneration and are usually fitted with rapid mounting fixtures. Permanent filters, as the name suggests, are mounted permanently 
and are similar to onboard filters. Snap-on filters are for temporary use and are used for short operational periods.

Meinig et al. described a new particulate trapping system of several traps of pleated, highly temperature-resistant metal fleece with parallel paths directly in the exhaust stream [38]. For regeneration, one of the pleated traps is brought to regeneration temperature by a rotary slide valve, by direct electrical heating of the metal fleece. The tested system had six traps consisting of sintered metal as the trapping medium.

Ceramic filters are considered most practical. But they have problems of cracking and melting due to heat spots. Matsunuma et al. presented the application of metal foam called Celmet to DPF in order to solve the above mentioned problems [39]. Celmet is made of Ni-Cr-Al alloy, which has sufficient reliability to withstand corrosion from high temperature exhaust gas. The Celmet filter also has a pressure loss less than the ceramic filters.

Dinesen et al. developed a new diesel particulate filter that is a combination of a ceramic filter and an electrochemical reactor [40]. When trapped in the filter, the soot particles are converted to $\mathrm{CO}_{2}$ by an electrochemical reaction. This reaction is accomplished by applying a small voltage to a reactor, consisting of the walls of the filter. The electrode material could be either metal or an electronic conducting ceramic material. Due to its porous structure, the filter traps the soot and converts it to $\mathrm{CO}_{2}$, thus making the filter self cleaning. Since the principle works as an inverse fuel cell, the materials used in developing the solid oxide fuel cell can be used for this purpose.

Romero et al. designed a new dual particulate filter system [41]. The system consisted of two ceramic catalyzed filters in parallel, so that when one is in operation, the other is in regeneration or stand by. The regeneration is done by injecting hot air in reverse relative to the filter flow. The air is heated by a thermal energy storage device. The exhaust gas enters into one of the filters controlled by a flip-flop valve. When this filter is filled with PM and increases the 
pressure drop, the flip-flop valve is activated to redirect flow to the other filter. The first filter now undergoes regeneration.

Majewski et al. used regular pleated intake-air filter elements for filtration of DPFs [42]. Disposable DPFs utilize pleated-media cartridges which are installed in the exhaust system. When the cartridge is loaded with soot until a certain limit, it must be removed from the exhaust and discarded. These filter elements have shown high filtration efficiency coupled with reliability and low cost. Cooling of the exhaust gas is necessary for proper functioning of the filter media.

Mayer et al. developed a particulate filter with ceramic fibers in a knitted structure [43]. The system offers elastic medium for filtration with high resistance to shock and is highly robust. These filters are different from normal ceramic filters in that they are able to capture smaller soot particles more effectively. Also, there is no increase in back-pressure once the filter is saturated with soot. This is because the fiber elements enlarge on deposition, hence allowing the pressure values to remain constant. Regeneration temperatures are also manageable because the filter medium does not allow the temperatures to increase due to its larger surface area. Hence, temperature hot-spots are seldom created.

\subsection{FUEL EFFECTS}

There are a number of papers on the effects of fuel properties on emissions. Changing the formulation of diesel fuel has been found to be a viable solution to reduce the emissions from compression ignition engines. It is of added value if the fuels can be used on existing diesel fueled engines without modifications to the engine.

ECD-1, CARB Off road and Laporte Fischer-Tropsch (FT) fuels were used in this study [44]. The EC-Diesel fuels are produced from crude oil using a conventional refining process. The original ECD contains less than 15 ppm sulfur, less than $12 \%$ aromatics by volume, and has a cetane number of greater than 60 . The production of ECD required extensive hydro treating which added to the costs. It was shown that the high cetane number and low aromatic levels have 
a negligible effect on DPF regeneration and conversion efficiency [5]. Hence, a second generation EC diesel fuel named ECD-1 was formulated, identifying the low sulfur content as the major property required for catalyzed DPF operation. ECD-1 has a maximum sulfur content of 15 ppm but has aromatic and cetane levels that are more typical of California diesel fuels. CARB diesel is a blend of one-third volumes from three different fuels, made by companies located in southern California [44].

A validation program was conducted, using ECD-1, CARB and Fischer-Tropsch fuels to study the effects of these fuels on emissions [5]. Different retrofit vehicles which included grocery trucks, tanker trucks, refuse haulers, school buses, and transit buses were tested using these fuels. Results showed that retrofit vehicles with ultra low sulfur diesel had over $90 \%$ lower particulate matter than vehicles without after-treatment. Grocery trucks fueled with ECD had 3\% lower fuel economy than vehicles fueled with California diesel. The fuel economy changed was attributed to the lower energy density of ECD. The energy density of ECD-1 was found comparable to typical California diesel fuels.

Fischer-Tropsch fuel is a hydrocarbon fuel produced from synthesis gas [45]. The process was developed by Sabatier and Senderens in Germany in 1902. The basic reactions in the FischerTropsch process are:

$$
\begin{aligned}
& \text { Paraffins: }(2 n+1) \mathrm{H}_{2}+n \mathrm{CO} \rightarrow \mathrm{C}_{n} \mathrm{H}_{2 n-2}+n \mathrm{H}_{2} \mathrm{O} \\
& \text { Olefins : } 2 n \mathrm{H}_{2}+n \mathrm{CO} \rightarrow \mathrm{C}_{n} \mathrm{H}_{2 n}+n \mathrm{H}_{2} \mathrm{O} \\
& \text { Alcohols }:(2 n) \mathrm{H}_{2}+n \mathrm{CO} \rightarrow \mathrm{C}_{n} \mathrm{H}_{2 n+1} \mathrm{OH}+(n-1) \mathrm{H}_{2} \mathrm{O}
\end{aligned}
$$

Due to the exothermic nature of the FT process, temperature control is of great importance to obtain the right end products. Three types of reactors (tubular fixed bed, fluidized bed, and slurry) provide good temperature control. The first plants used tubular reactors. Later, SASOL, in South Africa, used fluidized-bed reactors. Shell Oil operates a gas-based middle distillate synthesis plant at Bintulu in Malaysia. FT fuel can also be produced by indirect liquefaction of coal. Coal is fed to a gasifier, where it is reacted at high temperatures under 
moderate pressures in the presence of oxygen and steam. This generates $\mathrm{CO}$ and $\mathrm{H}_{2}$. Steam is added prior to entering a FT synthesis reactor and sulfur is removed. Further processing yields mixtures of end fuels including diesel. FT fuels are characterized by their high cetane number, low aromatic content, and low sulfur. Favorable attributes for use in compression ignition engines include: liquid at ambient conditions, miscible in conventional petroleum-derived diesel, energy density comparable to conventional diesel, suitable to use in unmodified engines, and transportable as liquid in existing infrastructure.

Care should be taken while interpreting emissions data from testing on different engines with different fuels. The effect of fuel properties may not be the same on every engine and fueling combination. In addition, changes in emissions cannot be attributed to a change in a single fuel property. However, it is certain that an increase in cetane number and paraffin content reduces $\mathrm{NO}_{\mathrm{x}}$. Low sulfur content reduces PM by reducing sulfate formation.

Liang et al. conducted tests on two particulate filters, a CRT and a catalyzed filter, to study the effects of ultra low sulfur fuel on the same [46]. The study was part of the DECSE Phase 1 program. The testing was done on a Caterpillar 3126 engine with nominal fuel sulfur levels of $3 \mathrm{ppm}, 30 \mathrm{ppm}, 150 \mathrm{ppm}$ and $350 \mathrm{ppm}$. The CR-DPF accomplished regeneration by generating $\mathrm{NO}_{2}$ from engine exhaust NO. It also formed sulfates which are measured as PM. The CDPF accomplished the regeneration by using a catalyst coating on the DPF element to promote oxidation of the PM using available oxygen from engine exhaust. The engine was run on OICA 13-mode cycle and steady-state cycles. Results showed that both DPFs were effective in reducing $\mathrm{HC}$ and $\mathrm{CO}$. CO was mostly independent of fuel sulfur levels. There was a slight decrease in $\mathrm{NO}_{\mathrm{x}}$ with increasing sulfur levels. Baseline PM emissions showed that PM increased with increase in sulfur levels. The effects of fuel sulfur on CDPF and CR-DPF were substantial. As fuel sulfur levels increased to $150 \mathrm{ppm}$, the reduction efficiencies reduced drastically, to near ineffective filtering. The balance point temperature (BPT) increased on both filters with increasing sulfur 
levels. On an average, BPT increased by $33 \mathrm{C}$ for the CDPF and $23 \mathrm{C}$ for the CR-DPF as fuel sulfur increased from 3 to $30 \mathrm{ppm}$.

Diesel diesel exhaust emissions from four diesel fuels were compared: a conventional low sulfur D2 diesel, CARB diesel, Swedish diesel and a Fischer-Tropsch diesel fuel [44]. Though the engine was not tuned to take advantage of the characteristics of each fuel, there were substantial reductions in emissions. Compression ignition engines generally have low $\mathrm{HC}$ and $\mathrm{CO}$ emissions but have high $\mathrm{NO}_{\mathrm{x}}$ and $\mathrm{PM}$ emissions. Fuel sulfur levels in turn affect the levels of $\mathrm{NO}_{\mathrm{x}}$ and PM in the exhaust. Fuel sulfur also affects after-treatment methods by acting as a poison to the filter medium, forming sulfates as a by-product. Testing was done using protocols defined in the 40 CFR Part 86 Subpart B and N, and Part 89. Engine testing was done using the EPA transient cycle. The EPA transient cycle consists of driving conditions found in New York City, and Los Angeles freeway and non-freeway driving. Chassis dynamometer testing was also done, using the Federal Test Procedure. Two fuel properties were selected for evaluation, aromatic content and the sulfur content. The aromatics varied from 28 percent with the D2 diesel to 0.1 percent with the Fischer-Tropsch. The fuel sulfur content varied from $300 \mathrm{ppm}$ with the D2 diesel to less than 1 ppm with the Fischer-Tropsch diesel. The results for heavy-duty testing showed that THC and $\mathrm{CO}$ was within limits for all four fuels. $\mathrm{NO}_{\mathrm{x}}$ and $\mathrm{PM}$ for the $\mathrm{D} 2$ diesel was near the requirement limits. CARB diesel showed a reduction in THC of 16 percent, CO of 15 percent, $\mathrm{NO}_{\mathrm{x}}$ of 8 percent, and particulate of 18 percent. The Swedish diesel produced an increase in the THC of 3 percent and a reduction in $\mathrm{CO}$ of 13 percent, $\mathrm{NO}_{\mathrm{x}}$ of 11 percent and particulate of 27 percent when compared to the D2 diesel. When compared to the FT fuel, the D2 diesel showed a reduction in $\mathrm{THC}$ of 41 percent, $\mathrm{CO}$ of 38 percent, $\mathrm{NO}_{\mathrm{x}}$ of 20 percent, and particulate of 40 percent without engine modifications or after-treatment. With engine modifications like injection timing advancement, $\mathrm{NO}_{\mathrm{x}}$ can be greatly reduced. 


\subsection{TEST CYCLES}

\subsubsection{Federal Transient Procedure}

Federal Transient Procedure (FTP) heavy-duty transient cycle is currently being used in the USA for on-road engines [47]. The FTP represents in-field operation of a variety of heavyduty trucks including city, expressway and on-road driving. The FTP uses percentage of engine speed and torque from the engine map as input set points. The emissions are reported on a brake specific basis. The first segment of the cycle is the New York Non Freeway. This contains light urban traffic with frequent stops and starts. The second segment is the Los Angeles Non Freeway, which represents crowded urban traffic with few stops. The third segment is the Los Angeles Freeway, which simulates crowded expressway traffic in LA. The fourth segment is a repeat of the first segment. The duration of the cycle is 1200 seconds and the average equivalent vehicle speed is $19 \mathrm{mph}$. The average distance traveled is 6.4 miles.
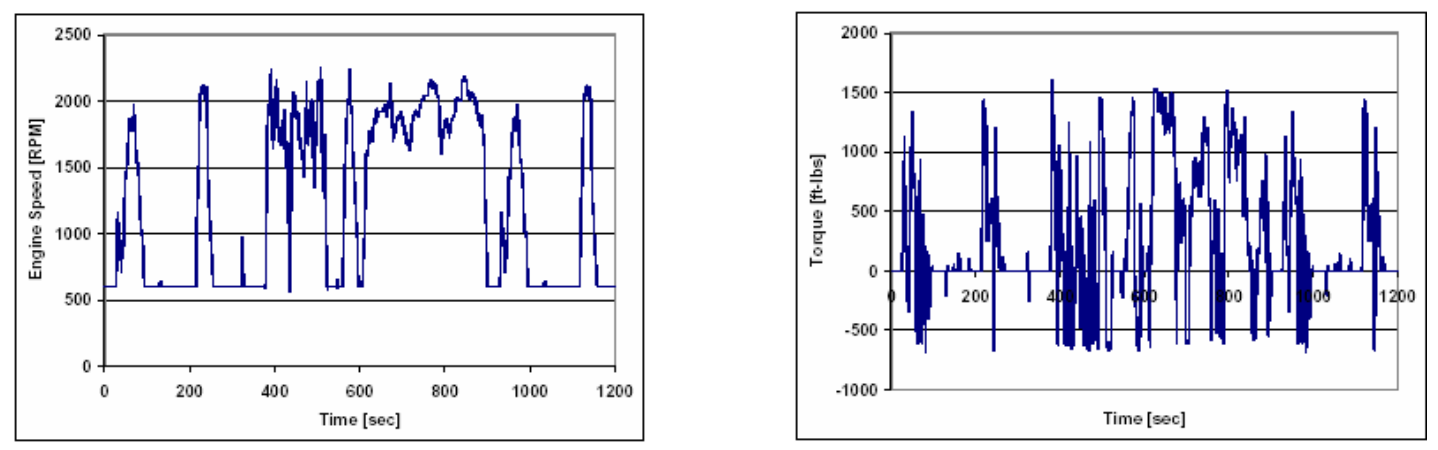

Figure 2.7: Target engine speed (left) and torque (right) versus time for the FTP based on engine map on a DDC Series 60 heavy-duty diesel engine [47]

\subsubsection{Non-road Transient Cycle (NRTC)}

Tier 4 standards (2008-2010) have to be met on both the steady state and non-road transient cycles [3]. The NRTC is a test cycle developed by the EPA along with the European Union. The cycle will be used internationally for emission certification of non-road engines. The 
cycle is an engine dynamometer transient driving schedule of total duration of about 1200 seconds. The speed and torque during the NRTC test are shown in Figure 2.8.
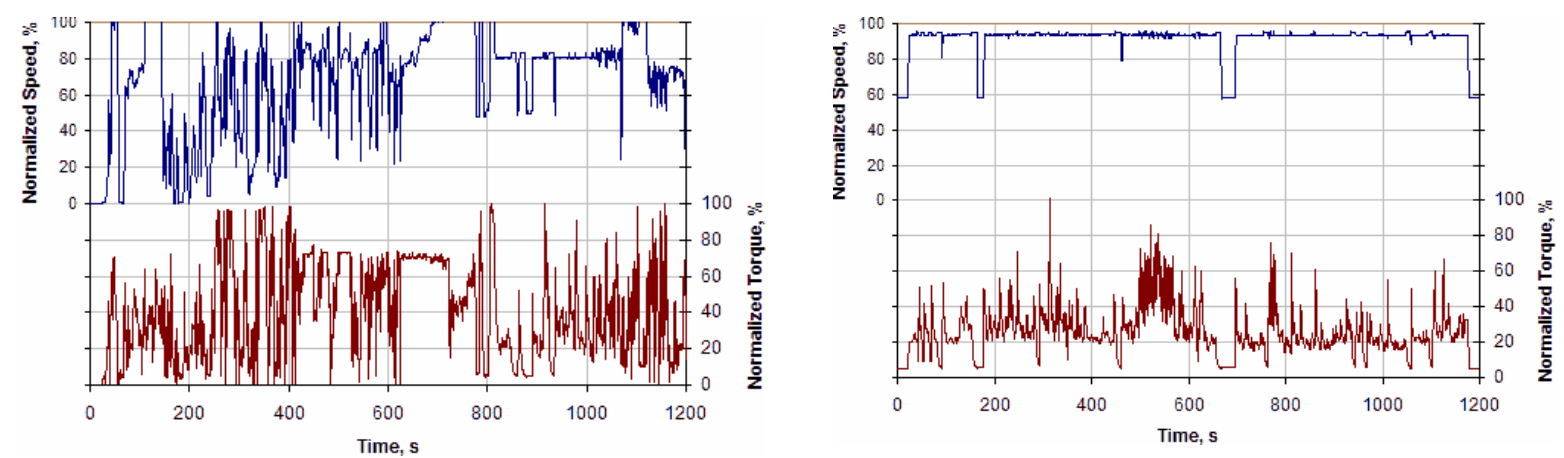

Figure 2.8: Normalized speed and torque over NRTC cycle (left), for constant speed engines (right)
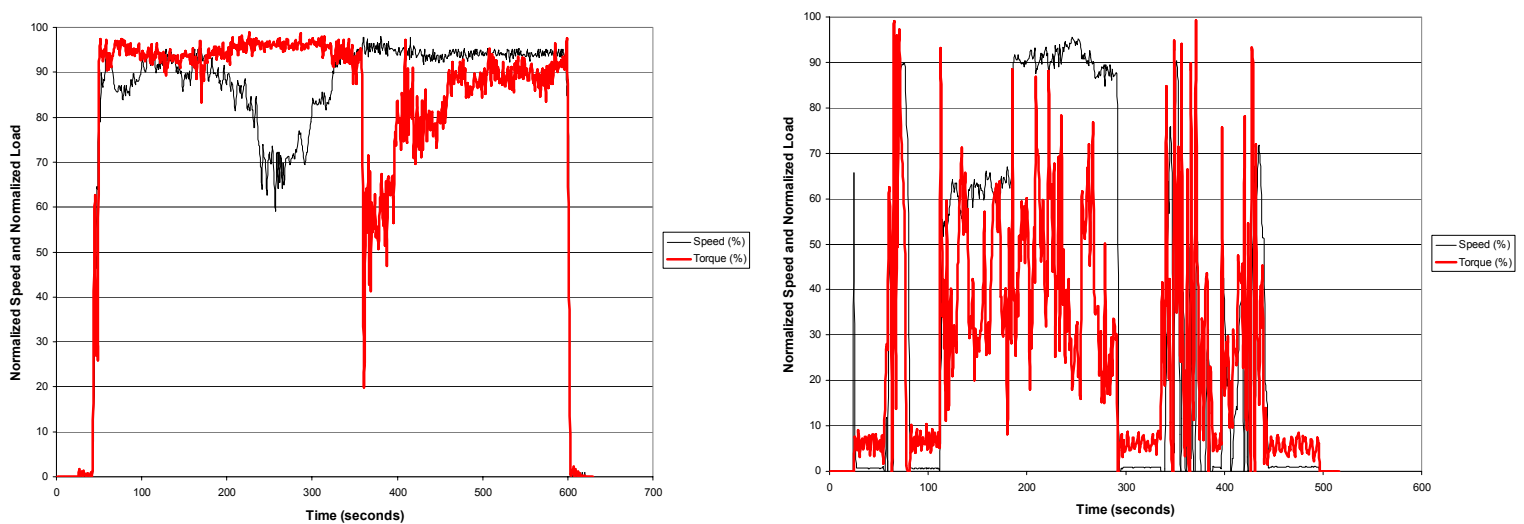

Figure 2.9: Agricultural tractor cycle (left) and Backhoe loader cycle (right)
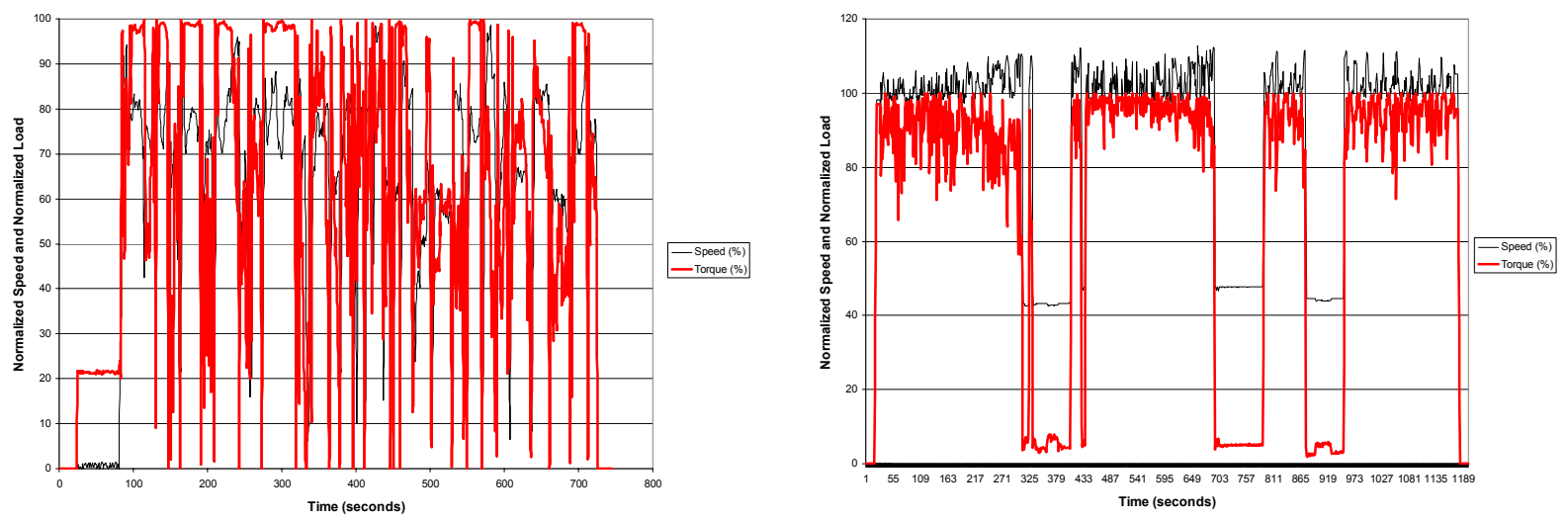

Figure 2.10: Crawler tractor cycle (left) and Excavator cycle (right) 

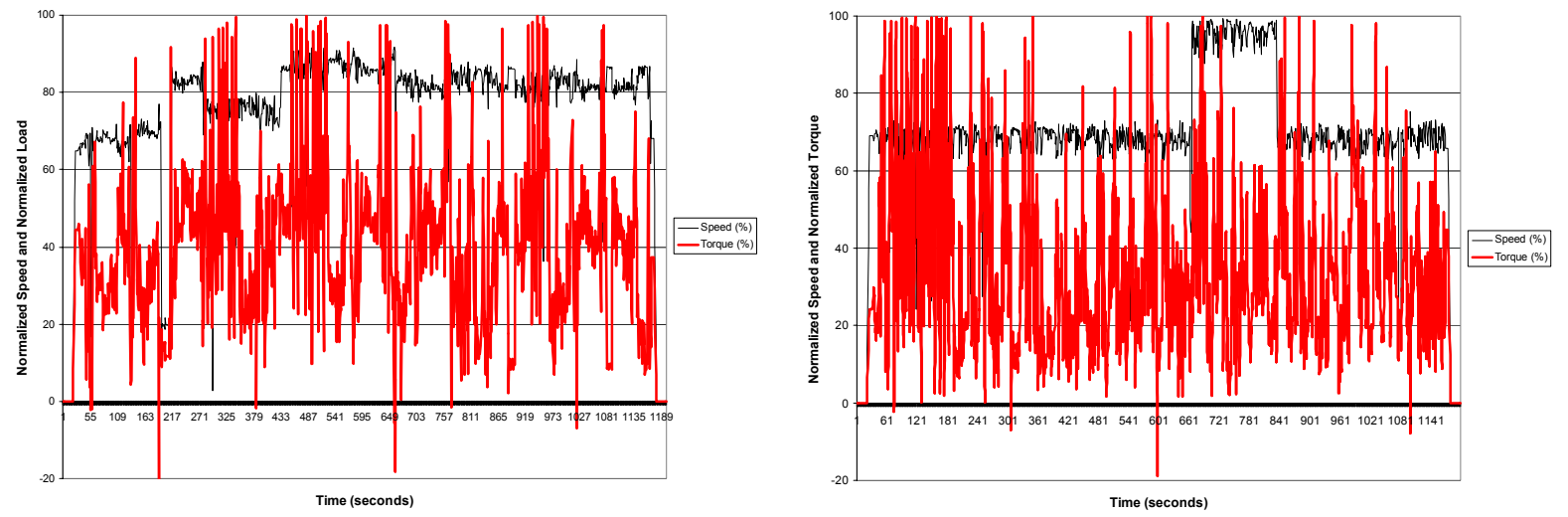

Figure 2.11: Skid steer loader high speed (left) and high torque (right) transient cycles
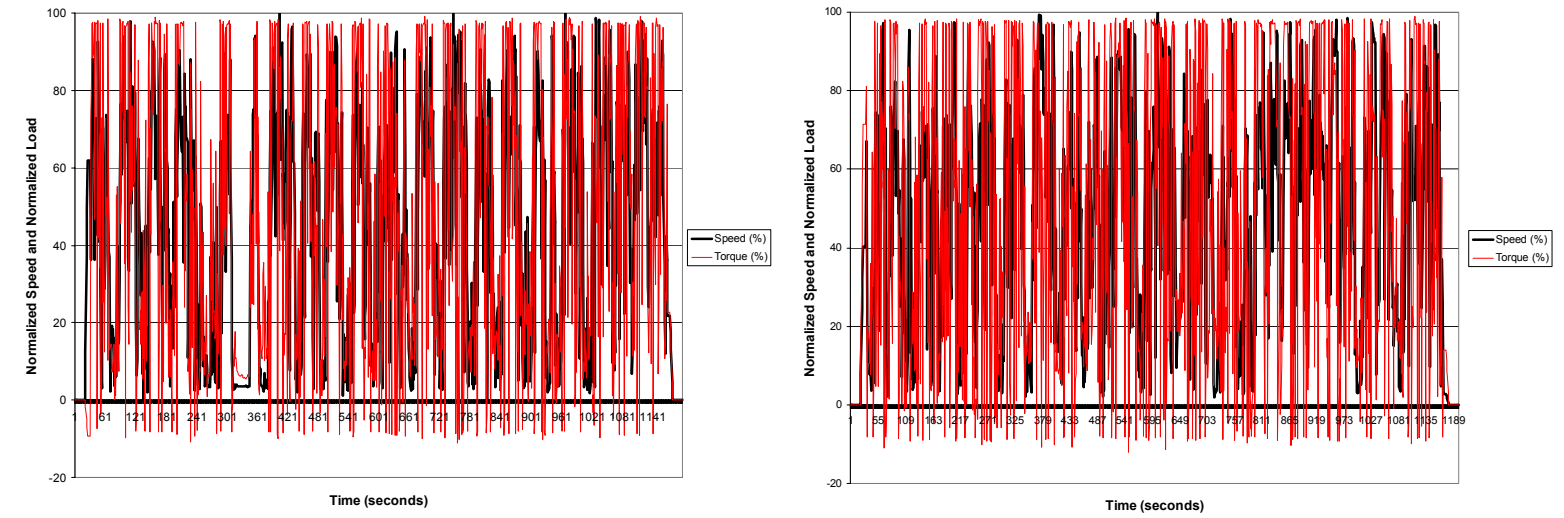

Figure 2.12: Wheel loader high speed (left) and high torque (right) transient cycles
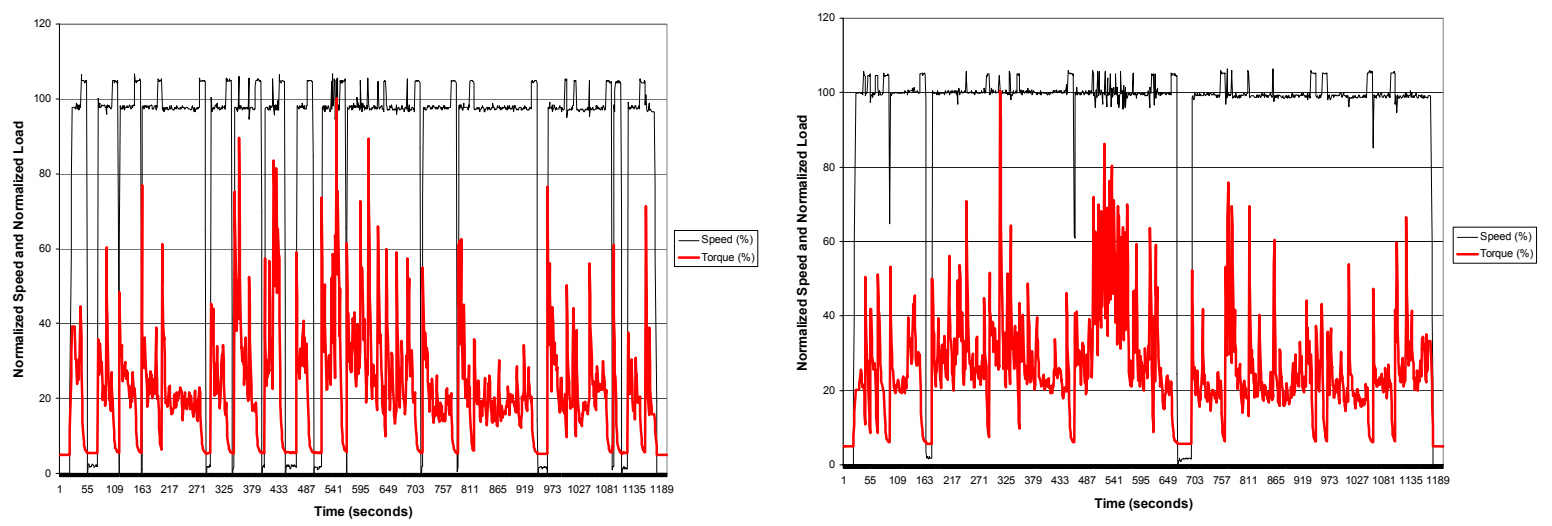

Figure 2.13: Arc welder high speed (left) and high torque (right) transient cycles 
The EPA has also developed non-regulatory non-road duty cycles for equipment, such as, agricultural tractors, backhoe loaders, crawler tractors, excavators, arc welders, skid steer loaders, and wheeled loaders [48]. Figures 2.9 to 2.13 depict these non-road cycles.

SWRI, under contract with the Engine Manufacturers Association (EMA), instrumented three non-road vehicles (agricultural tractor, backhoe loader, crawler tractor) and collected speed/load versus time data during typical in-use operation. Characteristics of engine operations corresponding to selected activities were established. Micro-trips from these operations were chosen to represent the activities, and the characteristics of these micro-trips were tested against the in-use characteristics established for the selected activity. After generating and validating a cycle for each piece of equipment, each of the scalar normalized cycles was unnormalized, and then transformed from a $3.33 \mathrm{~Hz}$ timebase to a $1 \mathrm{~Hz}$ timebase by applying a cubic spline interpolation to both the speed and the torque points. A new ten-minute agricultural tractor cycle was generated. A composite cycle encompassing all three vehicles was also developed. The composite cycle was of 30 minutes durations. Figure 2.14 shows this cycle.

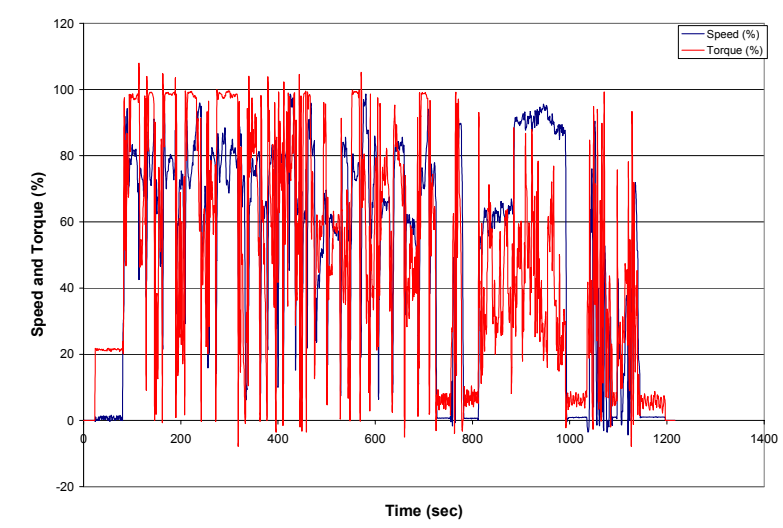

Figure 2.14: Agricultural tractor composite cycle

Ulmet et al. developed a transient cycle for non-road, spark-ignition engines [49]. The testing was done on two forklift trucks. The field data was analyzed by filtering out long idle times and engine start times. Segments of data collected were put together to represent transient 
operation based on the application. The most typical cycle consisted of 5-minute runs which closely represented the speed and throttle position of the trucks under transient operation. The entire data was sorted under speed and throttle bins and a frequency table were created. Incremental delta speed and delta throttle values were computed and summed to discriminate between data segments for defining the most transient 5-minute data segments. The delta segments having the largest summed value for the delta speed and throttle were selected. Four such 5-minute cycles were put together to make a 20-minute cycle. The goal was to select a variety of duty cycles that could effectively mimic the wide range of applications.

Ullman et al. developed three transient cycles while testing on an agricultural tractor, a backhoe-loader and a crawler tractor, using in-use speed and estimated torque data [50]. Using an iterative process, comparison of the chi-square data was processed to identify micro trips. With the support of the engine manufacturers, data on engine speed, rack position and actual fuel flow were correlated to the engine torque. The manufacturer defined a set of major activities commonly performed by each type of equipment. Each type of equipment was later made to perform these activities and data was recorded. The observed speed and torque data was normalized and the characteristic for each piece of equipment was noted. The length of an activity was proportional to the weightage given to the activity, relative to the total cycle time generated.

Samulski et al. tested two baseline non-road engines, two Tier 1 non-road engines, and two highway engines on steady state and transient operation [51]. It was concluded that PM emissions on non-road engines running on transient cycles are $50 \%$ higher than on steady-state cycles. The emissions from highway engines had a $112 \%$ corresponding number. This indicated that PM control can be more effective with a transient test cycle. The $\mathrm{NO}_{\mathrm{x}}$ emissions were an average $6 \%$ higher on transient versus the steady-state cycle. $\mathrm{HC}$ emissions were $125 \%$ higher on transient than on steady-state $\mathrm{C} 1$ cycles on highway engines and $56 \%$ on non-road engines. 


\section{CHAPTER 3 EXPERIMENTAL EQUIPMENT AND PROCEDURES}

This chapter discusses the experimental matrix, equipment and procedures that were used in this study. The engine dynamometer tests were conducted at the EERL, WVU. All the test equipment and procedures were in compliance with the requirements of 40 CFR Part 89 and ISO 8178.

\subsection{TEST VEHICLE}

A Caterpillar tandem-powered 657E Scraper, industrial, off-road equipment, was used for in-field, transient operation data collection. The data was collected at the Calabasas Landfill Site, Ventura, California.

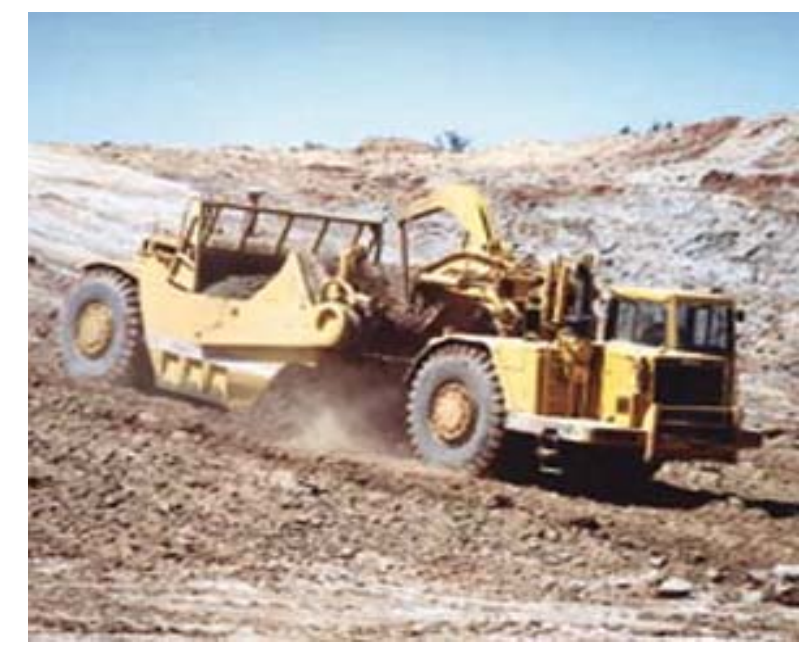

Figure 3.1: The 657E Scraper

The 657E has a V12, 3412E, turbocharged tractor engine and a V8, 3408E, rear scraper engine. The tractor engine is mainly used to power the vehicle, while the rear engine apart from 
rendering power to the vehicle also takes care of supplying power to the accessories. The $657 \mathrm{E}$ has an eight speed forward and single reverse transmission assembly. Since it is electronically controlled, the operation of the shift lever sends a signal to the Electronic Control Module (ECM) located in the driver compartment. The ECM also receives information regarding the output shaft speed and gear engagement.

The main component of the Scraper, which typifies the scraping action, is a hydraulically actuated quick drop open bowl and apron system. During the scraping action, the bowl is dropped open and the cutting edge lowered to the ground level. As the scraper moves, the raw material is scrapped into the bowl. The amount of raw material filled is visually controlled by the driver. The scraper has a front and a rear engine, which add up to $1000 \mathrm{Hp}$ of power available for hauling raw earth. The maximum load rating is $174000 \mathrm{lbs}$ with raw material in the bowl. A maximum of $70000 \mathrm{lbs}$ of material can be stored in the bowl. Once the required amount of material is filled, the bowl and apron system is closed. An angled top plate also assists in carrying much of the load. The tandem engine design acts as a push-pull arrangement. A typical material hauling round trip involving the activities of the vehicle at the Calabasas Landfill site contained the following check points.

The scraper started at idle at the Service Area (SA). After a 30-minute warm-up period, the vehicle was driven through a hilly terrain, to the Collection Site (CS) for hauling. A normal day would include multiple trips between the collection site and the service area. The two common raw materials were asphalt and raw earth. The scraper experienced load differences depending on the raw material being hauled. At the collection site, the scraper underwent the basic scraping action and loaded the bowl (reservoir). The first cycle involved hauling of loose asphalt from a collection area and dumping it at a Stockpile (SP). The scraping action mainly involved opening and closing the reservoir lids and then scraping through an intermediate loading action. The change in speed and load was due to a number of factors, such as, terrain, incline/decline, kind of material, operators driving style, and permeability of the earth. A water 
truck regularly sprayed water throughout the driving range to ease the scraping operation and also to settle the dust generated from the scraping action.

The second cycle involved scraping the earth and hauling it across an approximate distance of 3-4 miles and unloading it. Generally, while scraping raw earth, a bulldozer gives a much needed rear end push to handle the high inertial loads. Once the scraper got ahead, locked the blade and reservoir mouth to the ground, the bulldozer got behind the scraper, and pushed it with its front plate. The scraper then either returned to the landfill site to continue with another iteration of the above activities or returned to the service area for a recess, refueling or maintenance. The raw material was collected with the bulldozer push for a 45 second period and for a distance of 50 feet. The engines experience maximum loads at this point.

A typical duty cycle was approximately 25 minutes long. Hence, the transient cycle that was recreated for in-lab engine dynamometer was also of 25 minutes in duration. Speed and torque data was noted from the ECM log of the rear engine of the scraper, while it performed its normal duty cycle activities.

Table 3.1: Description of the recorded activities of a scraper duty cycle, in time and distance

\begin{tabular}{|l|l|l|l|l|}
\hline Route & Time (mins) & $\begin{array}{l}\text { Distance } \\
(\mathrm{miles})\end{array}$ & Terrain & Engine Condition \\
\hline SA-CS & 3 & 2 & Uphill & Lowload \\
\hline CS-SP & 5 & 2 & Uphill+Downhill & Motoring+Lowload \\
\hline SP-CS & 15 & 2 & Uphill+Downhill & Motoring+Highload \\
\hline CS-SA & 3 & 1.5 & Downhill & Lowload \\
\hline
\end{tabular}




\subsection{TEST ENGINE}

The Caterpillar 3408, chosen for this study, powered the rear axle of a tandem-powered 657E scraper. The 18 liter, V-8 cylinder, mechanically controlled, direct-injection, turbo-charged, after-cooled engine is a parallel manifold design, with two intake and exhaust valves per cylinder. It has two full-flow oil filters and a fuel filter. The camshaft is in the center of the "v" with conventional valve lifters, push rods and rocker arms. The in-field data was collected on an electronically controlled rear engine. However, the laboratory testing was performed using a similar mechanically controlled engine. Caterpillar Inc. provided data on both the electronically controlled and mechanical engine that showed that the speed and load values were well within $6 \%$ of each other.

\section{Table 3.2: CAT 3408 engine specifications}

\begin{tabular}{||l|l||}
\hline Engine Built & 1987 \\
\hline Engine Serial No. & $48 \mathrm{~W} 24270$ \\
\hline Model No. & Caterpillar 3408 DI \\
\hline Rated Power & $400 \mathrm{Hp}(299 \mathrm{KW})$ at $1900 \mathrm{rpm}$ \\
\hline Peak Torque & $375 \mathrm{lb}-\mathrm{ft}(1865 \mathrm{~N}-\mathrm{m})$ at $1200 \mathrm{rpm}$ \\
\hline Bore & $137.2 \mathrm{~mm}(5.40 \mathrm{in})$. \\
\hline Stroke & $152.4 \mathrm{~mm}(6.00 \mathrm{in})$. \\
\hline Number and Arrangement of Cylinders & $\mathrm{V} 8$ \\
\hline Fuel/Air ratio & 0.025 \\
\hline Firing Order (Injection Sequence) & $1,8,4,3,6,5,7,2$ \\
\hline $\begin{array}{l}\text { Rotation of Crankshaft } \\
\text { (seen from flywheel end) }\end{array}$ & Counterclockwise \\
\hline $\begin{array}{l}\text { Rotation of Fuel Pump Camshaft } \\
\text { (seen from pump drive end) }\end{array}$ & Counterclockwise \\
\hline \hline
\end{tabular}




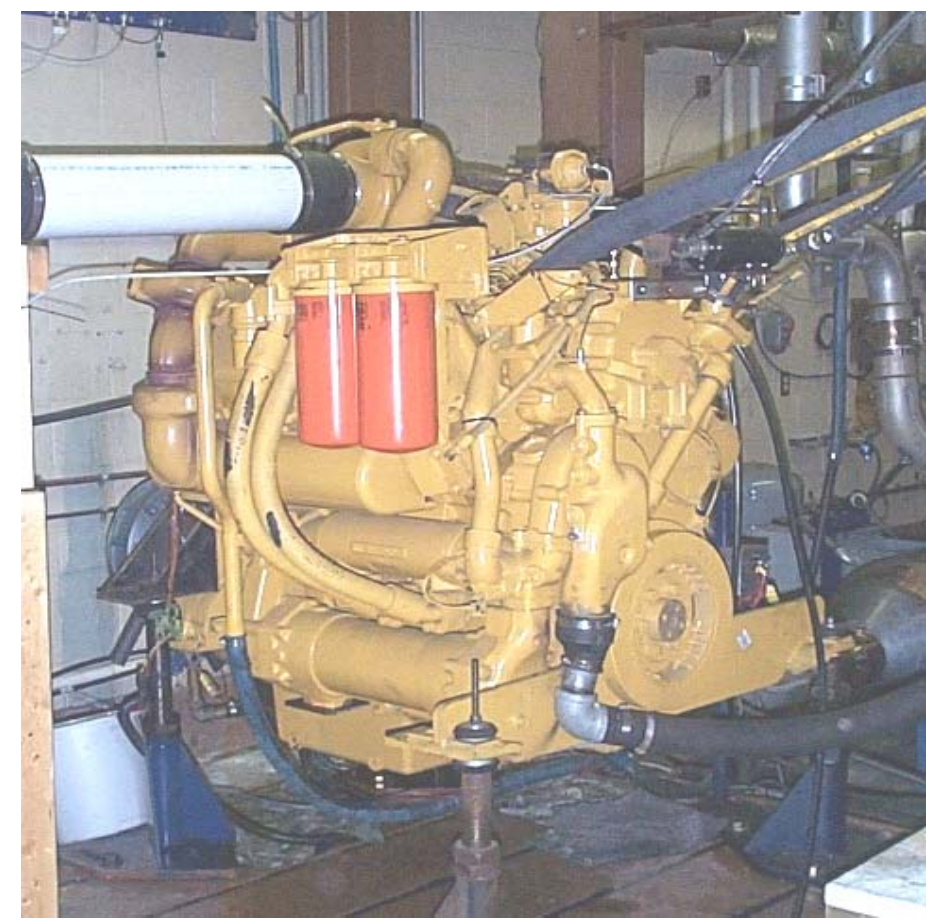

Figure 3.2: Test engine - Caterpillar 3408

\section{IN-FIELD DATA ACQUISITION EQUIPMENT/PROCEDURES}

\subsubsection{Exhaust Sampling Setup}

The in-field exhaust sampling and data logging setup consisted of the AMB-II analyzer; exhaust sampler, power inverter, Caterpillar Electronic Technician (CAT ET) communication adapter, and two laptops. All equipment was mounted on top of the scraper rear engine battery compartment. This location was chosen because of its proximity to the battery compartment, alternator attachments, the ECM connector pin and the exhaust stack. The setup was housed in a box, and covered to protect it from dust.

A stainless steel probe was used as the exhaust sampler. Stainless steel was used to prevent the exhaust gases reacting with the probe material. The probe was inserted three feet into the exhaust stack. The probe was then connected to the AMB-II analyzer to measure $\mathrm{CO}_{2}$ real time concentrations. The exhaust was routed through a Balston filter to filter out particulate 
matter from the sample stream entering into the analyzer. Concentrations of $\mathrm{NO}_{\mathrm{x}}$ and $\mathrm{HC}$ were not recorded. The analyzer was connected to one of the laptops through a RS-232 serial cable. The second laptop was used to log data that was being relayed from the ECM through the communication adapter. The data acquisition set-up was switched on while the vehicle was still at the service area prior to the commencement of the actual in-field work cycle. Data was collected on six different duty cycles over a period of two days. The vehicle operator was the same for all the six cycles.

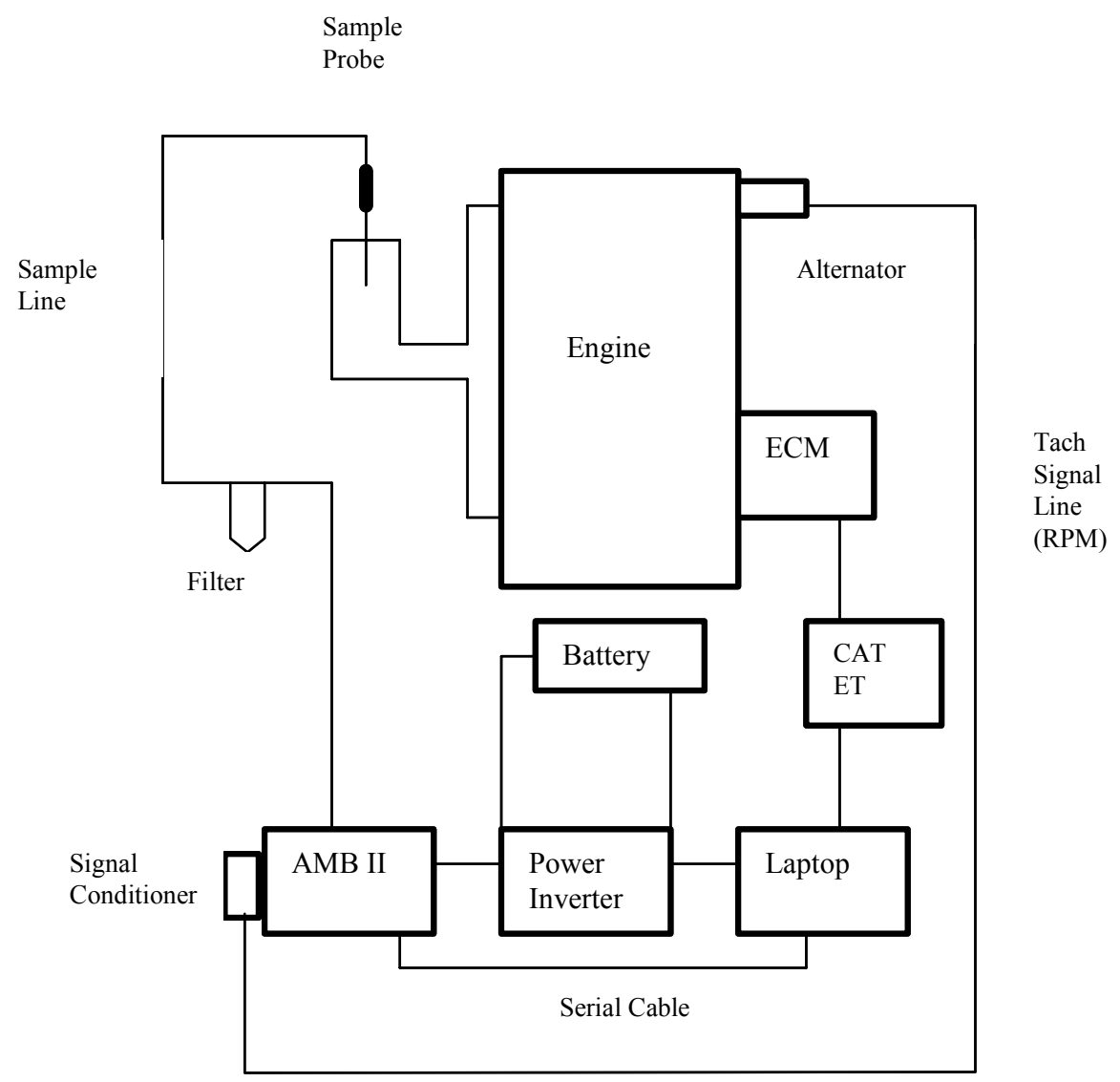

Figure 3.3: In-field data acquisition setup

\subsubsection{Sensors AMB-II Microbench}

The Microbench ${ }^{\mathrm{R}}$ is a small multi-gas, repair grade detection module used to determine different concentrations of gases in the automobile exhaust gas, on a continuous basis. It is based 
on the Non-Dispersive Infrared (NDIR) technology of gas measurement to measure $\mathrm{CO}, \mathrm{CO}_{2}$, and $\mathrm{HC}$ and used an electrochemical cell to measure $\mathrm{NO}_{\mathrm{x}}$. Each gas has a wavelength of absorption and the optical band pass filters that transmit electromagnetic energies only within the waveband are placed before the thermocouple detector. When the sample cell is filled with the sample gas, the Infra Red (IR) detector measures the resultant reduction of transmitted IR energy within the waveband of each gas. The bench also performs zeroing and calibration routines with the aid of in-built software. The gas readings and data are relayed to a host computer and displayed through the software, over a RS-232 line with a serial port interface. Refer to [52] for a complete literature on the Microbench. The AMB-II has measurement ranges of $2000 \mathrm{ppm}$ for HC, 0-20 percent for $\mathrm{CO}_{2}, 0-5000 \mathrm{ppm}$ for NO, and 0-15 percent for CO.

While $\mathrm{NO}_{\mathrm{x}}$ concentrations were not measured in this exercise, an electrochemical cell is available in the analyzer for measuring concentrations of NO in the sample stream. It consists of two or more electrodes separated by an electrolyte. A resistor is connected between the electrodes and voltage drop across is converted to gas concentration. Electrochemical cells typically have a $\mathrm{T}_{90}$ response time of at least 5 seconds for $\mathrm{NO}$, and approximately 30-40 seconds for $\mathrm{CO}$ and $\mathrm{NO}_{2}$. Due to technical difficulties in recording speed from the engine alternator or any other source via the AMB-II analyzer, data recorded by the analyzer was not used in this project. Hence, the $\mathrm{CO}_{2}$-speed method of calculating torque was not used [11].

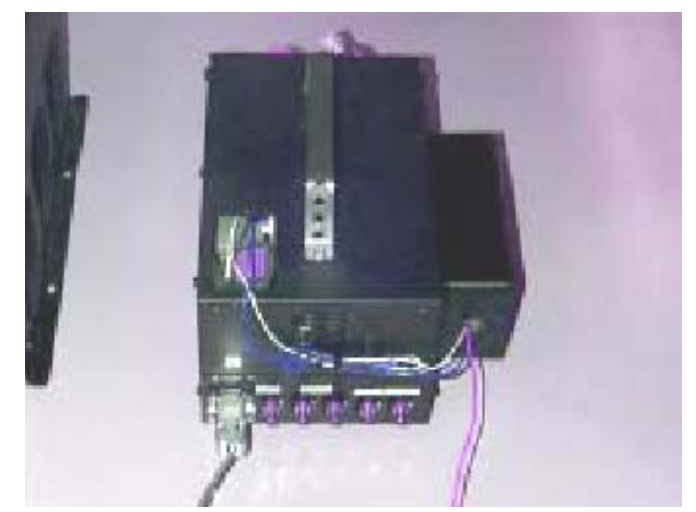

Figure 3.4: Sensors Inc. AMB-II microbench analyzer 


\subsubsection{Power Inverter}

In order to supply power to the analyzer, laptop and the communication adapter, a DC to AC power inverter was required. The batteries on the CAT 3408 engine were $24 \mathrm{~V}$ connected in parallel. Hence, a similar rated inverter was used to supply DC power from the battery as AC power to the data acquisition instruments.

\subsubsection{Caterpillar Electronic Technician Communication Adapter (CAT ET)}

The purpose of the communication adapter is to broadcast engine torque and speed through the ECM, using the J1587 data link. The adapter required the following computer and other hardware requirements: IBM PC compatible with Pentium $233 \mathrm{MHz}$ processor or greater, 48 MB RAM, 300 MB of available hard disk space, CD-ROM drive, Windows, RS 232 port with 16550AF UART, mouse. The engine ECM communicates engine torque, torque range and timing broadcast to the adapter in an encrypted mode. The CAT ET broadcasts the same information on to the computer. The broadcast information is controlled and relayed through Caterpillar's proprietary software. The broadcast information can be printed to a printer or to a file.

\subsection{ENGINE BREAK-IN}

Once the engine arrived in the laboratory, it was set up on a test bed, using engine mounts as supports. To ensure that oil requirements do not affect the emission measurements, a 50-hour break-in was performed. Any unknown prior damage to the engine can be fixed during the breakin period and does not hamper testing later. A Go-Power water brake dynamometer was used for torque control along with a Dyne Systems Co. DTC-1 Digital Throttle Controller and a DynlocIV Digital Dynamometer Controller. A new adapter plate was machined to accommodate the water-brake absorber on the engine (Figure 3.5). The bare engine was flushed using commercially available Citgo D2 diesel. Both the Johnson-Matthey and Engelhard traps were de-greened using 
ultra low-sulfur ECD-1 diesel, prior to actual emissions testing. Based on the manufacturer supplied engine performance data, a 4-mode cycle was set up for break-in.

Table 3.3: 4-mode set points used during break-in

\begin{tabular}{|c|c|c|}
\hline $\begin{array}{l}\text { Torque } \\
\text { (lb-ft) }\end{array}$ & $\begin{array}{l}\text { Speed } \\
\text { (rpm) }\end{array}$ & $\begin{array}{l}\text { Time } \\
\text { (mins) }\end{array}$ \\
\hline 0 & 770 & 10 \\
\hline 500 & 1000 & 10 \\
\hline 1400 & 1350 & 10 \\
\hline 1350 & 1800 & 10 \\
\hline
\end{tabular}

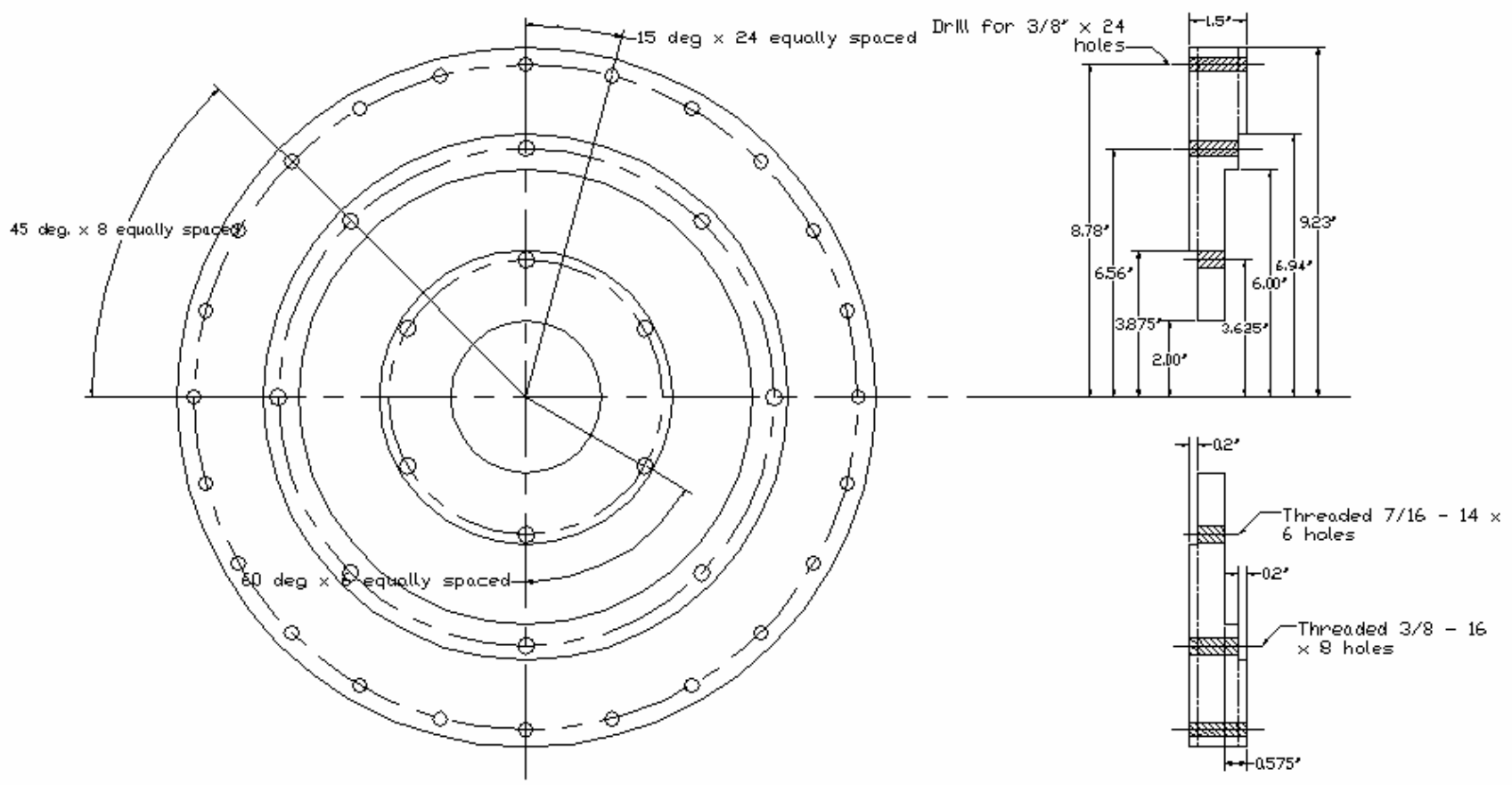

Figure 3.5: New adapter plate, machined on one side to couple the engine and water-brake, and the other side to couple the engine and DC dynamometer shaft coupling. 


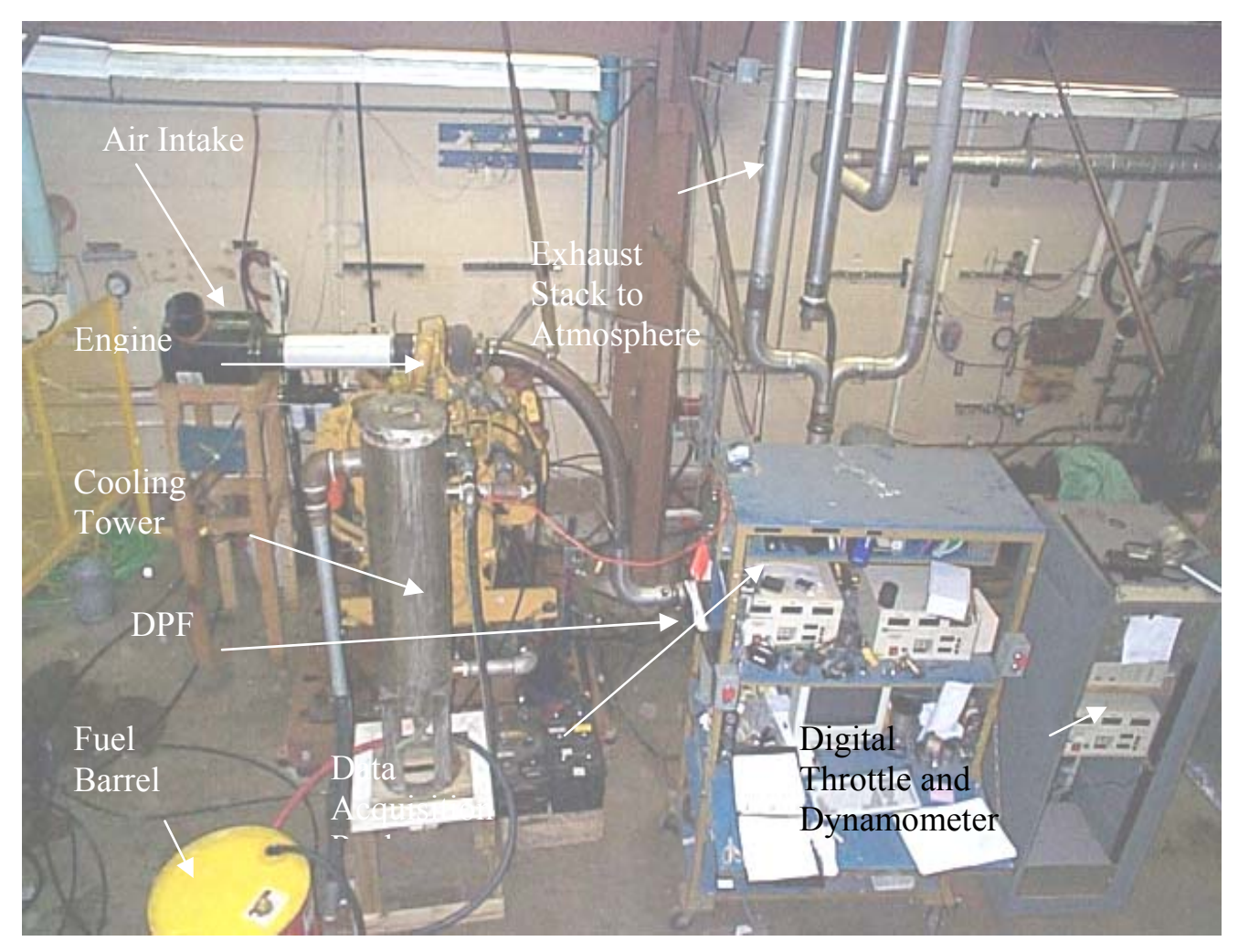

Figure 3.6: Engine break-in setup with cooling tower, instrumentation rack, and DTC

throttle and dynamometer controllers

\subsubsection{Trap De-greening}

New DPFs or oxidation catalysts should be "de-greened" for two reasons: De-greening is done to fill the particulate filter pores with the test fuel and flush out any residual ceramic particulate matter. Secondly, the filter is exposed to the exhaust gases to stabilize the operation. Both the CRT and DPX traps were de-greened for a period of 9 hours each, using ultra low-sulfur ECD-1 diesel fuel. The speed and torque set-points shown in Table 3.3 were used to de-green the two DPFs. 


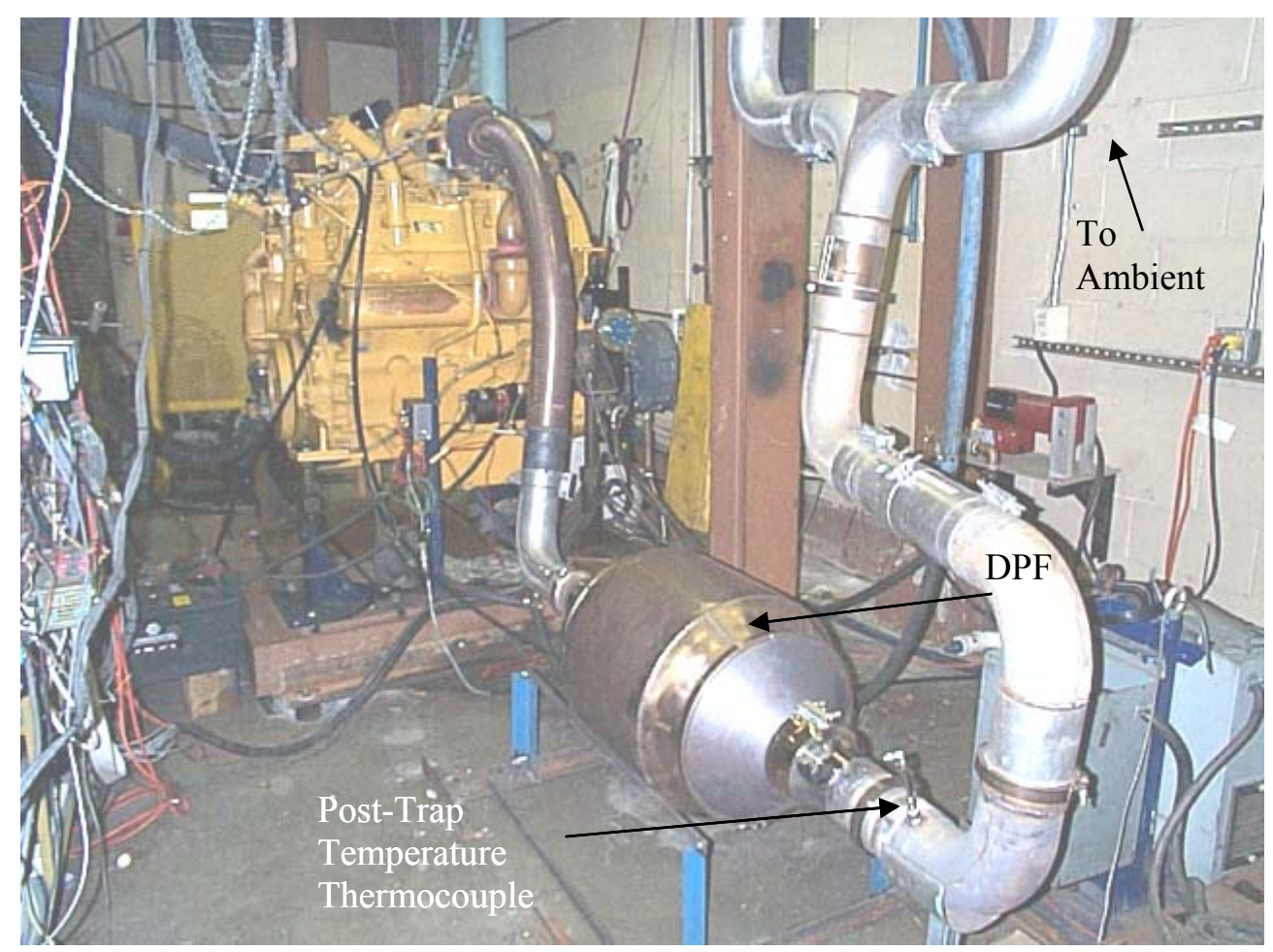

Figure 3.7: Engine retrofit with Engelhard particulate filter during break-in

\subsection{LABORATORY EQUIPMENT REVIEW}

This section describes the equipment and related systems that were used for emissions measurements.

\subsubsection{Full-flow Exhaust Dilution Tunnel}

The total exhaust double dilution constant volume sampler (CVS) used in this study dilutes the entire exhaust stream out of an engine with temperature controlled air. The dilution tunnel aims to simulate the cooling and mixing of post-tailpipe raw exhaust with ambient air. The exhaust temperature is reduced as it passes along the length of the tunnel. This aids in lowering the exhaust dew point temperature; hence avoids condensation. Condensation of moisture in the tunnel and/or sampling lines results in loss of water soluble pollutants. There are two main dilution processes recognized - full flow and mini dilution. A full-flow tunnel mixes the entire 
engine-out exhaust with dilution air whereas the mini dilution tunnel draws a partial sample of the exhaust and mixes it with dilution air. The 40 CFR, Part 86 recognizes only the full-flow method as a means of dilution for certification purposes. However, other standards, such as, ISO 8178, 40 CFR Parts 89, 92, 30 CFR Part 7, allow the use of partial flow dilution systems for the steady state testing of engines.

The EERL is designed and operated according to the regulations set forth in $40 \mathrm{CFR}$, Parts 86, 89, and 92, ISO 8178 and 30 CFR, Part 7. The full-flow system is based on the Critical Flow Venturi - Constant Volume Sampler (CFV-CVS) principle. The tunnel is approximately 40 ft. length and 18 in. $(0.46 \mathrm{~m})$ in diameter. It uses a $75 \mathrm{Hp}(56.2 \mathrm{KW})$ blower to draw diluted exhaust through a set of four venturis. Three of them are of $1000 \mathrm{scfm}\left(28.3 \mathrm{~m}^{3} / \mathrm{min}\right)$ capacity and the fourth is of $400 \mathrm{scfm}\left(11.32 \mathrm{~m}^{3} / \mathrm{min}\right)$. Only three venturis are operated at one time in order to give a total flow rate ranging from $400-3000 \mathrm{scfm}\left(3-68 \mathrm{~m}^{3} / \mathrm{min}\right)$. Due to blower capacity limitations, a total flow rate of $3400 \mathrm{scfm}$ is not available. At the entrance to the tunnel, there is an orifice plate of 8 in. diameter $3 \mathrm{ft}$. from the entrance. The plate aids in mixing the raw exhaust with dilution air; hence facilitating a fully mixed developed flow downstream in the tunnel. Sample probes are placed at the end of the tunnel, one each for every regulated emission measured. A 0.5 in. $(0.015 \mathrm{~m})$ diameter transfer tube draws the diluted exhaust sample into a secondary dilution tunnel. Additional dilution air can be added in order to reduce the filter face temperatures.

\subsubsection{Critical Flow Venturi}

A CFV-CVS is used to maintain constant tunnel flow rates, per requirements of $40 \mathrm{CFR}$, Part 89. The CFV functions under constant mass flow rates when it reaches choked conditions (Mach number equal to 1). During choked flow, the flow rate through the venturi is proportional to the diameter of venturi throat and upstream absolute pressure and temperature. The upstream absolute pressure $(\mathrm{P})$ is measured by a Viatran pressure transducer, Model 1042 AC3AAA20 and 
temperature (T) with a 3-wire resistive temperature device by Tayco Model 68-3839. The venturis were calibrated using a subsonic critical flow venturi that was traceable to NIST standards.

The mass flow rate can be calculated using the following equation:

$$
Q=\frac{K_{v}}{\sqrt{T}} P
$$

where,

$\mathrm{Q}=\quad$ flow rate in standard cubic feet per minute at standard conditions of $68^{\circ} \mathrm{F}, 29.92$ inches $\mathrm{Hg}\left(20^{\circ} \mathrm{C}, 101.3 \mathrm{KPa}\right)$

$\mathrm{K}_{\mathrm{v}}=$ calibration coefficient.

$\mathrm{P}=\quad$ absolute pressure at venturi inlet, inches $\mathrm{Hg}(\mathrm{KPa})$.

$\mathrm{T}=\quad$ absolute temperature at venturi inlet, ${ }^{\circ} \mathrm{F}\left({ }^{\circ} \mathrm{K}\right)$.

\subsubsection{Propane Injection Kit}

A propane injection test was performed on the dilution tunnel to verify the performance of the CFV-CVS system. Propane was injected into the tunnel using a Horiba Model 251-497-2CFO-210B dual orifice injection kit. The mass of propane injected was obtained from the data acquisition system, determined by using the calibration coefficients of the corresponding orifice, the inlet temperature and pressure of propane gas flowing through the orifice. Per established EERL procedures, the difference between the mass of propane measured in the tunnel and the mass injected was determined to be less than $2 \%$ prior to any testing. 


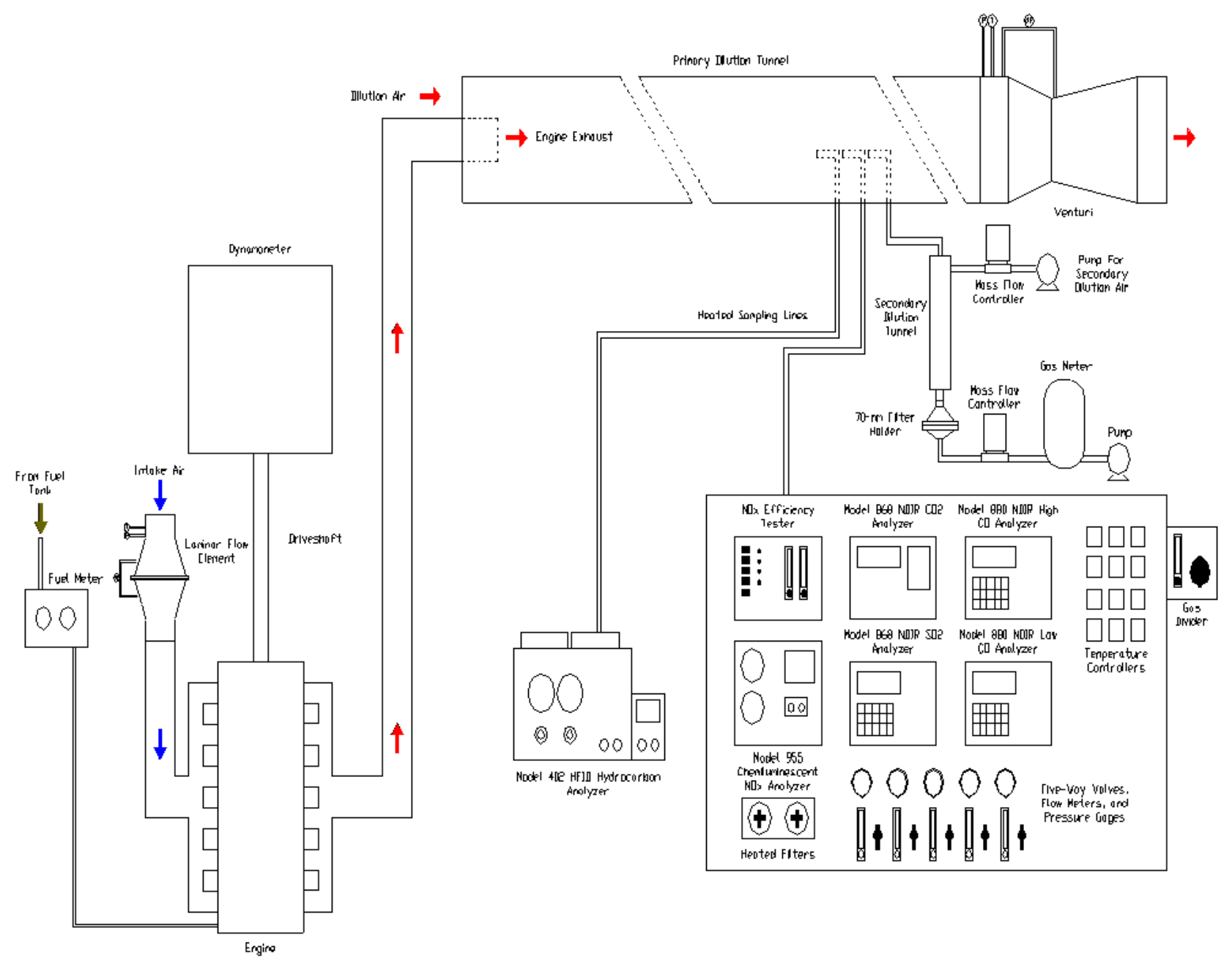

Figure 3.8 Schematic of the emissions sampling and measurement system at the EERL, WVU [53] 


\subsubsection{Secondary Dilution, Flow Measurement and Particulate Sampling System}

The engine exhaust is mixed with additional dilution air in a secondary dilution tunnel prior to particulate sampling on a filter. This secondary dilution reduces the exhaust temperature below $125^{\circ} \mathrm{F}\left(51.7^{\circ} \mathrm{C}\right)$ to allow "complete" gas-to-particle transformation of PM. The PM filters used in this study were Pallflex T60A20 70mm fluorocarbon coated fiberglass filters. The particulate sampling system was designed in accordance with the regulations in 40 CFR, Part 89. The system also conforms to 40 CFR, Part 86, Subpart N, and 30 CFR, Part 7. The exhaust sample is drawn through a 0.5 in $(0.015 \mathrm{~m})$ diameter transfer tube located at the sampling zone in the primary dilution tunnel. The inlet of the tube faces upstream towards the primary tunnel, and is approximately 7 in. $(17.8 \mathrm{~cm})$ in length. The total and secondary flow is controlled by two Sierra 740 L-1 mass flow controllers and two Gast series 1023-101Q-583X rotary vane pumps. The mass flow controllers have a working range of $0-5 \mathrm{slpm}$, and were calibrated using a Meriam Instruments laminar flow element Model 50MW20, rated at $0-6.52 \mathrm{~m}^{3} / \mathrm{min}(0-23 \mathrm{scfm})$. A stainless steel filter holder is used to house the PM filters. Stainless steel is used to prevent the diesel exhaust from reacting with the filter holder material. The PM sample was collected on primary and secondary Pallflex fluorocarbon coated glass fiber T60A20 filters, which are used commonly in EPA transient testing. The T60A20 filters have a filtration efficiency of $99.95 \%$ for $0.3 \mu \mathrm{m}$ DOP. 


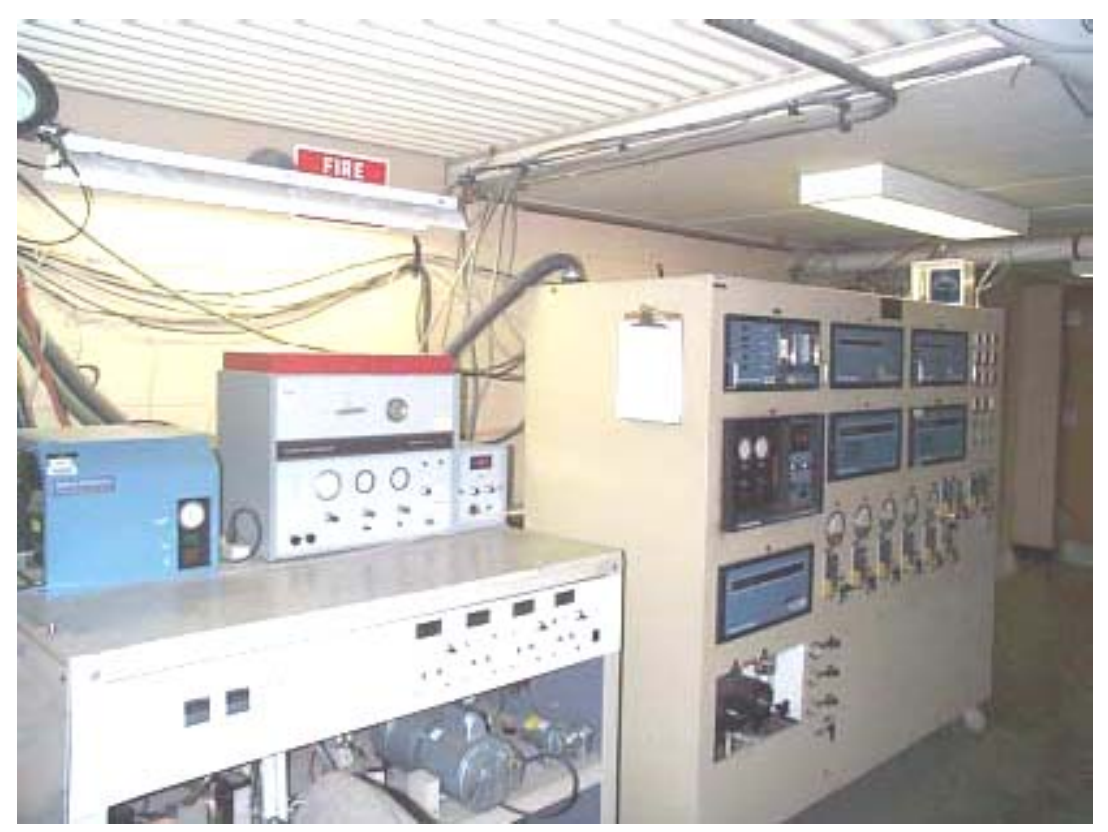

Figure 3.9: Gaseous emissions analyzer bench and

PM sampling cart at the EERL

Background PM samples were collected from the dilution tunnel, without the engine running, at the beginning and end of each testing day. This was performed to account for PM in the dilution air as well as to account for re-entrainment of PM from the dilution tunnel walls. The background filter weights were used to correct the test particulate filter weights in accordance with 40 CFR, Part 89.

$P_{\text {mass }}=\left(V_{\text {mix }}+V_{s f}\right) \times\left[\frac{P_{f}}{V_{s f}}-\left(\frac{P_{b f}}{V_{b f}} \times\left[1-\left(\frac{1}{D F}\right)\right]\right)\right]$

where,

$\mathrm{P}_{\text {mass }}=$ mass of particulate emitted during the test phase.

$\mathrm{V}_{\text {mix }}=$ total volume of dilute exhaust corrected to standard conditions.

$\mathrm{V}_{\mathrm{sf}}=$ volume of sample removed from the primary dilution tunnel.

$\mathrm{P}_{\mathrm{f}}=\quad$ combined weight of PM collected during a test cycle on both the primary and backup filter.

$\mathrm{V}_{\mathrm{bf}}=\quad$ volume of dilution air sampled during the background test. 
$\mathrm{P}_{\mathrm{bf}}=$ combined weight of PM collected on both background filters.

$\mathrm{DF}=$ dilution factor calculate from the following equation.

$\mathrm{DF}=\frac{13.4}{C O_{2 e}+\left(H C_{e}+C O_{e}\right) 10^{-4}}$

where, the subscript "e" identified a gaseous emission concentration collected from the dilute sample bag.

\subsubsection{PM Filter Handling and Conditioning}

The PM filters were conditioned for at least eight hours at a $50 \%$ relative humidity and $70^{\circ} \mathrm{F}$ environmental chamber both before and after the test runs. Continuity was maintained by having two reference filters in the environmental chamber at all times. These filters served as a quality assurance check in the gravimetric analysis. The reference filters were weighed before and after engine tests along with the test filters. In accordance with the 40 CFR, Part 89 specifications, if the average weight of the reference filters changed between $\pm 5 \%$ or more of the nominal filter loading (recommended minimum of $5.3 \mathrm{mg}$ ), then all sample filters in the process of stabilization are deemed invalid and the test runs have to be repeated. If the difference in weight is between $1 \%$ and $5 \%$, then two options are available - either repeat the test runs or add the weight lost to the sample weights. If the difference in weights varied by less than $1 \%$ the recorded weights are accepted. Since the dilution air was not filtered before entering the tunnel, a metered sample of air was drawn through a filter and post conditioned and weighed. The weight was then subtracted from the sample filters.

The glass Petri dishes containing these filters were cleaned with an alcohol solution every time they were used. These dishes were covered but not sealed in the environmental chamber to prevent dust from accumulating over the filters while allowing humidity exchange to take place. Ferguson [53], stated that glass Petri dishes need to be used because the static electric charge carried by the plastic dishes resulted in loss of particulate matter from the filter. Filters were 
handled with conducting stainless steel tweezers and a Nucleospot ${ }^{\mathrm{TM}}$ Polonium-210 charge neutralizer was used to condition the filters prior to weighing.

\subsubsection{Cahn Microbalance}

The Cahn C-32 microbalance was used to determine the weights of PM filters. The balance was placed on a vibration isolation table, in an environmental chamber. The environmental chamber temperature is maintained at $22{ }^{\circ} \mathrm{C} \pm 3{ }^{\circ} \mathrm{C}$, dew point temperature at 9.4 ${ }^{\circ} \mathrm{C} \pm 3{ }^{\circ} \mathrm{C}$ and relative humidity of $45 \% \pm 8 \%$. The balance has a $3.5 \mathrm{~g}$ weighing capacity with three weighing ranges and a sensitivity of $0.1 \mu \mathrm{g}$. The microbalance has a precision range of 25 $\mu \mathrm{g}$, which was used during testing. The balance was calibrated with NIST traceable weights.

\subsubsection{Gaseous Emissions Sampling}

Regulated gaseous emissions were measured by sampling diluted exhaust using stainless heated steel probes, heated sample lines, heated filters and gas analyzers. Heated lines were used to prevent condensation of moisture in the exhaust gases, and prevent condensation of heavy organics in the hydrocarbon sampling system. Probes were inserted into the dilution tunnel and a sample was drawn through individual heated lines connected to gas analyzers.

The sampling plane was located ten diameters downstream of the mixing zone in the dilution tunnel to allow for turbulent developed flow. Four sampling probes were inserted six inches into the tunnel and facing upstream. These probes were connected to the temperature controlled heated lines, which then transfer the sample to the analyzers.

The hydrocarbon line and probe were kept at a wall temperature of $375^{\circ} \mathrm{F} \pm 10^{\circ} \mathrm{F}(191$ ${ }^{\circ} \mathrm{C} \pm 6{ }^{\circ} \mathrm{C}$ ) to prevent condensation of higher molecular weight while the other lines and probes are kept at $235^{\circ} \mathrm{F} \pm 10^{\circ} \mathrm{F}\left(113{ }^{\circ} \mathrm{C} \pm 6{ }^{\circ} \mathrm{C}\right)$ at the wall. 


\subsubsection{Gas Divider}

For each gas analyzer, the zero and span gas values were checked prior to each test run, using calibration gases with $1 \%$ accuracy traceable to NIST standards and a ten point calibration curve was generated. Calibration gases included the "top bottle" (span gas), and zero gas (zero air and ultra zero air monitoring, (UZAM) gas). The temperature was controlled using Fuji Model 223-1806 temperature controllers. A STEC Inc. SGD-710C gas divider was used to provide stepped input to the analyzers, while calibrating. The gas divider comprises of two inlet ports, one for the span gas, and the other for balance air or zero gases, and an output port that supplies the blended gas to an analyzer. The gas can be supplied at increments of $10 \%$ of span concentration. The core of the gas divider consists of a set of ten capillaries, and the mass flow rate through each capillary is proportional to the pressure drop across the capillaries.

\subsubsection{Data Acquisition}

The calibrations were controlled automatically by a data acquisition computer. The divider's stepped increments are controlled manually. The software used for data acquisition was developed at WVU [54]. The program utilized an RTI-815F data acquisition board and a rackmounted signal conditioning board comprised of a number of Analog Devices 3B series conditioning modules. Pei [55] developed a program to convert the raw data, in the form of ADC codes, into proper engineering units. The final data is then written onto a file.

\subsubsection{Exhaust Sample Gas Analysis Equipment}

\subsubsection{1 $\mathrm{NO}_{\mathrm{x}}$ Analyzer}

$A \mathrm{NO}_{\mathrm{x}}$ analyzer works on the principle of chemiluminescence for measuring $\mathrm{NO}$ or $\mathrm{NO}_{\mathrm{x}}$ concentrations in the exhaust sample. A Rosemount Analytical Model $955 \mathrm{NO}_{\mathrm{x}}$ analyzer was used for this study [56]. It has a dual mode of operation, the $\mathrm{NO}$ and $\mathrm{NO}+\mathrm{NO}_{2}$ modes, to determine the concentration of $\mathrm{NO}_{\mathrm{x}}$. In the $\mathrm{NO}$ mode, the method is based upon the reaction between ozone and $\mathrm{NO}$ yielding $\mathrm{NO}_{2}$ and oxygen. 


$$
\begin{aligned}
& \mathrm{NO}+\mathrm{O}_{3} \rightarrow \mathrm{NO}_{2}^{*}+\mathrm{O}_{2} \\
& \mathrm{NO}_{2}^{*} \rightarrow \mathrm{NO}_{2}+h v
\end{aligned}
$$

Ozone for the reaction is produced by passing air or oxygen over an ultra violet source. The release of a photon molecule is proportional to the mass flow rate of NO present in the sample. The instrument has a photon detector (multiplier tube), which produces a low level DC voltage. This drives the readings on the front panel which produces a response of 0 to 5 volts. The principle is similar in the $\mathrm{NO}_{\mathrm{x}}$ mode, except that the $\mathrm{NO}_{2}$ is catalytically converted into $\mathrm{NO}$ in a $\mathrm{NO}_{\mathrm{x}}$ converter and the reading is the sum of the NO present in the sample plus the NO produced by the dissociation of $\mathrm{NO}_{2}$.

The analyzer has full-scale selectable ranges of 10, 25, 100, 250, 1,000, 2,500 and 10,000 ppm. It produces a linear output. The detector operating pressure was atmospheric and sample inlet temperature was $250^{\circ} \mathrm{F}\left(121^{\circ} \mathrm{C}\right)$. A heated sample line maintained at $250{ }^{\circ} \mathrm{F}\left(121^{\circ} \mathrm{C}\right)-$ $400{ }^{\circ} \mathrm{F}\left(204^{\circ} \mathrm{C}\right)$ is used to route the exhaust sample into the analyzer. These temperatures help prevent condensation on the line walls. The internal $\mathrm{NO}_{\mathrm{x}}$ converter is maintained between $660{ }^{\circ} \mathrm{F}$ $\left(350{ }^{\circ} \mathrm{C}\right)$ and $750{ }^{\circ} \mathrm{F}\left(399{ }^{\circ} \mathrm{C}\right)$ to facilitate maximum $\mathrm{NO}_{2}$ conversion efficiency. The converter efficiency always needs to be above $90 \%$ prior to testing. Converter temperature was recorded using a J-type thermocouple. The reaction chamber was maintained above $130{ }^{\circ} \mathrm{F}\left(54{ }^{\circ} \mathrm{C}\right)$, the dew point of diesel exhaust. Sample was drawn at $235^{\circ} \mathrm{F}$ from the tunnel and passed into a heated filter, which in turn feeds the analyzer, at a constant pressure of 4 psi. Filters were changed daily prior to testing.

The $\mathrm{NO}_{\mathrm{x}}$ analyzer requires a balance gas and a span gas supplied from pressurized cylinders. Nitrogen was used as the balance gas for calibration and air was used as a source of oxygen for ozone generation. A 500 ppm NO span gas was used for calibration. 


\subsubsection{HC Analyzer}

A Beckman Model 402 HFID hydrocarbon analyzer was used in this study [57]. The HFID measures $\mathrm{HC}$ concentration in relation to the number of carbon atoms present in the sample. A regulated flow mixture of air, $40 \%$ hydrogen and $60 \%$ helium produces a premixed flame. The sample gas is passed through this flame and ions are produced, which are attracted by polarized electrodes. The generation of ions produces a current in the circuitry, which is proportional to the number of carbon atoms in the sample, which in turn gives the concentration of the sample [58]. The analyzer can measure HC levels up to 250,000 ppm and has a full-scale linear output. The analyzer was calibrated using zero air, generated from a Balston 75-52 FTIR purge gas generator, and propane, supplied from a gas cylinder of $30 \mathrm{ppm}$ concentration.

The analyzer was subject to an analyzer "peaking process" to obtain the peak performance at certain fuel and air pressures. The response of the instrument at $100 \%$ span and zero air with various settings of burner fuel and air was noted. Letting the analyzer reach its operating temperature after switching it on started the process. By keeping the air settings constant while varying the fuel pressures, the difference in zero and span responses are noted. This process is repeated keeping the fuel pressure constant while varying the air pressure. The pressures at which the analyzer displays peak performance are noted. A $30 \mathrm{ppm}$ propane gas cylinder was used for this purpose.

\subsubsection{3 $\mathrm{CO} / \mathrm{CO}_{2}$ Analyzer}

Rosemount Analytical Model 868 and 880 NDIR analyzers were used to measure $\mathrm{CO} / \mathrm{CO}_{2}[59]$. These analyzers work on the principle of selective absorption of wavelengths. The infrared energy of a band of wavelength corresponding to a certain gas will be absorbed. The amount of energy absorbed or transmitted gives the concentration of the gas. The detector is a "gas microphone." It converts the difference of energy between sample and reference into a capacitance, which is proportional to the gas concentration. The NDIR does not produce a linear 
output. The analyzers were checked for zero and span gas values before every test run. Customized software automatically created a best-fit curve and gave the calibration constants and the $r^{2}$ value. The closer the value is to unity, the better the fit.

There are two $\mathrm{CO}$ analyzers on the gas bench, the high $\mathrm{CO}$ and low $\mathrm{CO}$. The high $\mathrm{CO}$ has ranges of $0-2 \%$ and $0-10 \%$ and the low $\mathrm{CO}$ has ranges of $0-1000 \mathrm{ppm}$ and $0-5000 \mathrm{ppm}$. The $\mathrm{CO}_{2}$ analyzer has ranges of $0-5 \%$ and $0-20 \%$. A low CO 500 ppm, high CO 5000 ppm bottles were used.

\subsubsection{Bag Sampling}

Samples of dilute exhaust and dilution air were collected in 80 liter Tedlar ${ }^{\mathrm{R}}$ bags. Bag samples were analyzed after the completion of a test run by routing the contents through the analyzers. The respective concentrations were measured and the bags were evacuated for the next test. The background concentrations were used to correct the dilute samples and the continuous readings. The dilute sample serves as a quality assurance/quality check to compare the results with the continuous sample. The following equation made this correction.

$$
\left[X_{\text {mass }}\right]=\sum_{i=1}^{n}\left[\frac{\left[X_{e}\right]_{i}}{10^{6}} \times\left(V_{m i x}\right)_{i} \times \text { density }_{x} \times \Delta T\right]-\frac{[X]_{d}}{10^{6}}\left(1-\frac{1}{D F}\right) \times V_{m i x} \times \text { density }_{x}
$$

where $\mathrm{X}$ represents the emission species being evaluated, subscripts e, I, and d represent gaseous emission concentration from the dilute bag, instantaneous values from the continuous data, and background air sample data values, respectively. $V_{\text {mix }}$ is the total dilute exhaust volume in cubic feet per test phase corrected to standard conditions, density $\mathrm{x}_{\mathrm{x}}$ is the density of the emission species being evaluate, and DF refers to the dilution factor (40 CFR, Part 89, 40 CFR, Part 86, Subpart N). 


\subsubsection{Dynamometers}

The required load is applied on an engine using dynamometers in a laboratory environment. Depending upon the load rating required, the size of the engine, and the application three types of dynamometers were used: the water-brake, eddy-current, and the electric dynamometers. In this study a water-brake dynamometer was used to break-in the engine and degreen the DPFs. Emissions tests were conducted on a absorbing/motoring dynamometer.

\subsubsection{Water-brake Dynamometer}

A Go-Power DT2000 water-brake dynamometer was used while performing the break-in procedure on the Caterpillar engine. This dynamometer produces torque by shearing through water, which is its active medium, between a rotor and stator housing. The force exerted by the torque from the engine acts on the fluid medium and rotates the rotor. Varying the flow rate of water into the housing controls the amount of load. A pressure regulator valve controls the water supply. A Dynloc-IV digital controller was used to read the speed and torque values while a compute was used to vary the load applied by the dynamometer. The torque is recorded from a signal originating from the load cell on the dynamometer. A Dyne Systems Co. DTC-1 digital throttle controller was used to vary the fueling rate. The throttle controller was coupled with the torque controller and a throttle actuator and was attached to the engine fueling linkage. By comparing the input speed and torque values, the desired fueling rate and speed were achieved. 


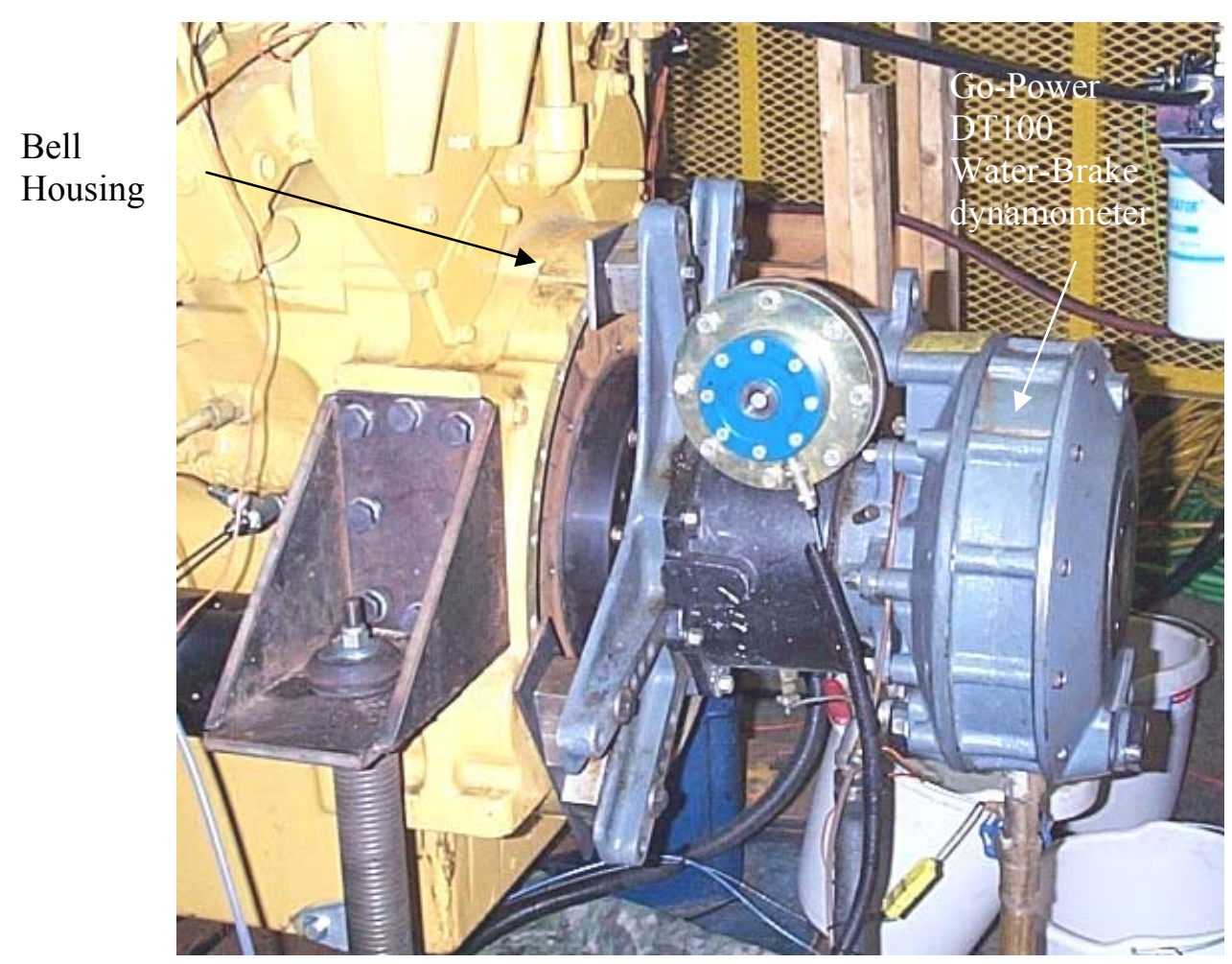

Figure 3.10: Go-Power water-brake dynamometer connected to the test engine during

\section{break-in}

\subsubsection{Electric Dynamometers}

The EERL uses a GE Model DYC-243 fan cooled, direct current dynamometer (with operational conditions: power rating of $200 \mathrm{Hp}$; current rating of $300 \mathrm{amps}$ at $3000 \mathrm{rpm}$ ). The dynamometer was capable of absorbing $550 \mathrm{hp}$ and providing up to $500 \mathrm{hp}$ during motoring. Electric dynamometers are similar to electric motors in operation. The dynamometer consists of an armature and stator assembly, which generates the torque. The engine output is measured by a load-cell mounted on the dynamometer frame and varying the load on the dynamometer may vary the load applied. The load cell is calibrated by hanging known weights from an arm of known length, mounted opposite to the load cell so as to provide tension to equal the maximum value of force reachable by the dynamometer. Engine speed was recorded with an internal digital speed 
encoder. The dynamometer attached to the engine flywheel using a driveshaft, an adapter plate, and a bonded-rubber coupling damper.

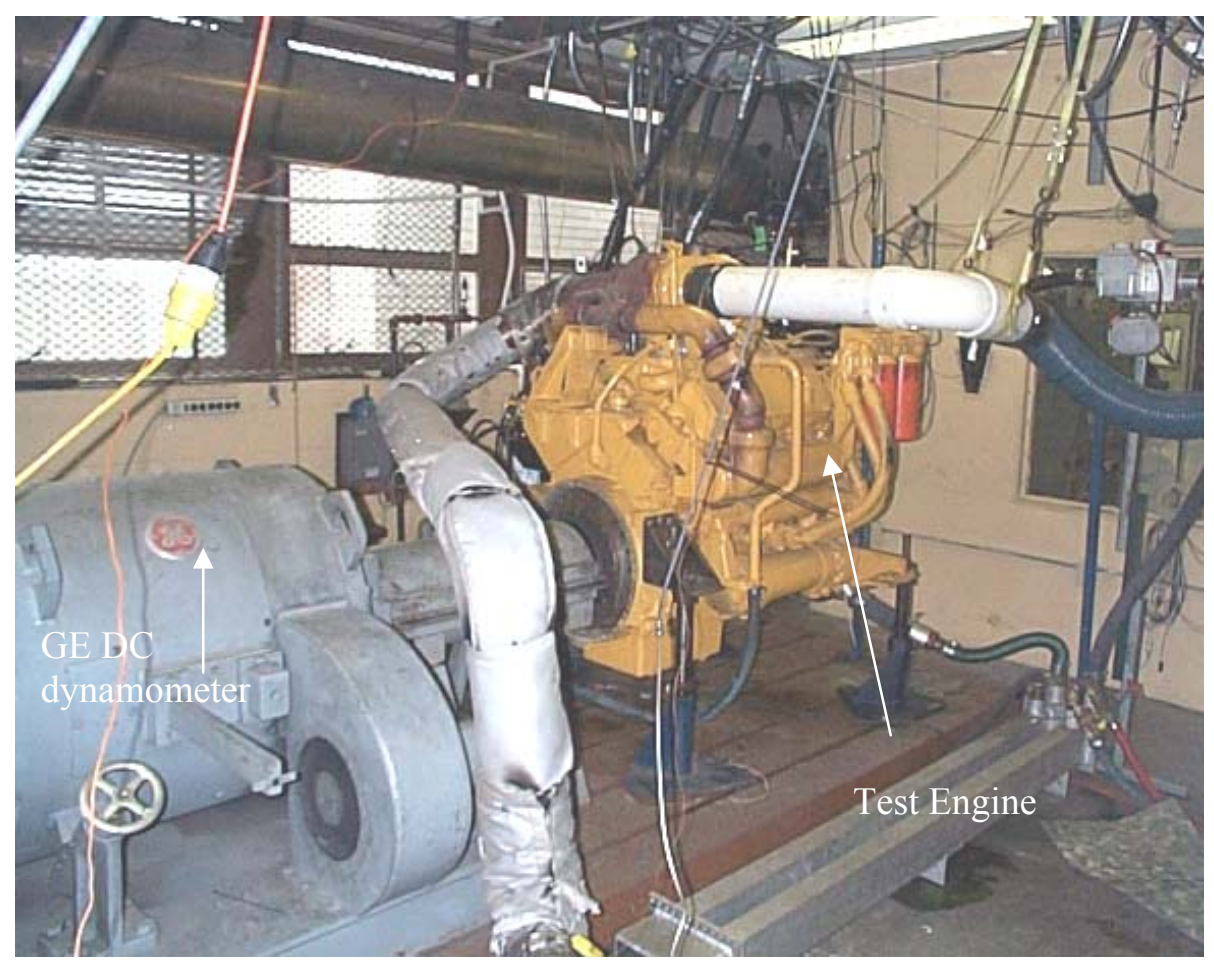

Figure 3.11: Test engine coupled with GE DC dynamometer 


\subsection{ALTERNATE FUELS AND FORMULATIONS}

Three fuels were used during testing; CARB Off road diesel, ultra low sulfur Emission Control Diesel-1 and Laporte Fischer-Tropsch synthetic diesel. Table 3.4 shows the properties of all the fuels used during testing. It also lists the ASTM testing methods utilized to arrive at the properties. Fuels were analyzed according to the ASTM methods specified in the CFR 40, Part 86, Subpart D. It has been shown that ultra low sulfur ECD1 reduces all regulated emissions when compared to CARB Off road diesel [47].

EC-Diesel fuels are produced from crude oil using a conventional refining process [47]. The original ECD contained less than $15 \mathrm{ppm}$ sulfur, less than $12 \%$ aromatics by volume, and a cetane number of greater than 60 . The production of ECD required extensive hydro treating which added to the costs. It was shown that the high cetane number and low aromatic levels have a negligible effect on DPF regeneration and conversion efficiency [3]. Hence, a second generation EC diesel fuel named ECD-1 was formulated, identifying the low sulfur content as the major property required for catalyzed DPF operation. ECD-1 has a maximum sulfur content of 15 ppm but has aromatic and cetane levels that are more typical of California diesel fuels. CARB diesel is a blend of one-third volumes from three different fuels, made by companies located in southern California [47]. The Fischer-Tropsch fuel was developed by the Department of Energy, at its Alternative Fuels Development Unit, in Laporte, Texas. Fischer-Tropsch is a gas-to-liquid process, which was patented by Franz Fischer and Hans Tropsch, synthesizing petroleum at normal pressure using metal catalysts. The synthesis gas is converted into liquid hydrocarbons [60]. Different companies like Sasol of South Africa, Shell, Exxon, Texaco, and others have developed methods for the commercial production of synthetic fuels using the FT process. McMillian and Gautam have reported different methodologies of reformulating FT diesel from synthesis gas [45]. 
Table 3.4: ASTM fuel analysis performed at Saybolt Laboratories, Carson, California

\begin{tabular}{|l|l|l|l|l||l||}
\hline Analysis & Units & ASTM & CARB & ECD1 & F-T \\
\hline \hline API gravity @ 60F & & D-1298 & 39.6 & 39.2 & 49.0 \\
\hline \hline Flash Point & ${ }^{\circ} \mathrm{F}$ & D-93(A) & 145 & 141 & 218 \\
\hline \hline Kinematic Viscosity @ 40F & cSt & D-445 & 2.073 & 2.115 & 3.360 \\
\hline \hline Cetane number & & D-613 & 53.2 & 52.8 & +74.8 \\
\hline \hline Aromatics & Wt\% & D-5186 & & & \\
Total Aromatics & & & 15.28 & 21.35 & 0.46 \\
Monoaromatics & & & 12.30 & 18.47 & 0.26 \\
PAH & & & 2.98 & 2.88 & 0.20 \\
\hline \hline Hydrocarbon type- FIA & Vol\% & D-1319 & & & \\
Aromatics & & & 11.1 & 16.2 & 0.8 \\
Olefins & & & 3.1 & 3.2 & 0.0 \\
Saturates & & & 85.8 & 80.6 & 99.2 \\
\hline \hline Sulfur, Total by X-ray Spec & Wt\% & D-2622 & 0.0216 & 0.0014 & 0.0010 \\
\hline \hline Distillation & & D-86 & & & \\
IBP & ${ }^{\circ} \mathrm{F}$ & & 359.4 & 341.1 & 425.5 \\
$5 \%$ Rec & ${ }^{\circ} \mathrm{F}$ & & 384.1 & 377.1 & 488.1 \\
10\% Rec & ${ }^{\circ} \mathrm{F}$ & & 390.7 & 388.2 & 498.2 \\
20\% Rec & ${ }^{\circ} \mathrm{F}$ & & 405.1 & 410.9 & 515.2 \\
30\% Rec & ${ }^{\circ} \mathrm{F}$ & & 419.5 & 430.7 & 528.7 \\
$40 \%$ Rec & ${ }^{\circ} \mathrm{F}$ & & 437.3 & 453.3 & 542.7 \\
50\% Rec & ${ }^{\circ} \mathrm{F}$ & & 456.9 & 476.9 & 556.8 \\
60\% Rec & ${ }^{\circ} \mathrm{F}$ & & 479.6 & 502.3 & 571.3 \\
$70 \%$ Rec & ${ }^{\circ} \mathrm{F}$ & & 507.1 & 530.2 & 585.2 \\
$80 \%$ Rec & ${ }^{\circ} \mathrm{F}$ & & 542.7 & 563.3 & 601.4 \\
90\% Rec & ${ }^{\circ} \mathrm{F}$ & & 593.7 & 608.9 & 619.3 \\
$95 \%$ Rec & ${ }^{\circ} \mathrm{F}$ & & 637.4 & 647.8 & 633.0 \\
FBP & ${ }^{\circ} \mathrm{F}$ & & 656.6 & 665.4 & 638.7 \\
Recovery & $\%$ & & 97.3 & 97.4 & 97.3 \\
Residue & & 1.4 & 1.4 & 1.8 \\
Loss & & & 1.3 & 1.2 & 0.9 \\
& & & & \\
\hline
\end{tabular}

Diesel fuel is a mixture of hydrocarbons obtained by distillation of crude oil. The important properties used to define diesel fuel are cetane number, fuel volatility, density, viscosity, and sulfur content. Crude oil of different paraffin and aromatic content gives different blends of diesel fuel.

Cetane Number is the readiness of a fuel to ignite when heated is indicated by its cetane number. The higher the number, the easier it is to ignite. The shorter the intervals between the 
time when the fuel is injected and the time when it begins to burn, called the ignition delay period, the higher the cetane number. The cetane number of a fuel is determined by comparing it with a reference fuel on a standard engine test. The CFR Cetane Engine, ASTM D613, is the most widely accepted method. Heptamethyl nonane with an assigned cetane number of 15 is used as a reference fuel. Cetane has very good ignition quality and is assigned a number of 100 [62]. If a fuel has the same ignition qualities as that of a mixture of cetane and heptamethyl nonane, then the cetane number is calculated as:

Cetane number $=\%$ n-cetane $+0.15(\%$ heptamethyl nonane $)$

In the U.S., the minimum cetane number is 40 . A value between 55-60 is the desirable number for proper operation of diesel engines. High paraffin content improves the cetane number and a high aromatic content impairs it. A low cetane number fuel will make cold starts difficult and increase combustion noise. A higher cetane number, on the other hand, can cause an increase in emissions. Some hydrocarbons ignite more readily than others and are desirable because of this short ignition delay. The preferred hydrocarbons in order of their decreasing cetane number are paraffins, olefins, naphthenes, isoparaffins, and aromatics.

Cetane Index is a calculated value, which has been introduced as a means of estimating the cetane number of a diesel fuel from its density and mid-boiling point. The equation to calculate cetane index is based on fuel density and volatility and a standard given by ASTM D 4737.

Viscosity is an indication of the fuel's resistance to flow. Viscosity of a fuel is important for the proper operation of fuel injection equipment to inject the right quantity of fuel. A high viscosity at low temperature could reduce fuel flow rates and result in incomplete filling of the metering chamber. A low viscosity fuel could result in leakage from pumping chambers at low speeds. Viscosity affects atomization and fuel delivery rate. Fuels for medium-speed and highspeed engines generally lie in the range 1.4 to 4.3 centistokes viscosity at $100{ }^{\circ} \mathrm{F}\left(38^{\circ} \mathrm{C}\right)$. 
Diesel Fuel Density is the weight of a unit volume of diesel fuel can provide useful information about its composition and performance-related characteristics, such as ignition quality, power, and economy. The higher the density, heavier the material. This characteristic is sometimes expressed as specific gravity (relative density), which is the ratio of the density of the fuel to that of an equal volume of water at the same temperature. Engine power increases with a slight increase in density.

Fuel sulfur is converted to sulfates, which along with water get converted to PM emissions. Oxidation of sulfur dioxide over exhaust oxidation catalysts may lead to an increase in PM. Sulfur in diesel can cause combustion chamber deposits, exhaust system corrosion, and wear on pistons. Fuel sulfur also affects catalytic after-treatment devices.

Aromatics are measured by the ASTM D-5186 test method and ASTM D-1319 is used to find the types of hydrocarbons in the fuel. Two alternative methods have also been developed relating density and viscosity to total aromatic content and to aromatic carbon content [62]. Aromatics mainly have an effect on $\mathrm{NO}_{\mathrm{x}}$ and $\mathrm{PM}$ emissions.

Flash point is the temperature at which the vapors of heated fuel ignite is the flash point. However, the flash point does not affect the engine performance or the auto ignition qualities. A portion of the fuel is heated slowly at a constant rate in a covered cup, and at regular intervals the cover is opened, to admit a small flame into the cup. The procedure is continued until the fuel temperature is high enough for flash ignition to occur.

Volatility is expressed in terms of the temperature at which successive portions are distilled from a sample of the fuel, under controlled heating in a standardized apparatus [62]. The distillation or boiling range of the fuel affects properties such as viscosity, flash point, cetane number, and density. Distillation is the way in which the refiner segregates component streams from which fuels are blended. The ASTM D-86 method is used to distill diesel. At atmospheric pressure, the vapors are condensed and collected in a graduated cylinder, in percentages of initial 
volume of fuel. The condensate is recovered in percentages up to $95 \%$ or until the fuel starts to decompose or no more condensate can be recovered.

\subsubsection{Test Matrix}

The Caterpillar 3408 diesel engine was tested with both Johnson-Matthey CRT and Engelhard DPX diesel particulate filters. Table 3.5 shows the fuel and filter combinations used in the test matrix. The global objective of this study was to analyze the mechanical durability of the DPFs that have been retrofitted on construction equipment, over prolonged periods of in-field operation, and to assess the emission benefits of retrofitting construction equipment with DPFs. The tasks over the year long testing period included fuel and diesel particulate filter procurement (Johnson-Matthey and Engelhard), engine baseline emissions testing, engine dynamometer testing, retrofitting the construction equipment with traps, on-board PM emissions testing, engine emissions testing, and final engine dynamometer testing on the same engine after a year long infield operation. The traps accumulated 1400 hours of operation and will be sent back to WVU for final engine dynamometer testing in mid to late Fall 2003. The specific objectives for WVU study were:

1. To procure the Caterpillar engine for laboratory testing from Sukut Construction Inc.

2. To collect in-field transient speed and torque data, in Calabasas, California.

3. To develop a representative cycle of the in-field transient data at EERL, WVU.

4. Break-in the engine over a pre-set cycle for 50 hours.

5. Procure Engelhard DPX and Johnson-Matthey CRT that were sized for the CAT 3408 .

6. De-green the DPFs over a pre-set cycle for 9 hours each on ultra low-sulfur diesel fuel. 
7. To measure brake-specific emissions from the retrofitted test engine, on a representative transient cycle and the ISO 8178 8-mode cycle, using CARB specification diesel fuel (baseline), ultra low-sulfur diesel fuel (ECD1) and Fischer-Tropsch fuel.

The test engine was a rebuilt, mechanically controlled, 8-cylinder, Caterpillar 3408, a rear engine taken out of a 657E Scraper. The in-field data was collected from a 657E Scraper with a Caterpillar 3408E electronically controlled rear engine. The engine speed and torque was logged using the Electronic Technician software to record the ECU generated data, using a communication adapter, both supplied by Caterpillar.

Table 3.5: WVU's engine-dynamometer test matrix

\begin{tabular}{||l||l||l||c||c||}
\hline \multirow{4}{*}{ Time Period } & $\begin{array}{l}\text { Diesel } \\
\text { Fuel }\end{array}$ & DPF & 8-mode & Transient \\
\hline \hline \multirow{3}{*}{$\begin{array}{l}\text { Pre-installation } \\
\text { of trap on in- } \\
\text { field vehicle }\end{array}$} & CARB & None & $\sqrt{ }$ & $\sqrt{ }$ \\
\cline { 2 - 6 } & ECD1 & None & $\sqrt{ }$ & $\sqrt{ }$ \\
\cline { 2 - 6 } & ECD1 & Engelhard & $\sqrt{ }$ & $\sqrt{ }$ \\
\cline { 2 - 6 } & ECD1 & $\begin{array}{l}\text { Johnson- } \\
\text { Matthey }\end{array}$ & $\sqrt{ }$ & $\sqrt{ }$ \\
\cline { 2 - 5 } & GTL & None & & $\sqrt{ }$ \\
\cline { 2 - 5 } & GTL & $\begin{array}{l}\text { Johnson- } \\
\text { Matthey }\end{array}$ & $\sqrt{ }$ & $\sqrt{ }$ \\
\hline
\end{tabular}

CARB Diesel $=$ California Air Resources Board Diesel

ECD1 = Emission Control Diesel-1

ULS Diesel = Ultra Low Sulfur Diesel, “EC-D” from British Petroleum-Arco

8-Mode and Transient are duty cycles where varying levels of throttle and resistance are applied to test performance

$\mathrm{GTL}=$ Gas-to-Liquid type fuel - fuel produced from the Fischer-Tropsch gas refining process resulting in a diesel grade liquid product 
The engine was tested on both steady state and transient cycles. Each mode of the steady state 8-mode cycles was varied in duration for proper PM filter loading. Generally, all 8-modes are of 480 seconds duration per mode, with 300 seconds of data collection (both gas and PM) and 180 seconds of stabilization period. Sixty seconds are allowed in between modes. The idle mode was of 1200 seconds, in which data was collected for 1020 seconds. However in this study, due to high percent loads and the high horsepower of the CAT 3408 engine, data collection time during the R100 and I100 modes was reduced (60 seconds) so as not to damage the PM filters due to excessive loading. On the other hand, the R10 and Idle modes required an increase in the data collection duration (1500 seconds) to obtain sufficient PM loading on the filters, due to the effectiveness of the DPFs in reducing PM.

The stabilization period also accounted for changing PM filters between modes. The PM sampling system downstream of the secondary tunnel comprised of the filter holder, a mass flow controller, and a pump. At the end of the stabilization period, the pump and the mass flow controller were turned on, drawing in $2 \operatorname{scfm}\left(2 \times 10^{-06} \mathrm{~m}^{3} / \mathrm{min}\right)$ from the main tunnel. On both steady-state and transient cycles, PM was collected using Pallflex T60A20 $70 \mathrm{~mm}$ filters and were gravimetrically analyzed using a Cahn C-32 Microbalance.

Specifically, the WVU study included the following tasks:

1. Assembled and qualified the in-field emissions and data acquisition system.

2. Became familiarized with the Caterpillar Electronic Technician by acquiring data from a Caterpillar engine at a Caterpillar service shop in Fairmont, WV.

3. Collected in-field data from Calabasas, California.

4. Created a transient cycle representative of in-field transient operation.

5. De-greened PM traps on a specific cycle.

6. Mapped the engine on each test fuel. 
7. Conducted engine dynamometer testing on different fuel/trap configurations as specified in the test matrix. The engine dynamometer testing included the following the tasks:

a. Obtained a CAT 3408 engine from Sukut, and transported the engine to WVU's EERC for engine dynamometer testing.

b. Used a 657E Scraper with a rear CAT 3408 engine to develop a transient cycle for the engine identified in Task 1.

c. Performed engine break-in.

d. Performed de-greening of DPFs.

e. Prior to installing DPFs, conducted baseline emission testing using CARB fuel and ECD-1, on both steady state 8-mode and transient cycles.

f. Installed the Engelhard DPX DPF and conducted tests to determine total $\mathrm{HC}, \mathrm{CO}, \mathrm{NO}_{\mathrm{x}}, \mathrm{PM}$ emissions from the engine, on both steady state 8mode and transient cycles.

g. Removed and stored the Engelhard DPF.

h. Installed the Johnson-Matthey CRT DPF and repeated the tests done in Task 4.

i. $\quad$ Removed and stored the Johnson-Matthey DPF.

j. Shipped engine back to Shepherd and DPFs to CSDLAC, for 1400 hours of further operation.

k. Procure engine and DPFs after one year to repeat the above tasks. 


\subsubsection{Uncertainty Analysis}

An examination of the systematic and random errors in the PM measurements was conducted. Details of the uncertainty analysis are given in Appendix E. Measurement of a physical parameter essentially entails making an estimate of the value of the quantity being measured. Two features of such estimates are measurement error and measurement uncertainty. The difference between the value of a measured quantity and a measurement estimate of its value is referred to as measurement error. Measurement error may be systematic or random. Systematic errors are those whose sign and magnitude remain fixed over a specified period or whose values change in a predictable way under specified conditions. Random errors are those whose sign and/or magnitude may change randomly over a specified period or whose values are unpredictable, given randomly changing conditions. In general, the result of a measurement is only an approximation or estimate of the value of the specific quantity subject to a measurement, and thus the result is complete only when accompanied by a quantitative statement of its uncertainty [64].

The error in engine out particulate matter measurements was calculated to be $\pm 1.95 \%$. 


\section{CHAPTER 4 LABORATORY TESTING RESULTS}

\subsection{INTRODUCTION}

The objectives of the current study were to generate a transient cycle representative for a scraper engine, and evaluate the emissions characteristics of a CAT 3408, non-road diesel engine that is installed in the rear of the scraper, by operating it on fuels with different sulfur content. The engine was tested with two different types of DPFs. No modifications were made to the physical or performance characteristics of the engine nor the DPFs. PM was of prime importance and its reduction was kept as the basis for the retrofit evaluation. Also back pressure values on DPF equipped runs were of particular interest. A high backpressure value was considered to be highly significant to the study. The results generated from this study were used in the SCAQMDsponsored retrofit non-road construction equipment evaluation project.

The engine was sequentially tested with every combination of fuel and DPF that is listed in Table 3.5. All engine-retrofit configurations were run on both the steady state and transient cycles. Table 4.1 shows the torque and speed set points of the ISO-8178 8-mode cycle. Table 4.1 also specifies the weighting factors for each mode, which are used to calculate the total weighted emissions. Engine speed and torque remain constant throughout the defined period of each mode. A transient cycle is a test period in which the engine speed and torque are continuously varying according to a predetermined set of values. Engine speed and torque set points were individually determined by mapping the engine on all the test fuels. The engine was warmed up on the US FTP cycle at the beginning of the test day, and whenever the engine was idle for more than 30 minutes.

As mentioned in Chapter 3, the test engine which was rebuilt prior to being received by WVU for testing was subjected to a break-in schedule. Additionally, both DPFs were de-greened for 9 hours following a pre-set de-greening cycle. Care was taken to keep the retrofit exhaust 
temperatures and back pressure values within the manufacturer specifications. During the breakin and de-greening processes, both temperatures and backpressures (in. of $\mathrm{H}_{2} \mathrm{O}$ ) were manually noted at two minute intervals. Figures 4.1 and 4.2 depict the reduction in back pressure over the break-in period when the engine was retrofitted with DPFs. Peak pressure values were noticed at the high speed-high load set point. Backpressure gradually decreased over time for the all the engine speed/load set points, which indicated that regeneration occurred. The engine, without the DPFs was then mapped with the test fuels. CARB fuel baseline testing was done as the first evaluation of the emission performance of the engine. Each configuration was tested on the ISO 8178 8-mode and the laboratory developed transient cycle.

Table 4.1: The ISO 8178 8-mode test cycle

\begin{tabular}{||l||l|l||l||}
\hline \hline Mode Number & Engine Speed & $\begin{array}{l}\text { Load Factor } \\
\text { (Percent Load) }\end{array}$ & $\begin{array}{l}\text { Weighting } \\
\text { Factor }\end{array}$ \\
\hline \hline 1 & Rated & 100 & 0.15 \\
\hline \hline 2 & Rated & 75 & 0.15 \\
\hline 3 & Rated & 50 & 0.15 \\
\hline \hline 4 & Rated & 10 & 0.10 \\
\hline \hline 5 & Intermediate & 100 & 0.10 \\
\hline \hline 6 & Intermediate & 75 & 0.10 \\
\hline \hline 8 & Intermediate & 50 & 0.10 \\
\hline \hline
\end{tabular}

The engine was coupled to a GE DC dynamometer and the exhaust was routed to the primary dilution tunnel by means of exhaust piping. Joints in the exhaust transfer tube were sealed with aluminum wrap capable of withstanding the high temperatures. More than $12 \mathrm{ft}$. (6.1m) of accessible transfer tube was insulated with exhaust insulation, which was made of glass wool and wire mesh covered with fibrous material. The piping length was insulated in accordance with the requirements of CFR 40, Part 89. The exhaust transfer tube was insulated to minimize thermophoretic losses of PM, and to avoid temperatures from falling below $375{ }^{\circ} \mathrm{C}$, which is 
essential to avoid condensation of higher molecular weight hydrocarbons. Thermocouples and pressure sensors were placed at the inlet and outlet of the DPFs to account for pre- and post-trap temperatures and pressure drop. Temperature was recorded using $\mathrm{J}$ type thermocouples. Differential pressure was recorded using SMAR Model LD301 pressure transducers. An electrically controlled butterfly valve was installed in the exhaust transfer tube downstream of the DPFs in order to regulate the backpressure during a test. Chasey [54] developed the data acquisition system. The data acquisition rack contains modules recording data of a particular parameter concerned with the engine or test cell operation. Software developed by Pei [55] was used for data acquisition and processing.

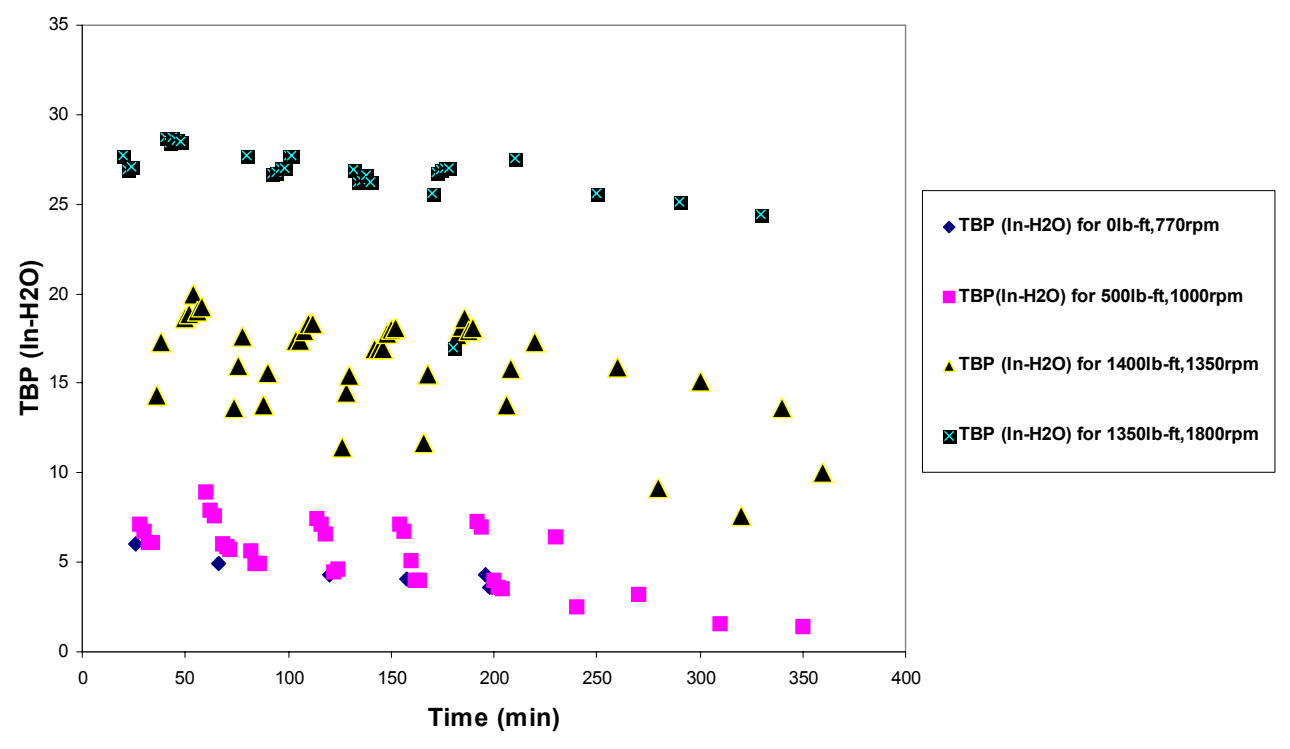

Figure 4.1: Total backpressure (TBP) during break-in for Johnson-Matthey CRT 


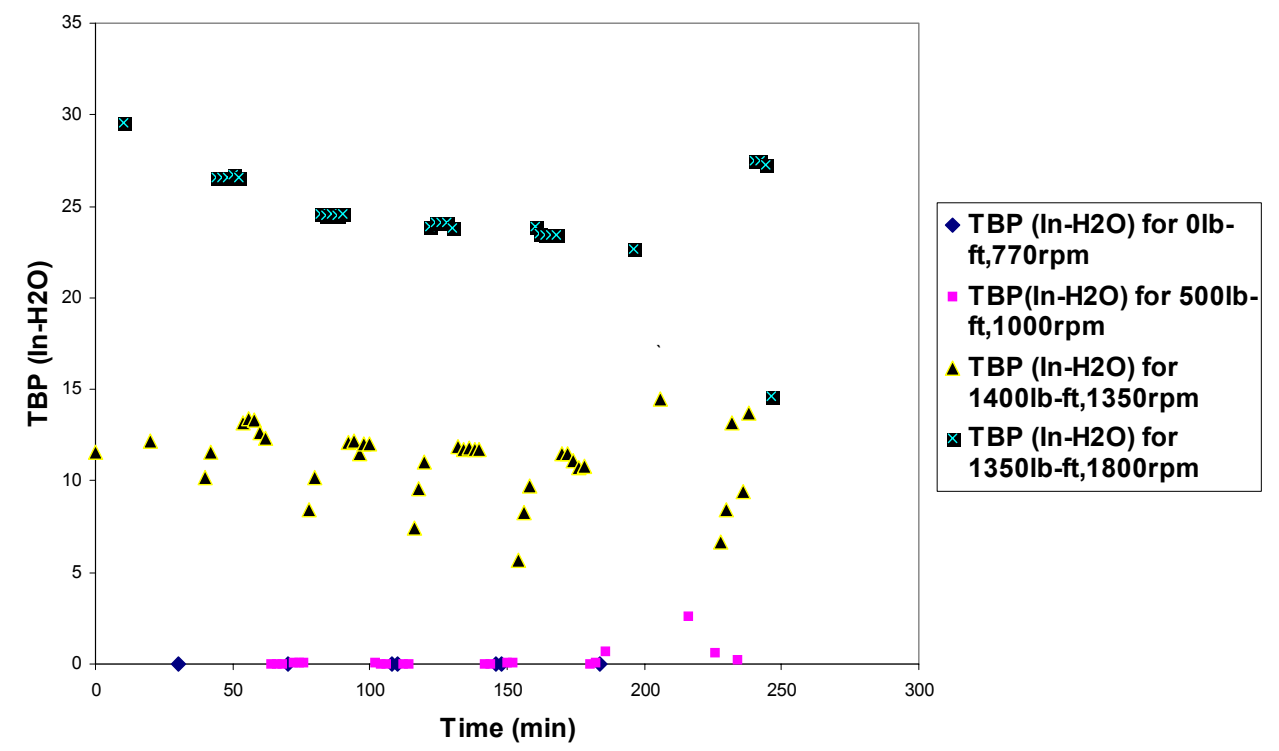

Figure 4.2: Total backpressure (TBP) during break-in for Engelhard DPX

\subsubsection{Pre and Post Trap Exhaust Temperatures}

Exhaust temperatures were recorded before and after retrofitting the traps to the engine. Pre-trap exhaust temperature was measured while testing the baseline with CARB and ECD1 diesel. Post-trap temperature was measured during the break-in period, while the engine was being fueled by ECD1 diesel. The temperature was recorded to check if it was high enough for regeneration to occur in the traps. Johnson-Matthey claims the CRT undergoes passive regeneration at exhaust temperature greater than $500^{\circ} \mathrm{F}\left(260^{\circ} \mathrm{C}\right)$. Engelhard claims that the DPX undergoes passive regeneration when exhaust temperatures are $700 \mathrm{~F}$ (375 C) or higher. Figure 4.3 shows the mode speed/torque set points on each mode using ECD1 diesel. Figure 4.4 shows the maximum temperatures attained in each mode using ECD1 diesel. Figure 4.5 shows the maximum temperatures attained in each mode using CARB diesel. The figure also shows the average maximum temperature attained under transient operation. The post-trap temperature was well above that required for regeneration for both the CRT and DPX DPFs. 


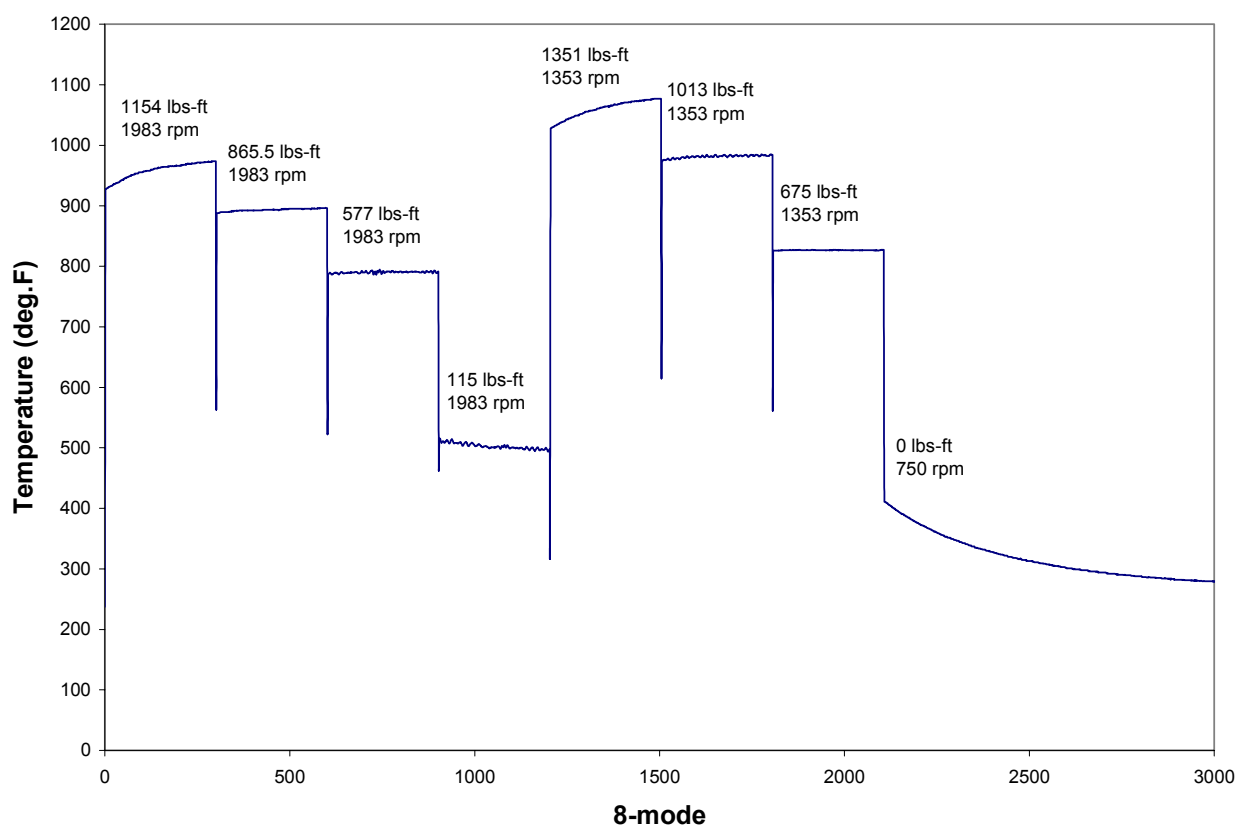

Figure 4.3: Continuous 8-mode exhaust temperature data on ECD1 baseline. The 8-mode set points are shown on top of each mode

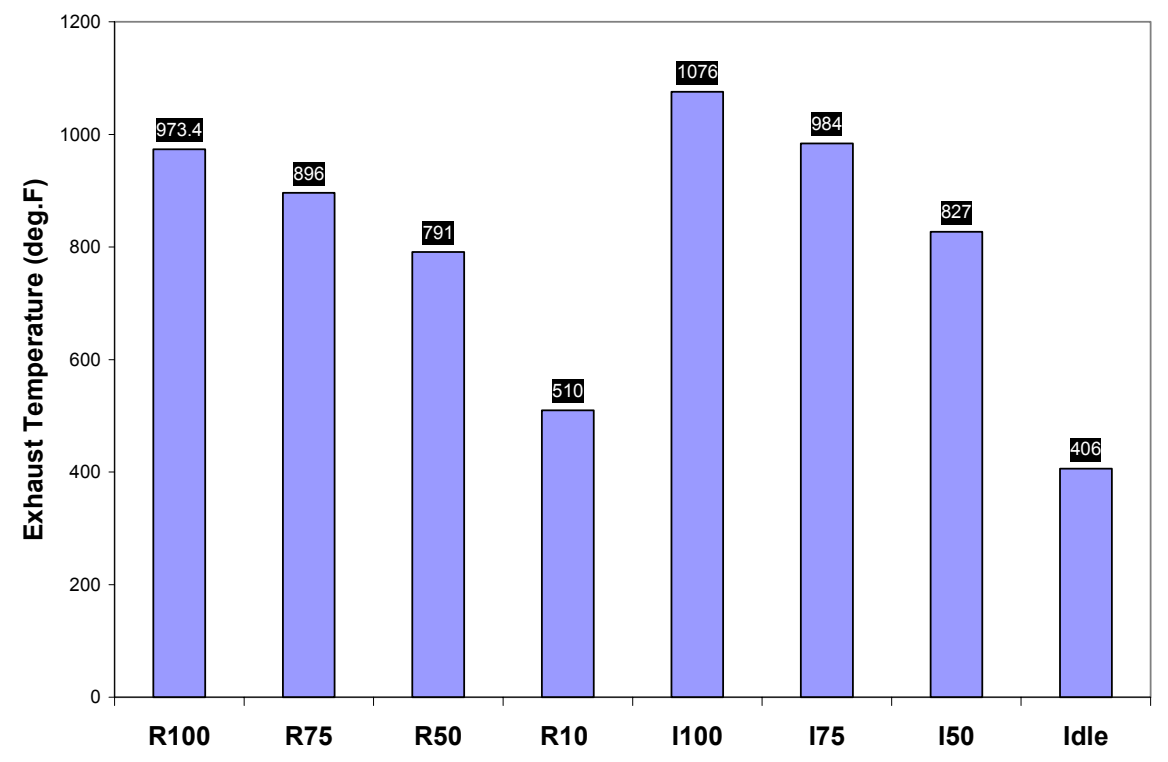

Figure 4.4: Maximum exhaust temperatures for each mode of ECD1 baseline 


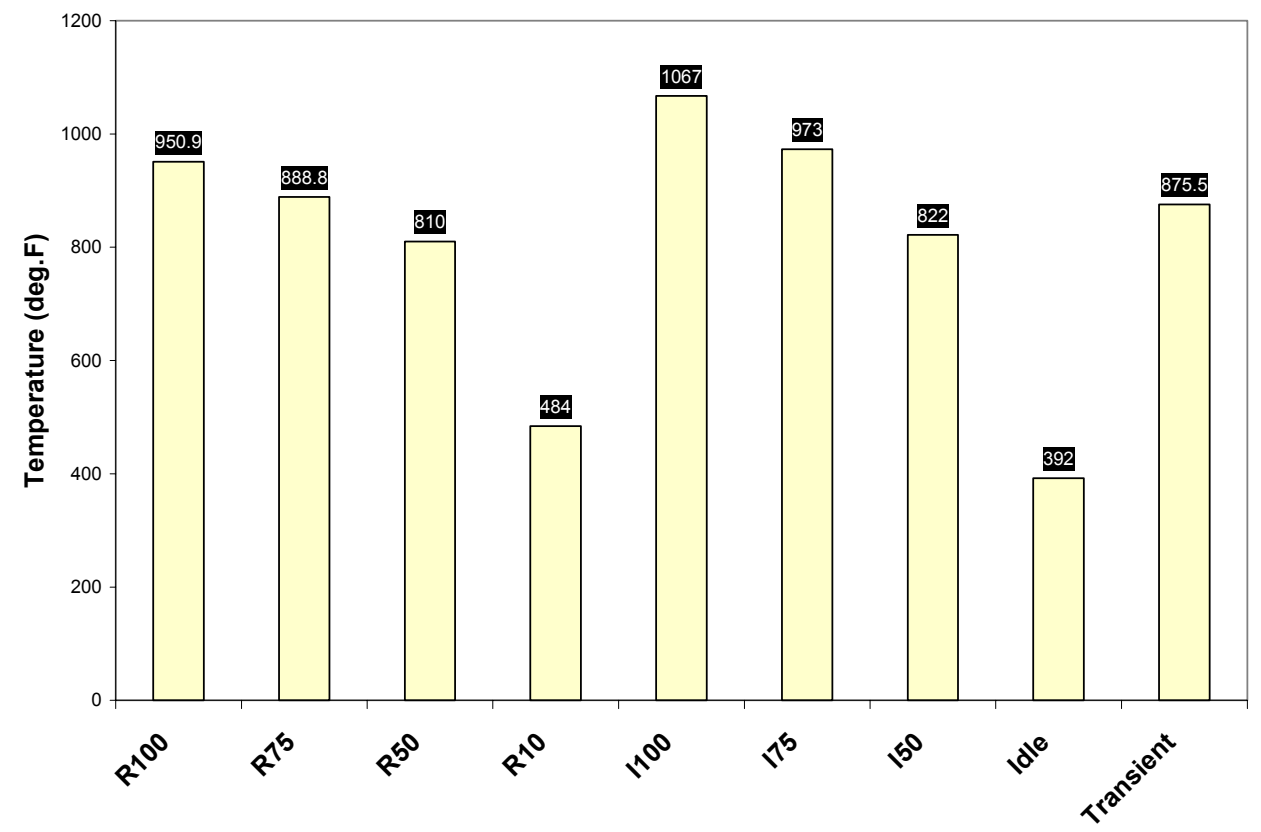

Figure 4.5: Maximum exhaust temperatures for each mode of CARB baseline. The last column depicts the maximum exhaust temperature on the CARB baseline transient run.

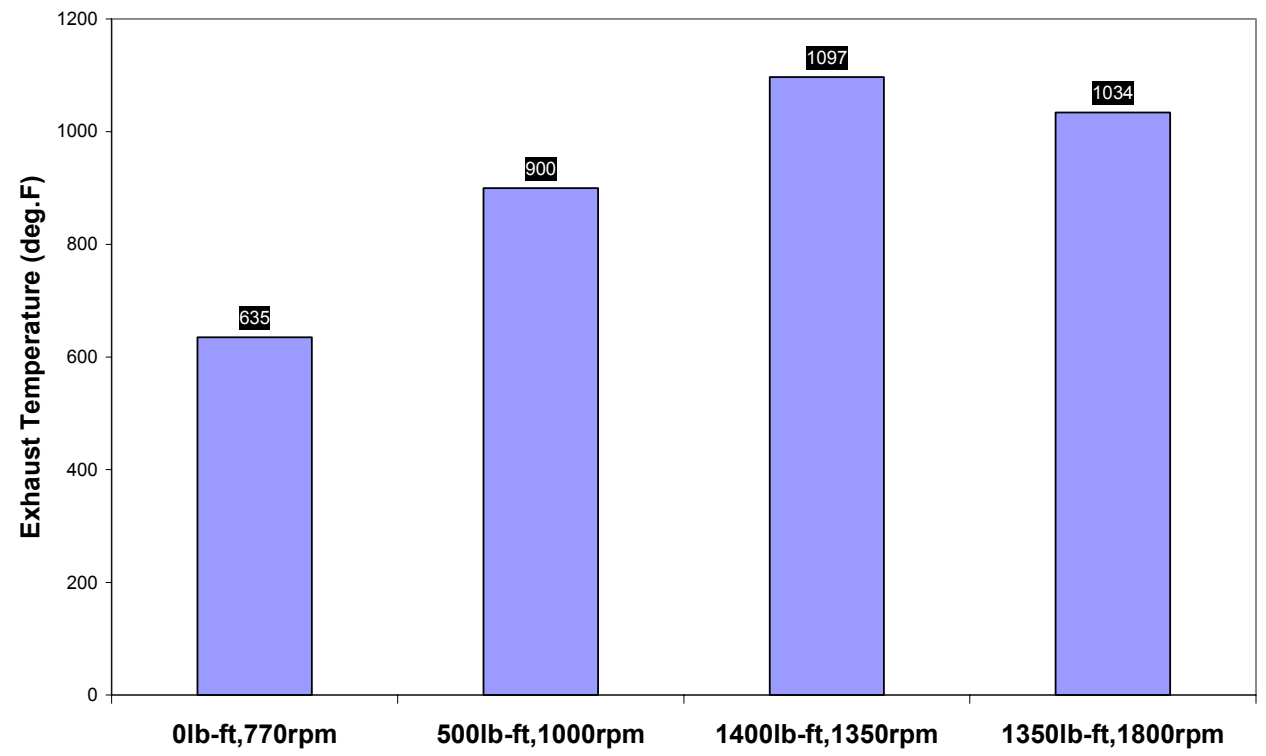

Figure 4.6: Maximum post-trap exhaust temperature during break-in set points for Johnson-Matthey trap using ECD1 diesel 


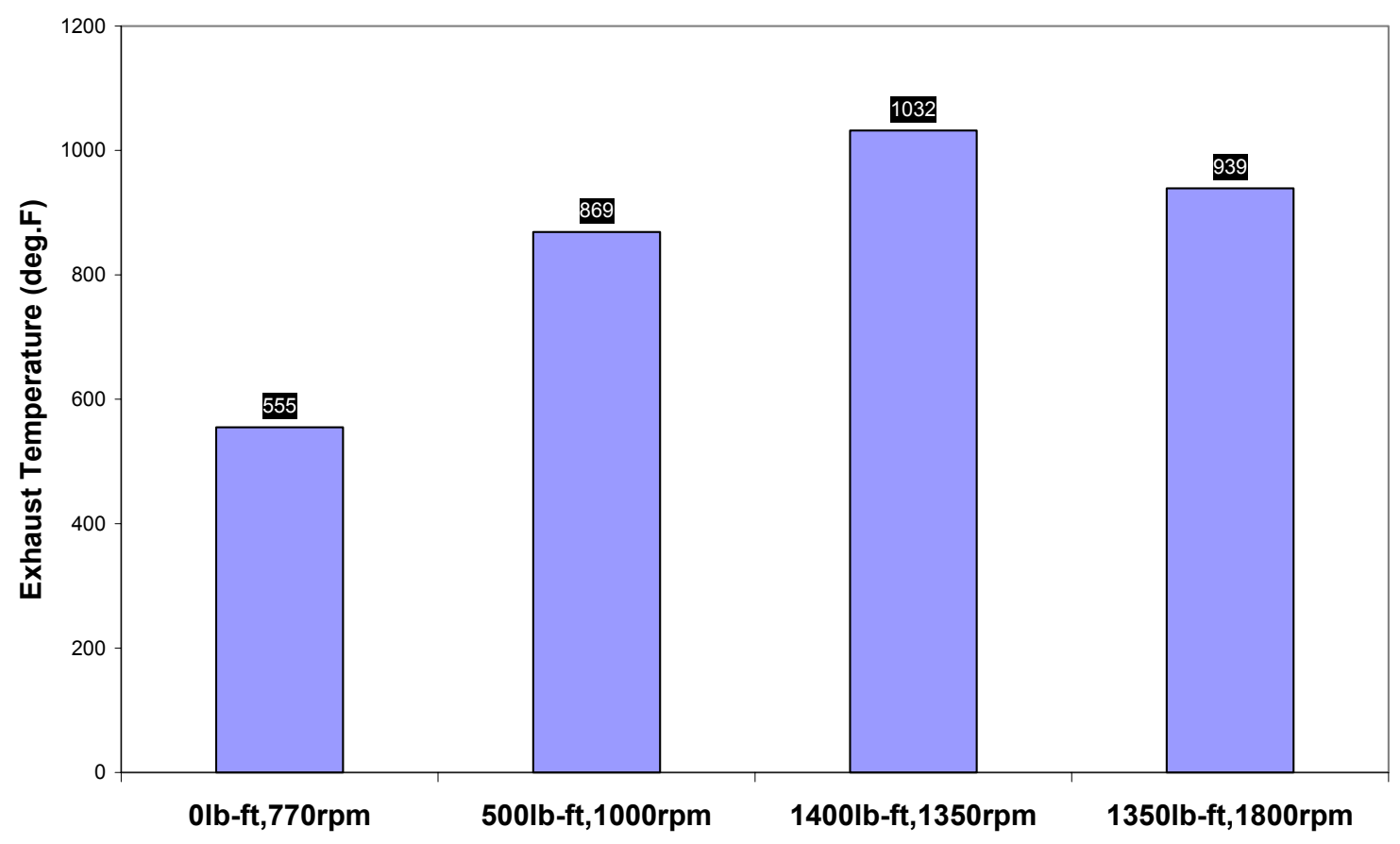

Figure 4.7: Maximum post-trap exhaust temperature during break-in set points for

Engelhard trap using ECD1 diesel

\subsection{ENGINE MAPPING AND 8-MODE DATA}

Prior to beginning emissions testing of the engine and its various configurations, the engine was mapped on the different test fuels. An engine map is a full-load curve for the entire speed domain ranging from low-idle speed to rated speed. CARB fuel was comparatively high in sulfur content than the other two fuels (see Table 3.4). CARB fuel was used as the base fuel with which all other fuel/trap comparisons were made. As a first step, a CARB baseline test was done. Figure 4.8 shows the engine map on all the test fuels. Tables $4.2,4.3$, and 4.4 are the 8 -mode torque and speed set points used for steady state testing with the different test fuels.

The mapping procedure conformed to requirements of CFR 40, Part 86, Subpart N. The procedure determines speed at which the engine attains peak torque and peak power. Tables 4.2 
4.3, and 4.4 give the peak torque at rated speed and the speed at intermediate peak torque. Peak power for CARB fuel was 424 bhp, ECD1 was 434 bhp, and 418 bhp for FT.

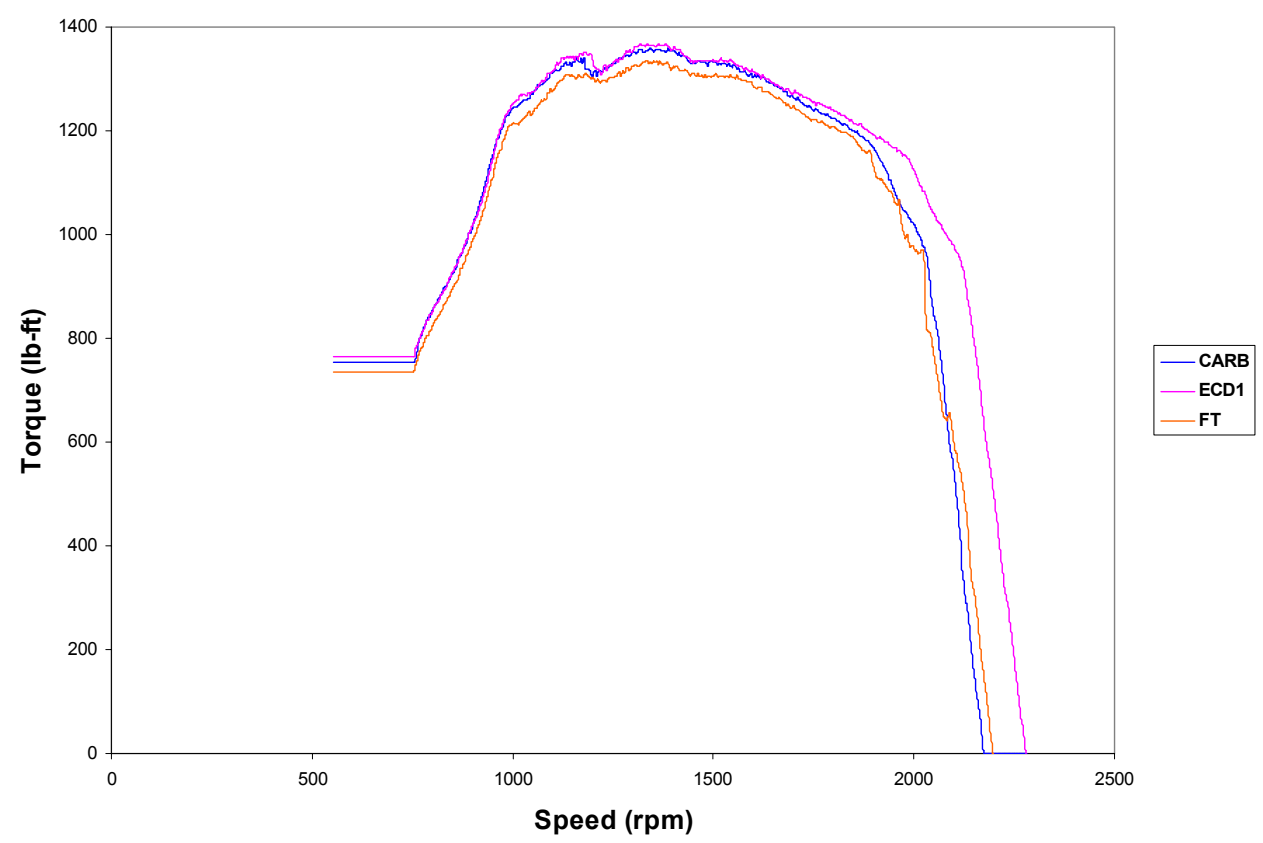

Figure 4.8: Engine map on CARB, ECD1 and FT fuels

Table 4.2: ISO 8178 C1 8-mode set points for CARB diesel

\begin{tabular}{||c||c||c||}
\hline $\begin{array}{c}\text { Engine } \\
\text { Mode }\end{array}$ & $\begin{array}{c}\text { Required } \\
\text { Torque }\end{array}$ & RPM \\
\hline \hline R100 & 1174 & 1900 \\
\hline \hline R75 & 880.5 & 1900 \\
\hline \hline R50 & 660.4 & 1900 \\
\hline \hline R10 & 495.3 & 1900 \\
\hline \hline I100 & 1344 & 1359 \\
\hline \hline I75 & 1008 & 1359 \\
\hline \hline I50 & 672 & 1359 \\
\hline \hline Idle & 0 & 750 \\
\hline \hline
\end{tabular}


Table 4.3: ISO 8178 C1 8-mode set points for ECD1 diesel

\begin{tabular}{|c||c||c|}
\hline $\begin{array}{c}\text { Engine } \\
\text { Mode }\end{array}$ & $\begin{array}{c}\text { Required } \\
\text { Torque }\end{array}$ & RPM \\
\hline \hline R100 & 1154 & 1983 \\
\hline \hline R75 & 865.5 & 1983 \\
\hline \hline R50 & 577 & 1983 \\
\hline \hline R10 & 115.4 & 1983 \\
\hline \hline I100 & 1351 & 1353 \\
\hline \hline I75 & 1013.3 & 1353 \\
\hline \hline I50 & 675.5 & 1353 \\
\hline \hline Idle & 0 & 750 \\
\hline
\end{tabular}

Table 4.4: ISO 8178 C1 8-mode set points for FT diesel

\begin{tabular}{|c||c||c||}
\hline $\begin{array}{c}\text { Engine } \\
\text { Mode }\end{array}$ & $\begin{array}{c}\text { Required } \\
\text { Torque }\end{array}$ & RPM \\
\hline \hline R100 & 1155 & 1900 \\
\hline \hline R75 & 866.3 & 1900 \\
\hline \hline R50 & 577.5 & 1900 \\
\hline \hline R10 & 115.5 & 1900 \\
\hline \hline I100 & 1335 & 1360 \\
\hline \hline I75 & 1001.3 & 1360 \\
\hline \hline I50 & 667.5 & 1360 \\
\hline \hline Idle & 0 & 1360 \\
\hline
\end{tabular}

\subsection{TRANSIENT CYCLE GENERATION}

Before creating a representative duty cycle of actual in-use operation, a few questions needed to be answered on the requirement for transient, in-use emission measurement.

Why measure emissions during transient cycle operation? 
Diesel engines undergo a wide variety of transient operation during their duty cycles. There is very little time spent on steady state operation in the field. Typically, diesel engines are calibrated, by the manufacturer, to meet a certain level of emission standards based upon engine operation at a discrete number of steady state points. But, transient operation may go well beyond the limits of steady state operation. However, running an engine on any one particular transient cycle also defeats the purpose. To get a true depiction of in-use, real-time emissions, every engine or piece of equipment must be exercised through engine application driven duty cycle. This duty cycle should be created from the engine's actual in-field data points, representing the whole range of speeds, loads and activities that the vehicle goes through.

Why measure emissions in the field?

Measuring emissions while a vehicle or equipment is in operation gives a picture of the level of emissions control that can be achieved. The alternative to this is laboratory testing. Different advanced technologies have been developed which enable real-time, on-board emissions measurements. This would allow measurement of speed and load conditions on the engine while it is in operation. Such activity would need adherence to newer standards, measurement, and calibration and test procedures.

So why do we still test under steady state operation?

Steady state cycles cover the range of intermediate speeds and loads that may not even be included in a typical transient cycle. Steady state cycles have always been used as bench-marks for emission testing, hence, provide an excellent means of comparison. They provide a high level of consistency in test procedures.

\subsubsection{Transient Cycle Characteristics}

The goal of generating a representative transient duty cycle is to cover the range of all the typical, repeatable activities undergone by a vehicle, engine or equipment and to record their 
corresponding speed-load data in real-time operation. Under transient operation, it is difficult to optimize the engine parameters for low emissions. Particulates may be formed due to excess fuel injected into the cylinder during speed and load changes and a whole host of engine parameters ranging from turbocharger, in-cylinder temperatures, injection timing, to exhaust system dynamics and after-treatment systems. When developing cycles or routes, the following criteria must be fulfilled:

1. The vehicle must be able to achieve every set point in the test cycle.

2. The vehicle must be able to achieve the acceleration and deceleration rates required by the test cycle.

3. Deceleration rates should not be too sudden or severe to affect the performance of the power absorbing equipment.

4. The developed cycle must involve all operations of the vehicle in-field.

5. The test cycle should go through the maximum range of speed and torque points in relation to in-field activity.

6. Lengthy idling times should be discarded.

7. The cycle should be able to account for the entire accessory load on the original vehicle.

8. As far as possible, data should be collected with the same operator during all the trips.

The cycle that was developed in this study met the above criteria; hence, it could be used as a common means of measuring emissions from non-road engines. Measurement of emissions was also performed in accordance with the ISO 8178 standards. Emissions were measured at eight combinations of speed and torque settings. The results were then weighed to a single value. As expected, the transient cycle results were not in agreement with the ISO 8178 cycles. Steady state 8-mode cycles were originally developed for certification purposes. There are differences in emissions for different applications and driving patterns, which load the engine in a transient manner. 


\subsubsection{Cycle Generation Flow Process}

Four main activities of the scraper were identified as defining the complete duty cycle. They consisted of the Transport, Scraping, Full-load Downhill Motoring, and Unloading. All these activities were included in the duty cycle. The operations of the scraper during a duty cycle have been explained in detail in section 3.1. Representative times of each of the above operations were selected from continuous in-field cycle data. The transport mode was typical of intermediate speed and low loads. The scraping and unloading were characterized by low speed and high loads because of the high inertia involved in the scraping action. The load of the raw material while unloading also added to the high percent load values. The full-load downhill motoring was specific to the landfill terrain in which data was collected. The route after scraping and loading the raw material included a downhill full-load travel. Over these periods, the operator would let go of the pedal and induce a very low percent load, high rpm operation of the scraper, which resembled coasting or motoring of the vehicle.

\subsubsection{Graphical Representation}

Figure 4.9 shows the transport, scraping, full-load downhill motoring, and unloading modes of the duty cycle, which are marked as A, B, C, and D, respectively. Dummy idle times were added in between these modes when the engine dynamometer cycle was being developed. This was done in order to relax the load on the engine periodically, and to prevent high exhaust temperatures from adversely affecting the particulate matter data. The in-field raw transient data consisted of several extended periods of idle and high load operation. A short string of raw data from actual equipment operation was chosen to represent each activity. The length of an activity was proportional to the weightage given to the activity, relative to the total cycle time generated. This formed one iteration. After several such iterations, the cycle was extended to 1500 seconds, 
since the in-field scraper duty cycle also lasted 1500 seconds ( 25 minutes). The cycle time was established on the basis of including all the representative modes of in-field operation, and collection of sufficient PM mass for gravimetric analysis.

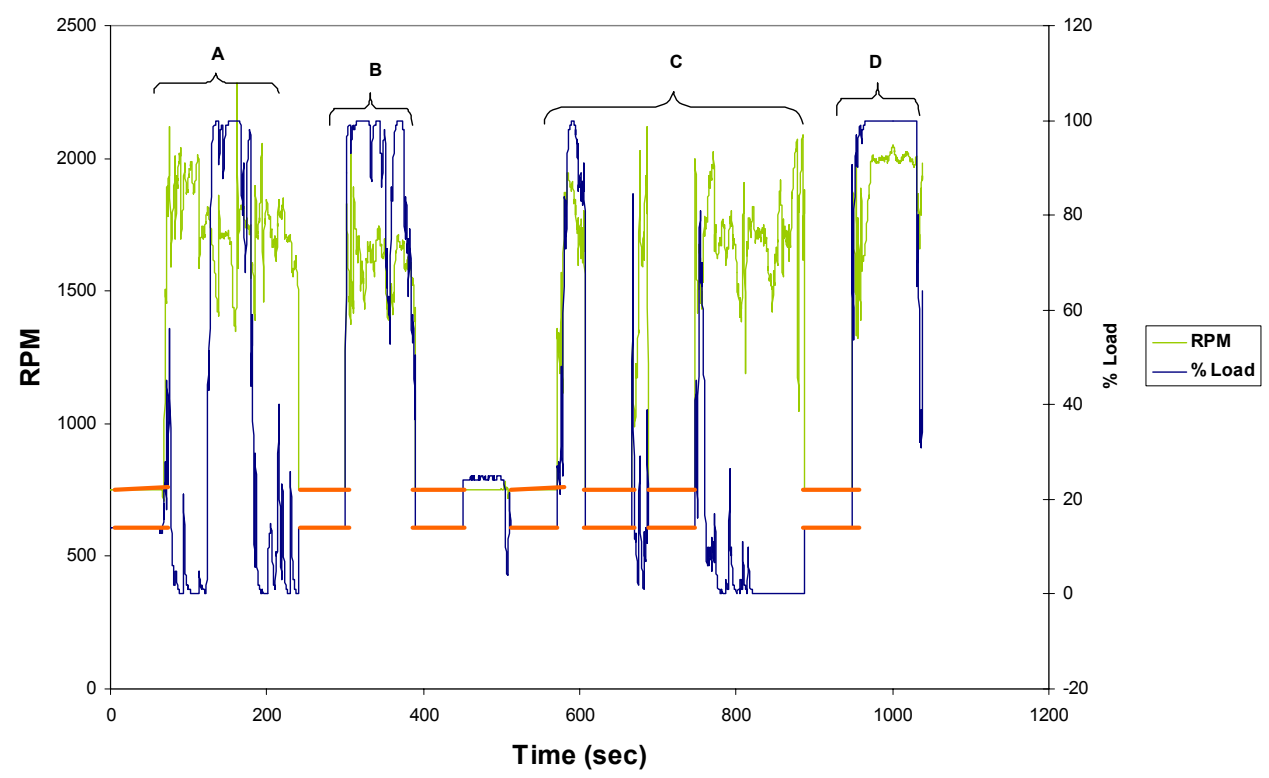

Figure 4.9: Preliminary piece-wise graph of actual operation times with dummy idle times highlighted by the thick orange lines

The final transient cycle is depicted in Figure 4.10 in terms of rpm and percent load. Two other cycles were also compiled, each from a different in-field data set than that used for the first test cycle. The above procedure of identifying the activities and putting them together in a cycle was repeated. The cycles that emerged (Figures 4.11 and 4.12) were very similar to the first test cycle, which is illustrated in Table 4.5. The cycles were compared on the basis of average speed, average percent load, maximum speed and percent idle. Since the first test cycle had the highest average speed and maximum speed values, it was selected to be converted into a normalized transient cycle. 


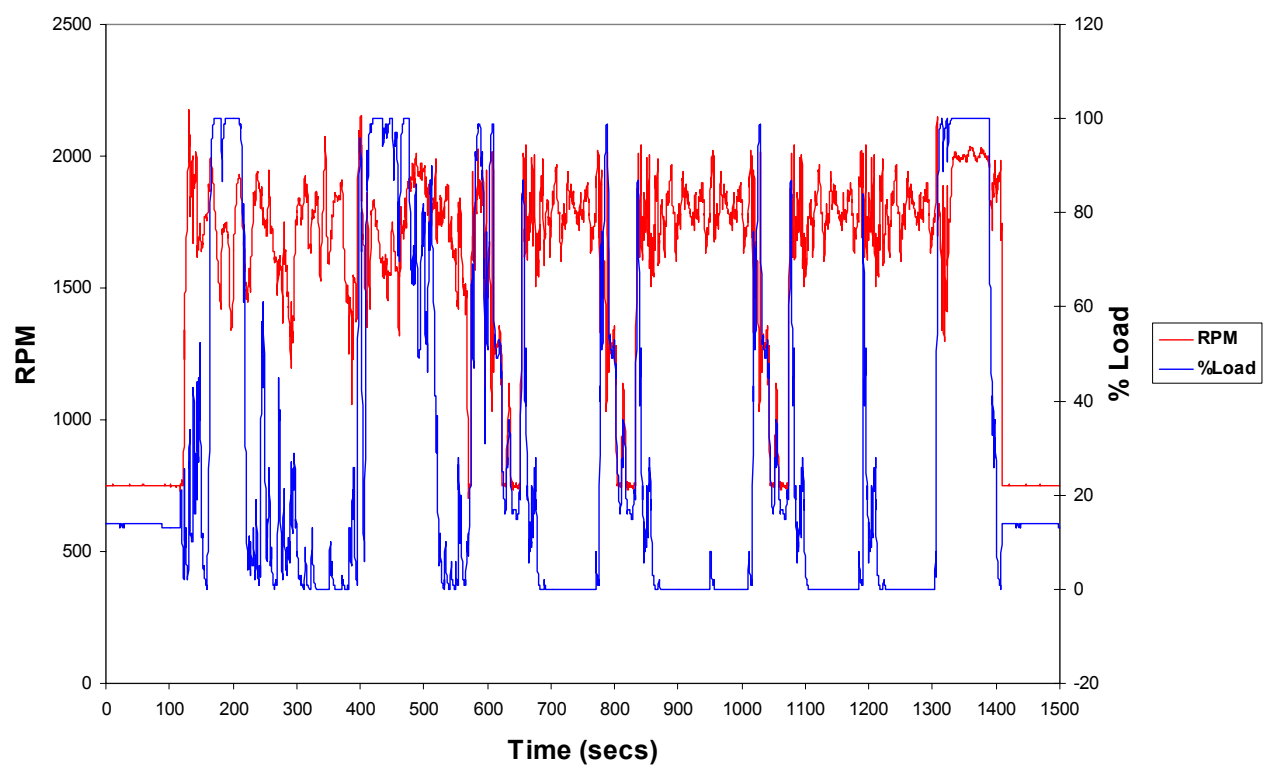

Figure 4.10: Selected transient test cycle developed from in-field 657E scraper operation data, used in laboratory testing

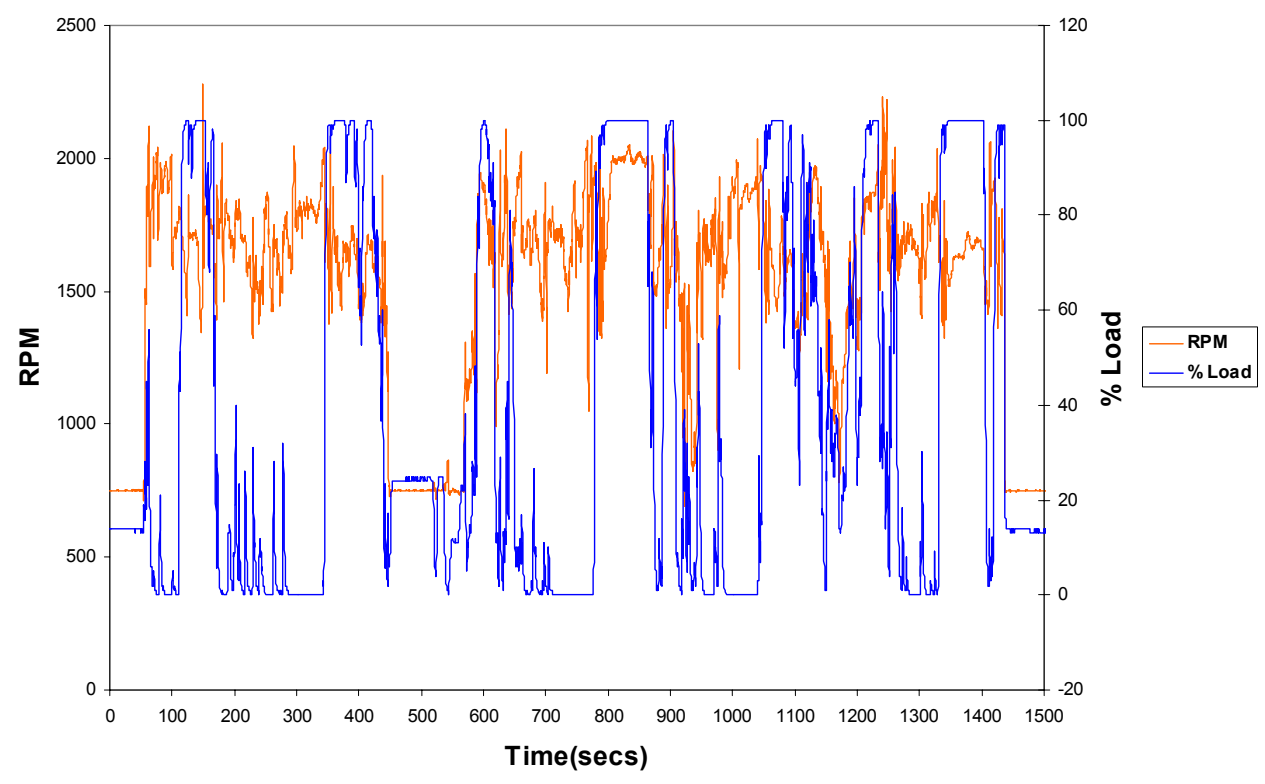

Figure 4.11: Transient test cycle- 2 developed from in-field 657E scraper operation data 


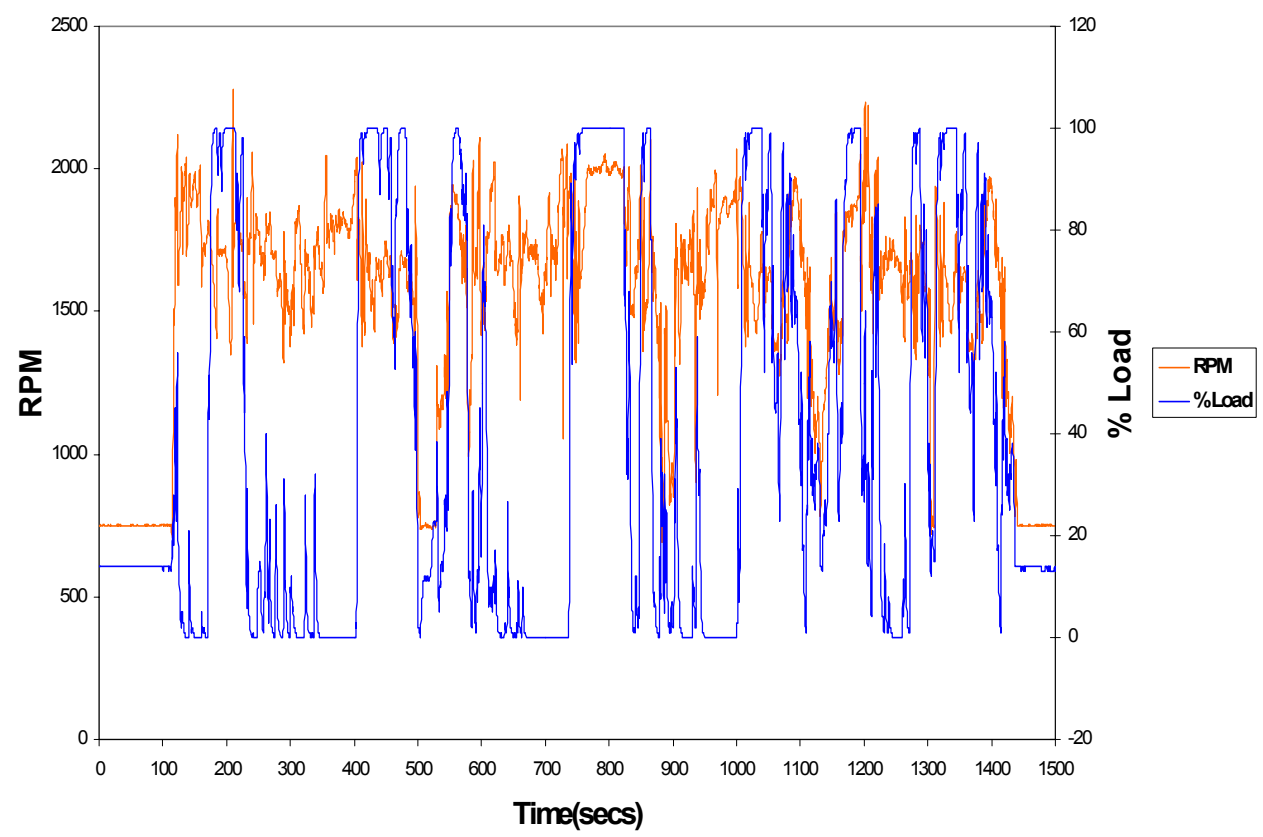

Figure 4.12: Transient test cycle-3 developed from in-field 657E scraper operation data

Table 4.5: Comparison of transient test cycles

\begin{tabular}{||c||c||c|c||}
\hline \hline Parameter & $\begin{array}{c}\text { Selected } \\
\text { Test } \\
\text { Cycle }\end{array}$ & $\begin{array}{c}\text { Test } \\
\text { Cycle-2 }\end{array}$ & $\begin{array}{c}\text { Test } \\
\text { Cycle-3 }\end{array}$ \\
\hline \hline $\begin{array}{c}\text { Average } \\
\text { Speed }\end{array}$ & 1540.93 & 1528.90 & 1521.65 \\
\hline \hline $\begin{array}{c}\text { Load } \\
\text { Factor }\end{array}$ & 38.49 & 38.83 & 27.71 \\
\hline \hline $\begin{array}{c}\text { Maximum } \\
\text { Speed }\end{array}$ & 2178 & 2281 & 2281 \\
\hline \hline Duration & 1500 & 1500 & 1500 \\
\hline \hline Percent Idle & 37.67 & 28.2 & 32.13 \\
\hline \hline
\end{tabular}

\subsubsection{Cycle Torque}

The next step in the process was to account for the frictional losses occurring due to the accessory load on the vehicle in the field. To duplicate the in-field vehicle effects for inlaboratory work, losses were calculated from the engine map and generated a polynomial data fit. 
The no-load condition was set as the actual percent load that was measured at idle conditions, and then determined by running the engine through a number of speed and torque set points. Figure 4.13 shows a lug curve generated using different torque inference equations. WVU presented a study on developing transient cycles from off-road vehicles using infield vehicle activity and $\mathrm{CO}_{2}$ data [11]. This data was used to calculate torque by a process of iterative engine testing to obtain similarities between in-field $\mathrm{CO}_{2}$ and laboratory $\mathrm{CO}_{2}$ data. Brake-specific $\mathrm{CO}_{2}$ maps were used along with speed and torque data, to infer engine loads from the recorded in-field cycle. The engine was then operated according to the in-field raw $\mathrm{CO}_{2}$ concentration and engine speed set points while engine torque was recorded using the load cell. Subsequent to the development of the cycle, engine load values from a vehicle operating in field were obtained on a John Deere 444 rubber-tired front-end loader. The loader was powered by a John Deere 6059, direct injected, naturally aspirated, in-line six cylinder diesel engine. A portable multi-gas Sensors Inc. analyzer was used to collect continuous $\mathrm{CO}_{2}$ data. The $\mathrm{CO}_{2} /$ speed/load mapping data was used to estimate the cycle torque based on raw $\mathrm{CO}_{2}$ emissions for comparison with actual engine torque measured with the dynamometer load cell.

Figure 4.14 shows the engine (CAT 3408) lug curve and the no-load friction curve. The upper boundary in the lug curve is the maximum torque that is available at the corresponding speed. The lower curve is the percent load necessary to operate the engine at idle and overcome the engine friction and accessory load at a particular speed. The polynomial curve fit equations are applied with their coefficients to calculate the friction values and the total torque. The difference between these values gives the wide-open throttle total torque values. The cycle torque was then calculated by multiplying the percent torque to the total cycle torque values. If the ECM broadcast, percent load was less than zero an arbitrary negative torque value was assigned, which was less than that at idle conditions. If the ECM broadcast, percent load was greater than 100 an arbitrary positive torque value was assigned that was greater than the maximum mapped torque. 


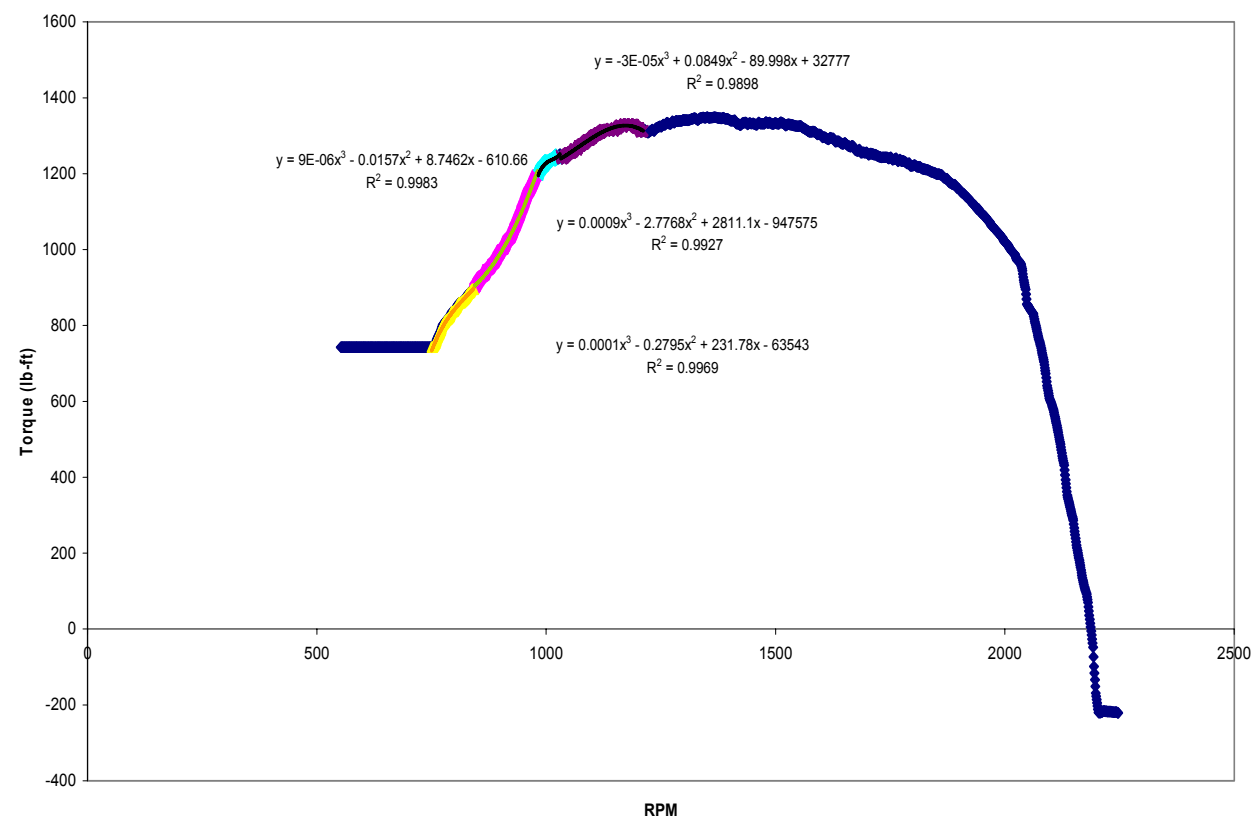

Figure 4.13: Example of engine lug curve generated by curve

fitting different torque inference equations

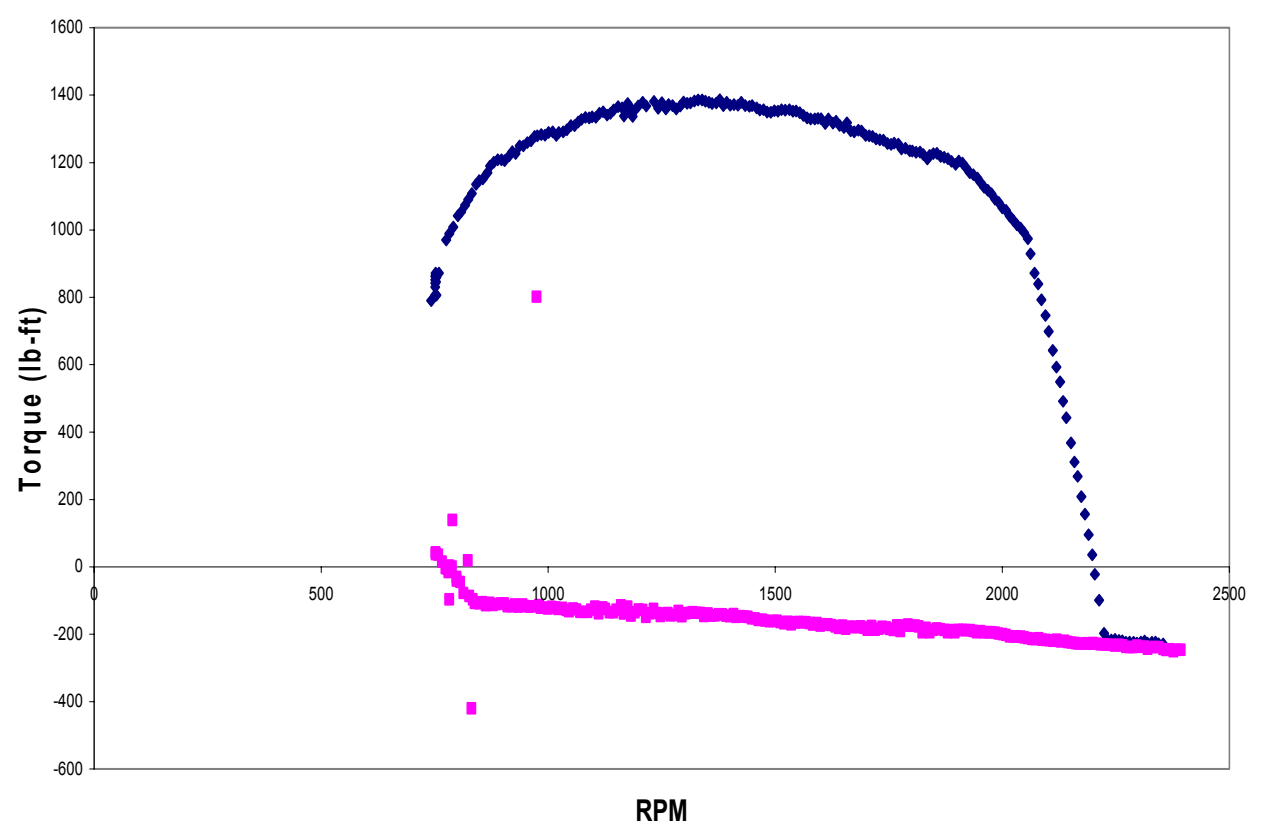

Figure 4.14: Example of the engine lug curve with the no-load friction curve below it 


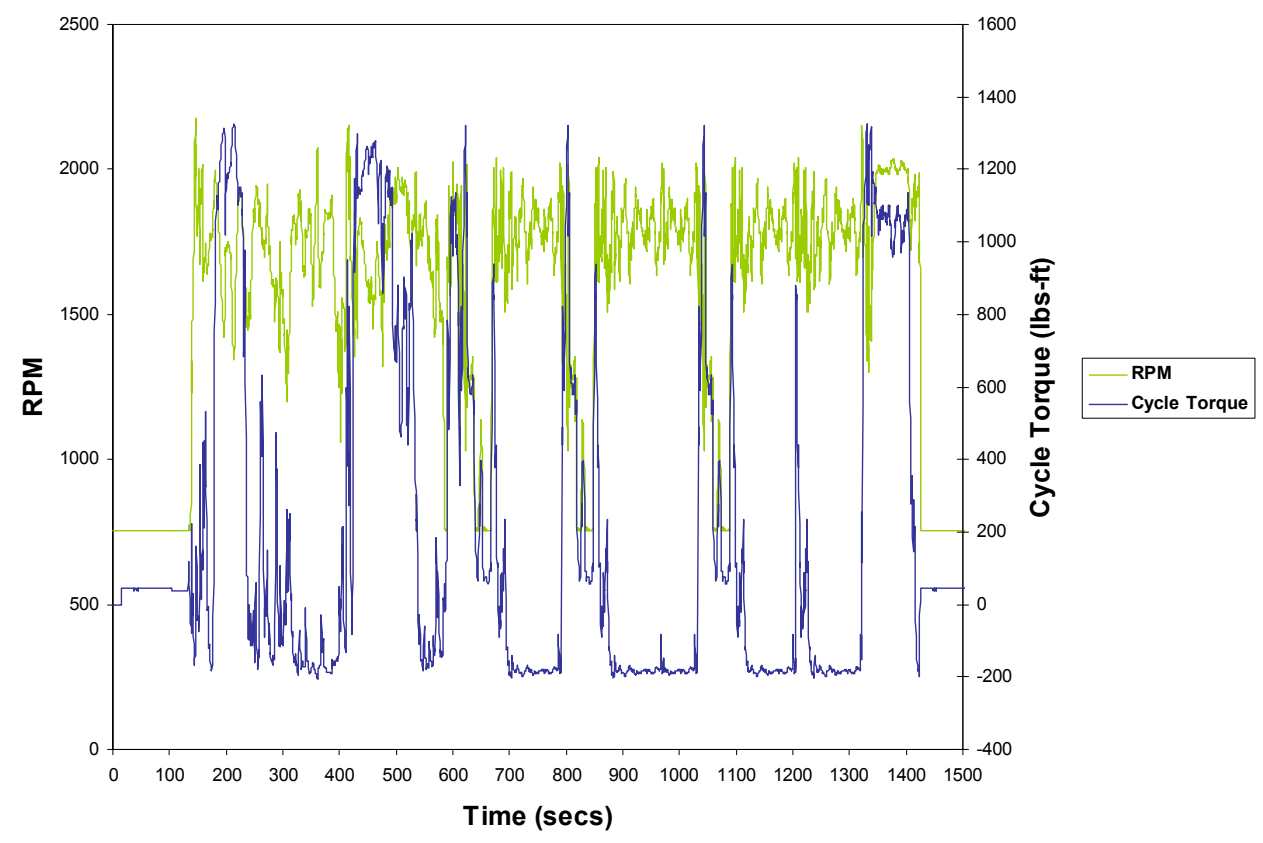

Figure 4.15: Transient cycle for CARB fuel in terms of speed and cycle torque values

Ullman et al. developed transient cycles for three off-road vehicles using the micro trip approach [50]. A breakdown of each equipment's activity and estimate of the percentage of time expended in performing each type of activity were recorded. The observed speed and torque data was normalized and the characteristic for each piece of equipment was noted. Characteristics for an activity provided a basis to identify the micro trip. A very short string of raw data from actual equipment operation was chosen to represent each activity for each piece of equipment. The length of an activity was proportional to the weightage given to the activity, relative to the total cycle time generated. 


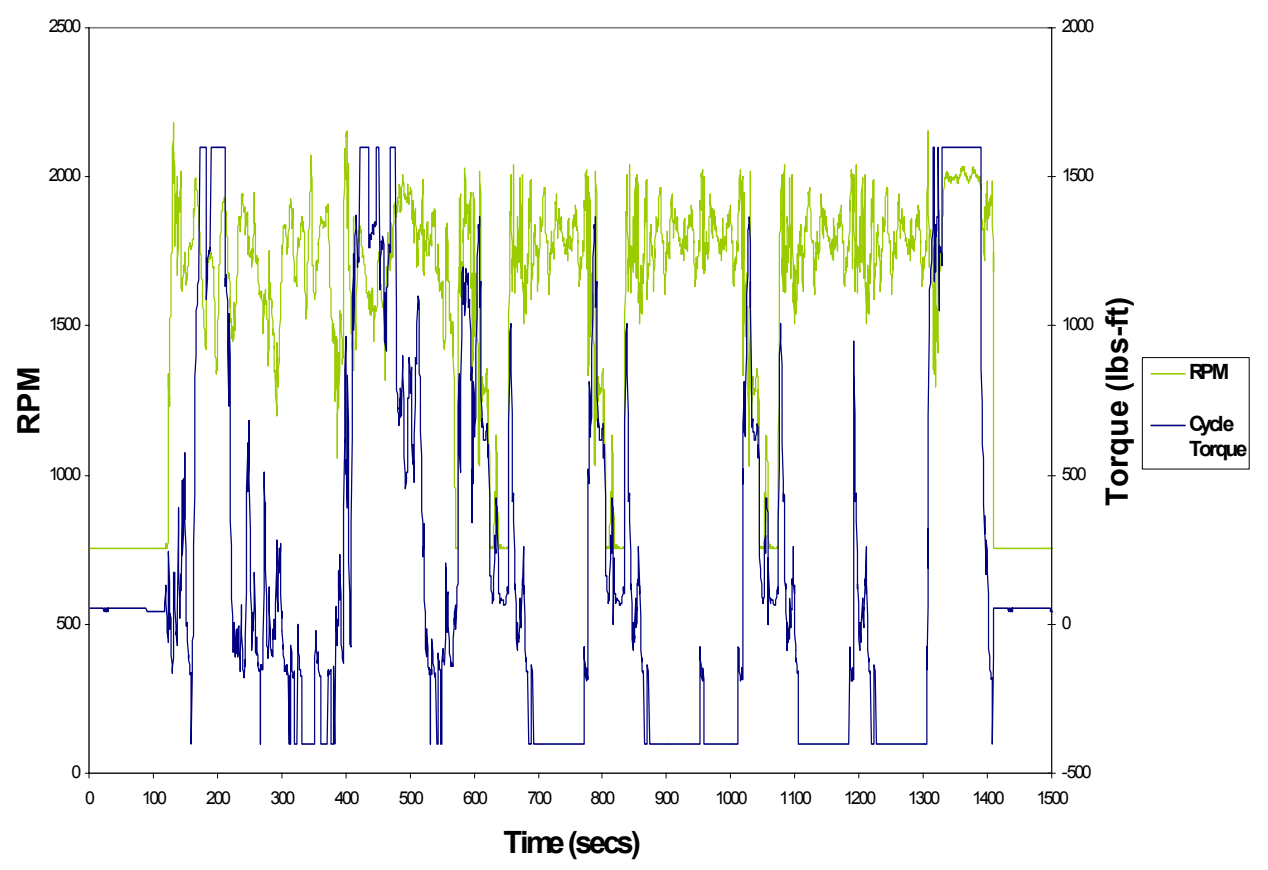

Figure 4.16: Transient cycle for ECD1 fuel in terms of speed and cycle torque values

Figures $4.15,4.16$ show the transient engine speed and torque values for CARB and ECD1 fuels, respectively. The average maximum torque between these cycles was $1349 \mathrm{lb}-\mathrm{ft}$ and the average maximum speed was $2178 \mathrm{rpm}$. The average idle time was 260 seconds. 


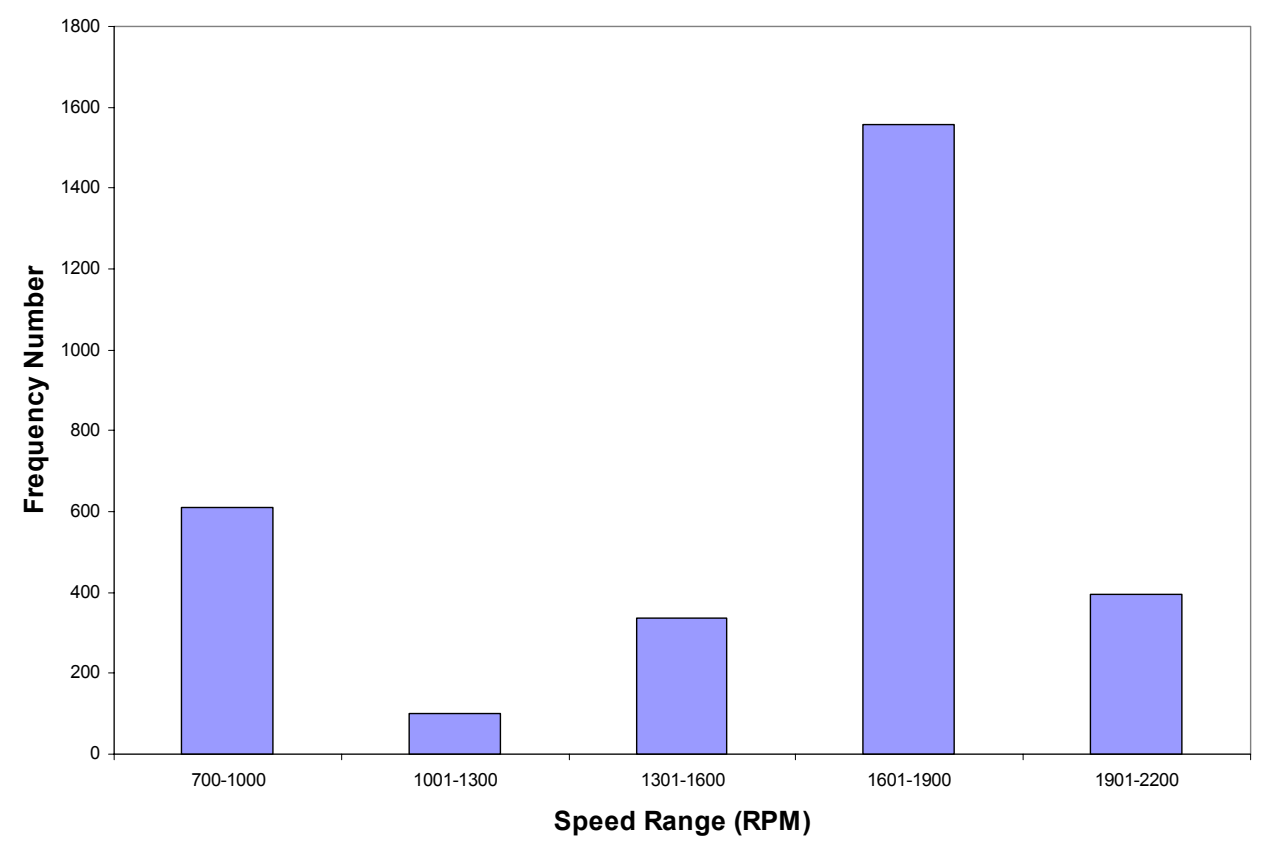

Figure 4.17: Representative engine speed frequency distribution, 300-rpm increments, for CARB diesel

Figure 4.17 shows the frequency distribution of the entire speed range that was used in the transient cycle for CARB diesel. The speed domain was divided into increments of $300 \mathrm{rpm}$. The maximum frequency of occurrence is for the 1601-1900-speed range. A frequency distribution of torque values over the entire transient cycle was also plotted as shown in Figure 4.18. The engine idling torque has the maximum frequency due to the dummy idles added previously in the cycle-development process followed by the high torque range of 1001-1400 lbsft. The 1601-1900 rpm range corresponds to the speeds observed during the first, second, third, and fourth mode of the rated 8-mode cycle. The 1001-1400 lbs-ft range corresponds to the rated load and the intermediate fifth mode of the 8-mode cycle. 


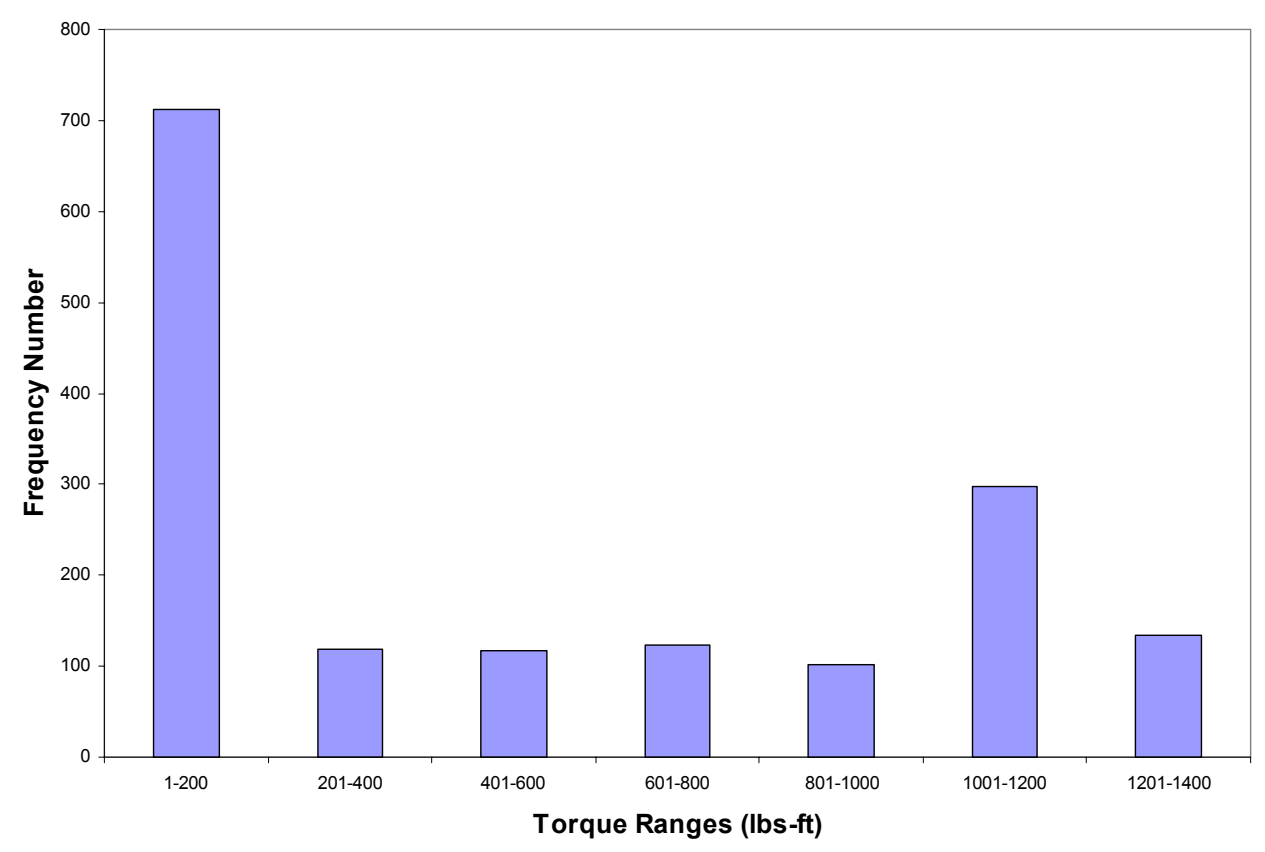

Figure 4.18: Representative engine torque frequency distribution, for CARB diesel

Figure 4.18 also shows a majority of engine operation occurred at loads that correspond to idle conditions. Figure 4.19 illustrates each load range of the pre-normalized percent load as a percent of total cycle time. Normalized percent load is the final cycle torque value calculated after accounting for factors such as frictional losses, no-load losses, and accessory loads. It can be seen that the engine operated at high loads for a substantial amount of time in the field. Next, the engine speeds were discretized according to the percentage of time the engine spent on each speed range during the entire cycle. Figure 4.20 reiterates the frequency distribution picture, illustrating the 1601-1900 rpm range as the local maximum. The 1601-1900 rpm and 1901-2200 rpm ranges were chosen as intermediate and rated, respectively. Figures 4.21 and 4.22 illustrate the percentage time that the engine spent at different torque increments at engine speeds of 1601 $1900 \mathrm{rpm}$ and 1901-2200 rpm. Information presented in Figures 4.17 to 4.22 has been replicated for ECD1, in Appendix B. 


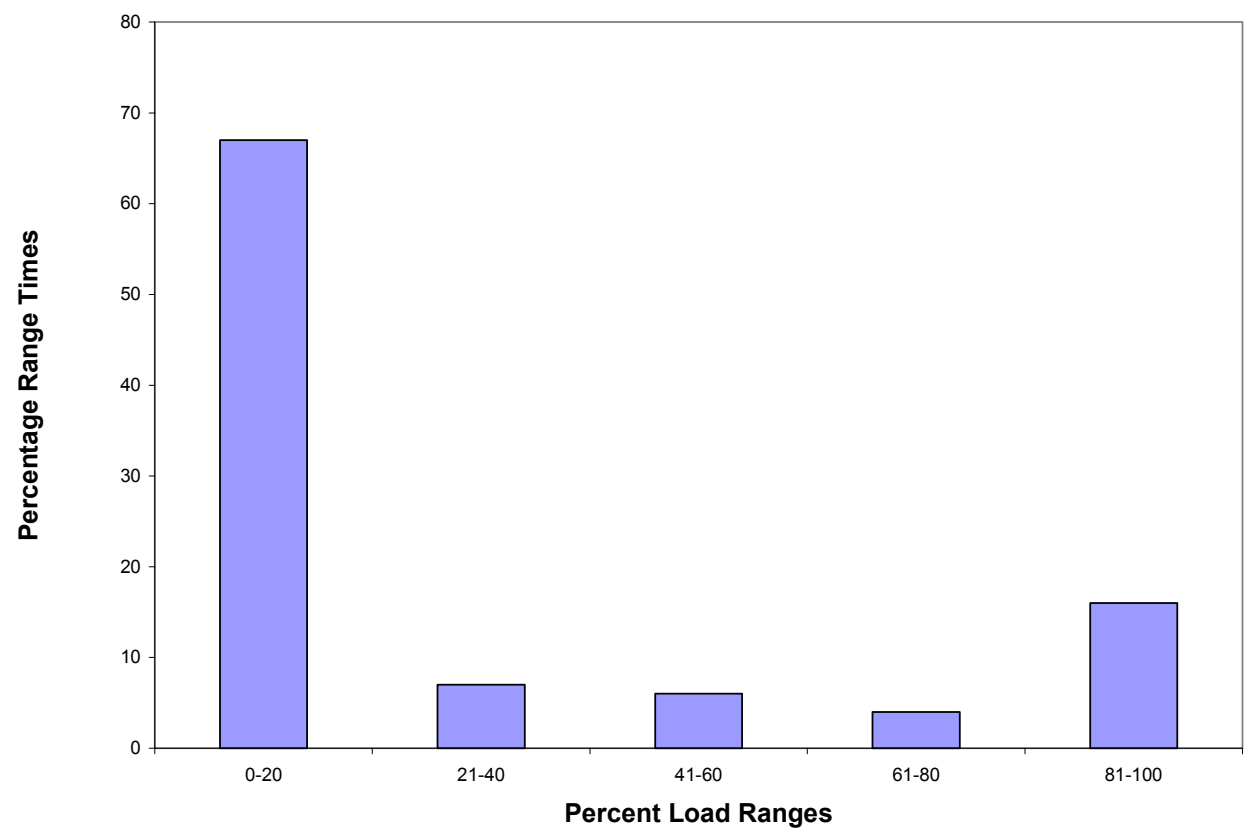

Figure 4.19: Percentage of total cycle time for load ranges versus percent load range in transient cycle-1

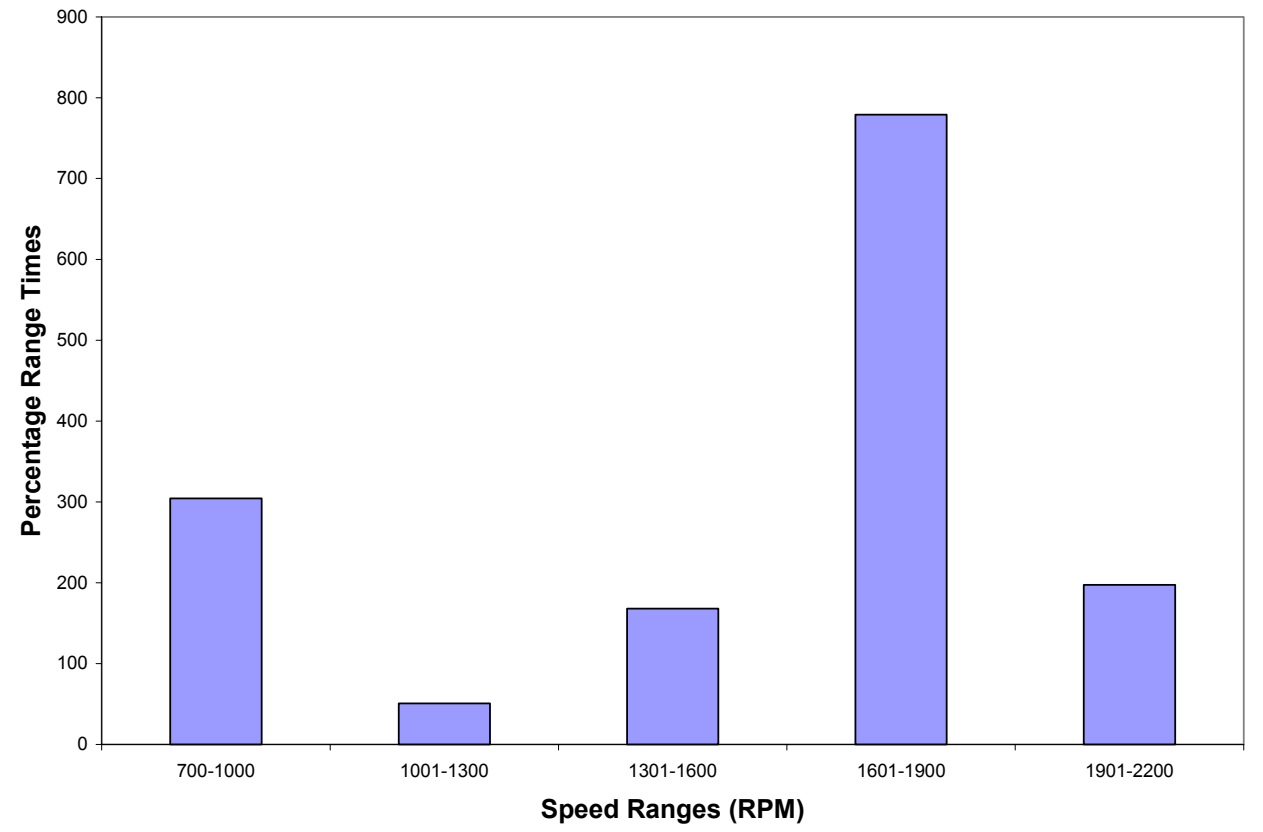

Figure 4.20: Percentage of total cycle time for speed ranges versus speed ranges, CARB diesel 


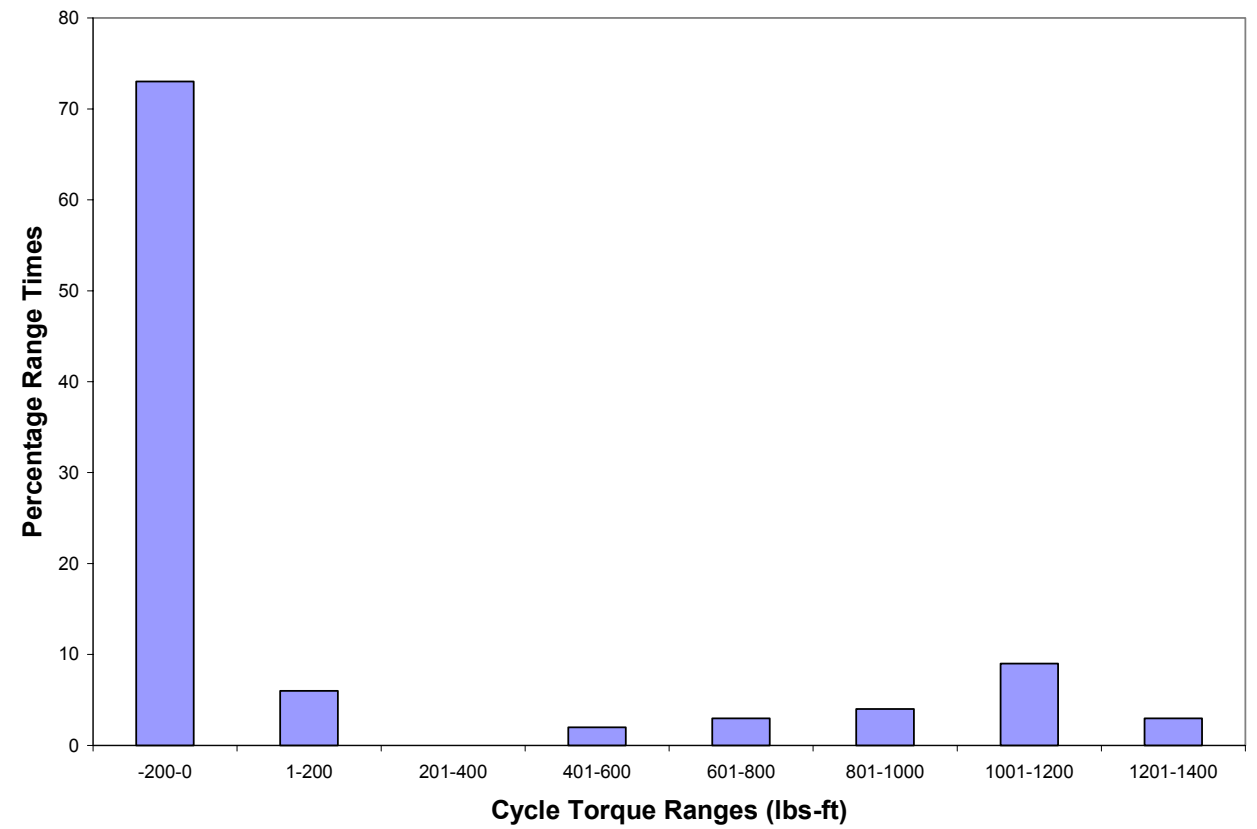

Figure 4.21: Percentage of total speed range time for cycle torque ranges versus cycle torque ranges in the $1601-1900 \mathrm{rpm}$ speed range. Total $1600-1900 \mathrm{rpm}$ time is 760 seconds.

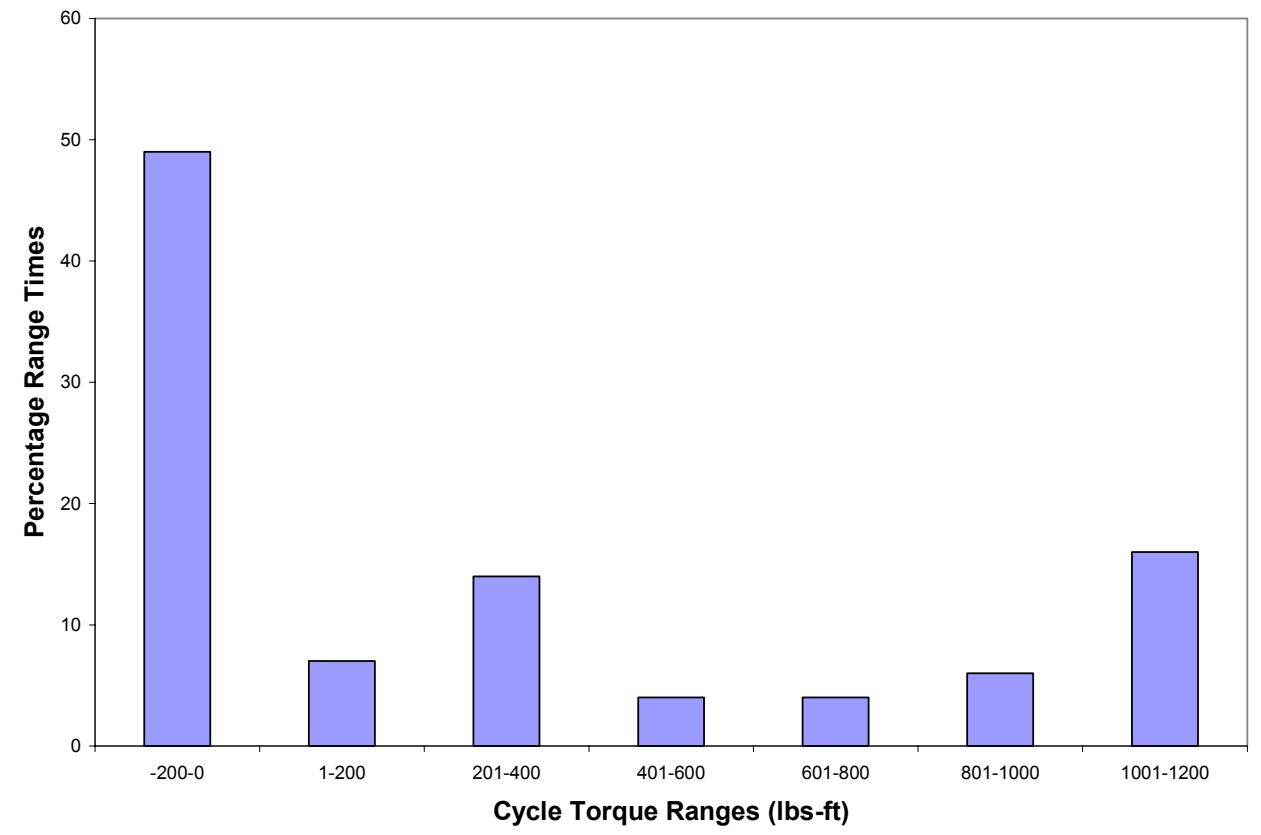

Figure 4.22: Percentage of total speed range time for cycle torque ranges versus cycle torque ranges in the $1901-2200 \mathrm{rpm}$ speed range. Total $1901-2200 \mathrm{rpm}$ time is 848 seconds. 


\subsection{CAT 3408 TESTING RESULTS}

The Caterpillar 3408 non-road engine was used to compare brake specific emissions between three fuels of varying sulfur content along with two DPFs; Johnson-Matthey CRT and Engelhard DPX. CARB diesel had the highest sulfur content among the three test fuels, with 0.0216 percent by weight, followed by ECD1 with 0.0014 percent by weight, and FischerTropsch with 0.0010 percent by weight. The data obtained, after testing both baseline and retrofit versions, was compiled in terms of cycle averaged emissions. Weighted average per mode results were obtained for the 8-mode steady state. The ISO $8178 \mathrm{C} 1$ cycle was used for all steady state testing. The result was again averaged between the two test runs. The test runs from the transient cycles were also averaged. In this section, the results have been presented by comparing the ability of fuels in reducing the regulated emissions, and analyzing the effectiveness of DPFs in reducing $\mathrm{PM}$.

\subsubsection{Baseline Results}

\subsubsection{CARB Diesel}

At the onset of the laboratory testing, the engine was put through a series of 8-mode steady state test runs with CARB and ECD1 diesel. PM mass emission results are presented graphically in Figure 4.23. In this figure each bar represents the weighted average emission between two test runs, in $\mathrm{g} / \mathrm{bhp}$-hr per mode of the 8-mode cycle. The modes are defined in Table 4.1. As seen from Figure 4.23, the low sulfur ECD1 works well in reducing PM at high rpm and low loads compared to CARB fuel. CARB diesel being slight higher in sulfur content was used as the baseline for comparison. $\mathrm{HC}, \mathrm{CO}$, and $\mathrm{NO}_{\mathrm{x}}$ had weighted averages of $9.86 \mathrm{~g} / \mathrm{bhp}-\mathrm{hr}, 3.9$ $\mathrm{g} / \mathrm{bhp}-\mathrm{hr}$, and $1.7 \mathrm{~g} / \mathrm{bhp}-\mathrm{hr}$, respectively on steady state cycle. On the transient cycle the corresponding values for $\mathrm{HC}, \mathrm{CO}$ and $\mathrm{NO}_{\mathrm{x}}$ were $0.21 \mathrm{~g} / \mathrm{bhp}-\mathrm{hr}, 1.99 \mathrm{~g} / \mathrm{bhp}-\mathrm{hr}$, and $0.70 \mathrm{~g} / \mathrm{bhp}-\mathrm{hr}$, respectively. Brake specific emissions values were generally higher when compared with ECD1 and FT diesel with and without traps. 


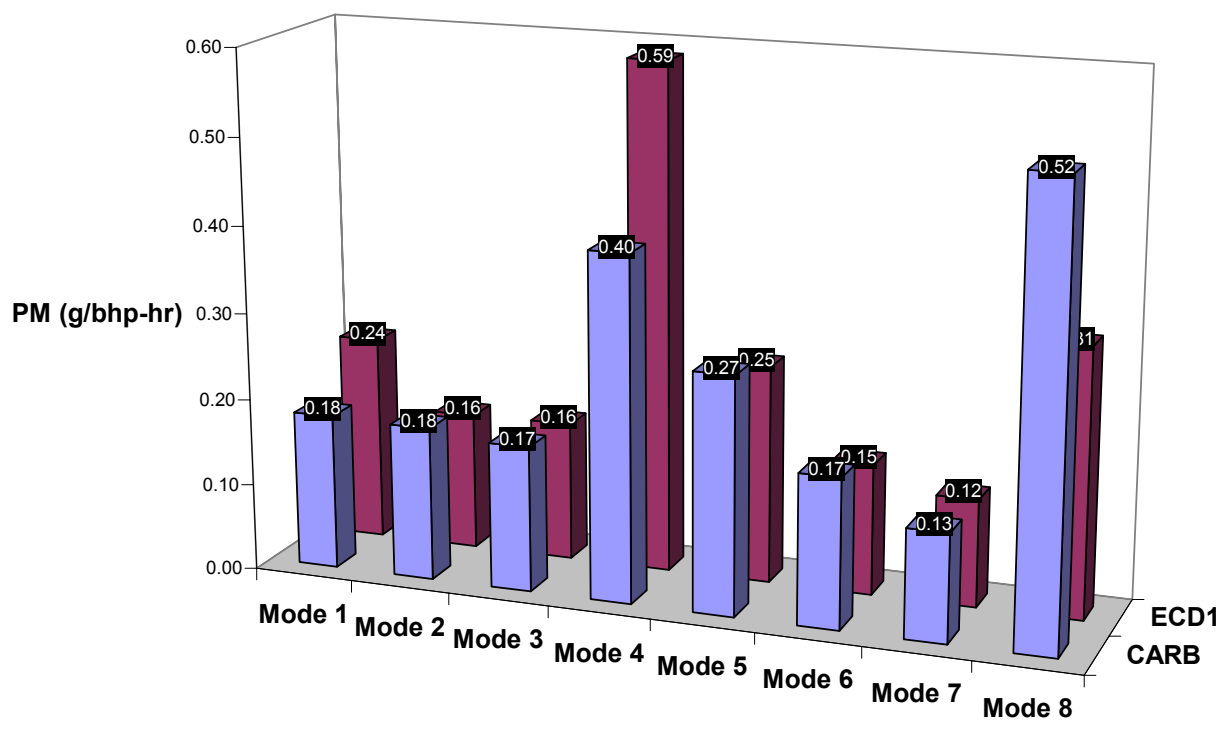

Figure 4.23: Comparison of PM mass emission rates between

CARB baseline and ECD1 baseline

A repeatable PM reading of $0.32 \mathrm{~g} / \mathrm{bhp}-\mathrm{hr}$ was obtained during both the transient runs. ECD1 yielded $0.34 \mathrm{~g} / \mathrm{bhp}-\mathrm{hr}$ of PM. The difference in these values does not mean much unless compared with after-treatment results because ECD1 essentially serves as an enabling technology. Subsequent retrofit configurations were compared with CARB baseline to evaluate the extent of emissions reduction. Appendix D shows graphically the reduction percentages of all the fuel/filter configurations when compared to CARB diesel for both steady state and transient operation. It also gives the brake specific emissions in $\mathrm{g} / \mathrm{bhp}$-hr. Figure 4.24 presents the continuous emissions rates $(\mathrm{g} / \mathrm{sec})$ data for all $\mathrm{HC}, \mathrm{CO}, \mathrm{NO}_{\mathrm{x}}$ and $\mathrm{PM}$, over the entire length of the transient cycle. 


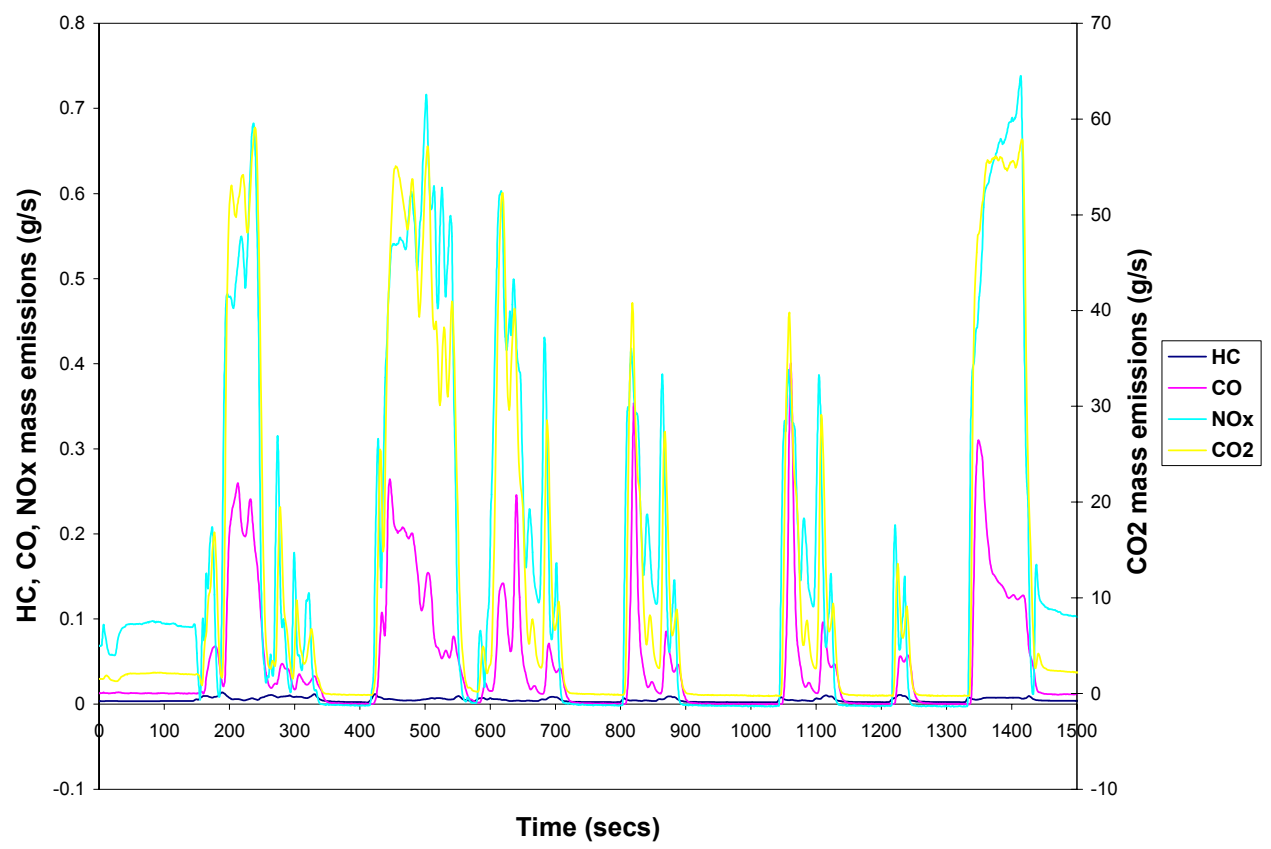

Figure 4.24: Transient cycle continuous emissions data plotted against time for CARB diesel

\subsubsection{ECD1 Diesel}

Compared to CARB diesel ECD1 has higher aromatics but lower sulfur content. The cetane number is approximately equal to that of CARB diesel. ECD1 baseline results showed HC reduction of $85 \%$ over steady state operation. However, the transient cycle yielded a $40 \%$ increase in $\mathrm{HC}$ from ECD1 compared to CARB diesel. It should be noted that $\mathrm{HC}$ emission levels are extremely low; hence, a low percentage translates into a very small increase on absolute basis. Changing the fuel from CARB to ECD1 did not result in a significant reduction of CO emission. $\mathrm{NO}_{\mathrm{x}}$ was reduced by an average $10 \%$ on both steady state and transient. PM was evened out between the two cycles, with a reduction of $5 \%$ in steady state operation and increase of $6 \%$ in transient operation. Substantial reduction percentages were observed when ECD1 was used to fuel the retrofit configurations. Previous studies have found that HC levels are very low with filter equipped non-road vehicles. Clark et al. went into detail on the results of class 8 trucks [61]. Authors found that regulated emissions were very low. PM was also measured using the Tapered 
Element Oscillating Microbalance (TEOM). They reported that trucks tested with CARB diesel and no DPFs did accumulate PM, while the TEOM on DPF equipped trucks collected only water. However, this author believes that TEOM was capturing organics as well and the continuous mass measurement reported by the TEOM was affected by the dilution tunnel pressure fluctuations during the transient cycles. With DPF equipped vehicles, the TEOM was most likely reporting artifacts. Figure 4.25 shows the transient cycle emissions continuous data for ECD1 over a period of 1500 seconds. Only a slight variation can be noticed between Figures 4.24 and 4.25 with respect to the $\mathrm{CO}_{2}$ and $\mathrm{NO}_{\mathrm{x}}$ readings.

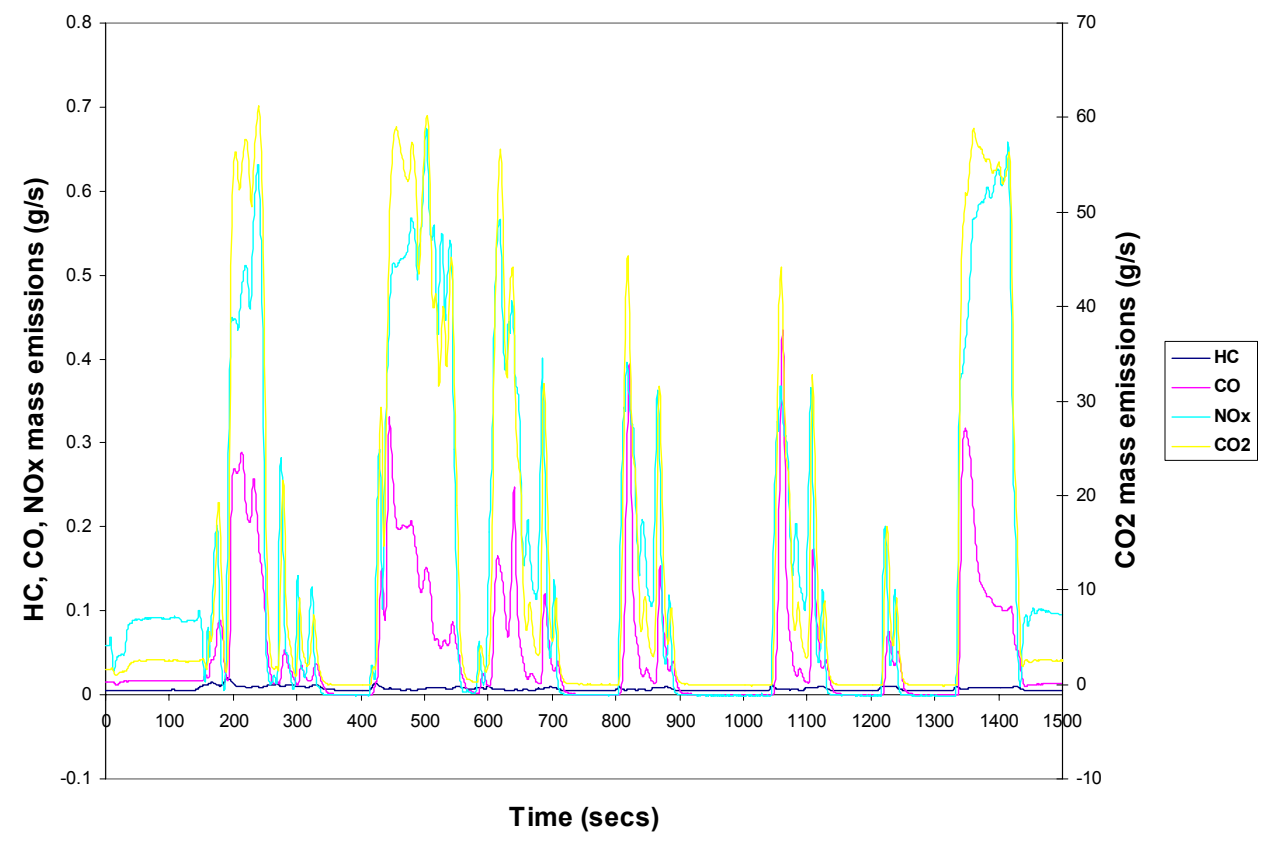

Figure 4.25: Transient cycle continuous emissions data plotted against time for ECD1 baseline

\subsubsection{Fischer-Tropsch Diesel}

Figure 4.26 shows the comparison of the test fuels under transient operation. The fuels match up in all emissions except for the high $\mathrm{NO}_{\mathrm{x}}$ for FT diesel. The effect of low sulfur is not apparent unless the fuel is running through an after-treatment device. Hence, the only parameter affecting baseline performance is the cetane number and aromatic content. FT diesel has the 
highest cetane number of the three test fuels and hence reduces the ignition delay. McMillian and Gautam tested FT fuel and proposed the FT fuel as fuel injection emission control parameter [45]. It was reported that the reduction in ignition delay results in a smaller volume of fuel being injected during the ignition delay period thus resulting in less premixed combustion. The reduction in delay period effectively advances combustion, which may have the same effect as advancing the start of injection timing. This results in higher combustion pressure and temperature, hence generating excessive $\mathrm{NO}_{\mathrm{x}}$. A comparison of emissions of FT fuels from natural gas reforming with standard diesel fuel was made [28]. Transient emissions tests were performed to compare emissions using fuels produced by the Sasol Slurry Phase Distillate Process (SSPD), to those with US diesel fuels. The SSPD fuels produced significantly lower emission than the standard and CARB fuels in all four regulated emission categories. The SSPD fuel had a high cetane number, low aromatics and sulfur content, and lower density than standard fuels.

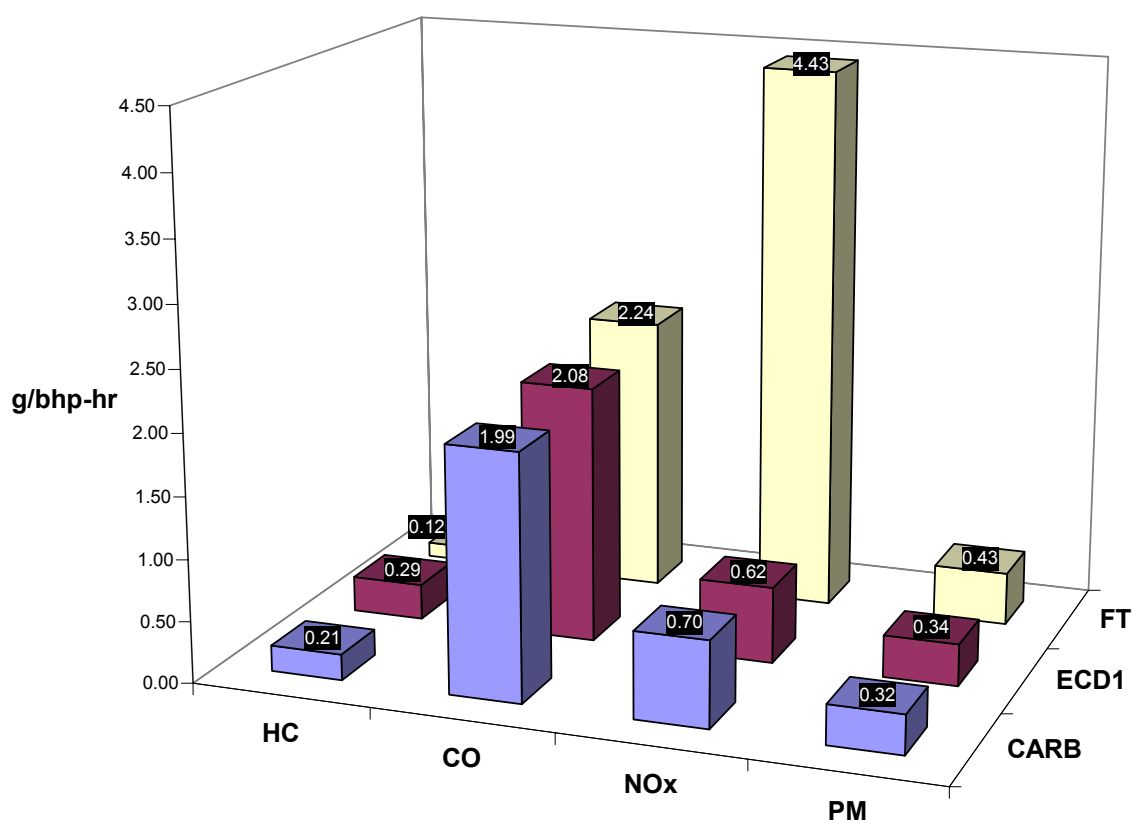

Figure 4.26: Baseline comparison of all test fuels under transient operation 


\subsubsection{Emissions from ECD1 and Fischer-Tropsch Diesel Fueled Engine with DPX and CRT DPFs}

\subsubsection{Effect of ECD1 on Regulated Emissions}

ECD1 diesel was used to test the engine as well as with CRT and DPX particulate filters. Previous studies $[5,61]$ have shown ECD1 to be a favorable alternate fuel in reducing regulated emissions. Ultra low sulfur fuels such as the ECD1 have been termed as "enabling technologies" because such fuels make it possible to retrofit diesel engines with catalyzed DPFs. The effect of particulate filters has been substantial in terms of reducing PM to meet the 2007 standards. The result of a highly active catalyst formulation in the particulate filters can also give excellent PM reductions. This is particularly evident during transient operation where high loads cause the exhaust temperatures to reach high values, thereby aiding the DPFs to enter the regeneration mode early during the cycle. Since this thesis was more concerned about the performance of the filters themselves and not in details of DPF's catalyst formulation and its characteristics, more information about the cell structure and catalyst formulation is not presented here. Khair et al. have studied the effects of diesel oxidation catalysts on PM emissions. Their paper evaluated advanced emission control technologies, including diesel particulate filters and selective catalytic reduction control technique.

PM emissions below $0.02 \mathrm{~g} / \mathrm{bhp}$-hr have been achieved using DPFs. It can be noted from Figure 4.27 that there is a significant effect of the lower sulfur content in ECD1 than CARB fuel. The effect is more pronounced for PM. The error bars represent standard deviation between test runs. The results are similar under transient operation. Figure 4.28 shows the effects of using ECD1 to fuel the engine under transient operation. Both CRT and DPX DPFs yielded PM reduction of $98 \%$, the CRT yielded HC reduction of $92 \%$ while the DPX yielded $71 \%$. 


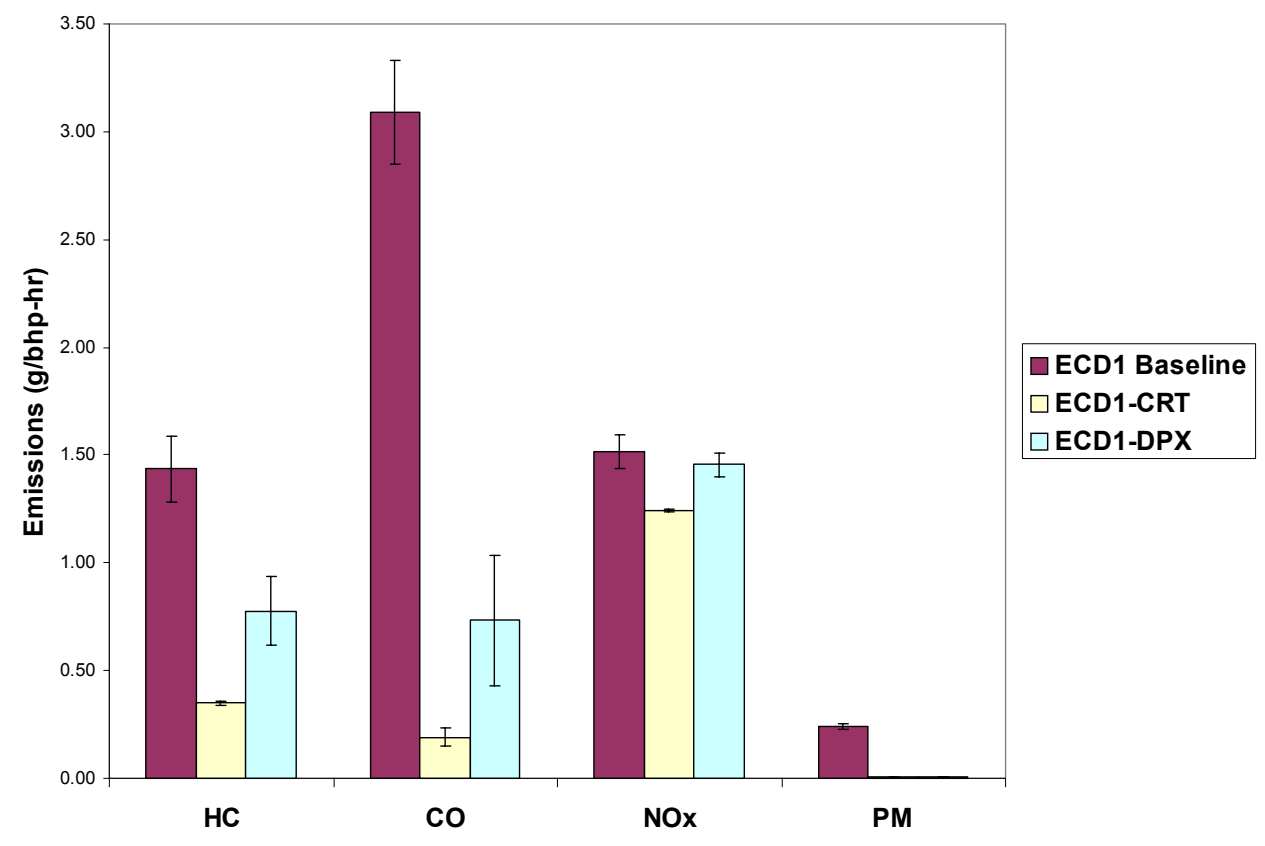

Figure 4.27: ECD1 8-mode weighted average results for all regulated emissions

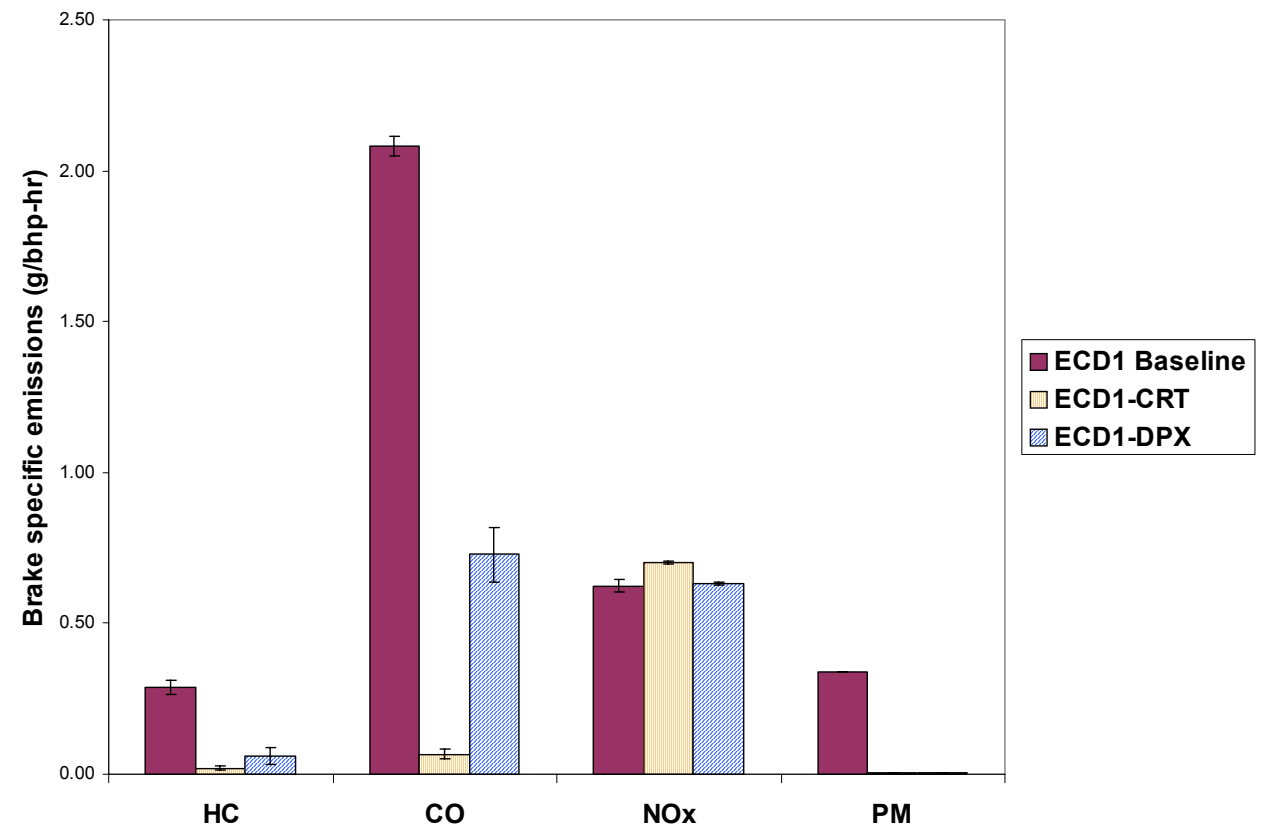

Figure 4.28: ECD1 transient cycle average results for all regulated emissions 


\subsubsection{Effect of FT Diesel on Emissions}

Figure 4.29 further illustrates the effects of FT diesel with CRT trap (see Figure 4.26) and a comparison is made with $\mathrm{CARB}$ diesel. $\mathrm{HC}$ and $\mathrm{CO}$ oxidation was excellent while using FT diesel. Reductions in $\mathrm{HC}$ and $\mathrm{CO}$ of $94 \%$ and $99 \%$, respectively, were realized in comparison to CARB diesel. The error bars represent standard deviation. The high paraffinic content of FT diesel assists in oxidation of hydrocarbons and carbon compounds. However, $\mathrm{NO}_{\mathrm{x}}$ was higher than the CARB baseline result. Again, this can be attributed to the high FT cetane number. A high cetane number usually reduces ignition delay and hence reduces $\mathrm{NO}_{\mathrm{x}}$. But, the shorter ignition delay period also causes early combustion and raises the pressure and temperature, thus increasing $\mathrm{NO}_{\mathrm{x}}$. Of particular concern to this study were reductions in PM emissions. Engines retrofitted with DPFs yielded PM reductions 98\% compared to the CARB baseline. The values were $0.25 \mathrm{~g} / \mathrm{bhp}-\mathrm{hr}$ for CARB diesel and 0.02 for FT diesel.

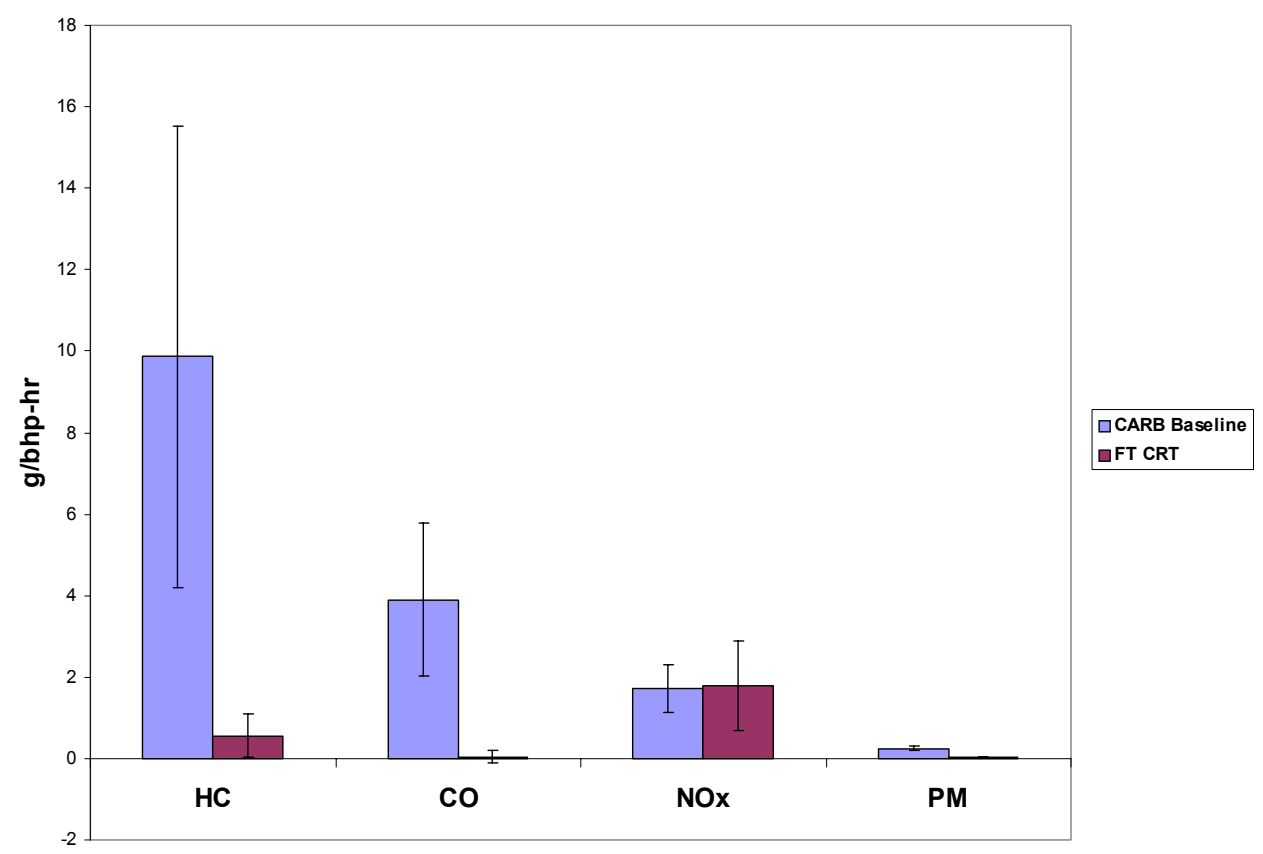

Figure 4.29: Comparison of cycle averaged emissions of Fisher-Tropsch diesel with CRT trap and CARB baseline, under steady state operation 
Figure 4.30 shows the effect of FT diesel with CRT trap compared to CARB baseline. $\mathrm{HC}$ was reduced by $88 \%$, and CO and PM are reduced by $98 \%$ compared to CARB baseline. $\mathrm{NO}_{\mathrm{x}}$ was reduced only by $6 \%$. Owing to the $\mathrm{PM}-\mathrm{NO}_{\mathrm{x}}$ tradeoff, $\mathrm{NO}_{\mathrm{x}}$ has been compromised in this case, as explained earlier in this section.

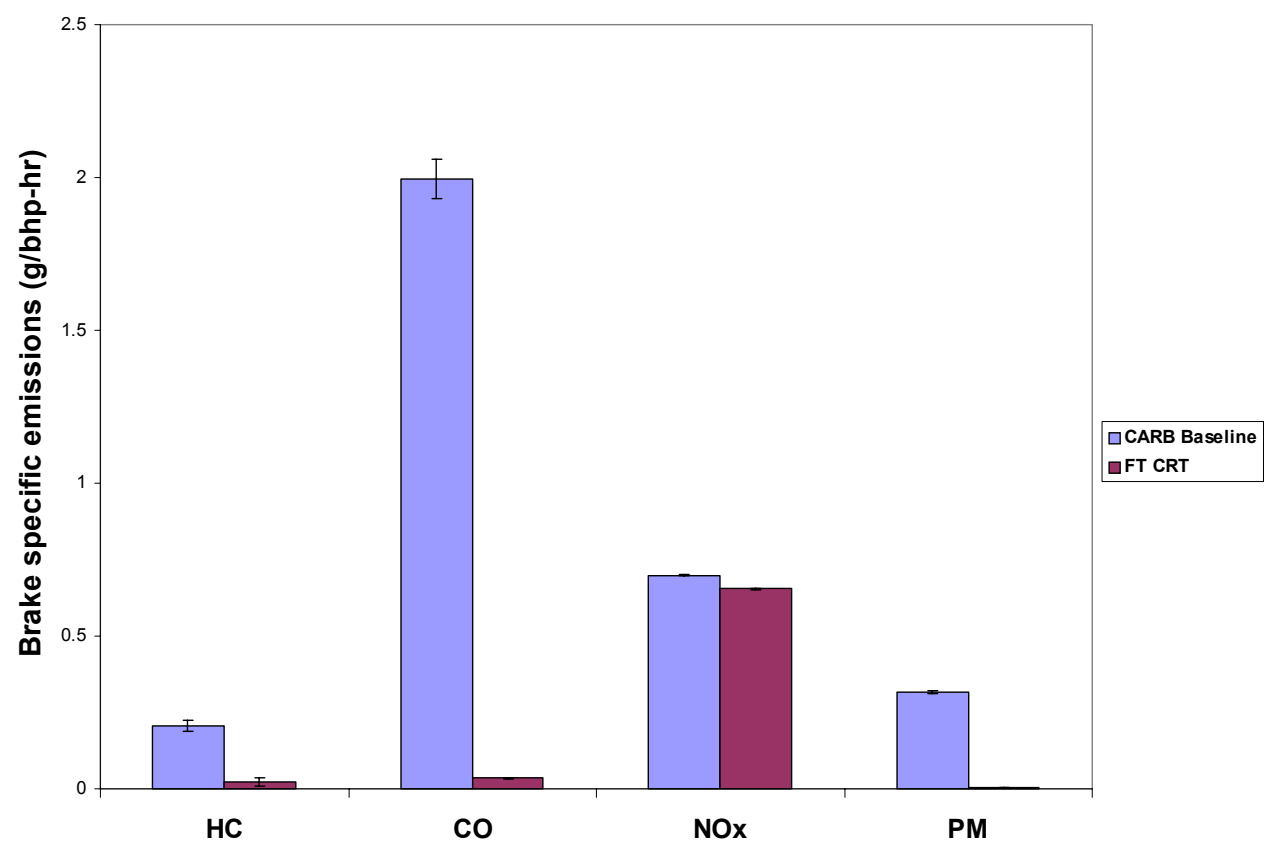

Figure 4.30: Comparison of cycle averaged emissions of Fisher-Tropsch diesel with CRT trap and CARB baseline, under transient operation

\subsubsection{Retrofit versus CARB Baseline Evaluation}

The use of DPFs has slowly become popular over the last decade owing to their improved durability and obviously their ability to drastically reduce particulate matter from engine exhaust. While DPFs have been used on highway vehicles for several years, their use on off-road vehicles is being currently investigated. Switzerland has made it mandatory to retrofit underground construction equipment with particulate filters since 1994 [30]. This section compares the overall effect of using DPFs on emissions, against CARB baseline.

DPFs need high temperatures for regeneration. The first mode of the 8-mode cycle is the R100 mode, which raises the exhaust temperatures to approximately $1000{ }^{\circ} \mathrm{F}$. At high 
temperatures the DPF enters the regeneration mode. The first retrofit configuration was ECD1 diesel with the CRT trap. It should be noted that sampling times were lengthened for retrofitted engine tests to allow collection of sufficient PM sample. After the R100 mode which was originally for 1500 seconds, the filter face temperature was noted to be very high. The Pallflex 70mm PM filter was also damaged due to excessive particulate loading. Hence, the length of the mode was reduced to 600 seconds. The rest of the modes were also of the same duration except for the idle mode which operated for 1020 seconds.

Appendix $\mathrm{C}$ lists the cycle averaged weighted emissions data for all $\mathrm{HC}, \mathrm{CO}, \mathrm{NO}_{\mathrm{x}}$ and PM for each mode of the steady state, and transient cycle. It also lists the standard deviation and coefficient of variance between test runs. The high variation in $\mathrm{HC}$ measurements for the retrofit versions could be attributed to measurement uncertainties of ultra low levels of HC emissions. Fluctuations in operating conditions and ambient conditions also contributed to the errors. The PM coefficient of variance values seem to be high because of the very low PM values that were obtained. The PM collected on some of the filters was very low to quantify them with a high degree of certainty.

Figures 4.31 and 4.32 show the overall retrofit results when compared to CARB baseline configuration, under steady state and transient operation, respectively. Figure 4.33 shows the overall brake-specific PM emissions for all configurations, under steady state and transient operation. Figure 4.33 also shows the reduction percentages (steady state and transient operation) when compared to CARB baseline. The diesel particulate filters have been highly successful in reducing PM from engine out exhaust emissions. 


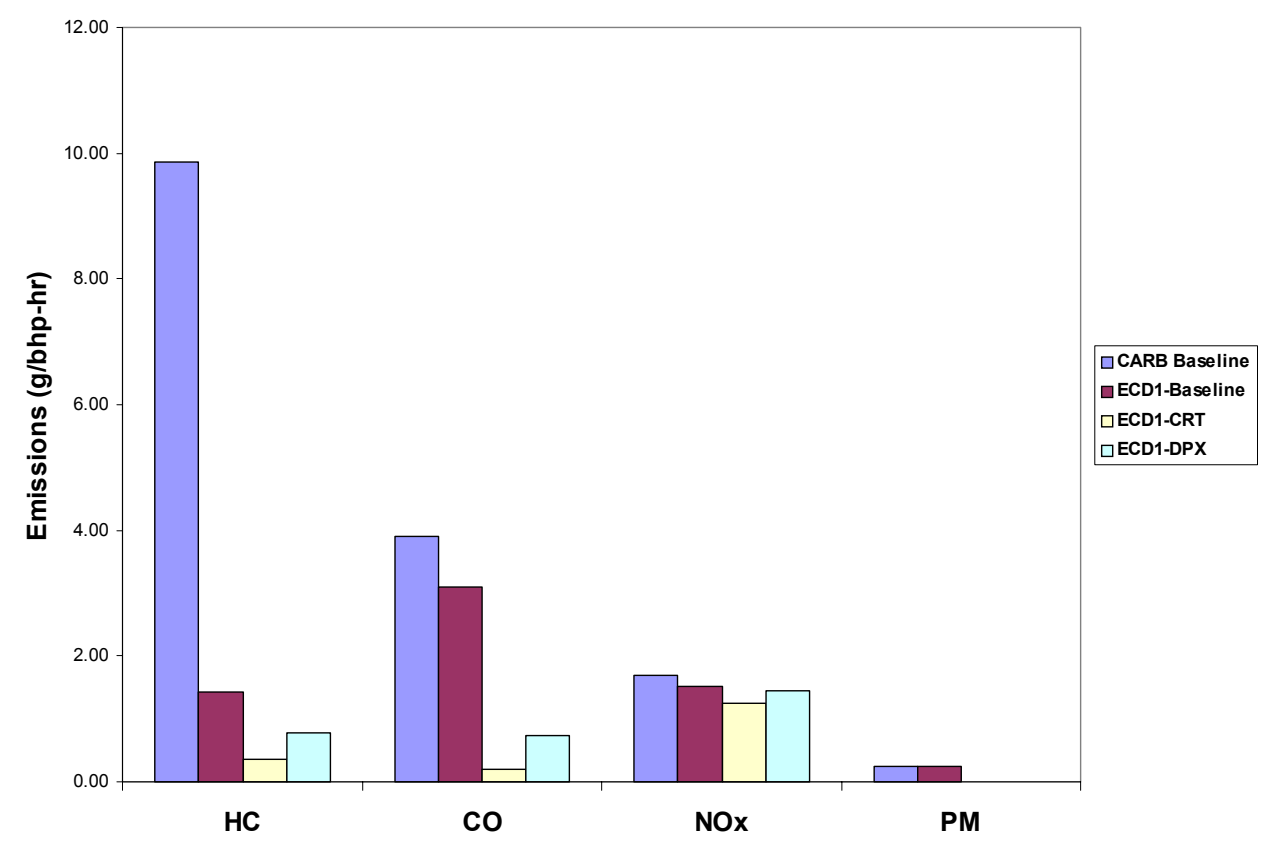

Figure 4.31: Comparison of CARB baseline with ECD1, with and without trap, under 8mode steady state operation

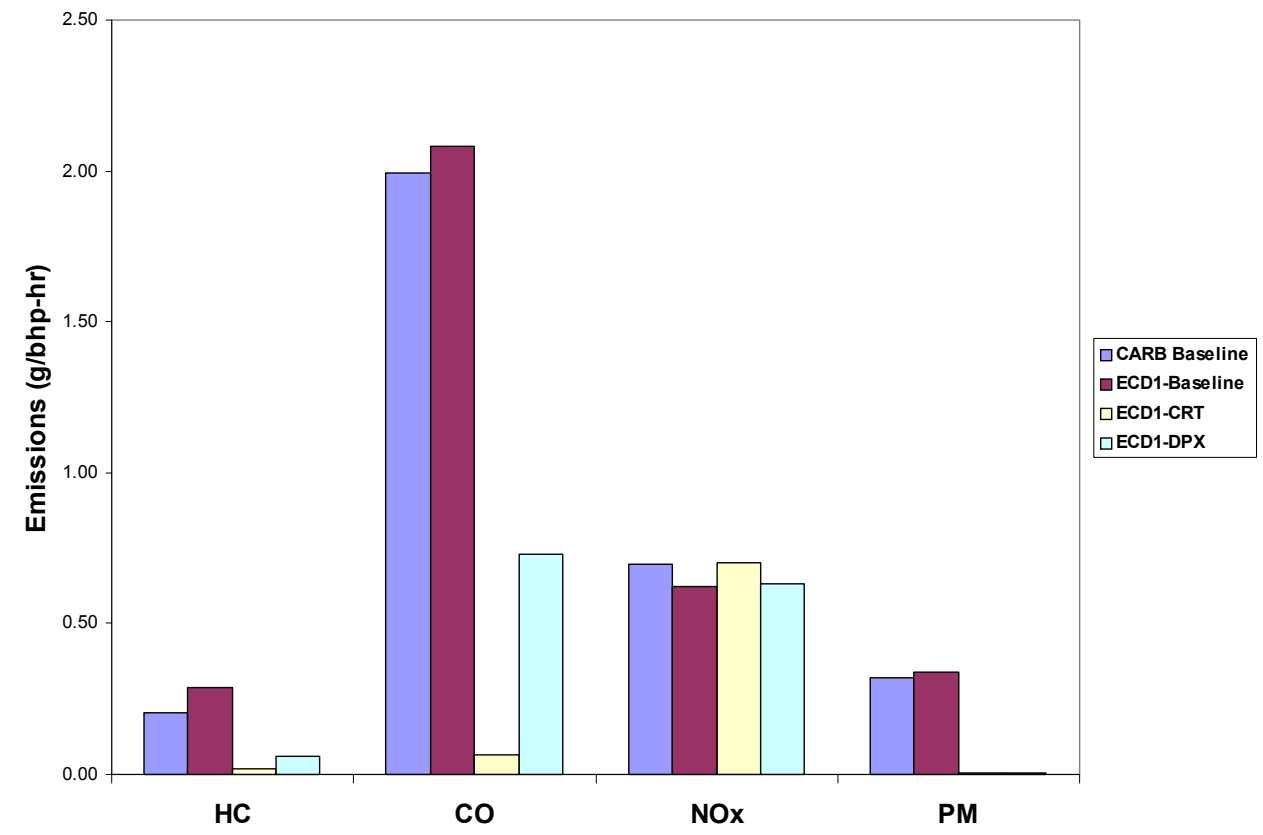

Figure 4.32: Comparison of CARB baseline with ECD1, with and without trap, under transient operation 


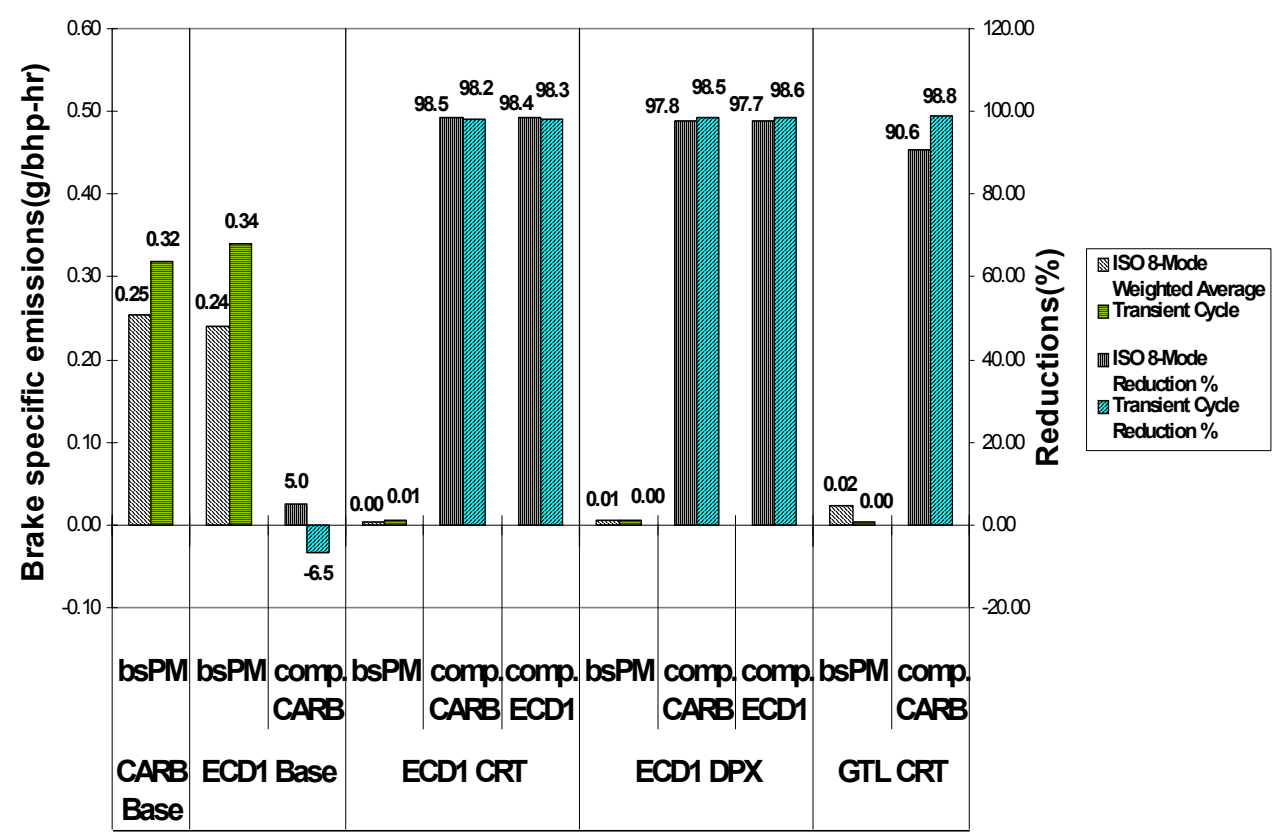

Figure 4.33: Overall brake-specific and corresponding reduction percentages for PM emissions, compared to CARB baseline

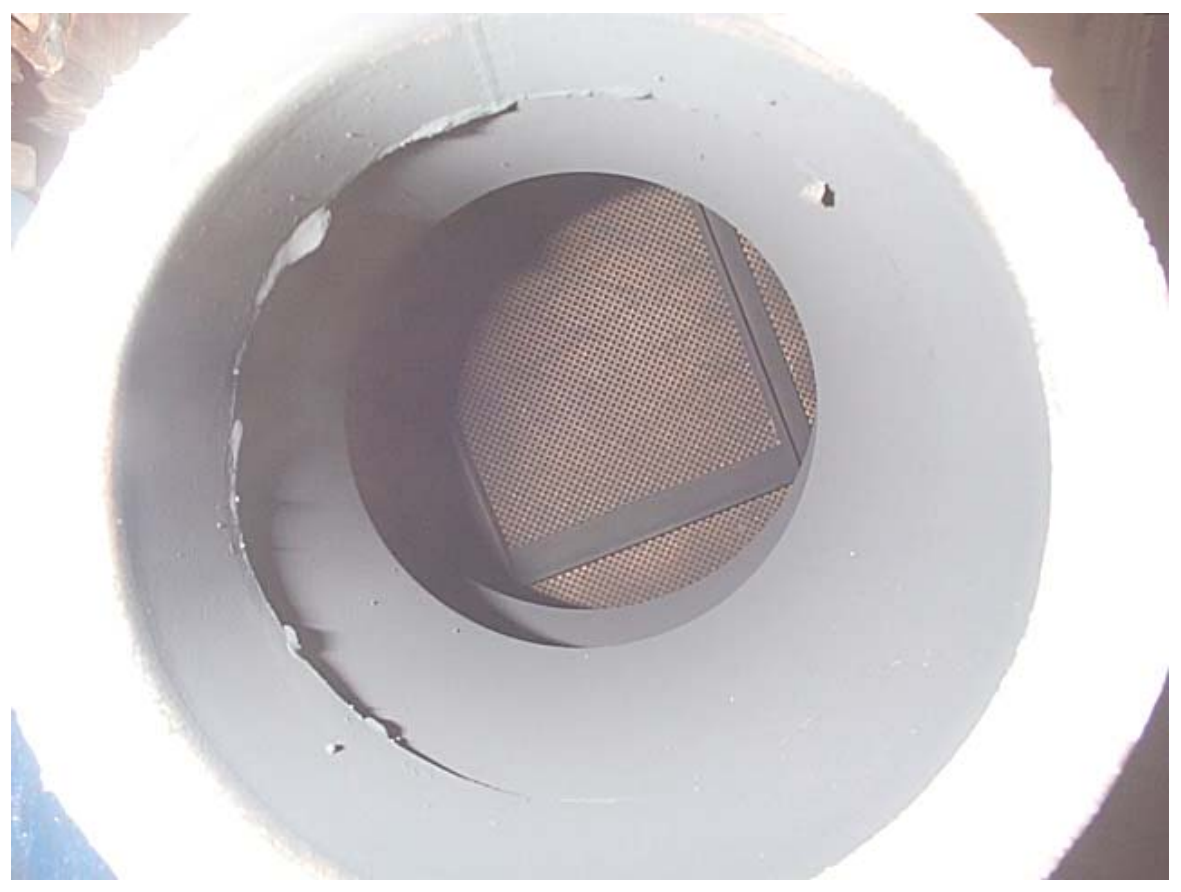

Figure 4.34: View of the inlet face of PM laden Engelhard DPF (post-testing) 


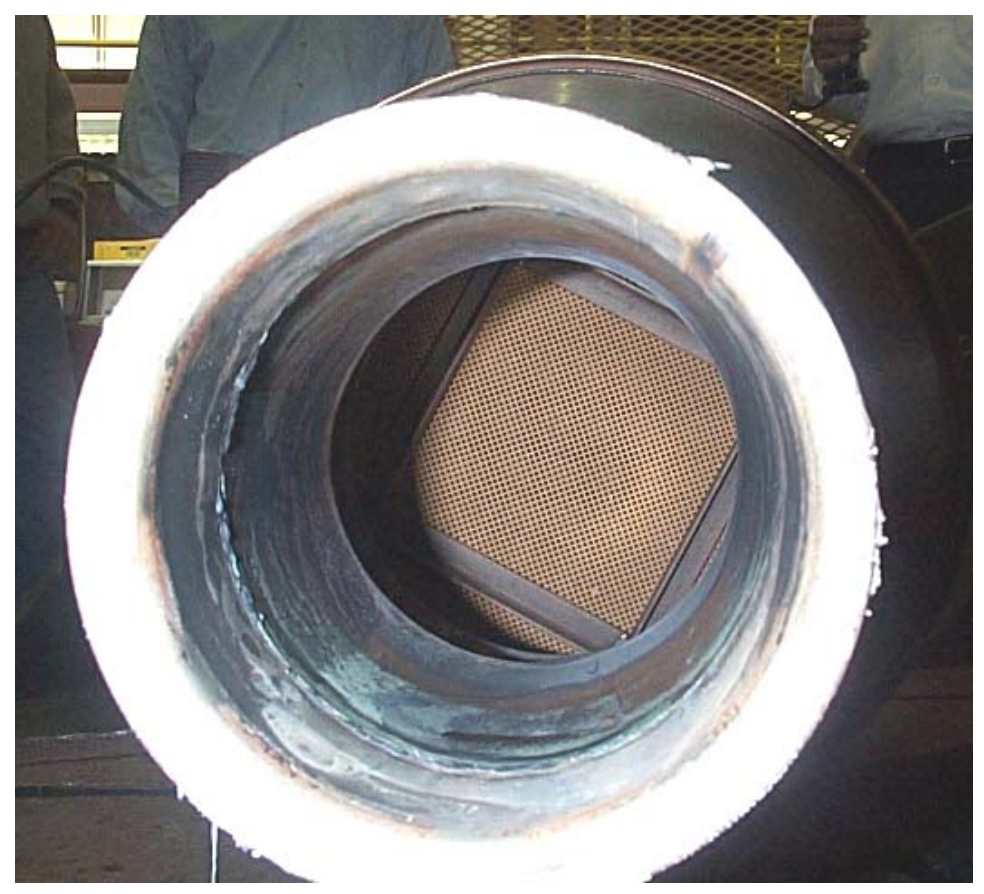

Figure 4.35: View of the downstream end of Engelhard DPF (post-testing), note the clean filter element

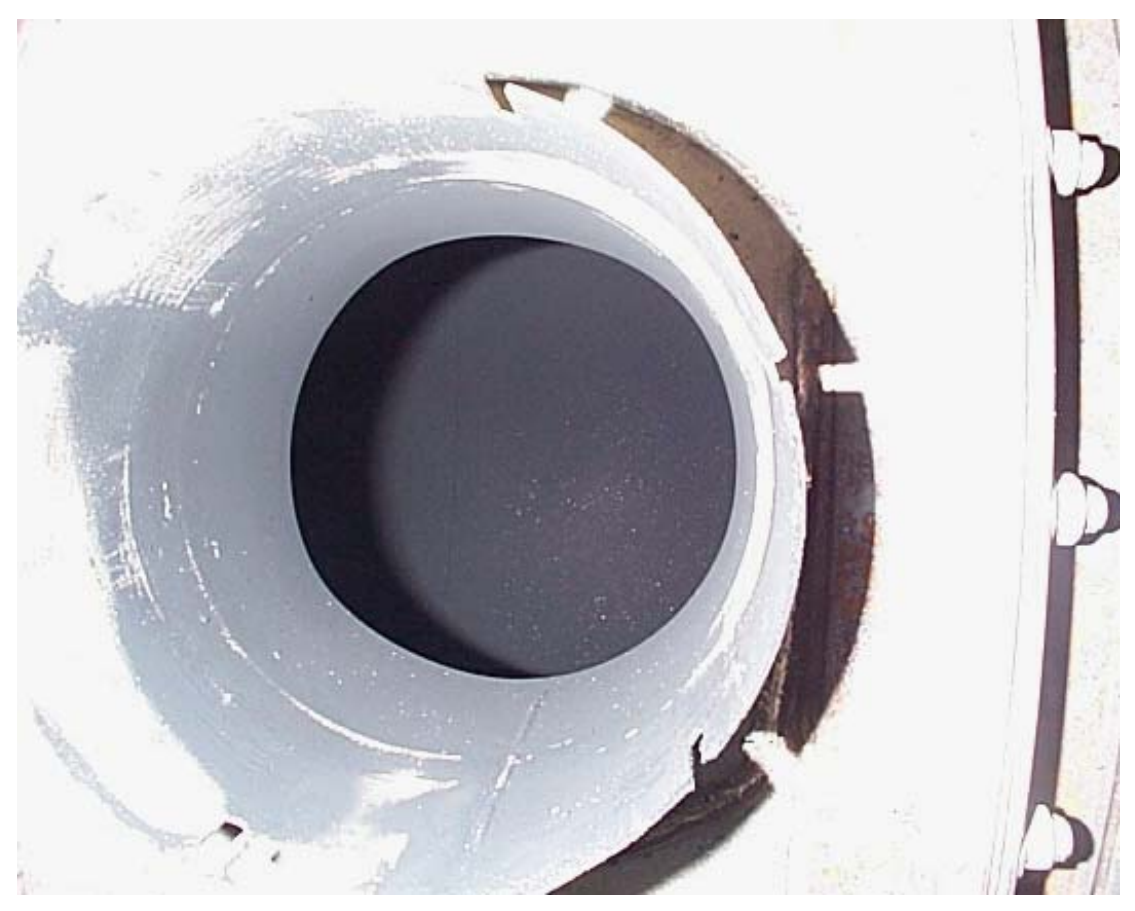

Figure 4.36: View of the inlet face of PM laden Johnson-Matthey DPF (post-testing) 


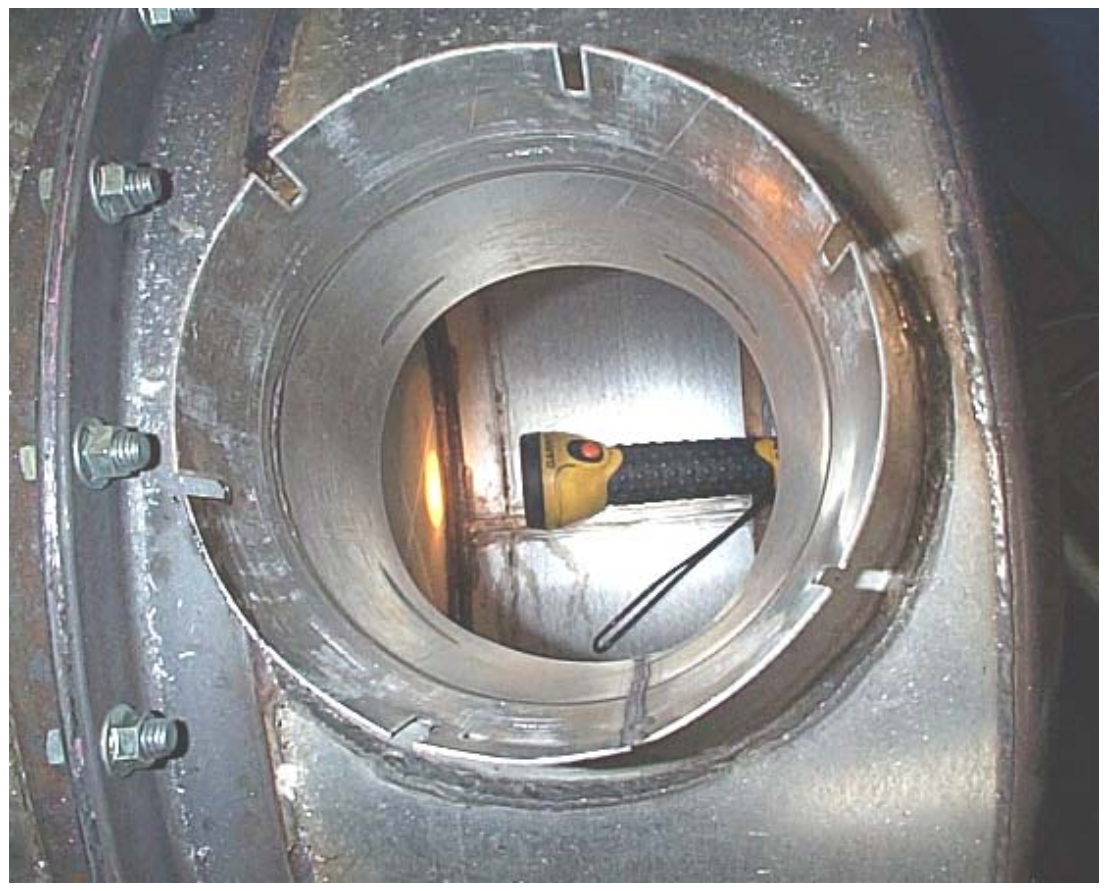

Figure 4.37: View of the downstream end of Johnson-Matthey DPF (post-testing), note the clean filter element

\subsubsection{Steady State versus Transient Evaluation}

Table 4.6 presents the total weighted average emissions for $\mathrm{HC}, \mathrm{CO}, \mathrm{NO}_{\mathrm{x}}$, and $\mathrm{PM}$ under steady state operation, in $\mathrm{g} / \mathrm{bhp}-\mathrm{hr}$. It also presents the total continuous sampling emissions under transient operation, in g/bhp-hr.

The general formula for calculating percentage difference was:

$$
\% \text { difference }=\left(\frac{\text { referencevalue }- \text { actualvalue }}{\text { referencevalue }}\right)
$$


Table 4.6: Overall weighted emissions for steady state and average continuous emissions for transient cycle

\begin{tabular}{|c|c|c|c|c|c|c|}
\hline Configuration & $\begin{array}{l}\text { 8-mode } \\
\text { Weighted } \\
\text { Average } \\
\text { (g/bhp-hr) }\end{array}$ & $\begin{array}{l}\text { Transient } \\
\text { Cycle } \\
\text { (g/bhp-hr) }\end{array}$ & $\begin{array}{l}\text { Percentage } \\
\text { Difference }\end{array}$ & $\begin{array}{l}\text { 8-mode } \\
\text { Weighted } \\
\text { Average } \\
\text { (g/bhp-hr) }\end{array}$ & $\begin{array}{l}\text { Transient } \\
\text { Cycle } \\
\text { (g/bhp-hr) }\end{array}$ & $\begin{array}{l}\text { Percentage } \\
\text { Difference }\end{array}$ \\
\hline CARB- Baseline & 9.86 & 0.21 & 97.91 & 3.90 & 1.99 & 48.88 \\
\hline ECD1 Baseline & 1.44 & 0.29 & 79.90 & 3.09 & 2.08 & 32.66 \\
\hline ECD1-CRT & 0.35 & 0.02 & 94.11 & 0.19 & 0.06 & 65.41 \\
\hline ECD1-DPX & 0.78 & 0.06 & 92.15 & 0.73 & 0.73 & 0.75 \\
\hline \multirow[t]{2}{*}{ GTL -CRT } & 0.56 & 0.02 & 95.89 & 0.04 & 0.04 & 0.73 \\
\hline & \multicolumn{3}{|c|}{$\mathrm{HC}$} & \multicolumn{3}{|c|}{$\mathrm{CO}$} \\
\hline CARB- Baseline & 1.70 & 0.70 & 59.03 & 0.25 & 0.32 & 25.50 \\
\hline ECD1 Baseline & 1.52 & 0.62 & 58.83 & 0.24 & 0.34 & 40.74 \\
\hline ECD1-CRT & 1.24 & 0.70 & 43.69 & 0.004 & 0.006 & 51.71 \\
\hline ECD1-DPX & 1.46 & 0.63 & 56.54 & 0.006 & 0.005 & 13.78 \\
\hline \multirow[t]{2}{*}{ GTL -CRT } & 1.79 & 0.65 & 63.37 & 0.024 & 0.004 & 83.49 \\
\hline & \multicolumn{3}{|c|}{ NO $_{x}$} & \multicolumn{3}{|c|}{ PM } \\
\hline
\end{tabular}

In Equation 14, the steady state values were taken as reference and the transient values are taken as "actual values" because they represent real-world emissions. There exist large differences in emissions for every configuration tested except for CO. This suggests that the steady state cannot be used as a means of determining real-world emissions. CO and PM seem to be reasonable in their percent differences. $\mathrm{HC}$ and $\mathrm{NO}_{\mathrm{x}}$ values are very different between steady state and transient. Except for PM emission, the baseline percentage differences using CARB diesel are more than $50 \%$ for $\mathrm{HC}, \mathrm{CO}$, and $\mathrm{NO}_{\mathrm{x}}$. Similarly, while using ECD1 diesel, the percentage difference was more than $40 \%$ for $\mathrm{HC}, \mathrm{NO}_{\mathrm{x}}$ and $\mathrm{PM}$. As previously mentioned in Section 4.3.1, the ISO $8178 \mathrm{C} 1$ steady state cycle is used more for certification purposes than to mimic real-world conditions. Referring back to Figures 4.17 through 4.22 , it was deduced that the maximum time the engine operated was in the rated condition region of 1601-1900 rpm and 1001-1200 lbs-ft. This can be equated to the first rated 100 mode of the 8-mode cycle. 
Essentially, the engine seems to be operating higher than the $75 \%$ full load and not at the other intermediate modes. Though the idling rpm and torque values seem to have a higher frequency of occurrence, they can be overlooked because most of the idling values have been intentionally added. Therefore, the steady state 8-mode does not compare well with the transient set points.

\subsubsection{Effects of Fuel Properties on Emissions}

Fuel density influences the formation of $\mathrm{NO}_{\mathrm{x}}$. The heavier the fuel, the higher the content of $\mathrm{NO}_{\mathrm{x}}$ in the exhaust. This is due to the increased amount of fuel injected per brake horsepower output. Due to the higher density, fuel injection pressures increase and so more fuel is burnt. The API gravity is inversely proportional to the density (or specific gravity which is relative density) and hence the higher the API gravity the lighter the fuel [62]. From the fuel properties in Table 3.4, it can be seen that densities of CARB and ECD1 are greater than that of FT diesel, hence, FT diesel fueled engines should have a lower $\mathrm{NO}_{\mathrm{x}}$ emission. Previous studies have indicated a reduction in $\mathrm{HC}$, and $\mathrm{CO}$ emissions if fuel density is high. Figures 4.31 and 4.32 show a reverse effect for this study. $\mathrm{NO}_{\mathrm{x}}$ turned out high for all 8-mode tests. Due to the high speed and loads in transient cycles, abrupt changes in fueling may occur. This might cause excess fuel being injected per injection stroke. We can see that PM has drastically decreased from higher to lower density. This effect has also reduced $\mathrm{HC}$ and $\mathrm{CO}$ emissions.

Cetane number is an indicator of a fuels ability to ignite. Studies have shown that $\mathrm{NO}_{\mathrm{x}}$ emissions reduce with increasing cetane numbers with advancements in engine technology [62]. Figures 4.31 and 4.32 indicate decreasing PM with increasing cetane number. It has been reported that the soluble organic content of PM reduces with high cetane numbers [28]. 


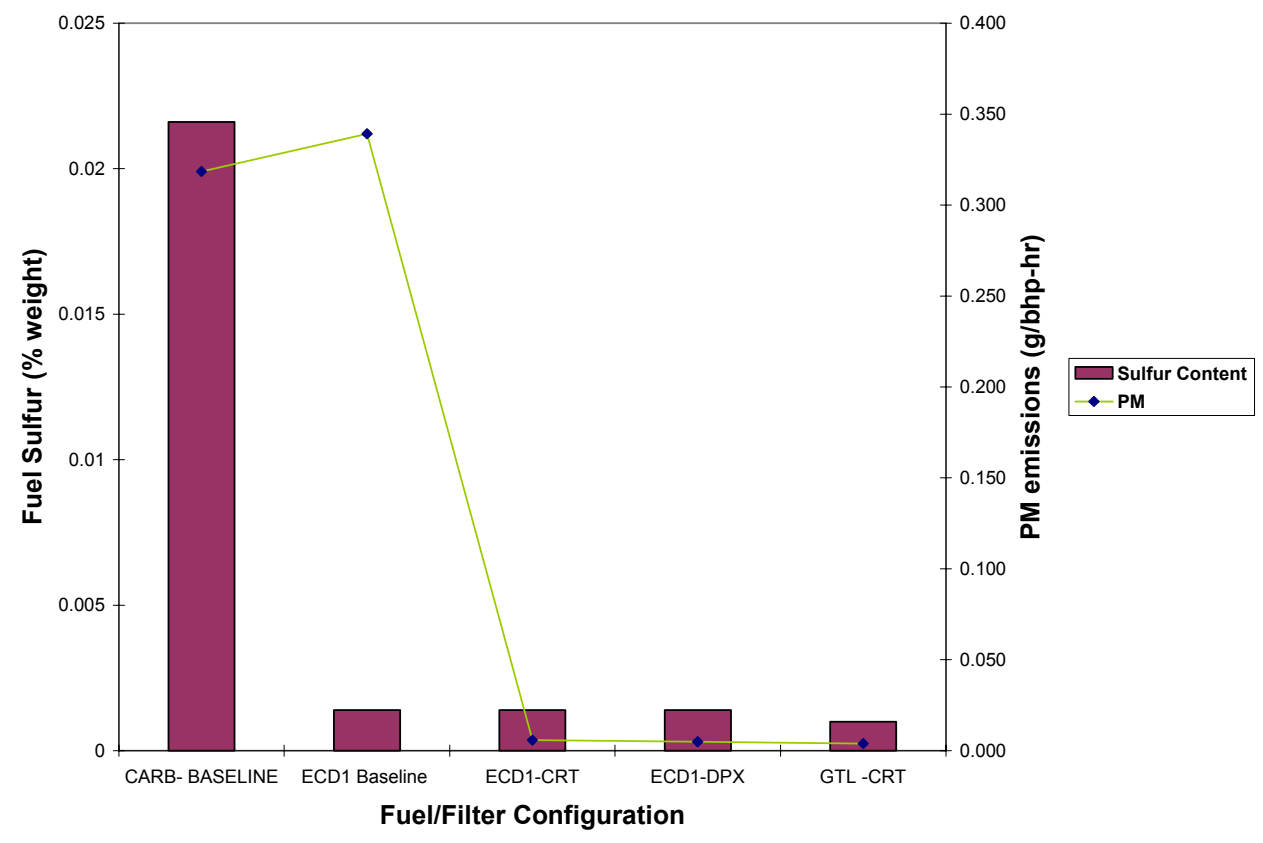

Figure 4.38: PM versus fuel sulfur content against all fuel/filter configurations

Sulfur content is one of the most important reasons for reformulating existing diesel fuels. Since the 1990s, CARB and EPA have been trying to reduce the amount of sulfur in diesel fuel. Recently, the use of ultra low sulfur diesel $(<15 \mathrm{ppm})$ has been widespread. The use of low sulfur diesel in this study has been reflected in Figure 4.38. Figure 4.38 shows the PM generated against fuel sulfur content. CARB diesel which was used as a basis for comparison has the highest amount of fuel generated percent weight of sulfur. PM on the ECD1 versions is similar irrespective of the use of particulate filters. FT diesel as was expected due to its low sulfur content has yielded the lowest PM content of the group. Emissions of $\mathrm{HC}$ and $\mathrm{CO}$ were not significantly affected by the presence of sulfur in the baseline configurations. 


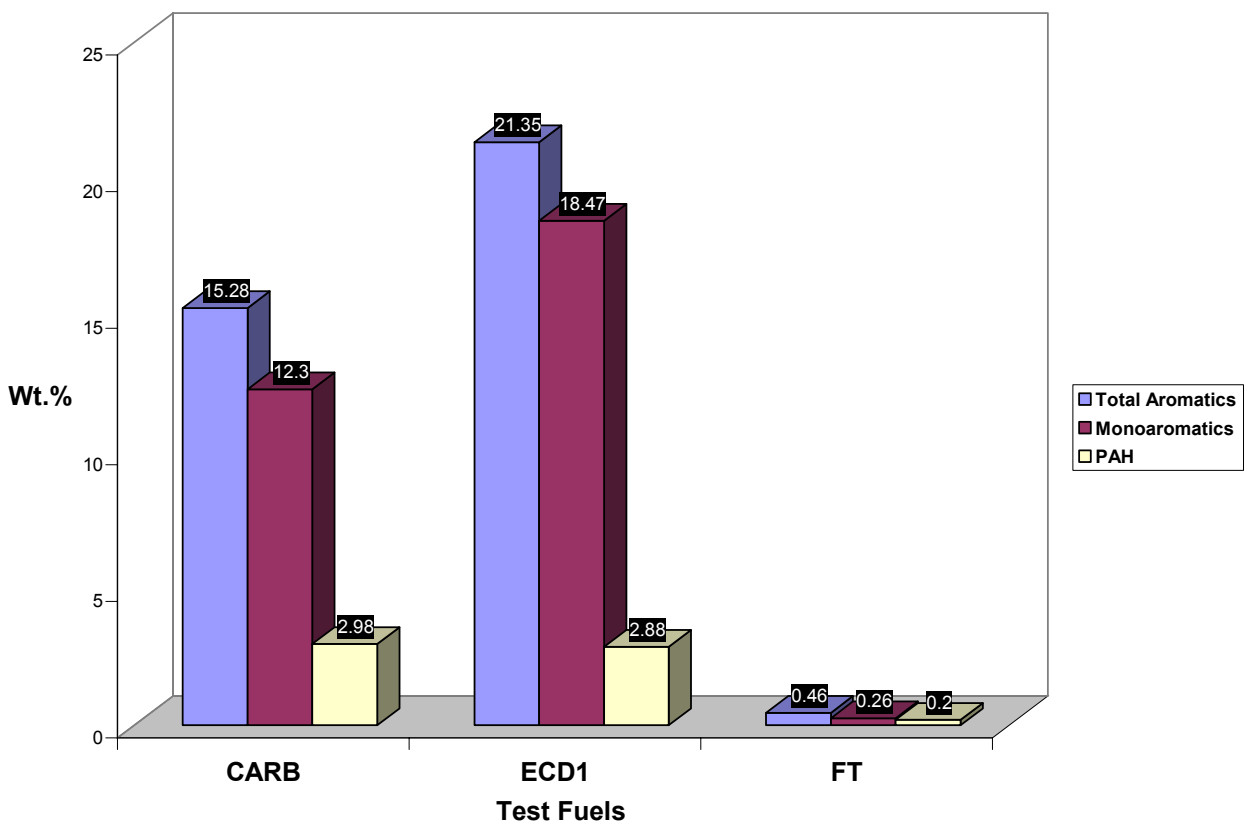

Figure 4.39: Percentage weight of aromatics in the test fuels

As can be seen from Figure 4.39, Fischer-Tropsch diesel is very low in aromatics. Schaberg et al. have reported that fuel aromatic content was found to reduce all regulated emissions [28]. The cetane numbers of the test fuels are 53, 52, and 74 for CARB, ECD1, and FT diesel, respectively. Due to the high aromatic content CARB and ECD1 have a lower cetane number than FT diesel. FT diesel, with a cetane number of 74, has produced very low emissions with and without a particulate filter. Table 4.7 shows the variation of regulated emission with increasing aromatic content.

Volatility, as explained in Section 3.6, of diesel can be evaluated in terms of the front and back end volatility. The front end is the $10 \%$ recovery temperature and back end is $95 \%$. Figure 4.40 shows the range of recovery temperatures for all the test fuels, from front-end boiling point to the back-end boiling point. 
Table 4.7: Total aromatics versus $\mathrm{HC}, \mathrm{CO}, \mathrm{NO}_{\mathrm{x}}$ and $\mathrm{PM}$ under transient operation

\begin{tabular}{|c|c|c|c|c|c|}
\hline $\begin{array}{c}\text { Configuration } \\
\text { CARB }\end{array}$ & $\begin{array}{c}\text { Total } \\
\text { Aromatic } \\
\text { Content }\end{array}$ & $\mathbf{H C}$ & $\mathrm{CO}$ & NOx & PM \\
\hline Baseline & 15.28 & 0.21 & 1.99 & 0.70 & 0.32 \\
\hline ECD1 CRT & 21.35 & 0.02 & 0.07 & 0.70 & 0.0058 \\
\hline ECD1 DPX & 21.35 & 0.06 & 0.73 & 0.63 & 0.0048 \\
\hline FT CRT & 0.46 & 0.02 & 0.04 & 0.65 & 0.0039 \\
\hline
\end{tabular}

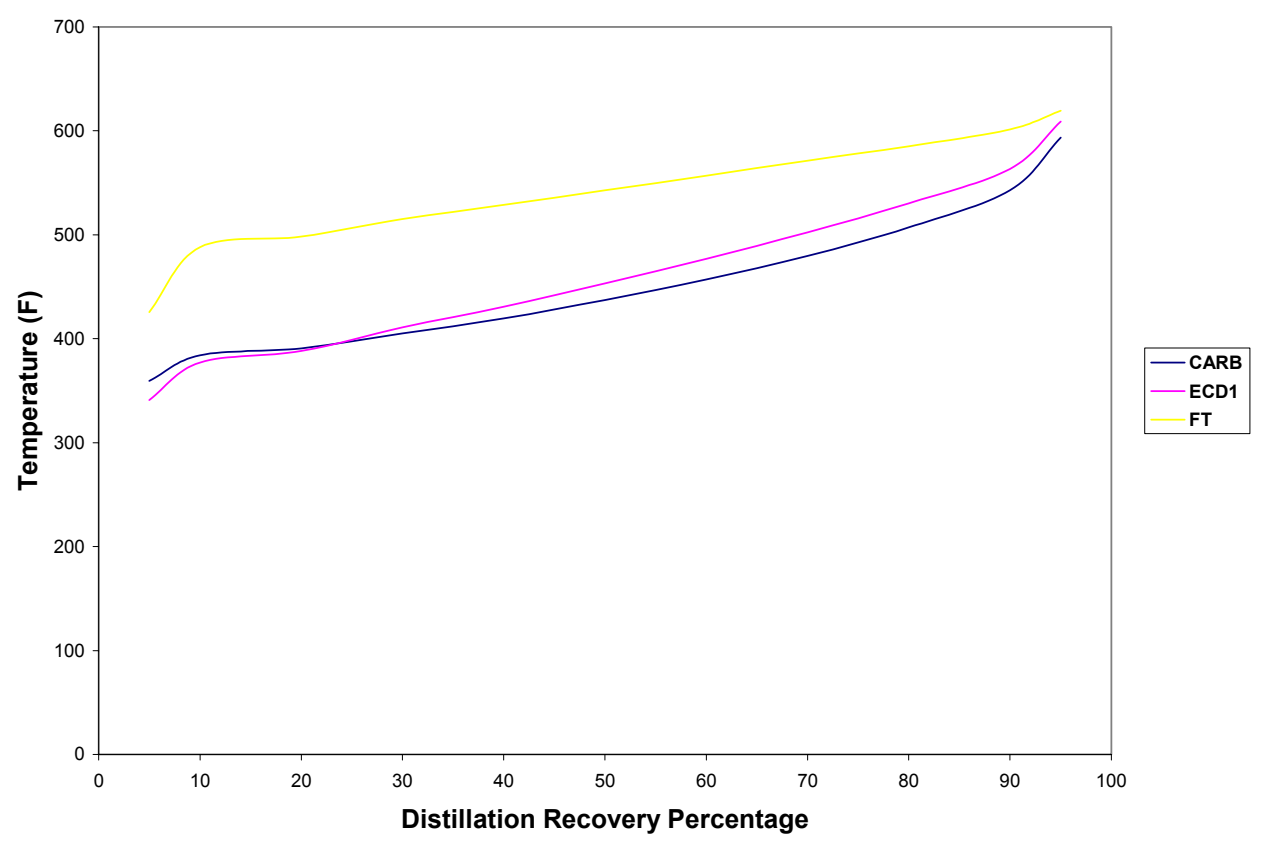

Figure 4.40: Distillation recovery percentages and temperatures for all test fuels

Kinematic Viscosity is measured by the ASTM D-445 test method. The method measures the time taken for a fixed volume of fuel to flow under gravity through a capillary tube viscometer immersed in a thermostatically controlled bath [62]. For diesel fuel the temperature at which viscosity is measured is either $20{ }^{\circ} \mathrm{C}$ or $40{ }^{\circ} \mathrm{C}$. The viscosity of FT diesel is higher than either CARB or ECD1 diesel (Table 3.4). A higher viscosity causes hindrance in the flow of fuel 
through injectors, causing a reduction in fuel pressure. This causes incomplete combustion to occur and increases $\mathrm{HC}$ and $\mathrm{CO}$ emissions. This study however, has no such effects for FT diesel. 


\subsection{AQMD Construction Equipment Trap In-field Durability Study Report}

Throughout the course of the year long testing, the trap performance and mechanical durability issues were monitored and carefully documented. The following text and figures list some of the common issues recorded on more than one vehicle, but not all of them were on the same vehicle. These are based on monthly and quarterly reports provided by Booz-Allen and Hamilton, Inc. The particulate filters used were the Johnson-Matthey CRT and Engelhard DPX.

1. CRT and DPX filters had structural failures due to vibrations (see figure 4.43).

2. CRT and DPX mounting brackets and braces under extreme strain due to vibration and filter weight (300 lbs CRT, 100 lbs DPX, see figure 4.41).

3. CRT shifted out of place and moved close to the outlet manifold. The catalyst matrix was intact, but had cuts in the structure from opposing reinforcing struts of the outlet manifold (see figure 4.43). A thin dry layer of ash coated the face of the filter.
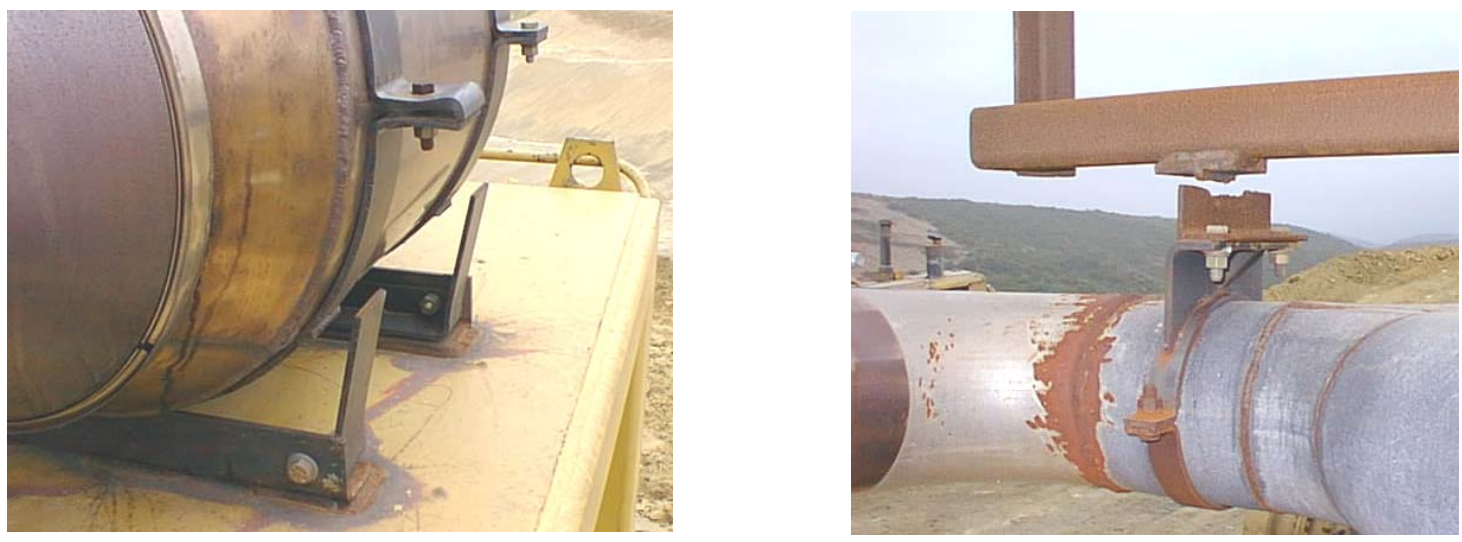

Figure 4.41: Failure of mounting bracket on Engelhard trap (left) and exhaust pipeline (right)

4. Flex pipe that connects the exhaust piping to the filter inlet of Engelhard trap was torn apart on both ends, presumably due to the extreme vibration in this vehicle (see figure 4.42). Cracks developed in the exhaust manifold. The filter exhaust manifold is bolted to the filter can and supports the upright exhaust stack. The inertia of the upright exhaust 
stack caused strain cracks in the nearby surface structure of the exhaust manifold.

Shepherd technicians welded these cracks closed and reinforced the surrounding metal.
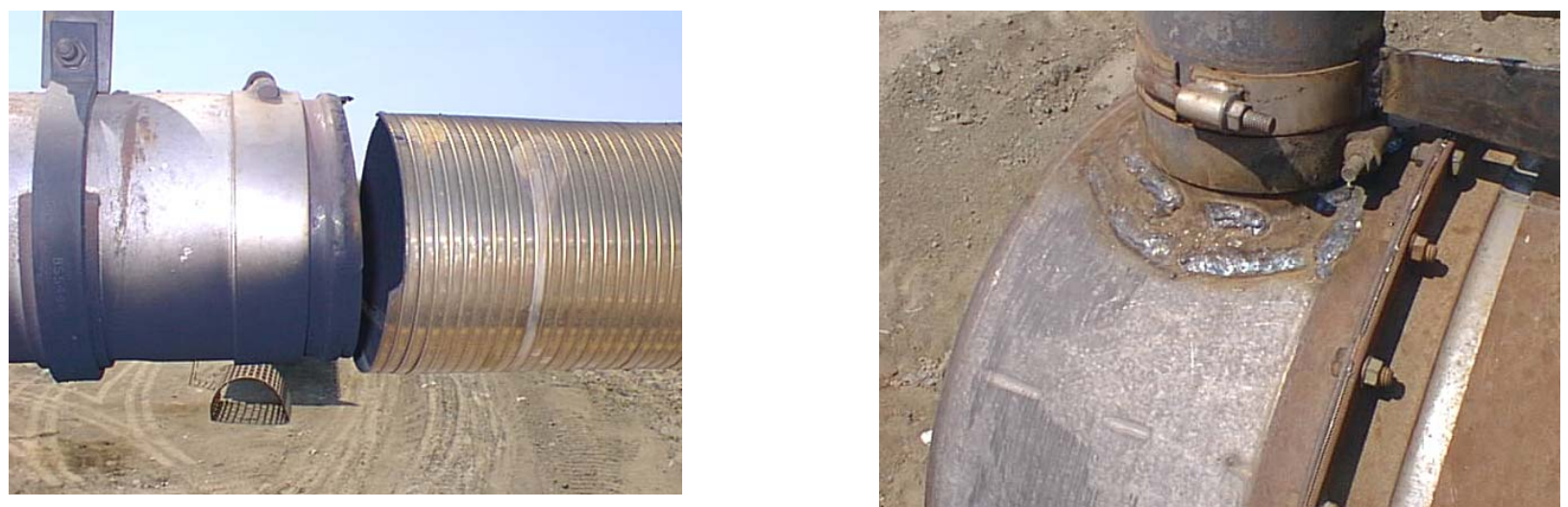

Figure 4.42: Damage to flex pipe connecting Engelhard trap to exhaust outlet (left) and exhaust pipe reinforcement on Johnson-Matthey trap (right)

5. Steel band at the inlet to the Engelhard DPF torn.

6. CRT and DPX filters experienced high backpressure. Burning of carbon soot had caused significant burn-through of the ceramic trap element.

7. Air conditioner had to be moved to make way for the particulate trap.

8. Engelhard filter elements were broken (see figure 4.43). The substrate inside the canning had shifted and was partially broken up so that loose chunks were present. Visual inspection revealed that the substrate had become dislodged from the center-body and allowed to "beat" itself against the outlet cross-members and the housing, resulting in substrate attrition and fracture. The major demise was due to mechanical stress. No sign was evident that the substrate experienced excessive temperatures, local hotspots and/or chemical attack. The trap had not experienced burn through as no soot was observed on the outlet channels. The preliminary finding was that the ceramic contacted the restraining crossbars which first scored, and then cracked the ceramic. The excessive 
contact between the ceramic and the crossbars may have been due to backpressure or due to vehicle vibration.
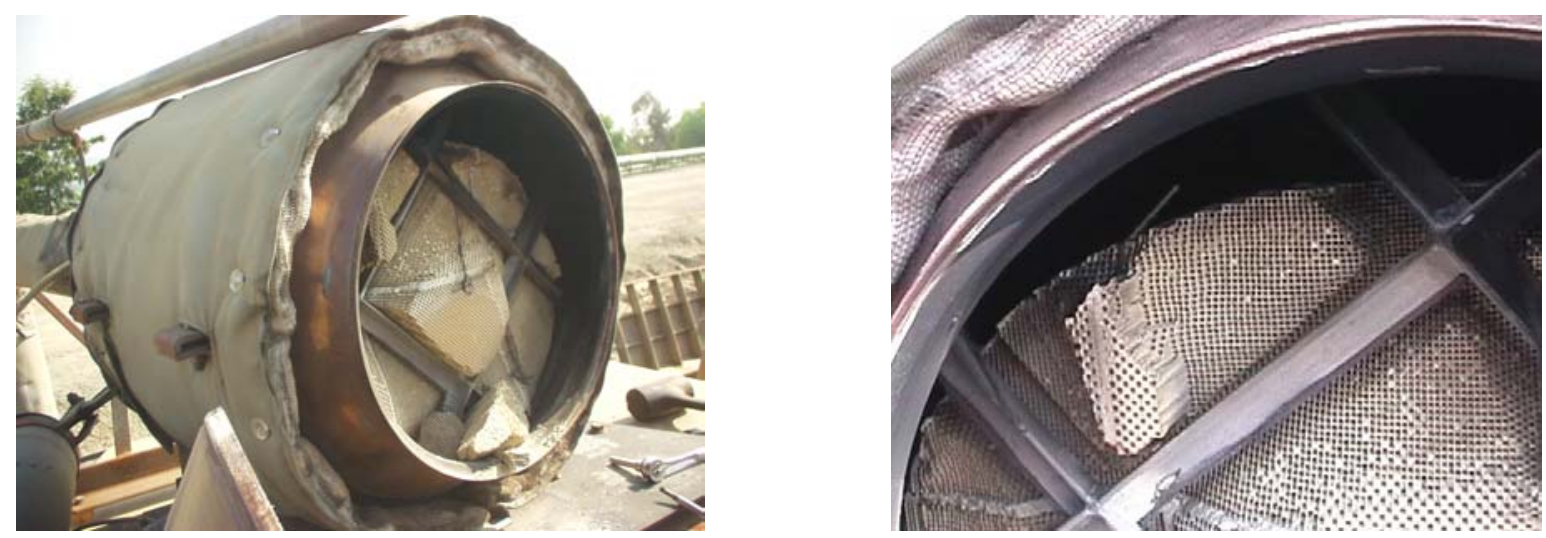

Figure 4.43: Filter damage on Engelhard trap

9. Stress analysis conducted by Donaldson (results will be available in a future report on the AQMD off road trap study) on the filters showed that the inertia of the catalytic ceramic is greater, as is the ratio of the mass to the bonding surface area. The duty cycles of offroad construction equipment provide greater shocks and heavier vibrations than are found in on-road vehicles. Careful attention to manufacturing techniques will be needed to produce a commercial product for off-road applications. 


\section{CHAPTER 5 CONCLUSIONS}

During the year long in-field evaluation of Johnson-Matthey and Engelhard DPFs, satisfactory results have been obtained in terms of their performance. The areas of particular concern have been the durability, and the mechanical fixtures needed to mount the cumbersome traps on the vehicles. This thesis has focused on the emissions results with respect to the DPFs, in particular the DPFs that were used with CAT 3408 engines on scrapers. The results presented herein are limited to the performance of the CAT 3408 retrofitted with the CRT and DPX traps. A future report on the AQMD off road trap study should present all the results from the in-field study.

Table 5.1: Status summary for traps and construction vehicles as of August 2003

\begin{tabular}{|c|c|c|c|c|c|c|c|}
\hline Opr & Equip Type & Eq\# & $\begin{array}{l}\text { Engine Type/ } \\
\text { Installation }\end{array}$ & DPF Type & $\begin{array}{l}\text { Trap } \\
\text { Mfr }\end{array}$ & Date Installed & $\begin{array}{c}\text { Estimated } \\
\text { Hours by } \\
8 / 31 / 03\end{array}$ \\
\hline CSD & 657E scraper & 6604 & 3412 (Front) & 15X15 CRT (2) & $\overline{J M}$ & $10 / 7 / 02$ & 998 \\
\hline CSD & 657E scraper & 6604 & 3408 (Rear) & 20X15 CRT & $\mathrm{JM}$ & $10 / 7 / 02$ & 917 \\
\hline CSD & D9N dozer mec & 6621 & 3408 & 20X15 CRT & $\mathrm{JM}$ & $6 / 17 / 03$ & 251 \\
\hline CSD & D9N dozer elec & 6655 & 3408 & 20X15 CRT & $\mathrm{JM}$ & $5 / 23 / 03$ & 410 \\
\hline Poss & 824B dozer & 407 & D343 & 15X15 CRT & JM & |11/21/02 & (766 by $6 / 26)$ \\
\hline Poss & 834A dozer & 409 & 3408 & 15X15 CRT & $\mathrm{JM}$ & $11 / 25 / 02$ & $(675$ by $6 / 26)$ \\
\hline Poss & 651B scraper & 605 & D346 & 20X15 CRT & $\mathrm{JM}$ & $11 / 25 / 02$ & (386 by $4 / 22)$ \\
\hline CSD & 657E scraper & 6605 & 3412 (Front) & DPX 20X15 (2) & Eng & $3 / 11 / 03$ & 693 \\
\hline CSD & 657E scraper & 6605 & 3408 (Rear) & DPX 20X15 & Eng & $3 / 11 / 03$ & 693 \\
\hline CSD & 657E scraper & 6606 & 3412 (Front) & DPX 20X15 (2) & Eng & $3 / 7 / 03$ & 778 \\
\hline CSD & 657E scraper & 6606 & 3408 (Rear) & DPX 20X15 & Eng & $3 / 7 / 03$ & 778 \\
\hline CSD & D9N dozer elec & 6654 & 3408 & DPX 20X15 & Eng & $3 / 8 / 03$ & $(381$ by $5 / 22)$ \\
\hline Poss & 651B scraper & 625 & D346 & DPX 20X15 & Eng & $3 / 11 / 03$ & 545 \\
\hline Poss & 651B scraper & 628 & D346 & DPX 20X15 & Eng & $3 / 11 / 03$ & 531 \\
\hline Poss & 825C dozer & 415 & D3406 & DPX 15X15 & Eng & $4 / 26 / 03$ & 451 \\
\hline CSD & 657E scraper & 6607 & 3412 (Front) & Control (CARB- & None & $10 / 2 / 02$ & 958 \\
\hline CSD & 657E scraper & 6607 & 3408 (Rear) & Control (CARB- & None & $10 / 2 / 02$ & 958 \\
\hline CSD & 657E scraper & 6608 & 3412 (Front) & Control (ULSD) & None & $10 / 8 / 02$ & 1109 \\
\hline CSD & 657E scraper & 6608 & 3408 (Rear) & Control (ULSD) & None & $10 / 8 / 02$ & 1109 \\
\hline CSD & D9N dozer mec & 6620 & 3408 & Control (CARB- & None & $10 / 17 / 02$ & 1387 \\
\hline CSD & D9N dozer elec & 6653 & 3408 & Control (ULSD) & None & $10 / 1 / 02$ & 1653 \\
\hline
\end{tabular}

The 2007 standards set forth by the EPA for PM is $0.15 \mathrm{~g} / \mathrm{bhp}-\mathrm{hr}, \mathrm{NO}_{\mathrm{x}}$ is $4.0 \mathrm{~g} / \mathrm{bhp}-\mathrm{hr}$.

The PM emission standard will take full effect in the 2007 heavy-duty engine model year. The 
$\mathrm{NO}_{\mathrm{x}}$ and NMHC standards will phase-in for diesel engines between 2007 and 2010 (PM - 0.01 g/bhp-hr, NOx - $0.3 \mathrm{~g} / \mathrm{bhp}-\mathrm{hr}$ ). Diesel fuel of maximum $15 \mathrm{ppm}$ sulfur (currently $500 \mathrm{ppm}$ ) will be required beginning mid-2006.

The data generated by this study will be used in evaluating the performance of DPFs during the second round of testing. Since the ability of the DPFs in reducing emissions in general, and PM emissions in particular, was of prime concern, it can be concluded that the DPFs were very effective in achieving the objective. All the retrofit configurations generated less than $0.02 \mathrm{~g} / \mathrm{bhp}-\mathrm{hr}$ of average PM emissions, both steady state and transient. Hence, the retrofits not only fulfill the 2006 emission non-road standards requirements, but also come close to meeting the 2010 emissions standards.

The only requirement for the proper operation of the DPFs is the use of low sulfur diesel. The speed and load variations of the transient cycle did not affect the performance of DPFs.

Results from the steady state and transient cycles showed significant differences. PM emissions were $14 \%$ lower for transient than steady state cycles, and the $\mathrm{HC}$ emissions for transient operation were $97 \%$ lower than for steady state cycle. In most of the test configurations, the 8-mode weighted average emissions were greater than the transient average emissions, though the results were within the standards. The 8-mode cycle does not cover all aspects of in-field vehicular activity typical of scraper application. Hence, the steady state tests cannot be used to directly verify the in-field emissions activity of non-road diesel engines. These results are in agreement with the findings of Barnett [9] and Carder [11].

The measurable filter mass on some configurations was so low that quantification of PM mass was a challenge.

The R100 and Idle modes were extreme cases of highest and lowest loading of PM, respectively. 


\section{$5.1 \quad$ RECOMMENDATIONS}

1. Extensive research is needed in developing cycles that represent real world off-road equipment activities. A transient cycle closely representing the maximum vehicle in-field activity should be developed.

2. Filter weight measurement needs a new improved method, because the post trap filter face weight is a bare minimum and hence is extremely difficult to quantify.

3. During the second round of the engine testing, care must be taken to clean the filters thoroughly before testing. This is due to the accumulation of soot in the filters after being run for a long time, which could in turn increase the backpressure on the engine.

4. An in-depth study into the exhaust temperatures and backpressure values should provide vital information on the performance of the traps. The results can used to make any necessary changes in the transient cycle.

5. The blower capacity in the stationary laboratory needs to be increased to increase the dilution ratio during overheating of the exhaust gases due to high loads and high engine horsepower.

\subsection{FUTURE RESEARCH}

The traps are currently being used in-field accumulating 1400 hours of operation. After the year-long testing, they will be shipped to WVU for a second round of laboratory testing which is scheduled for Fall 2003. The entire experimental procedure will be repeated and the data generated will be compared with the results published herein. The results should essentially match up in terms of the percentage reductions of emissions. The comparison will give a true picture of the durability of the traps in reducing emissions, PM in particular, over prolonged operation. The EPA is currently evaluating catalyzed traps, oxidation catalysts, $\mathrm{NO}_{\mathrm{x}}$ adsorbers, 
and selective catalytic reduction systems as after-treatment methodologies to be implemented in 2007 and later model year engines.

Since the duty cycles of off-road construction equipment provide greater shocks and heavier vibrations than are found in on-road vehicles, careful attention to manufacturing techniques will be needed to produce a commercial DPF specifically for off-road applications. 


\section{REFERENCES}

1. "Diesel Emissions,” www.epa.gov, 2002.

2. Code of Federal Regulations, Title 40 Part 89, U.S. Government Printing Office, Washington, DC, 2001.

3. Emission Test Cycles, www.dieselnet.com.

4. "Voluntary Diesel Retrofit Program,” www.arb.ca.gov, 2002.

5. LeTavec, C., Uihlien, J., Vertin, K., Chatterjee, S., Hallstrom, K., Wayne, S., Clark, N., Lyons, D., Chandler, K. and Coburn, T., "Year-Long Evaluation of Trucks and Buses Equipped with Passive Diesel Particle Filters," SAE Technical Paper 2002-01-0433, 2002.

6. http://www.healtheffects.org/Pubs/DieselProgSumm-C.pdf, Cambridge, MA, 1999.

7. Khair, M.K., "Technical and Synergistic Approaches Towards the Twenty-First Century Diesel Engine," SAE Technical Paper 972687, 1997.

8. NESCAUM, "Heavy Duty Engine Emissions in the North East States for Coordinated Air Use Management," Boston, MA, 1997.

9. Barnett, R.A., "Characterization of Infield Vehicle Activity Data and Exhaust Emissions from Diesel Powered Off-Road Vehicles," M.S. Thesis, Department of Mechanical and Aerospace Engineering, West Virginia University, Morgantown, WV, 2001.

10. Rohrbaugh, J.C., "Characterization of Infield Duty Cycles and Exhaust Emissions from Diesel Powered Off-Road Heavy-Duty Equipment," M.S. Thesis, Department of Mechanical and Aerospace Engineering, West Virginia University, Morgantown, WV, 2002. 
11. Carder, D.K, Gautam, M., Thompson, G.J, and Barnett, R.A., "Determination of In-Use Brake-Specific Emissions from Off-Road Equipment Powered by Mechanically Controlled Diesel Engines," SAE Paper 02SFL-170, 2001

12. Cadle, S. H., Gorse, Jr. R. A., Bailey, B.K., and Lawson, D.R., "Real world Vehicle Emissions: A Summary of the Eleventh Coordinating Research Council On-road Vehicle Emissions Workshop,” Journal of Air and Waste Water Management, Vol. 52, 2002.

13. Cadle, S. H., Gorse, Jr. R. A., Bailey, B.K., and Lawson, D.R., "Real world Vehicle Emissions: A Summary of the Ninth Coordinating Research Council On-road Vehicle Emissions Workshop,” Journal of Air and Waste Water Management, Vol. 51, 2001.

14. Jiang, Q and Van Gerpen, J.H., "Prediction of Diesel Engine Particulate Emissions During Transient Cycles,” SAE Paper 920466, 1992.

15. Balek, S.J and Heitzman, R.C, "Caterpillar 3406E Heavy-duty Diesel Engine," SAE Technical Paper 932969, 1993.

16. Mano, T., Kawasaki, T and Miyakawa, K., "Development of Low-Fuel Consumption, High-durability, Low-emissions J-Series Engines," SAE Technical Paper 1999-01-0830, 1999.

17. McCarthy, C.I., Slodowske, W. J., Sienicki, E.J. and Jass, R.E, "Diesel Fuel Property Effects on Exhaust Emissions from a Heavy Duty Diesel Engine That Meets 1994 Emissions Requirements,” SAE Technical Paper 922267, 1992.

18. Siewert, R. M., Krieger, R. B., Huebler, M. S., Baruah, P. C., Khalighi, B., and Wesslau, M., "Modifying an Intake Manifold to Improve Cylinder-to-Cylinder EGR Distribution in a DI Diesel Engine Using Combined CFD and Engine Experiments," SAE Paper 200101-3685, 2001.

19. Browning, L. H., “Technologies and Costs for On-Road Heavy-Duty Engines Meeting 2004 Emissions Standards,”, SAE Paper 973256, 1997. 
20. Su, T.F., Chang, C., Reitz, R., Farrell, P., Pierpont, A., and Tow, T., "Effects of Injection Pressure and Nozzle Geometry on Spray SMD and D.I. Emissions,” SAE Paper 952360, 1995.

21. "Diesel Emission Control Strategies Verification," www.arb.ca.gov/diesel/verifieddevices.

22. Khair, M. and McKinnon, D.L., "Performance Evaluation of Advanced Emission Control Technologies for Diesel Heavy-Duty Engines," SAE Technical Paper 1999-01-3564, 1999.

23. Diesel Particulate Filter CRT, www.jmcsd.com.

24. DPX Soot Filter, www.engelhard.com

25. DECSE, 2000a. “Phase I Interim Data Report No.4: Diesel Particulate Filters,” U.S.DOE, January 2000.

26. Allansson, R., Blakeman, P. G., Cooper, B. J., Phillips, P. R., Thoss, J. E., and Walker, A. P., "The Use of the Continuously Regenerating Trap $\left(\mathrm{CRT}^{\mathrm{TM}}\right)$ to Control Particulate Emissions: Minimizing the Impact of Sulfur Poisoning,” SAE Paper 2002-01-1271, 2002.

27. Clark, N. N., Atkinson, C.M., Thompson, G.J., and Nine, R.D., “Transient Emissions Comparisons of Alternative Compression Ignition Fuels," SAE Paper 1999-01-1117, 1999.

28. Schaberg, L., Myburgh, I., Botha, J., Roets, P., Viljoen, C., Dancuart, L., and Starr, M., "Diesel Exhaust Emissions Using Sasol Slurry Distillate Process Fuels," SAE Paper 972898, 1997.

29. Norton, P., Vertin, K., Bailey, B., Clark, N., Lyons, D., Goguen, S., and Eberhardt,J., “Emissions from Trucks Using Fischer-Tropsch Diesel Fuel,” SAE Paper 982526, 1998.

30. Mayer, A., Czerwinski, J., Legerer, F., and Wyser, M., "VERT Particulater Trap Verification," SAE Paper 2002-01-0435, 2002. 
31. "Exhaust Emission Controls Available to Reduce Emissions from Non-road Diesel Engines," Manufacturers of Emission Controls Association, April 2003.

32. Hashimoto, S., Miyairi, Y., Hamanaka, T., Matsubara, R., Harada, T., and Miwa, S., "SiC and Cordierite Diesel Particulate Filters Designed for Low Pressure Drop and Catalyzed, Uncatalyzed Systems,” SAE Paper 2002-01-0322, 2002.

33. Ohno, K., Taoka, N., Furuta, T., Kudo, A., and Komori, T, "Characterization of High Porosity SiC-DPF," SAE Paper 2002-01-0325, 2002.

34. Blanchard, G., Sequelong, T., Michelin, J., Schuerholz, S., and Terres, F., "Ceria-based, Fuel-borne Catalysts for Series Diesel Particulate Filter Regeneration,” SAE Paper 200301-0378, 2003.

35. "Demonstration of Advanced Emission Control Technologies Enabling Diesel-Powered Heavy-Duty Engines to Achieve Low Emission Levels," Final Report, Manufacturers of Emission Controls Association, June 1999.

36. Luders, H., Stommel, P., and Backes, R., “Application for the Regeneration of Diesel Particulate Traps by Combining Different Regeneration Systems," SAE Paper 970470, 1997.

37. Konstandopoulos, A.G., and Kostoglou, M., "Periodically Reversed Flow Regeneration of Diesel Particulate Traps,” SAE Paper 1999-01-0469, 1999.

38. Meinig, U., Spies, K.-H., and De Bruyne, R., "Tests on a New Diesel Particulate System with Traps of Metal Fleece,” SAE Paper 982597, 1998.

39. Matsunuma, K., Ihara, T., Hanamoto, Y., Nakajima, S., and Okamoto, S., "Development of Diesel Particulate Filter Made of Porous Metal,” SAE Paper 960132, 1996.

40. Dinesen, J., Nissen, S. S., and Christensen, H., "Electrochemical Diesel Particulate Filter,” SAE Paper 980547, 1998. 
41. Romero, A. F., Pech, R., Arambula, G., Hernandez, G., and Teutle, J., "Heavy Duty Diesel Engines Emissions Reduction through Filtering and Catalytic Combustion," SAE Paper 980538, 1998.

42. Majewski, W. A, and Martin, E. P., "Diesel Particulate Filter with a Disposable Pleated Media Paper Element,” SAE Paper 930370, 1993.

43. Mayer, A., Buck, A., and Bressler, H., "The Knitted Particulate Trap: Field Experience and Development Progress,” SAE Paper 930362, 1993.

44. Fanick, E.R., Schubert, P. F., Russell, B. J., and Freerks, R. L., " Comparison of Emission Characteristics of Conventional, Hydro treated, and Fischer-Tropsch Diesel Fuels in a Heavy-Duty Diesel Engine," SAE Paper 2001-01-3519, 2001.

45. McMillian, M.H., Gautam, M., "Consideration of Fischer-Tropsch Derived Liquid Fuels as a Fuel Injection Emission Control Parameter," SAE Paper 982489, 1998.

46. Liang, C. Y., Baumgard, K. J., Gorse, Jr. R. A., Orban, J. E., Storey, J. M. E., Tan, J. C., Thoss, J. E., and Clark, W., "Effects of Diesel Fuel Sulfur Level on Performance of a Continuously Regenerating Diesel Particulate Filter and a Catalyzed Particulate Filter," SAE Paper 2000-01-1876, 2000.

47. Clark, N.N., Daley, J.J., Nine, R.D., and Atkinson, C.M., "Application of the New CitySuburban Heavy Vehicle Route (CSHVR) to Truck Emissions Characterizations," SAE Paper 1999-01-1467, 1999.

48. Non-road Engine, Equipment and Vehicles, www.epa.gov.

49. Ulmet, V., White, J. J., Stout, A., Salardino, D., "Development of a Transient Duty Cycle for Large Non-road SI Engines,” SAE Paper 2002-01-1716, 2002.

50. Ullman, T. L., Webb, C. C., Jackson, Jr. C. C., and Doorlag, M. H., "Non-road Engine Activity Analysis and Transient Cycle Generation,” SAE Paper 1999-01-2800, 1999. 
51. Samulski, M. J. and Jackson, C. C., "Effects of Steady-State and Transient Operation on Exhaust Emissions from Non-road and Highway Diesel Engines," SAE Paper 982044, 1998.

52. Sensors Microbench, http://www.sensors-inc.com/pdfs/AMBII.pdf.

53. Ferguson, D.H., "Design, Fabrication and Testing of an Emissions Measurement System for a Transportable Heavy Duty Vehicle Emissions Testing Laboratory,” M.S. Thesis, Department of Mechanical and Aerospace Engineering, West Virginia University, Morgantown, WV, 1993.

54. Chasey, T.D., "Design and Data Acquisition and Control System Hardware and Software for Transportable Emissions Testing Laboratory,” M.S.Thesis, Department of Mechanical and Aerospace Engineering, West Virginia University, Morgantown, WV, 1992.

55. Pei, Y., "Development of Software for the Heavy-Duty Engine Testing at Engine Research Center," M.S. Thesis, Department of Mechanical and Aerospace Engineering, West Virginia University, Morgantown, WV, 1993.

56. Rosemount Analytical Model $955 \mathrm{NO} / \mathrm{NO}_{\mathrm{x}}$ Analyzer Product Data Sheet, 1992, Rosemount Analytical Inc., La Habra, California.

57. Rosemount Analytical Model 402 Hydrocarbon Analyzer Product Data Sheet, 1992, Rosemount Analytical Inc., La Habra, California.

58. Reschke, G.D., "Optimization of a Flame Ionization Detector for Determination of Hydrocarbon in Diluted Automotive Exhausts," SAE Paper 770141, 1977.

59. Rosemount Analytical Model 868/880 NDIR Analyzer Product Data Sheet, 1992, Rosemount Analytical Inc., La Habra, California.

60. Norton, P., Vertin, K., Bailey, B., Clark, N., Lyons, D., Goguen, S. and Eberhardt, J., "Emissions from Trucks Using Fischer-Tropsch Diesel Fuel," SAE Technical Paper $982526,1998$. 
61. Clark, N.N., Boyce, J.E., Xie, W., Gautam, M., and Lyons, D.W., "Class 8 Trucks Operating on Ultra-Low Sulfur Diesel With Particulate Filter Systems: Regulated Emissions," SAE Paper 2000-01-2815, 2000.

62. Owen and Coley, “Automotive Fuels Handbook,” SAE International, 1990.

63. Thompson, G.J., Clark, N.N., Gautam, M., Carder, D.K., and Lyons, D.W., "Inference of Torque and Power from Heavy-Duty Diesel Engines for On-road Emissions Monitoring," SAE Paper 2002-01-0614, 2002.

64. "NIST at a Glance", www.nist.gov. 


\section{APPENDICES}

\section{APPENDIX A}

ADDITIONAL DATA FOR THE 657E SCRAPER - SPECIFICATIONS OF THE

TRACTOR AND SCRAPER ENGINE

\begin{tabular}{|c|c|}
\hline Vehicle Number & $86 Z 0199$ \\
\hline Arrangement Number & $2 \mathrm{~W} 0165$ \\
\hline Test Number & 0901079 \\
\hline DLR Code & $\mathrm{H} 430$ \\
\hline \multicolumn{2}{|l|}{ Tractor Engine } \\
\hline Tractor Engine & $3412 / 3408 \mathrm{E}$ \\
\hline Gross Power-Gears 1-2 & $430 \mathrm{KW}(577 \mathrm{Hp})$ \\
\hline Gross Power-Gears 3-8 & $472 \mathrm{KW}(632 \mathrm{Hp})$ \\
\hline Caterpillar Net Power & $410 \mathrm{KW}(550 \mathrm{Hp})$ \\
\hline SAE J1349 & $406 \mathrm{KW}(544 \mathrm{Hp})$ \\
\hline Bore & $137 \mathrm{~mm}$ (5.4 in.) \\
\hline Stroke & $152 \mathrm{~mm}$ (6 in.) \\
\hline Displacement & $27 \mathrm{~L}\left(1649 \mathrm{in}^{3}\right)$ \\
\hline \multicolumn{2}{|l|}{ Scraper Engine } \\
\hline Net Power-Gear 1 & $298 \mathrm{KW}(400 \mathrm{Hp})$ \\
\hline Gross Power-Gear 1 & $312 \mathrm{KW}(418 \mathrm{Hp})$ \\
\hline Caterpillar Net Power & $298 \mathrm{KW}(400 \mathrm{Hp})$ \\
\hline SAE J1349 & $295 \mathrm{KW}(396 \mathrm{Hp})$ \\
\hline Bore & $137 \mathrm{~mm}$ (5.4 in.) \\
\hline Stroke & $152 \mathrm{~mm}$ (6 in.) \\
\hline Displacement & $18 \mathrm{~L}\left(1099 \mathrm{in}^{3}\right)$ \\
\hline \multicolumn{2}{|l|}{ Scraper Bowl } \\
\hline Headed Capacity & $33.6 \mathrm{~m}^{3}\left(44 \mathrm{yd}^{3}\right)$ \\
\hline Rated Load & $47174 \mathrm{Kg}(104000 \mathrm{lbs})$ \\
\hline Maximum Depth of Cut & $440 \mathrm{~mm}$ (17.3 in.) \\
\hline
\end{tabular}


APPENDIX B

TRANSIENT CYCLE ENGINE SPEED AND TORQUE DISTRIBUTION USING ECD1 DIESEL

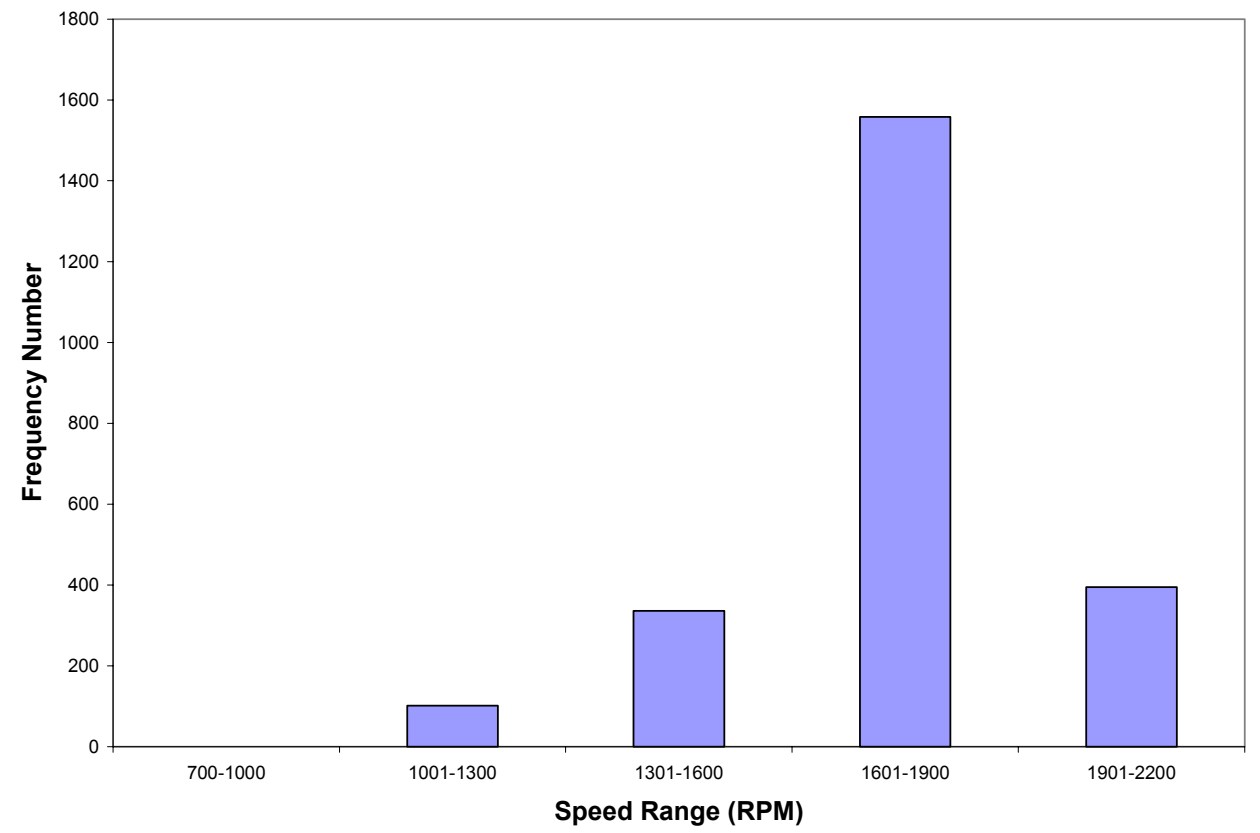

Figure C1: Representative engine speed frequency distribution, $300 \mathrm{rpm}$ increments

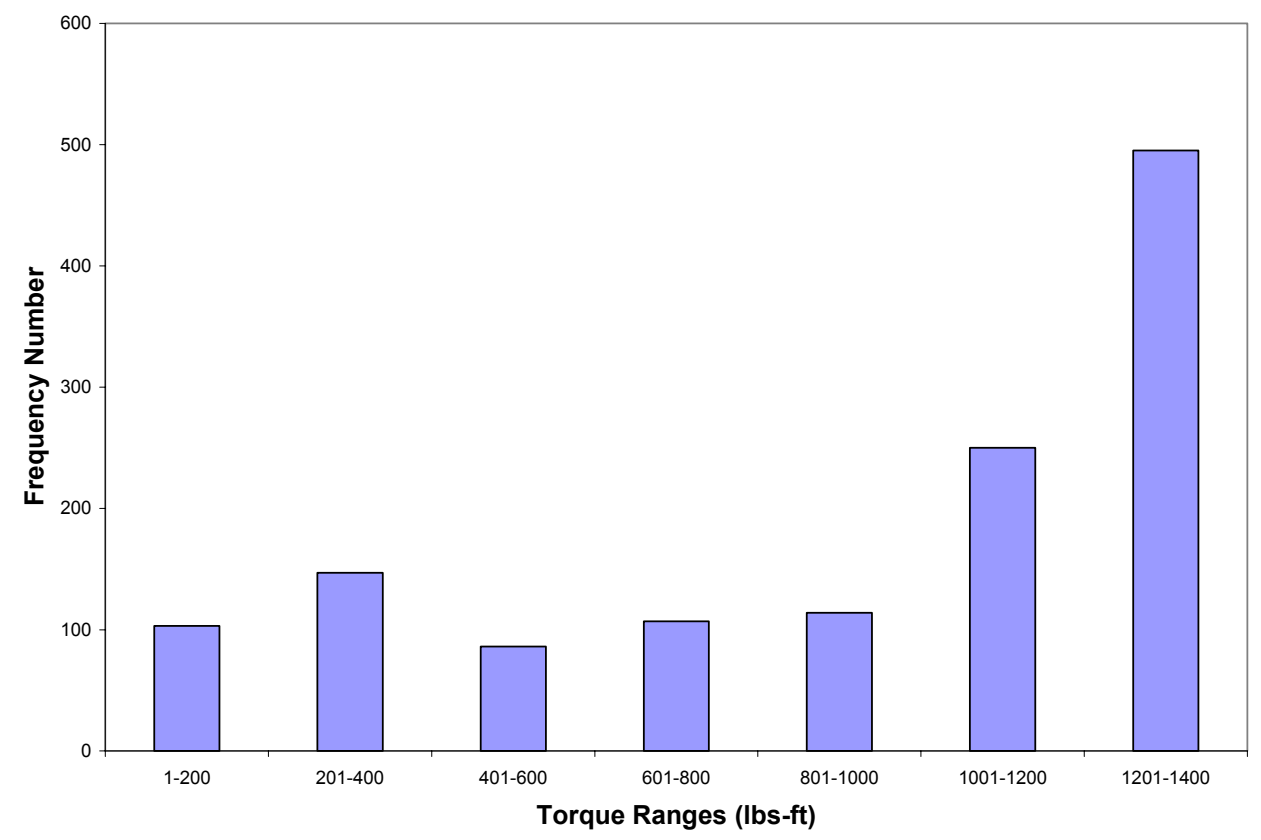

Figure C2: Representative engine torque frequency distribution 


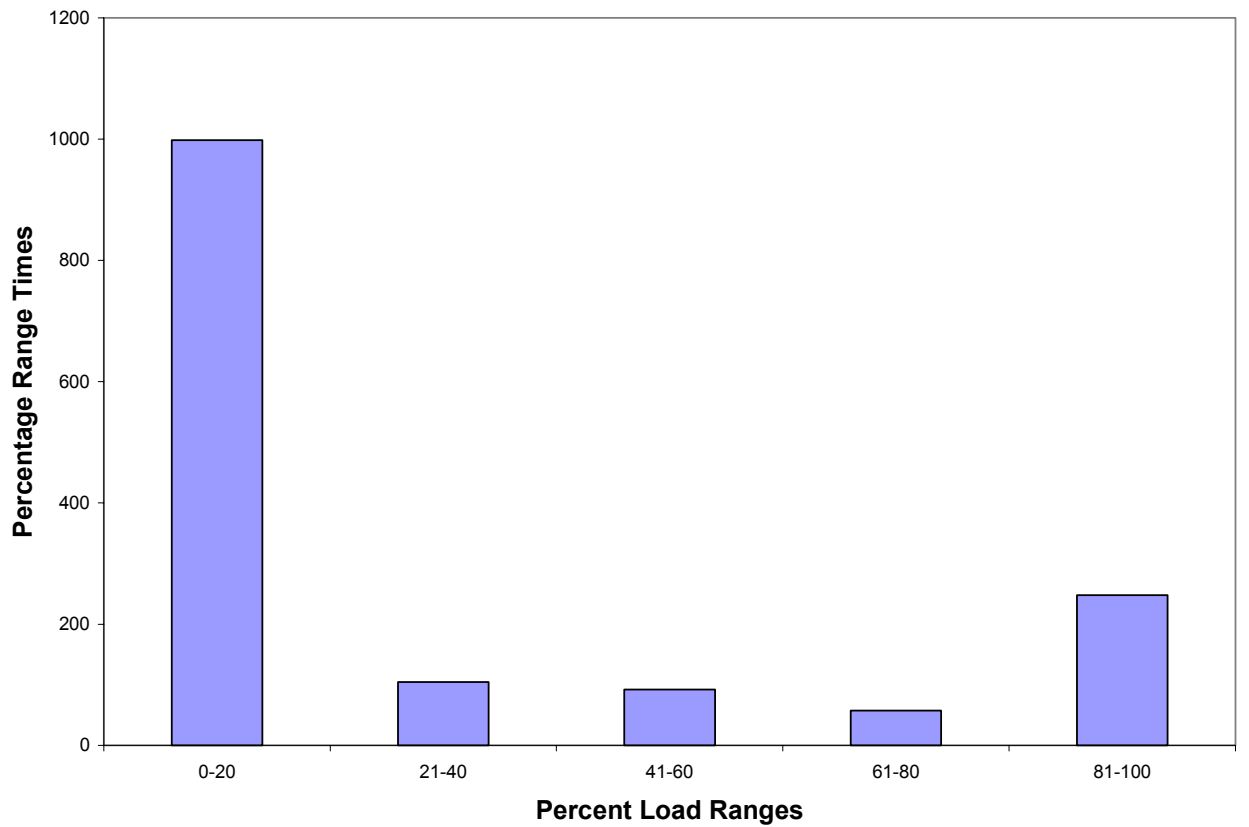

Figure C3: Percentage of total cycle time for load ranges versus percent load range in the selected test cycle

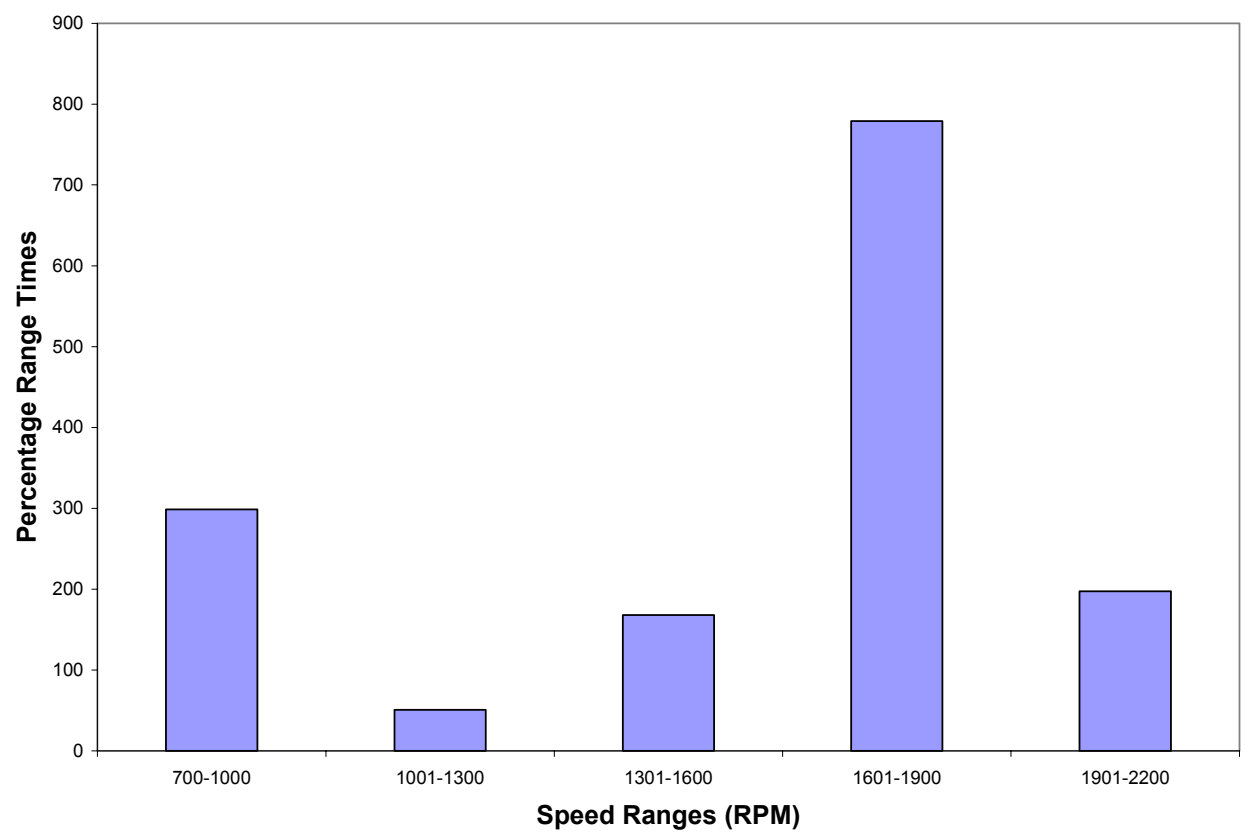

Figure C4: Percentage of total cycle time for speed ranges versus speed ranges 


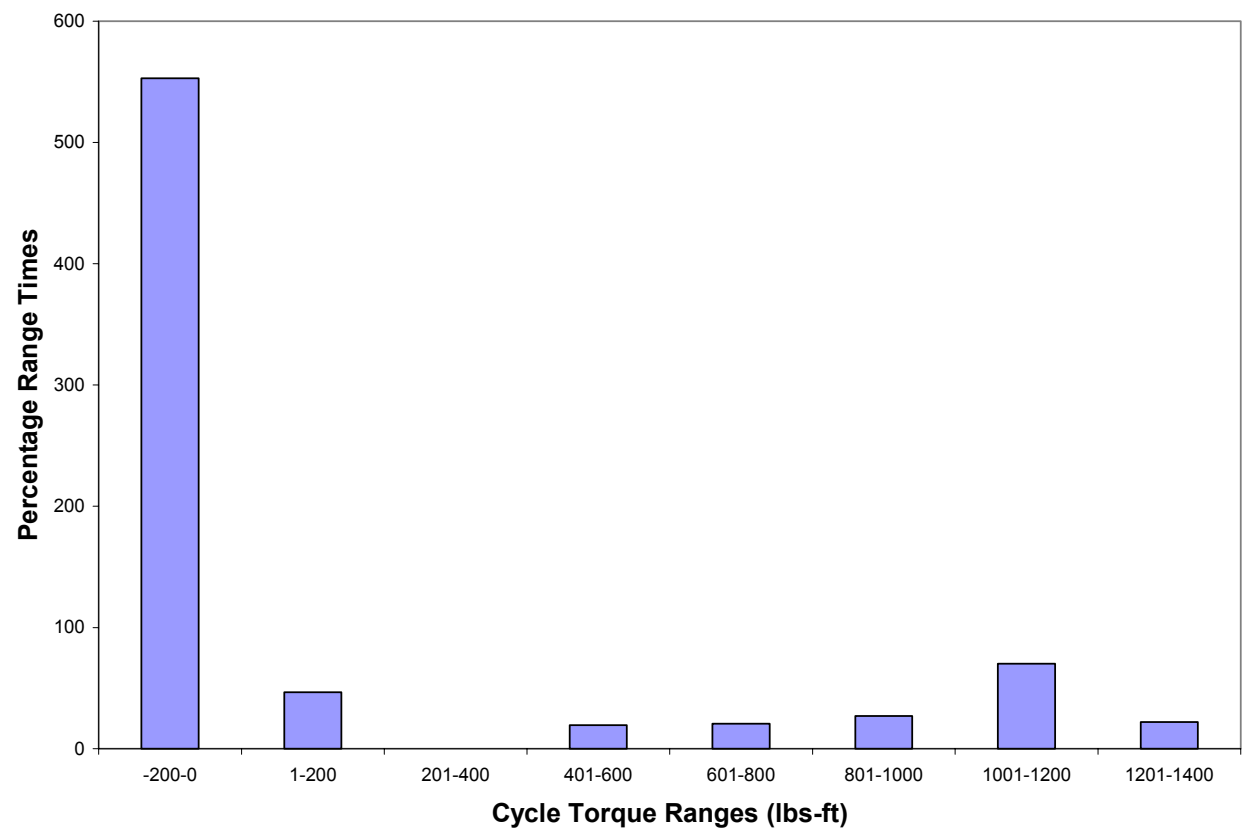

Figure C5: Percentage of total cycle time versus cycle torque ranges in the 1601-1900 rpm speed range. Total $1600-1900 \mathrm{rpm}$ time is 847.5 seconds.

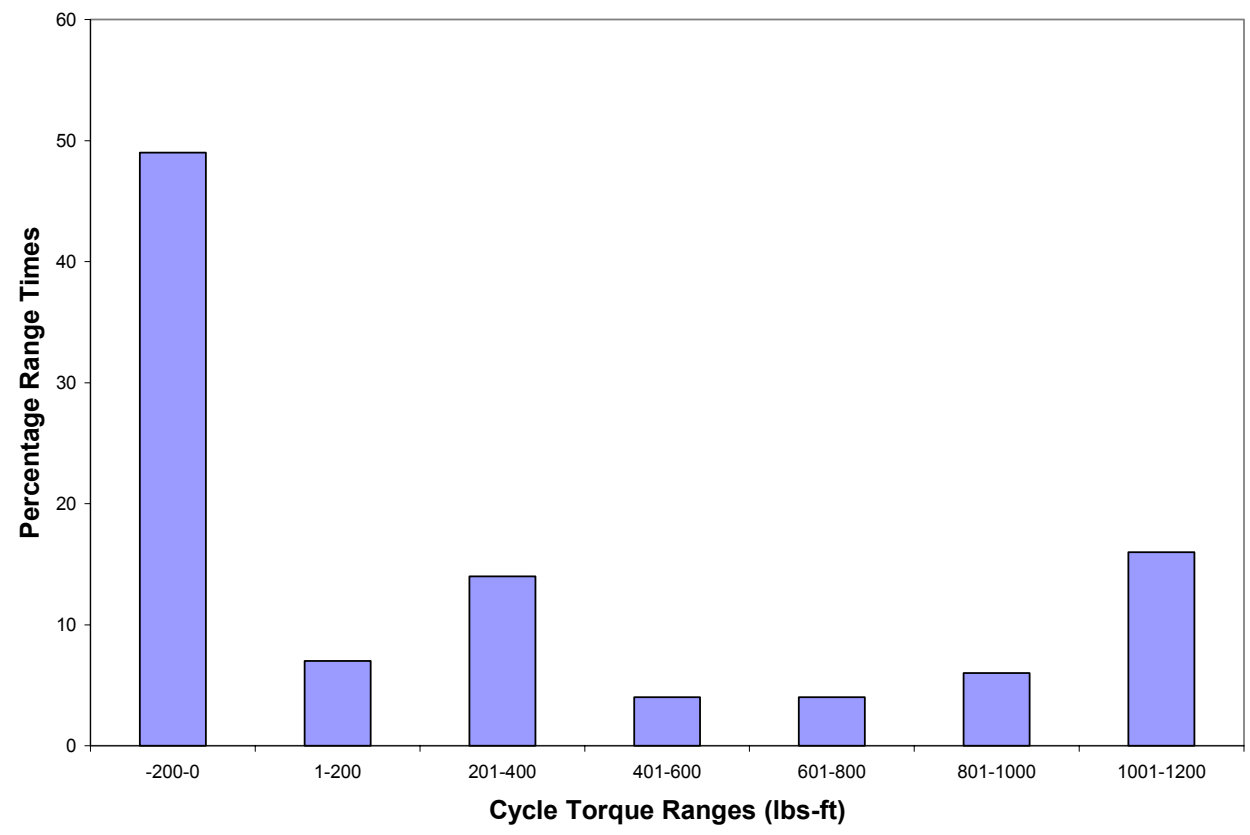

Figure C6: Percentage of total cycle time for cycle torque ranges versus cycle torque ranges in the 1901-2200 rpm speed range. 


\section{APPENDIX C}

\section{8-MODE AND TRANSIENT DATA WITH STANDARD DEVIATION AND COEFFICIENT OF VARIANCE FOR HC, CO.}

\section{NO $_{\mathrm{X}}$, AND PM RESPECTIVELY}

HC (SD - Standard Deviation (g/bhp-hr); CV - Coefficient of Variation (\%) between test runs).

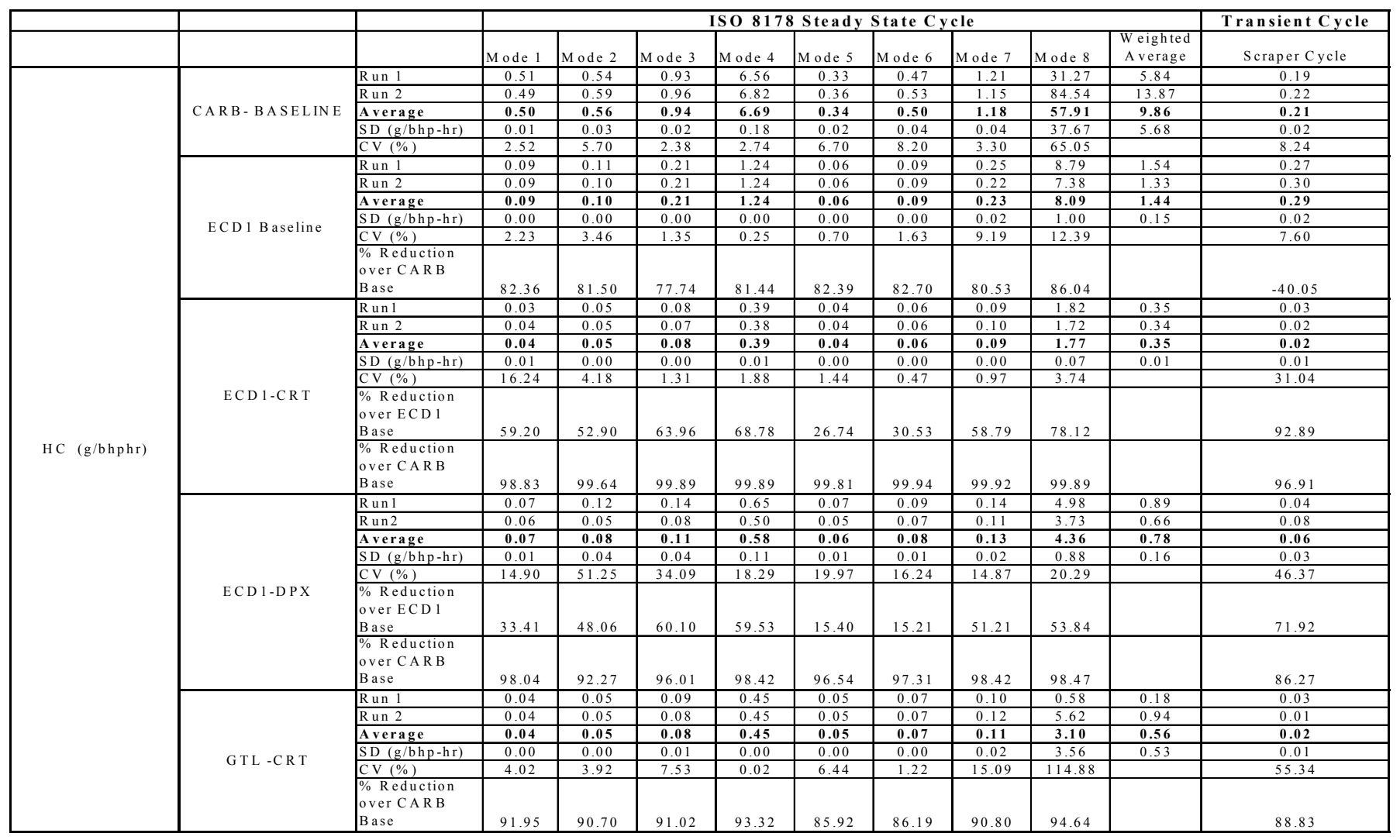




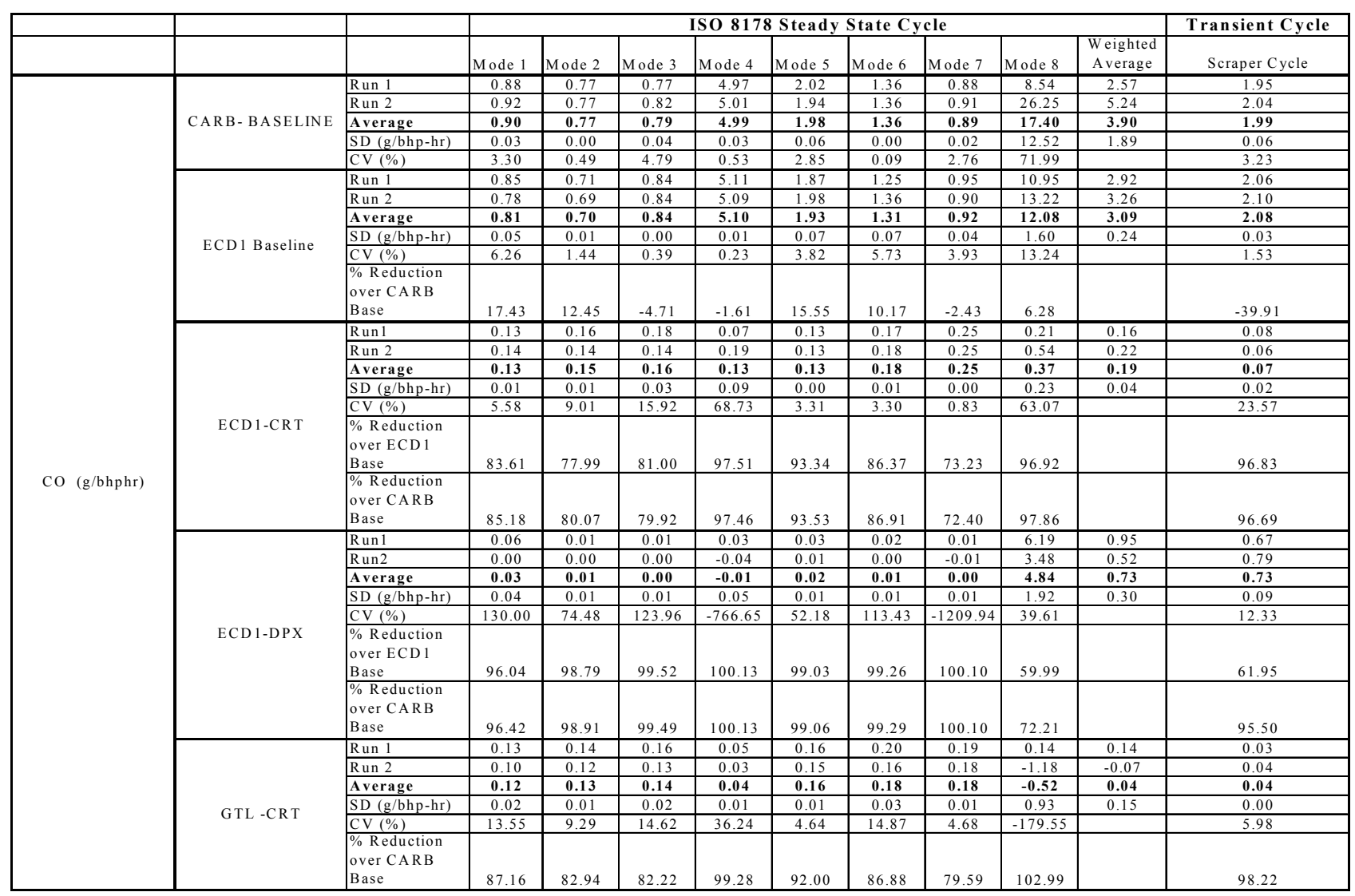


$\mathrm{NO}_{\mathrm{x}}$

\begin{tabular}{|c|c|c|c|c|c|c|c|c|c|c|c|c|}
\hline & & & & & & ISO 81 & 8 Steady & State Cy & & & & Transient Cycle \\
\hline & & & Mode 1 & Mode 2 & Mode 3 & Mode 4 & Mode 5 & Mode 6 & Mode 7 & Mode 8 & $\begin{array}{l}\text { Weighted } \\
\text { A verage }\end{array}$ & Scraper Cycle \\
\hline & & \begin{tabular}{|l|l|} 
Run 1 \\
Run?
\end{tabular} & 0.66 & \begin{tabular}{|l|l|}
0.67 \\
0.70
\end{tabular} & 0.72 & 1.11 & 0.60 & \begin{tabular}{|l|l|}
0.69 \\
\end{tabular} & 0.78 & 4.43 & 1.29 & 0.70 \\
\hline & CARB Baseline & \begin{tabular}{|l|} 
Run 2 \\
Average \\
\end{tabular} & \begin{tabular}{|l}
0.66 \\
0.66 \\
\end{tabular} & \begin{tabular}{|l|}
0.70 \\
$\mathbf{0 . 6 9}$ \\
\end{tabular} & $\begin{array}{l}0.75 \\
0.73 \\
\end{array}$ & \begin{tabular}{|l|}
1.23 \\
1.17 \\
\end{tabular} & $\begin{array}{l}0.62 \\
0.61 \\
\end{array}$ & \begin{tabular}{|l|}
0.71 \\
$\mathbf{0 . 7 0}$ \\
\end{tabular} & \begin{tabular}{|l}
0.80 \\
0.79 \\
\end{tabular} & \begin{tabular}{|l|}
9.75 \\
7.09 \\
\end{tabular} & $\begin{array}{l}2.12 \\
1.70 \\
\end{array}$ & 0.70 \\
\hline & & $\mid \frac{\text { SD }(g / h \text { hp-hr })}{\text { CV (\%) }}$ & \begin{tabular}{|l|l|}
0.00 \\
0.67 \\
\end{tabular} & \begin{tabular}{|l|}
0.02 \\
2.75 \\
\end{tabular} & $\frac{0.01}{2.02}$ & \begin{tabular}{|l}
0.08 \\
7.16 \\
\end{tabular} & \begin{tabular}{|l|}
0.01 \\
2.13 \\
\end{tabular} & \begin{tabular}{|l|l|}
0.01 \\
1.85 \\
\end{tabular} & $\begin{array}{l}0.01 \\
1.72 \\
\end{array}$ & \begin{tabular}{|l|}
3.76 \\
53.09 \\
\end{tabular} & 0.58 & 0.00 \\
\hline & & Run 1 & 0.63 & $\begin{array}{l}0.66 \\
\end{array}$ & 0.70 & 1.13 & 0.57 & \begin{tabular}{|l|l|}
0.66 \\
\end{tabular} & 0.81 & 6.38 & 1.57 & 0.61 \\
\hline & & \begin{tabular}{|l|} 
Run 2 \\
Average \\
\end{tabular} & \begin{tabular}{|l|l|}
0.62 \\
0.62 \\
\end{tabular} & \begin{tabular}{|l|}
0.64 \\
0.65 \\
\end{tabular} & $\begin{array}{l}0.70 \\
0.70 \\
\end{array}$ & \begin{tabular}{|l}
1.11 \\
1.12 \\
\end{tabular} & \begin{tabular}{|l|}
0.55 \\
0.56 \\
\end{tabular} & \begin{tabular}{|l}
0.64 \\
0.65 \\
\end{tabular} & \begin{tabular}{|l}
0.73 \\
0.77 \\
\end{tabular} & \begin{tabular}{|l|}
5.77 \\
6.08 \\
\end{tabular} & $\begin{array}{l}1.46 \\
1.52 \\
\end{array}$ & $\begin{array}{l}0.64 \\
0.62\end{array}$ \\
\hline & ECD 1 Baseline & \begin{tabular}{|l|l|} 
SD (g/hhp-hr) \\
CV (\%)
\end{tabular} & \begin{tabular}{|l|l|}
0.01 \\
0.94 \\
\end{tabular} & \begin{tabular}{|l|}
0.01 \\
2.14 \\
\end{tabular} & $\begin{array}{l}0.00 \\
0.58\end{array}$ & \begin{tabular}{|l|l|}
0.01 \\
1.19
\end{tabular} & \begin{tabular}{|l|}
0.01 \\
2.52 \\
\end{tabular} & \begin{tabular}{|l|}
0.01 \\
1.94 \\
\end{tabular} & $\begin{array}{l}0.06 \\
7.21\end{array}$ & \begin{tabular}{|l|l|}
0.43 \\
7.13
\end{tabular} & \begin{tabular}{|l|l|}
0.08 \\
\end{tabular} & $\frac{0.02}{3.40}$ \\
\hline & & \begin{tabular}{|l} 
\% Reduction \\
over CARB B \\
Base A
\end{tabular} & & & & & & & & & & \\
\hline & & \begin{tabular}{|l|} 
Buse 1 \\
Runl \\
\end{tabular} & \begin{tabular}{|l|l|}
0.78 \\
0.78 \\
\end{tabular} & \begin{tabular}{|l}
.22 \\
0.86 \\
\end{tabular} & $\begin{array}{l}\frac{4.48}{0.98} \\
\end{array}$ & $\begin{array}{l}4.29 \\
1.20 \\
\end{array}$ & $\begin{array}{l}8.99 \\
0.73 \\
\end{array}$ & \begin{tabular}{|l}
.50 \\
0.90 \\
\end{tabular} & \begin{tabular}{|l}
3.39 \\
1.03 \\
\end{tabular} & \begin{tabular}{|l|}
14.30 \\
3.07 \\
\end{tabular} & 1.24 & $\frac{10.52}{0.70}$ \\
\hline & & \begin{tabular}{|l|} 
Run 2 \\
Averag \\
\end{tabular} & \begin{tabular}{|l|l|}
0.80 \\
0.79 \\
\end{tabular} & \begin{tabular}{|l|}
0.93 \\
0.90 \\
\end{tabular} & 0.94 & $\begin{array}{l}1.23 \\
1.21 \\
\end{array}$ & \begin{tabular}{|l|}
0.74 \\
$\mathbf{0 . 7 3}$ \\
\end{tabular} & \begin{tabular}{|l|}
0.90 \\
0.90 \\
\end{tabular} & $\begin{array}{l}1.04 \\
1.04 \\
\end{array}$ & \begin{tabular}{|l|}
3.03 \\
3.05 \\
\end{tabular} & \begin{tabular}{|l}
1.25 \\
1.24 \\
\end{tabular} & 0.70 \\
\hline & & \begin{tabular}{|l|l|} 
SD (g/hhp-hr) \\
CV $(\%)$
\end{tabular} & \begin{tabular}{|l|l|}
0.01 \\
1.84 \\
\end{tabular} & \begin{tabular}{|l|}
0.05 \\
5.39
\end{tabular} & $\begin{array}{l}0.03 \\
3.48 \\
\end{array}$ & $\begin{array}{l}0.02 \\
1.84\end{array}$ & \begin{tabular}{|l|}
0.01 \\
1.12
\end{tabular} & \begin{tabular}{|l|l|}
0.01 \\
0.60
\end{tabular} & $\begin{array}{l}0.01 \\
1.11\end{array}$ & \begin{tabular}{|l|l|}
0.03 \\
0.92
\end{tabular} & 0.00 & 0.00 \\
\hline & ECD 1-CR T & \begin{tabular}{|l|} 
\% Reduction \\
over ECD 1 \\
Base \\
ose
\end{tabular} & -26.49 & \begin{tabular}{|l|l|} 
& -37.87 \\
\end{tabular} & -36.78 & -8.09 & -31.25 & \begin{tabular}{|l|l|} 
\\
\end{tabular} & -35.01 & 49.75 & & -12.00 \\
\hline NOx (g/bhphr) $\times 10$ & & $\begin{array}{l}\% \text { Reduction } \\
\text { over CARB }\end{array}$ & & & & & & & & & & \\
\hline & & Base & -18.91 & \begin{tabular}{|l}
-30.67 \\
\end{tabular} & -30.65 & -3.45 & -19.44 & -27.86 & -30.43 & 56.94 & & -0.21 \\
\hline & & $\begin{array}{l}\frac{R \text { un1 } 1}{\text { Run2 }} \\
\text { Ren }\end{array}$ & \begin{tabular}{|l|l|}
0.71 \\
0.55
\end{tabular} & \begin{tabular}{|l|}
0.77 \\
0.80
\end{tabular} & $\begin{array}{l}0.82 \\
0.87\end{array}$ & $\begin{array}{l}1.26 \\
1.30\end{array}$ & $\begin{array}{l}0.70 \\
0.71\end{array}$ & \begin{tabular}{|l|l|}
0.83 \\
0.86
\end{tabular} & $\begin{array}{ll}0.93 \\
0.96\end{array}$ & \begin{tabular}{|l|}
4.66 \\
5.20
\end{tabular} & $\begin{array}{l}1.42 \\
1.50 \\
\end{array}$ & $\begin{array}{ll}0.63 \\
0.64\end{array}$ \\
\hline & & \begin{tabular}{|l|l|} 
Average \\
SD regh
\end{tabular} & \begin{tabular}{|l}
0.63 \\
0.63 \\
\end{tabular} & \begin{tabular}{|l|}
0.79 \\
0.92
\end{tabular} & 0.85 & 1.28 & 0.71 & \begin{tabular}{|l|l|}
0.85 \\
0.82
\end{tabular} & 0.95 & \begin{tabular}{|l|}
4.93 \\
.98
\end{tabular} & \begin{tabular}{|l}
1.46 \\
1.06
\end{tabular} & 0.03 \\
\hline & & $\begin{array}{l}\mathrm{SD}(\mathrm{g} / \mathrm{n} \mathrm{p}-\mathrm{nI}) \\
\end{array}$ & \begin{tabular}{|l|l|}
0.17 \\
17.96 \\
\end{tabular} & \begin{tabular}{|l|}
.02 \\
2.70 \\
\end{tabular} & $\begin{array}{l}0.04 \\
.18 \\
\end{array}$ & 0.03 & $\frac{0.01}{0.00}$ & \begin{tabular}{|l|}
0.02 \\
2.51 \\
\end{tabular} & 0.022 & \begin{tabular}{|l}
0.08 \\
7.75 \\
\end{tabular} & & 0.91 \\
\hline & ECD 1-DPX & $\begin{array}{l}\% \text { \%eduction } \\
\begin{array}{l}\text { over EC ED 1 } \\
\text { Base }\end{array}\end{array}$ & \begin{tabular}{|l|l|} 
\\
\end{tabular} & -20.43 & -20.40 & -14.09 & -26.27 & -29.92 & -23.16 & 18.86 & & -1.92 \\
\hline & & $\begin{array}{l}\% \text { \%eduction } \\
\text { over CARB } \\
\text { Base }\end{array}$ & 4.66 & \begin{tabular}{|l|l|l|} 
\\
\end{tabular} & -15.00 & -9.19 & -14.91 & -20.17 & -18.98 & 30.47 & & 99.13 \\
\hline & & \begin{tabular}{|l|} 
Run 1 \\
Run 2 \\
\end{tabular} & \begin{tabular}{|l|l|}
0.70 \\
0.70
\end{tabular} & \begin{tabular}{|l|}
0.84 \\
0.88 \\
\end{tabular} & 0.96 & $\frac{1.04}{1.06}$ & $\begin{array}{ll}0.68 \\
0.73 \\
\end{array}$ & \begin{tabular}{|l|}
0.89 \\
0.98 \\
\end{tabular} & $\begin{array}{l}.07 \\
1.15 \\
\end{array}$ & \begin{tabular}{|l|l}
1.70 \\
12.00
\end{tabular} & $\frac{1.00}{2.57}$ & $\begin{array}{l}0.65 \\
0.65\end{array}$ \\
\hline & & Averas & 0.70 & 0.86 & 0.96 & 1.05 & 0.70 & 0.93 & 1.11 & \begin{tabular}{|l|}
6.85 \\
\end{tabular} & 1.79 & 0.05 \\
\hline & GTL-CRT & \begin{tabular}{|l} 
SD (g/hph-hr) \\
CV (\%)
\end{tabular} & \begin{tabular}{|l|l|}
0.00 \\
0.02 \\
\end{tabular} & \begin{tabular}{|l|}
0.02 \\
.57 \\
\end{tabular} & $\begin{array}{l}0.00 \\
0.11 \\
\end{array}$ & $\begin{array}{l}0.01 \\
1.20 \\
\end{array}$ & $\begin{array}{l}0.03 \\
4.47 \\
\end{array}$ & \begin{tabular}{|l|}
0.06 \\
6.94 \\
\end{tabular} & $\begin{array}{l}0.06 \\
5.21 \\
\end{array}$ & \begin{tabular}{|l|}
7.28 \\
106.32 \\
\end{tabular} & 1.11 & 0.00 \\
\hline & & $\begin{array}{l}\text { \% Revuction } \\
\text { over CARB } \\
\text { Base }\end{array}$ & -6.30 & -25.06 & -30.09 & 10.58 & -14.76 & -32.85 & -39.63 & 3.36 & & 6.35 \\
\hline
\end{tabular}


PM

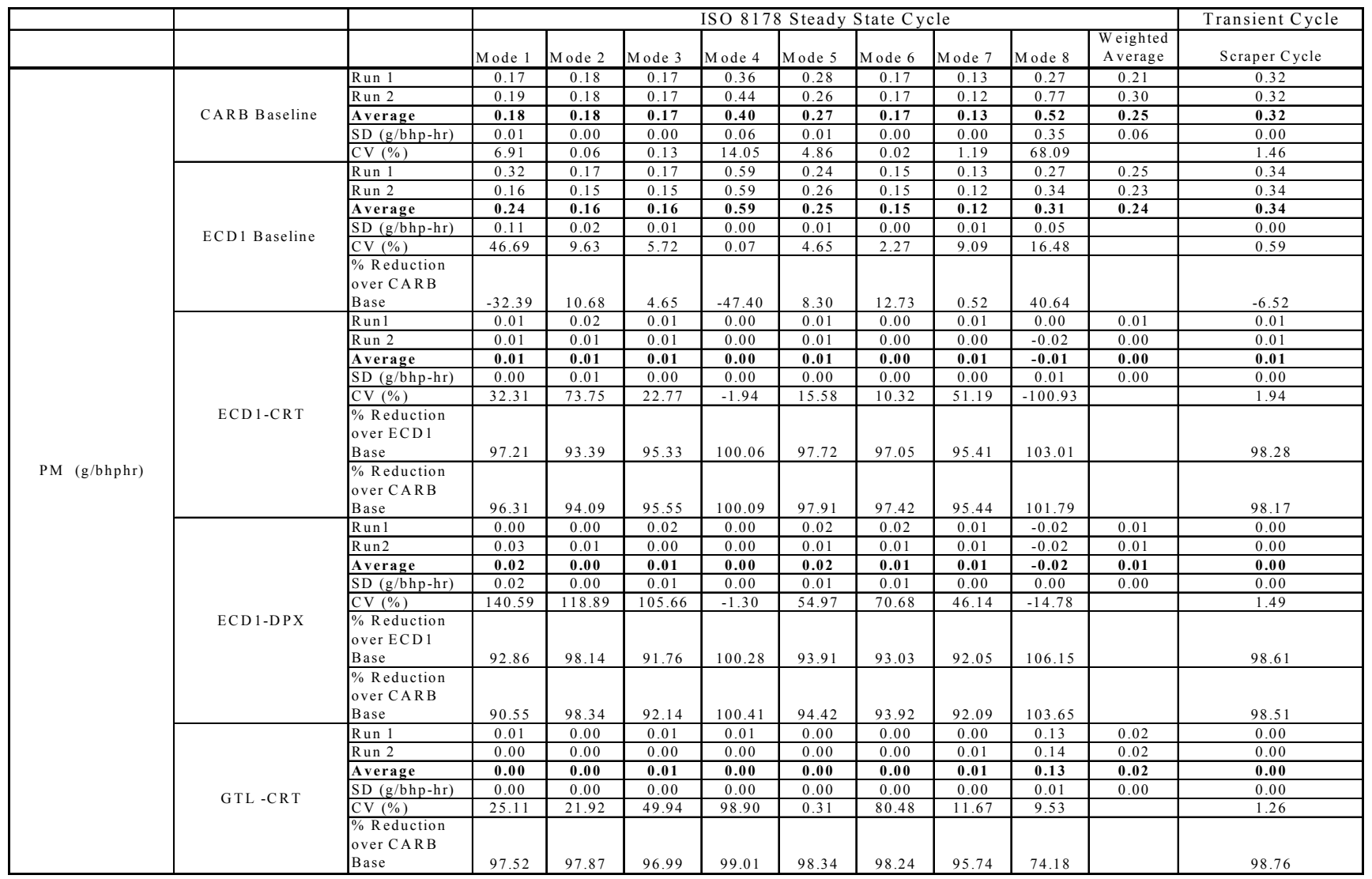




\section{APPENDIX D}

REDUCTION PERCENTAGES COMPARED TO CARB BASELINE FOR HC, CO, NO ${ }_{\mathrm{X}}$, AND PM RESPECTIVELY.

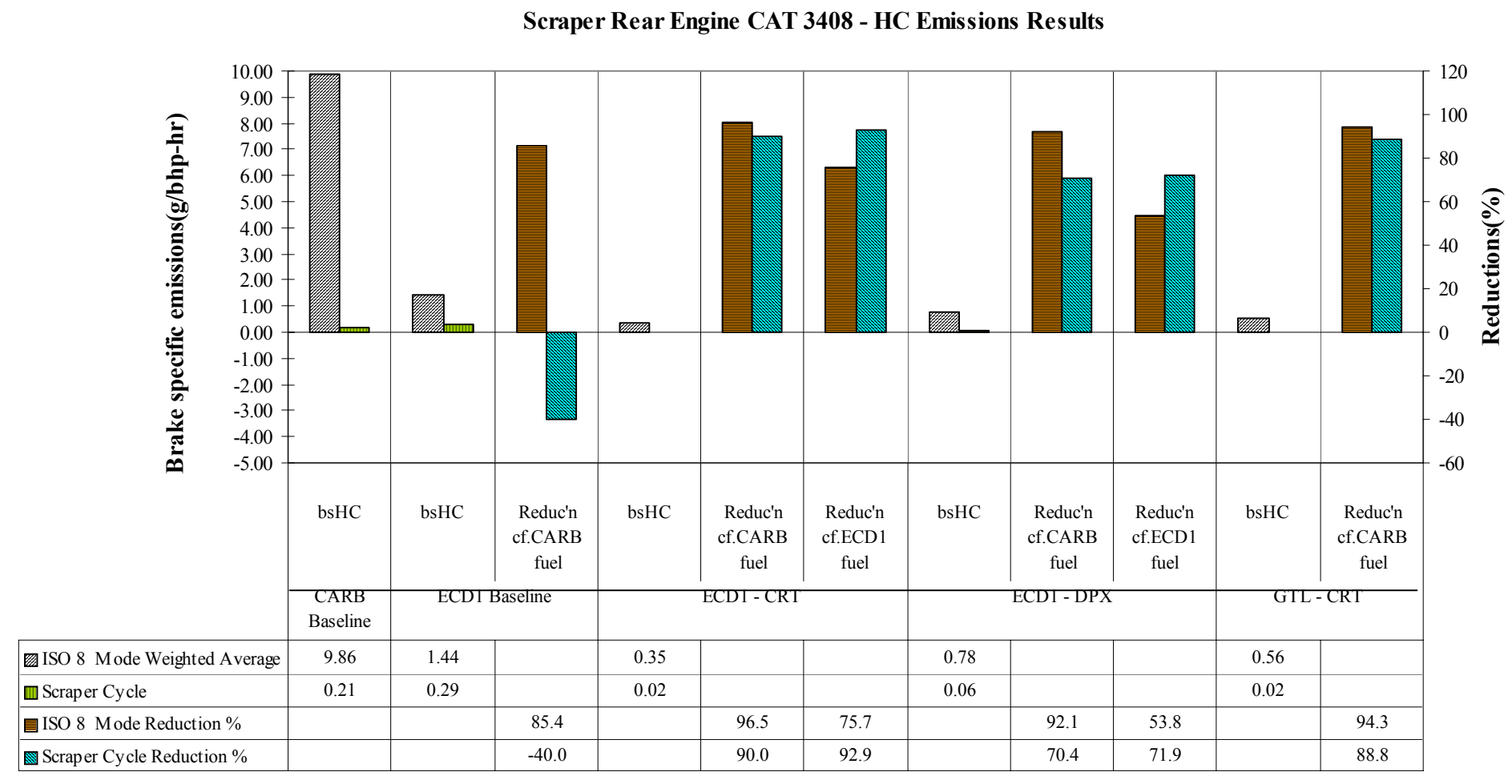


Scraper Rear Engine CAT 3408 - CO Emissions Results

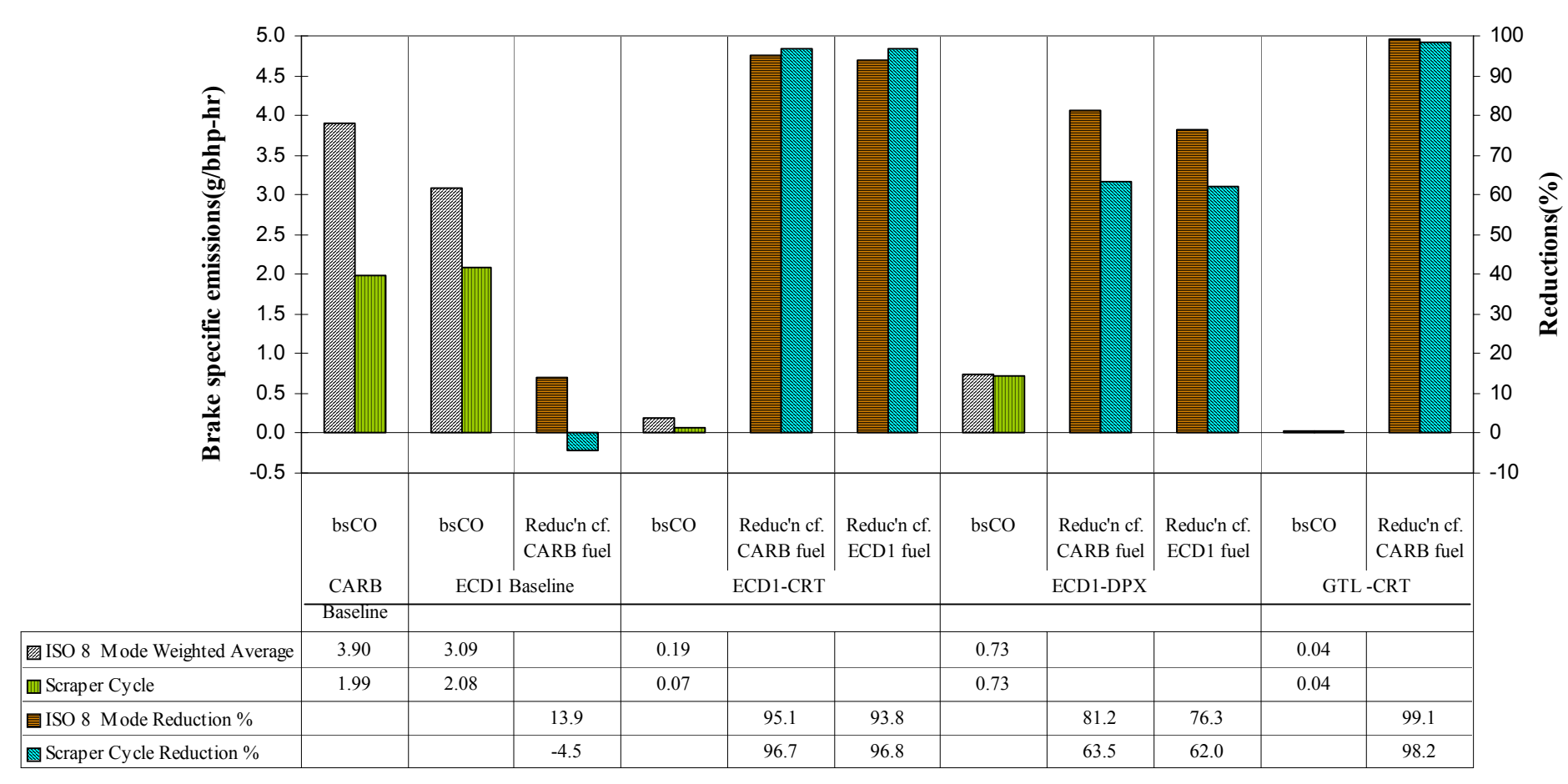




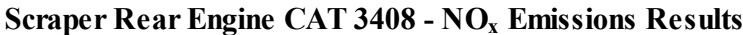

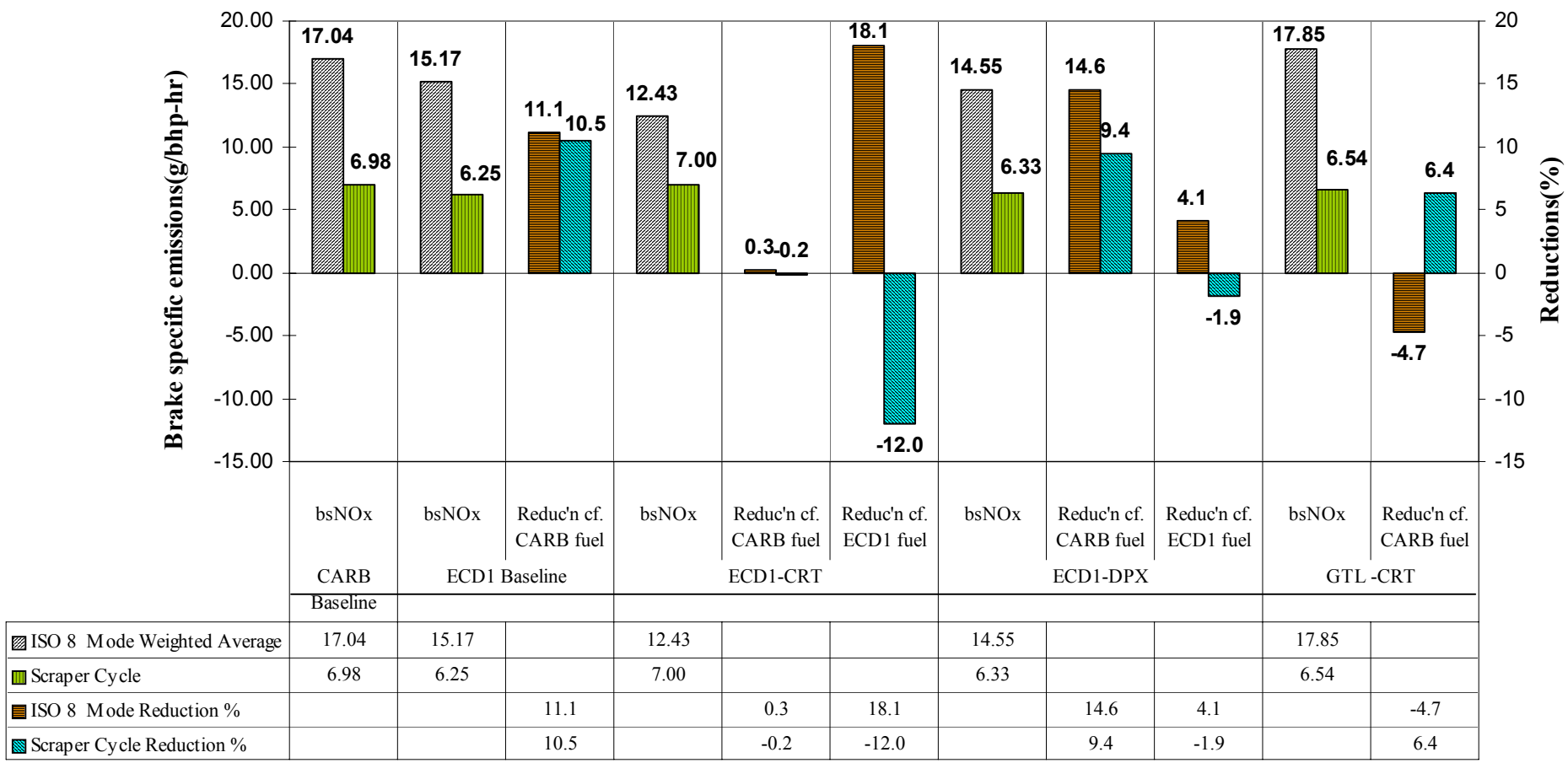


Scraper Rear Engine CAT 3408 - PM Emissions Results

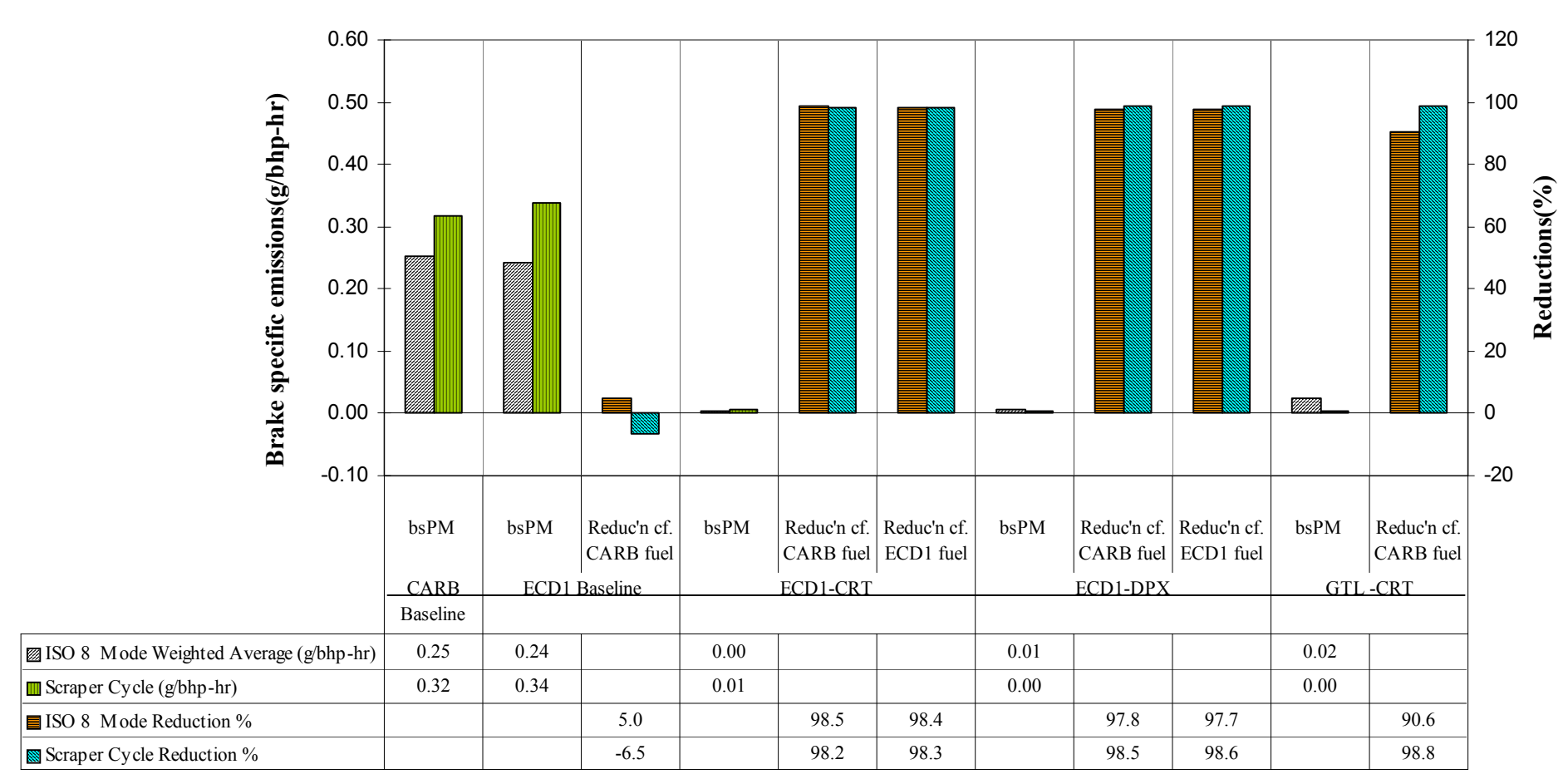




\section{APPENDIX E}

\section{UNCERTAINTY ANALYSIS}

The determination of the uncertainty was approached by considering a quantity $\mathrm{N}$, where $\mathrm{N}$ is a function of known variables:

$$
N=f\left(u_{1}, u_{2}, \ldots u_{n}\right)
$$

The absolute error is given by:

$$
E_{a}=\Delta N=\left|\Delta u_{1} \frac{\partial f}{\partial u_{1}}\right|+\left|\Delta u_{2} \frac{\partial f}{\partial u_{2}}\right|+\ldots+\left|\Delta u_{n} \frac{\partial f}{\partial u_{n}}\right|
$$

However, when the $\Delta$ u's are not considered as absolute limits, but instead as $\pm 3 \sigma$ limits; the method of computing the errors is according to the root-sum square formula.

$$
E_{a_{\text {rss }}}=\Delta N=\left[\left(\Delta u_{1} \frac{\partial f}{\partial u_{1}}\right)^{2}+\left(\Delta u_{2} \frac{\partial f}{\partial u_{2}}\right)^{2}+\ldots+\left(\Delta u_{n} \frac{\partial f}{\partial u_{n}}\right)^{2}\right]^{\frac{1}{2}}
$$

A normal distribution is assumed for the random errors. The " $Z$ value" for the normal distribution for a $95 \%$ confidence level is 1.96 . Adding all the bias and random errors, the totat error obtained was $Z_{95 \%}=1.96$.

The full dilution tunnel particulate mass equation is:

$$
P_{\text {mass }}=\left(V_{\text {mix }}+V_{\text {sample }}\right) *\left[\frac{P_{e}}{V_{\text {sample }}}-\left(\frac{P_{\text {back }}}{V_{\text {back }}} *\left[1-\frac{1}{D F}\right]\right)\right]
$$

where:

$\mathrm{P}_{\text {mass }}=$ volume corrected particulate mass

$\mathrm{V}_{\text {mix }}=$ total dilution exhaust volume

$\mathrm{V}_{\text {sample }}=$ volume of dilute exhaust flow across the primary and secondary filters

$\mathrm{P}_{\mathrm{e}}=$ particulate mass from the gravimetric analysis 
$\mathrm{P}_{\text {back }}=$ particulate mass from the background filter

$\mathrm{V}_{\text {back }}=$ volume of background flow across the background filter

$\mathrm{DF}=$ dilution factor

and the uncertainty, $\mathrm{DP}_{\text {mass }}$ is:

$$
\Delta P_{\text {mass }}=\left[\begin{array}{l}
\left(\frac{\partial P_{\text {mass }}}{\partial V_{\text {mix }}} \Delta V_{\text {mix }}\right)^{2}+\left(\frac{\partial P_{\text {mass }}}{\partial V_{\text {sample }}} \Delta V_{\text {sample }}\right)^{2}+\left(\frac{\partial P_{\text {mass }}}{\partial V_{e}} \Delta P_{e}\right)^{2}+ \\
\left(\frac{\partial P_{\text {mass }}}{\partial P_{\text {back }}} \Delta P_{\text {back }}\right)^{2}+\left(\frac{\partial P_{\text {mass }}}{\partial V_{\text {back }}} \Delta V_{\text {back }}\right)^{2}+\left(\frac{\partial P_{\text {mass }}}{\partial D F} \Delta D F\right)^{2}
\end{array}\right]
$$

where:

$$
\begin{aligned}
& \frac{\partial P_{\text {mass }}}{\partial V_{\text {mix }}}=\left[\frac{P_{e}}{V_{\text {sample }}}-\left(\frac{P_{\text {back }}}{V_{\text {back }}} *\left[1-\frac{1}{D F}\right]\right)\right] \\
& \frac{\partial P_{\text {mass }}}{\partial V_{\text {sample }}}=\left[-\frac{V_{\text {mix }} P_{e}}{V_{\text {sample }}^{2}}-\left(\frac{P_{\text {back }}}{V_{\text {back }}} *\left[1-\frac{1}{D F}\right]\right)\right] \\
& \frac{\partial P_{\text {mass }}}{\partial P_{e}}=\frac{V_{\text {mix }}+V_{\text {sample }}}{V_{\text {sample }}} \\
& \frac{\partial P_{\text {mass }}}{\partial P_{\text {back }}}=-\left(\frac{V_{\text {mix }}+V_{\text {sample }}}{V_{\text {back }}}\right) *\left(1-\frac{1}{D F}\right) \\
& \frac{\partial P_{\text {mass }}}{\partial P_{\text {back }}}=\frac{P_{\text {back }}{ }^{2}}{V_{\text {back }}}\left(V_{\text {mix }}+V_{\text {sample }}\right) *\left(1-\frac{1}{D F}\right) \\
& \frac{\partial P_{\text {mass }}}{\partial D F}=\frac{P_{\text {back }}}{V_{\text {back }} D F^{2}} *\left(V_{\text {mix }}+V_{\text {sample }}\right)
\end{aligned}
$$

